\title{
STRATEGIC ADSORPTION/DESORPTION OF CELLULASES NS 50013 ONTO/FROM AVICEL PH 101 AND PROTOBIND 1000
}

by

\author{
Khurram Shahzad Baig
}

B.E., University of Punjab, Lahore, Pakistan, 1985

M.A.Sc., Ryerson University, Toronto, Canada, 2008

\author{
A Dissertation \\ Presented to the School of Graduate Studies at \\ Ryerson University \\ in partial fulfilment of the \\ requirements for the degree of \\ Doctor of Philosophy \\ in the Program of Chemical Engineering
}

Toronto, Ontario, Canada, 2016

(C) Khurram Shahzad Baig, 2016 


\section{Author's Declaration}

I hereby declare that I am the sole author of this dissertation. This is a true copy of the dissertation, including any required final revisions, as accepted by my examiners.

I authorize Ryerson University to lend this dissertation to other institutions or individuals for the purpose of scholarly research.

I further authorize Ryerson University to reproduce this dissertation by photocopying or by other means, in total or in part, at the request of other institutions or individuals for the purpose of scholarly research.

I understand that my dissertation may be made electronically available to the public. 


\section{Abstract}

CKhurram Shahzad Baig, 2016

Doctor of Philosophy in Chemical Engineering

Ryerson University

Desorption of active cellulases from lignocellulosic substrates is a potential technique to reuse cellulases for the production of bioethanol. For desorption studies, adsorption of cellulases had to be performed first. Adsorption of cellulases NS 50013 onto microcrystalline cellulose (Avicel PH 101) and wheat straw lignin (Protobind 1000) was studied. It was found that Protobind adsorbed twice the amount of cellulases than Avicel did. An adsorption strategy developed was to work at pH 5 and a temperature less than $323 \mathrm{~K}$ to get maximum adsorption on the cellulose component, less adsorption on the lignin component of lignocellulosic materials, and to harmonize adsorption temperature with the industrial hydrolysis situation. Desorption of cellulases from Avicel and Protobind over a range of $298 \mathrm{~K}$ to $343 \mathrm{~K}$ and a pH of 6 to 9 was studied. Desorption obtained at pH 9 and 333K was optimum for both Avicel and Protobind. Hence, desorption was enhanced by $21 \%$ and $11 \%$ for Avicel and Protobind respectively. The cellulases activity for Avicel was 48 FPU $\mathrm{mL}^{-1}$ at $\mathrm{pH} 9,333 \mathrm{~K}, 5 \%$ glycerol, representing $91 \%$ of the initial activity and for Protobind, the activity was 33 FPU mL $\mathrm{m}^{-1}$ which represents about $66 \%$ of the initial activity. All of these values were higher than ever reported in literature. At pH 5 and $298 \mathrm{~K}$ the amount of cellulases desorbed from untreated wheat straw (WS) was $33 \%$ of those initially used for the adsorption step. It was increased to $42 \%$ when $30 \%$ delignified WS was used, and was further increased to $48 \%$ for 60 $\%$ delignified WS. Desorption obtained for $60 \%$ delignified WS was $75 \%$ at pH 9, 333K and 5\% 
glycerol. The desorption strategy recommended for bioethanol producing industries, is: 1) removal of lignin; 2) adsorption of cellulases at pH 5 and lower than $323 \mathrm{~K} ; 3$ ) hydrolysis of lignocellulosic material; and 4) desorption of cellulases from non-hydrolyzed material at $333 \mathrm{~K}, \mathrm{pH}$ 9, with 5-10 $\%$ glycerol. The proposed strategic desorption of cellulases may reduce the cost of Canadian bioethanol production by $26.5 \%$ due to $75 \%$ recyclability of active cellulases. 


\section{Acknowledgements}

\section{At one stage it was appearing impossible to finish my dissertation without guidance from Dr. G. Turcotte, support from my family and help from friends.}

I would like to express my deepest gratitude to my advisor, Dr. G. Turcotte, for her excellent guidance, caring, patience, and providing me with an excellent atmosphere for doing research.

I would also like to thank Dr. H. Doan for guiding my research for the past several years and helping me to develop my background in biosorption. Special thanks to Dr. S. Upreti who encouraged me at every unstable moments in study as an affectionate teacher. I cannot forget Dr. M. Mehrvar and Dr. R. Dhib for helping me when I was destitute.

Special thanks goes to Dr. G. Wolfaardt, who was willing to participate in my final Candidacy exam committee at the last moment, for his dedication and for being an excellent role model as a professor.

I would like to thank the technologists and staff in the Department of Chemical Engineering at Ryerson University for the assistance they provided to me during the conduction of this research, especially Ali Hemmati and Daniel Boothe.

I would like to thank Dr. Amman and Dr. Yousef (Department of Chemistry and Biology), Dr. Valeri (Environmental Program), Robin Luong (Department of Civil Engineering) who were good friends, and always willing to help and give their best suggestions. It would have been a lonely lab without Ali Al Jibouri and Dr. Samin Eftekhari. Many thanks to them and other workers in the Environmental and Biotechnology Laboratory of Chemical Engineering. Many thanks to grad 
student in KHE 135 specially Dr. Ciro, Dr. Arjang Kazemzadeh for always standing by my side. My research would not have been possible without their help.

I would also like to thank my parents, two younger sisters [Barjees Roohi and Shahzena Saboohi (late)], and a niece. They were always supporting, sacrificing and encouraging me with their best wishes. 


\section{Dedication}

Dedicated to my beloved mother

\section{Surrayia Baigum}

who dreamed about my higher studies

Dream is not that which you see while sleeping it is something that does not let you sleep 


\section{List of Contents}

Author's Declaration ......................................................................................................................... ii

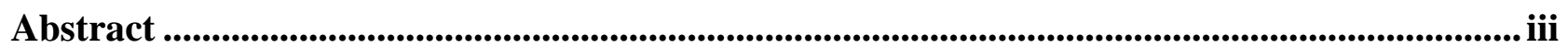

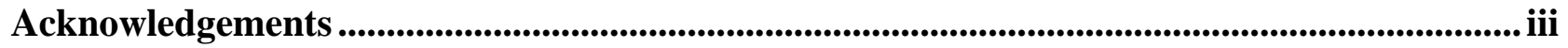

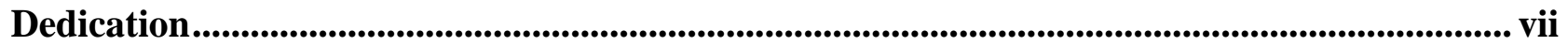

List of Contents.................................................................................................................................... viii

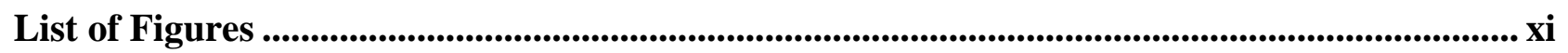

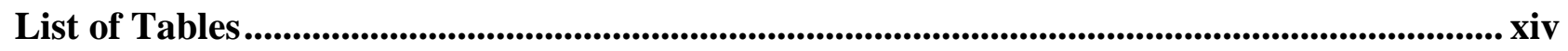

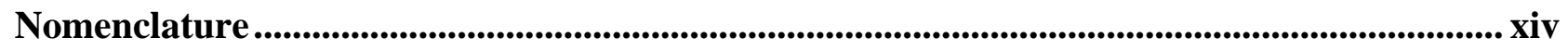

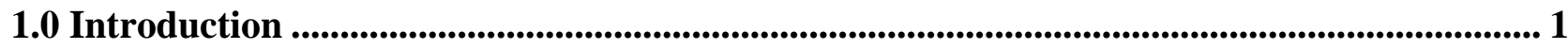

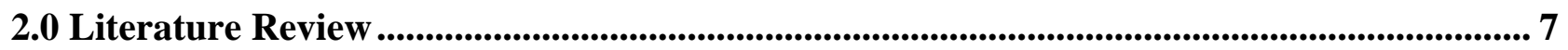

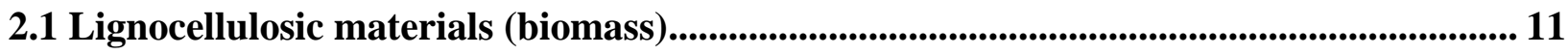

2.2 Components of lignocellulosic materials................................................................ 13

2.3 Cellulases

2.3.1 Cellulases adsorption isotherms ...................................................................................... 32

2.3.2 Adsorption of mixtures of endoglucanases and exoglucanases..................................... 36

2.4 Thermodynamics of enzymatic adsorption and desorption ......................................... 44

2.5 Desorption of cellulases from substrates................................................................... 49

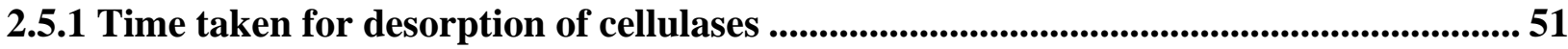


2.5.3 Effect of pH on desorption ................................................................................................................ 53

2.5.4 Decrease in desorption due to entrapment of cellulases..................................................... 57

2.6 Enhancement of desorption ....................................................................................5

Ethylene glycol ............................................................................................................................... 60

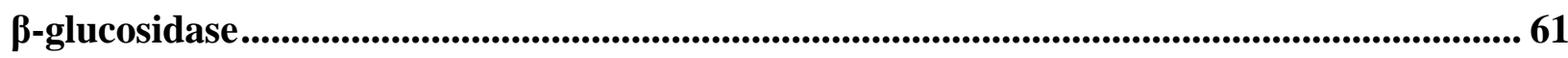

3.0 Objectives ............................................................................................................................................ 63

4.0 Material and Methods ........................................................................................................................ 66

4.1 Materials .................................................................................................................................... 67

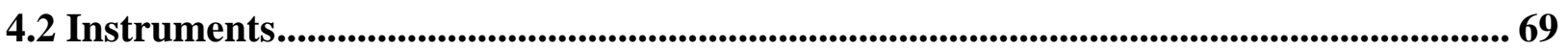

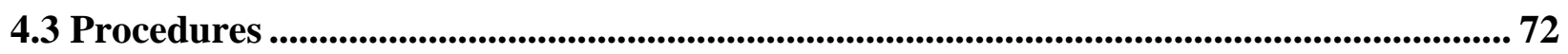

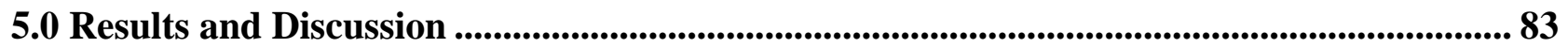

5.1 Delignification ................................................................................................................................. 84

5.2 Adsorption of cellulases............................................................................................................................. 89

5.3 Cellulases adsorption isotherms .......................................................................................................... 95

5.4 Enthalpic and entropic changes for adsorption under the influence of temperature .. 107

5.5 Desorption of cellulases ........................................................................................................................ 111

5.6 Enthalpic and entropic changes for desorption under the influence of temperature.. 117

5.7 Enhancement of desorption of cellulases ........................................................................................ 124

5.8 Application of novel desorption strategy on lignocellulosic material ............................... 137 


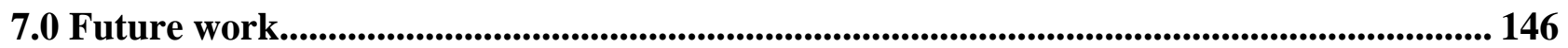

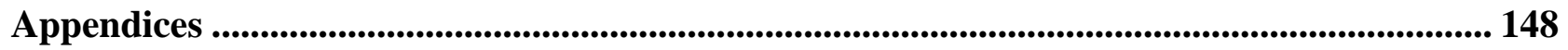

Appendix A, Measurement of the activity of cellulases....................................................... 149

Appendix B, Error in readings by using standard curves for cellulases concentration .... 157

Appendix C, Error in readings by using standard curves for reducing sugars .................. 161

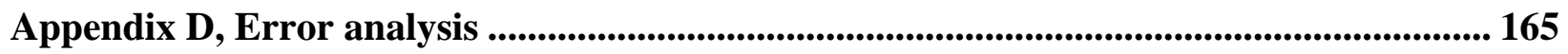

References............................................................................ 172 


\section{List of Figures}

Figure 1: A glucose unit in cellulose chain .............................................................................................. 14

Figure 2: Glucose units in a cellulose chain ( $\beta$-1, 4-D- linkages)...................................................... 15

Figure 3: Chemical structure of hemicellulose ................................................................................ 16

Figure 4: A lignin molecule................................................................................................................................. 17

Figure 5: A conceptual diagram on functioning of cellulases onto cellulose................................ 24

Figure 6: A conceptual diagram on action of CBDs on cellulose for adsorption......................... 26

Figure 7: Delignification by using ozone ...................................................................................................... 69

Figure 8: Incubator used for adsorption and desorption studies.................................................... 70

Figure 9: Detection mechanism of a spectrophotometer .................................................................. 71

Figure 10: Procedure for adsorption and desorption.......................................................................... 73

Figure 11: Hydrolysis of wheat straw for measurement of acid insoluble lignin ....................... 77

Figure 12: Glucose calibration curve (DNS method) used for the measurement of reducing sugars formed during adsorption process .................................................................................................. 79

Figure 13: Calibration curve for the determination of cellulases concentration......................... 80

Figure 14: Glucose calibration curve (DNS method) used for cellulase enzyme activity

measurement ................................................................................................................................................... 82

Figure 15: : Effect of water contents on lignin removal ..................................................................... 85

Figure 16: Lignin removal with various ozone flow rates ............................................................... 87

Figure 17: Adsorption of cellulases on Avicel PH 101 ........................................................................... 89

Figure 18: Adsorption of cellulases on Protobind 1000 ........................................................................ 91

Figure 19: Adsorption of cellulases on Avicel PH 101 at varyious temperatures..................... 92

Figure 20: Adsorption of cellulases on Protobind 1000 at varyious temperatures .................... 93 
Figure 21: Adsorption of cellulases on Avicel PH 101 according to Nernst isotherm. 96

Figure 22: Adsorption of cellulases on Protobind 1000 according to Nernst isotherm ........... 97

Figure 23: Langmuir adsorption isotherm for Avicel PH 101 ..............................................98

Figure 24: Langmuir adsotherm isotherm for Protobind 1000 ........................................... 99

Figure 25 : Freundlich adsorption isotherm for Avicel PH 101 ............................................ 100

Figure 26: Freundlich adsorption isotherm for Protobind 1000......................................... 101

Figure 27: Pore diffusion plot for Avicel PH 101 ..................................................................... 105

Figure 28: Pore diffusion plot for Protobind 1000 ............................................................. 106

Figure 29: Van't Hoff plots for adsorption on Avicel PH 101 and on Protobind 1000......... 107

Figure 30: Desorption of cellulases from Avicel PH 101 using distilled water ........................ 111

Figure 31: Desorption of cellulases from Avicel with varying temperature ............................ 112

Figure 32: Activity of desorbed cellulases from Avicel with varying temperature ................ 113

Figure 33: Desorption of cellulases from Protobind 1000 using distilled water ...................... 114

Figure 34: Desorption of cellulases from Protobind with varying temperature...................... 115

Figure 35: Activity of desorbed cellulases from Protobind 1000 with varying temperature

(from $25{ }^{\circ} \mathrm{C}$ to $\left.70{ }^{\circ} \mathrm{C}\right)$, pH (from pH 6 to pH 9) ........................................................................... 116

Figure 36: Desorption of cellulases NS 50013 from Avicel PH101 at varying pH (from pH 6 to

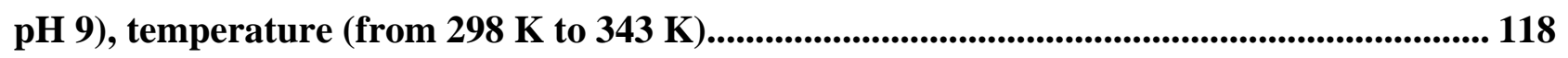

Figure 37: Desorption of cellulases NS 50013 from Protobind 1000 at varying pH (from pH 6

to pH 9), temperature (from 298 K to 343 K) .................................................................. 120

Figure 38: Desorption of cellulases from Avicel by using glycerol ........................................ 125

Figure 39: Activity of cellulases desorbed from Avicel PH 101 by using glycerol.................. 126

Figure 40: Desorption of cellulases from Protobind 1000 by using glycerol............................ 127

Figure 41: Activity of desorbed of cellulases from Protobind 1000 by using glycerol ........... 128 
Figure 42: Desorption of cellulases from Avicel PH 101by using ethylene glycol 129

Figure 43: Activity of desorbed cellulases from Avicel by using ethylene glycol 130

Figure 44: Desorption of cellulases from Protobind 1000 by using ethylene glycol 131

Figure 45: Activity of desorbed cellulases from Protobind 1000 by using ethylene glycol.... 132

Figure 46: Desorption of cellulases from Avicel by using $\beta$-glucosidases................................. 133

Figure 47: Activity of the desorbed cellulases from Avicel by using $\beta$-glucosidases .............. 133

Figure 48: Desorption of cellulases NS 50013 from Protobind 1000 using $\beta$-glucosidases .... 134

Figure 49: Activity of the desorbed cellulases NS 500113 from Avicel PH 101 using $\beta$ glucosidases 135

Figure 50: Adsorption of cellulases NS 50013 onto wheat straw 137

Figure 51: Desorption of cellulases at $\mathrm{pH} 5,25^{\circ} \mathrm{C}$, and $100 \mathrm{rpm}$ from wheat straw 138

Figure 52: Comparison of \% desorbed cellulases and activity of the desorbed cellulases among substrates at $\mathrm{pH} 9,60^{\circ} \mathrm{C}, 100 \mathrm{rpm}$ 139

Figure 53: Comparison of \% desorbed cellulases and activity of the desorbed cellulases from $30 \%$ delignified wheat straw and different experimental conditions 140

Figure 54: Comparison of \%desorbed cellulases and activity of the desorbed cellulases from $60 \%$ delignified wheat straw and different experimental conditions 141 


\section{List of Tables}

Table 1: Average Composition of Various Biomass Materials.................................................... 13

Table 2: Summary of enzymes adsorption on cellulosic substrates.....................................21

Table 3: Enzyme components from $T$. reesei cellulases complex .............................................. 22

Table 4: Enzymes used for adsorption onto substrates...................................................... 28

Table 5: Denaturing temperatures of amino acids present in cellulases ...................................... 40

Table 6: Denaturing temperatures of the components of the cellulases system ........................ 41

Table 7: $\Delta H$ values for adsorption for various enzyme and substrate systems ....................... 46

Table 8: $\Delta \mathrm{S}$ values for various adsorption systems ................................................................... 47

Table 9: Denaturing pH of component amino acids............................................................. 55

Table 10: Charges on component amino acids at various pH levels of desorption system...... 56

Table 11: $\Delta \mathrm{G}_{\mathrm{d}}$ obtained for desorption of cellulases from Avicel PH 101 for $\mathrm{pH} 6$ to $\mathrm{pH} 9$ at

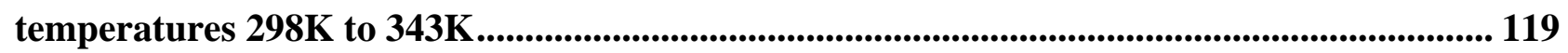

Table 12: $\Delta \mathrm{G}_{\mathrm{d}}$ obtained for desorption of cellulases from Protobind 1000 for $\mathrm{pH} 6$ to $\mathrm{pH} 9$ at temperatures 298 K to 343 K.......................................................................................... 122

Table 13: Dilution of Cellulase enzyme NS50013 from enzyme stock that had been diluted 1:15

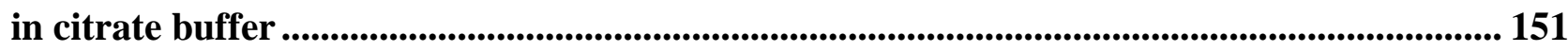

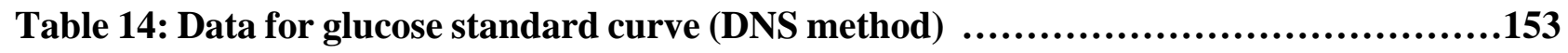

Table 15: Dilution and glucose concentration of cellulase enzyme NS50013 stock that had been

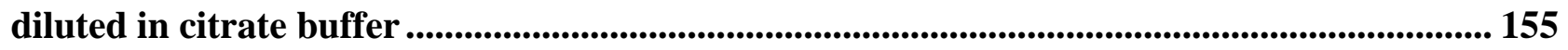

Table 16: Activity of cellulases NS 50013 measured by filter paper unit method. ................ 156

Table 17: Data ffor absorbance of standard samples......................................................... 157

Table 18: Statistical manipulation of data given in Table 17 ................................................ 157 
Table 19: Standard deviation of one set of data from Table 17 against Standard Curve ..... 160

Table 20: Data for absorbance of standard samples of glucose ............................................. 161

Table 21: Statistical manipulation of data given in Table 20 ............................................... 161

Table 22: Standard deviation of one set of data from Table 20 against Standard Curve ..... 164

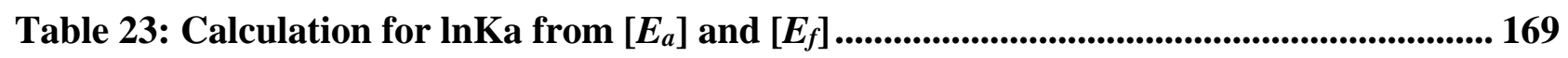




\section{Nomenclature}

$\begin{array}{ll}\text { acel }, & \text { area occupied by cellulases molecules, } 60 \text { x } 50 \AA^{2} \\ \text { BG } & \text { B-glucosidase } \\ \text { BSA } & \text { Bovine Serum Albumin } \\ \text { CBH I } & \text { Cellobiohydrolase I } \\ \text { CBH II } & \text { Cellobiohydrolase II } \\ \text { CBM } & \text { Carbohydrate Binding Module } \\ \text { Cel5A } & \text { Glycoside hydrolase family } 5 \text { endoglucanase } \\ \text { Cel6A } & \text { Glycoside hydrolase family } 6 \text { CBH II } \\ \text { Cel7B } & \text { Glycoside hydrolase family } 7 \text { CBH I } \\ \text { Cys } & \text { Cysteine at location 181 } \\ \text { EG } & \text { Eatalytic Domain } \\ \text { EG I } & \text { Endoglucanase I } \\ \text { En } & \text { Endoglucanase II } \\ & \end{array}$




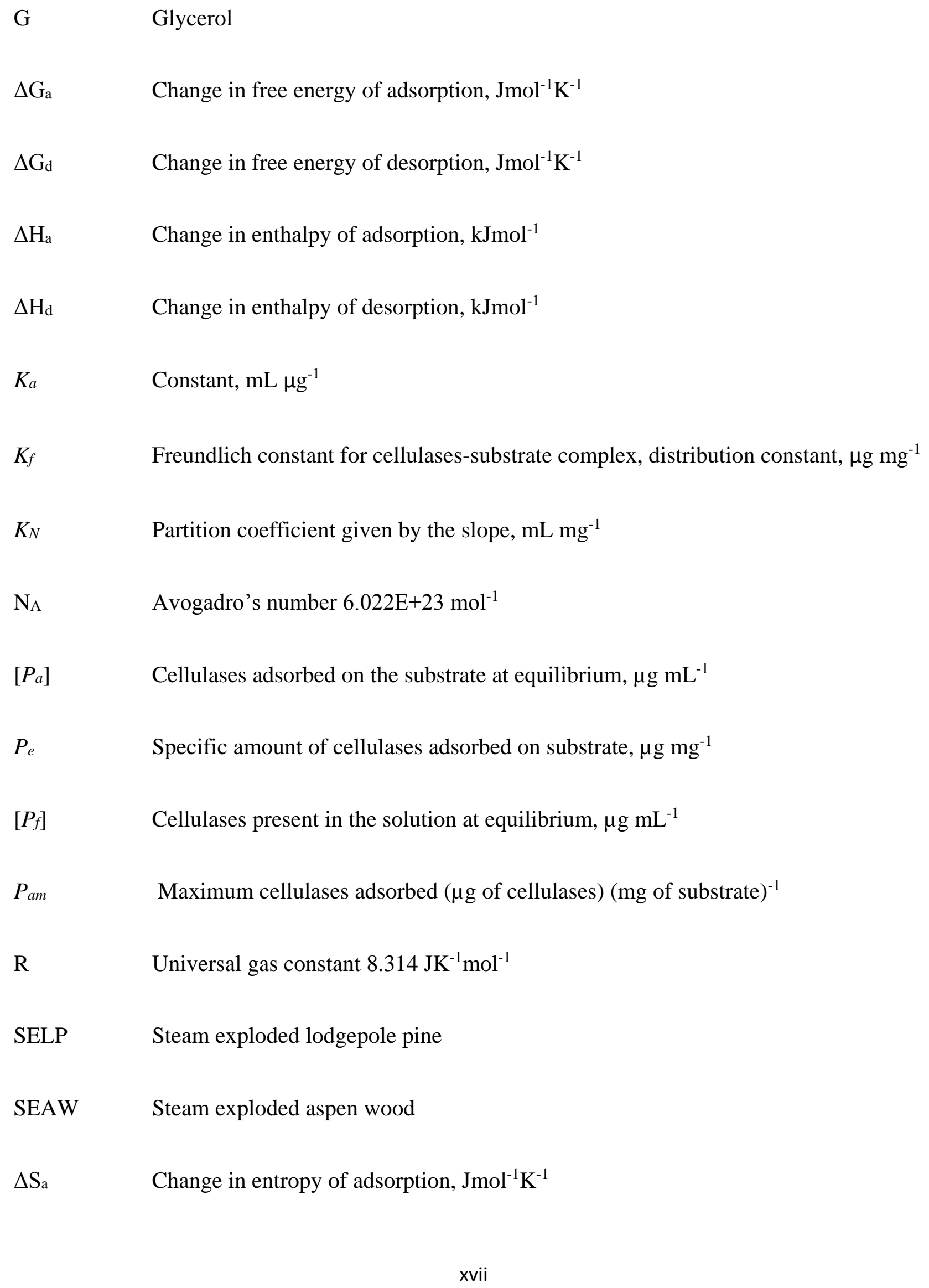


$\Delta \mathrm{S}_{\mathrm{d}} \quad$ Change in entropy of desorption, $\mathrm{Jmol}^{-1} \mathrm{~K}^{-1}$

STP Standard temperature and pressure

$\mathrm{T} \quad$ Absolute temperature

$V_{m} \quad$ Volume of gas adsorbed at STP to produce an apparent monolayer on the sample surface, $\mathrm{mL}$

$\overline{y_{c}} \quad$ Mean of the absorbance measured in replicates \#1 and \#2

$\sigma P_{e} \quad$ Variance in $P_{e}$ 
1.0 $0_{\text {Introduction }}$ 
Lignocellulosic materials are used as a source for production of bioethanol. These materials consist of lignin, cellulose and hemicellulose, which are interweaved in the cell walls. Cellulose component of biomass is insoluble and cellulases have to adsorb to cellulose to proceed for sugar release. Costeffective liberation of fermentable sugars from lignocellulosic resource is still the largest obstacle to large-scale commercialization of this technique. There are two main problems associated with the process of liberating reducing sugars: the first one is presence of lignin that compete with cellulose for cellulases hence increased processing cost and the second problem is the cost of enzymes used in ethanol production process.

The solution to the first problem is to remove the lignin to prevent enzyme-lignin interaction and expose more and more cellulose. Several methods were suggested, such as performing enzymesubstrate reactions with surfactants because surfactants restrict interaction of cellulases with lignin. Another approach was to destroy and/or remove the lignin by pre-treatment. However, due to one or a combination of factors involved in, cost of some of pre-treatments, less amount of lignin removal, health and/or environmental concerns, the potential for bioethanol production is not promising. For example, to use steam explosion, high temperature and pressure resistant fabrication material for the reactor are required. Ammonia fiber expansion (AFEX) needs pressure resistant and corrosion resistant fabrication material for reactors and ammonia may trigger asthma in workers. Similarly, cellulose solvent and organic solvent-based lignocellulose fractionation (COSLIF), ionic liquids, or organosolv require expensive corrosion resistant fabrication materials and vapors of solvents may harm to workers. In our lab we have successfully removed $90 \%$ of lignin by a novel technique which is a sequential use of water and ozone [Baig et al., 2015]. All reactions occurred at normal temperature and pressure therefore no expensive material would be required to construct a reactor. The half-life of ozone indoor is 7-10 min therefore it was considered less harmful (less health 
concerns) than $\mathrm{Cl}_{2}, \mathrm{H}_{2} \mathrm{O}_{2}$, etc. The cost of ozone is dependent on electricity price (less costly) because $\mathrm{O}_{3}$ is produced when $\mathrm{O}_{2}$ molecules are dissociated by an electricity source into oxygen atoms. Removal of lignin decrease process cost because lignin adsorbed more enzymes than cellulose, hence consume enzymes non-productively. The common features of all pretreatment methods were that they rearranged and removed some parts of the cell wall structure and hence, made cellulose more accessible for cellulases. Some of the lignin residues may be present even after pretreatment. However, such a pretreated biomass still offer much more exposed structures for cellulase to access cellulose. Since a pretreatment change the chemical composition and structure of a pretreated biomass, it is perceived that pretreatment might affect the adsorption of the enzymes during hydrolysis and fermentation and thereby probably also the recyclability of the enzymes.

The solution to second problem is to reduce the cost of enzymes. In 2001, the cost to produce enzymes from Trichoderma reesei (cellulases) was \$0.8-1.32 U.S. per liter of ethanol [Novozyme, 2005]. Through collaboration between Novozymes and NREL the price was reduced to $\$ 0.03-0.05$ per liter of ethanol in 2005 [Mathew et al., 2008]. The cost of cellulases is still far more expensive than the cost of starch-hydrolyzing enzymes used for grain based ethanol biorefineries (i.e., $\$ 0.01$ 0.02 per liter of ethanol) [Zhu et al., 2009]. The reduction in cost of cellulases has been a main assignment for the researchers for production of bioethanol from waste lignocellulosic materials instead of food grains. To decrease the costs of cellulases some efforts were made by: (i) decreasing cellulases loading (e.g., gram of cellulases used per gram of cellulose) by increasing cellulose interaction with enzymes which can be achieved by pretreating the biomass, (ii) recycling costly cellulases by adding fresh substrates, and (iii) increasing cellulase performance (activity) by using genetically modified cellulase (modified for thermal stability and binding ability). Some of these efforts were not practicable such as addition of substrate to reuse / readsorb enzymes from the 
previously used substrate resulting in a build-up of lignin rich residues that increased capability of cellulases to adsorb but reduce the capability of cellulases to desorb. Other authors reported desorption agents to perform desorption of cellulases such as alkaline media [Otter et al., 1984; Zhu et al., 2009; Rodrigues et al., 2012], Tween [Seo et al., 2011], urea [Deshpande and Eriksson, 1984], glycerol [Beldman et al., 1985], and Triton X-100 [Bai et al., 2010]. In alkaline medium (beyond pH 10) enzymes were reported inactive due to denaturing. For reuse of enzymes in bioethanol production, desorption of cellulases alone is insufficient. Desorption of active cellulases is of utmost importance.

This study has a special focus on desorption of active cellulases. Previously, some work has been done on the effect of $\mathrm{pH}$ on cellulases adsorption, less attention has been given to the temperature dependence of the adsorption process which is still under continuing debates. The debate is to suggest a suitable temperature for adsorption and desorption of cellulases while maintaining their activity. Because researchers have conducted studies under different temperatures, various sources and type of enzymes. Therefore a study on wide range of temperature was required for adsorption and desorption. Furthermore, the enzymatic adsorption on insoluble substrates is complex. The complexity involves chemical composition, physical structure of substrates, and from the cellulases part, it's the transport and diffusion approach of cellulases to target sites. Some contrasting results were presented by researchers about cellulases showing optimal activity at various $\mathrm{pH}$ values. Correlations between structural changes in cellulases and changes in the activity of the enzymes were of great interest for desorption and reuse of cellulases in biofuel industry. Adsorption of cellulases was not strictly reversible [Hong et al., 2007; Shao et al., 2008]. For example, adsorption of all Thermobifida fusca cellulases to bacterial microcrystalline cellulose was irreversible [Jung et al., 2002]. On the other hand Palonen et al. (1999) reported that only $10 \%$ of the adsorbed Trichoderma 
cellobiohydrolase I and 30-40 \% of the adsorbed Trichoderma cellobiohydrolases II were desorbed. Present study for adsorption and desorption of cellulases onto/from cellulose and lignin would help to estimate adsorption and desorption onto/from lignocellulosic substrates.

The main goal of present study was to develop a novel integrated desorption strategy by using environmental parameters and suitable chemical/s for cost-effective active desorption of cellulases from lignocellulosic substrates (the idea is to adapt this technique on exhausted solid residues from bioethanol producing industry for active desorption of cellulases for reuse) as well as optimize environmental parameters and the concentration of chemical/s used. During the course of meeting this goal some other objects were served, automatically. In this study, adsorption and desorption were conducted and evaluated through a series of the adsorption experiments under varying temperature, $\mathrm{pH}$ and concentration of cellulases, for Avicel PH 101 and Protobind 1000 to help settle the controversy (monolayer or multilayer) on type of adsorption occurred. The kind of adsorption play a key role in designing strategy for desorption of cellulases from lignocellulosic components and explore optimum conditions to get active desorption of cellulases. Although much has been accomplished in adsorption, less attention has been given to the change in enthalpy and entropy of adsorption / desorption processes, which is still under continuing debate (Medve, 1994; Radeva et al., 2011; Gan et al., 2012; Kumar and Wayman, 2013). It was difficult to evaluate desorption and/or reuse of cellulases, because of insufficient knowledge on the characteristics of cellulase adsorption /desorption onto/from cellulosic substrates. Therefore, adsorption /desorption of cellulases onto/from cellulose and lignin were studied under similar experimental conditions because cellulose and lignin exist together in lignocellulosic materials and undergo same operational conditions during bioethanol production. This study may help to decide whether lignin removal from lignocellulosic material for the conversion of lignocellulosic to biofuel should be conducted or not. Delignification of wheat 
straw (a lignocellulosic material) is important for two reasons: first, to stop non-productive adsorption on lignin and second, to increase accessible surface area for cellulases to get adsorb and desorb. Further, getting all the insight for adsorption and desorption onto/from the pure components of lignocellulosic materials the knowledge was applied for desorption of cellulases from preadsorbed wheat straw. 
2.0 $0_{\text {Literature Review }}$ 
The price of regular grade gasoline touched the peak of $\$ 4.25$ per gallon in July 2008 [US Energy Administration, 2008] somehow it came back to its normal value i.e. \$1.71, in January 2009 for a short time then it started rising again. In the May 2011 the price was $\$ 3.91$ per gallon and it was $\$ 3.43$ per gallon in 2016 [Knipping, 2016]. A decrease of $\$ 0.48$ per gallon could not make any significant impact on the living cost of a Canadian individual. An average Canadian living in Toronto was paying \$129.01 for $1000 \mathrm{kWh}$ consumption of electricity in 2011, in 2013 the price fell down to $\$ 124.75$ and in 2014 the prices rose to $\$ 137.84$ without taxes and the individual was paying $\$ 143.72$ in 2015 [Hydro Quebec, 2015]. An $11.4 \%$ increase in electricity prices was observed with a $24 \%$ increase in food prices with reference to the prices in 2011. From the presented brief history, it can be figured out that the cost of living was affected by increased fuel price which made people to think about an alternative source of fuel. At the same time the desire for safe environment and clean energy motivated to demand for biofuel. Biofuel is a fuel produced from biomass. Biomass is a generic term for all animate organic matter (except fossil fuels) encircling crops, forestry and marine products but also organic wastes. Biomasses, as an energy source, have two prominent distinctiveness's:

- biomass is the only renewable organic resource

- $\quad$ biomass fixes carbon dioxide in the atmosphere by photosynthesis.

Among the various kinds of biomass, woody biomass was used traditionally as an energy source, for a long time and, even to this day, it is being used in the form of firewood or charcoal. It is, however, difficult to use firewood or charcoal as an alternative fuel for commercial equipment and industrial processes where fossil fuels, in particular oil, are used at present. It is necessary to develop technologies which could make possible conversion of biomass to a more useable form, such as liquid or gas. 
Agricultural and forestry residues such as corn stover and wheat straw are inexpensive and readily available source of renewable lignocellulosic biomass [Mussato et al., 2008]. Exploitation of biomass as a carbohydrate source for glucose and ethanol production has been severely hindered by the low efficiency with which cellulose degrading organisms and enzymes are able to convert the polysaccharide portion of the residue into monomeric sugars. The production of biofuel from lignocellulosic biomass is facing a problem of not economically releasing cellulosic sugars [Lynd et al., 2008; Zhang, 2008; Yousuf, 2012; Limayem and Ricke, 2012]. The cellulosic sugars are protected by lignin in biomass. Therefore, a pretreatment is required to remove lignin. Various pretreatment techniques were tried for delignification, using physical, chemical, and physicochemical and /or biological methods. For example steam explosion, hot water extraction [Rosgaard et al., 2007], traditional chemicals like sulfuric acid, sulfur dioxide, sodium hydroxide and lime were studied. The new technologies explored were ozonolysis [Silverstein et al., 2007] ammonia fiber explosion (AFEX) [Sendich et al., 2008] and wet oxidation [Hendricks and Zeeman, 2009]. A novel technique has removed over $92 \%$ of lignin from wheat straw by strategic use of water and ozone [Baig et al., 2015]. The obtained results demonstrated that ozonation of wheat straw using the proposed technique was practical, easy to manage for the removal of lignin and it may be considered as an alternative method for delignification of biomass in production of biofuel. Removal of lignin makes cellulose more accessible for enzymes to convert the cellulose into fermentable sugars [Mosier et al., 2005]. In next step, the fermentable sugars are converted to ethanol $\left(\mathrm{CH}_{3} \mathrm{CH}_{2} \mathrm{OH}\right)$ which is one of the biofuels. The achievability of bioethanol process depends either on the increase in yield of sugars or decrease in cost of process or both. These two influencing factors can be controlled by improving the existing pretreatment technologies or developing new technologies [Sathitsuksanoh et al., 2009; Ekwe, 2012] or developing enzyme of very precise performance [Heinzelman et al., 2009; Liu et al., 2009], or developing recyclable enzymes [Tu et 
al., 2007; Zhu et al., 2009b, Weiss et al., 2013], or producing low cost enzyme [Himmel et al., 2007], or discovering easy to process bio-energy crops [Bomgardner, 2013]. The basic conversion process can be depicted in the following two reactions:

$$
\begin{array}{lccc}
\left(\mathrm{C}_{6} \mathrm{H}_{10} \mathrm{O}_{5}\right)_{n}+\mathrm{nH}_{2} \mathrm{O} \stackrel{\text { Cellulases }}{\longrightarrow} \mathrm{nC}_{6} \mathrm{H}_{12} \mathrm{O}_{6} & \ldots & 2.1 \\
\text { Cellulose } & \text { Glucose } & & \\
& & & \\
\mathrm{C}_{6} \mathrm{H}_{12} \mathrm{O}_{6} \stackrel{\text { microbes }}{\longrightarrow} 2 \mathrm{C}_{2} \mathrm{H}_{5} \mathrm{OH}+2 \mathrm{CO}_{2} & \ldots & 2.2 \\
\text { Glucose } & \text { Ethanol } & & \\
& &
\end{array}
$$

In Canada, since 1991, the grain-based ethanol production process exists, representing $92 \%$ of actual production capacity. Canadian ethanol plants are presently using corn $68 \%$, wheat $29.9 \%$, municipal waste $1.8 \%$, forestry waste $0.2 \%$, agriculture waste $0.1 \%$ [Quaiattini, 2010]. It was estimated that Canada will produced 1.745 billion liters of bioethanol in 2015 [Zimmerman and Dessureault, 2014]. For its need, Canada had to import 1.34 billion liters of bioethanol [Pratt, 2015]. Canada produced 26.8 million tons of wheat in the year 2009-2010 [Lyddon, 2011]. Depending upon the ethanol production process employed, commercial ethanol is yielded from 340 to over 500 liters per ton of wheat, depending on the type of wheat [Cheminfo Services Inc. et al., 2000]. Though Canada is among top ten producers of wheat in the world [Montane, 1998] yet the use of grain for fuel is not appreciated. A potential use of low cost ethanol production is to utilize waste lignocellulosic materials such as crops residues, grasses, saw dust, wood chips and animal waste. In last decade research has been done on the conversion of lignocellulosic materials to ethanol [Azzam, 1989, Cadoche and Lopez, 1989; Reshamwala et al., 1995, Bjerre et al., 1996]. The viability of wheat straw which is an agricultural waste and a renewable source was chosen to investigate in this study to produce a valuable product such as bioethanol. The average yield of straw is $1.3-1.4 \mathrm{~kg}$ per $\mathrm{kg}$ of 
grain, which means that Canada has capability to produce 37.52 million tons of straw per year. The reactants (biomass, cellulases) and their interaction during adsorption and desorption steps of bioethanol production are discussed in following sections.

\subsection{Lignocellulosic materials (biomass)}

In recent years, there has been a great search for biomass as an energy source. In the biomass, energy of sunlight is stored in chemical bonds between adjacent carbon, hydrogen and oxygen molecules. When the bonds are broken, these substances release their stored chemical energy. The process by which biomass (chlorophyll containing organisms) capture energy in the form of light and convert to chemical energy is called, photosynthesis. This process is accompanied by the release of oxygen $\left(\mathrm{O}_{2}\right)$. The basic equation for photosynthesis can be written [Raven et al., 2005] as

$$
6 \mathrm{CO}_{2}+12 \mathrm{H}_{2} \mathrm{O}+\text { Light enrgy } \rightarrow \quad \mathrm{C}_{6} \mathrm{H}_{12} \mathrm{O}_{6}+6 \mathrm{H}_{2} \mathrm{O}+6 \mathrm{O}_{2} \quad \ldots \quad 2.3
$$

The total energy captured from solar energy by plant photosynthesis is about $2 \times 10^{23} \mathrm{~J}_{\text {year }}{ }^{-1}$ [Ito and Oikawa, 2004].

Biomass can be classified as four main types, namely; woody plants, herbaceous plants/grasses, aquatic plants and manures. Biomass contains varying amounts of cellulose, hemicellulose, lignin and a small amount of other extractives.

The properties of the material of interest, during subsequent processing as an energy source are related to

i. moisture contents

ii. calorific value

iii. proportions of fixed carbons and volatiles 
iv. ash/residues contents

v. alkali metal contents

vi. cellulose /lignin ratio

The first five properties are of interest for dry conversion processes while the first and sixth properties are of concern for wet biomass conversion processes. High moisture contents in biomass such as herbaceous plant lends itself to a wet conversion process which involves biologically mediated reaction such as fermentation. Dry biomass such as wood chips is more economically suited to gasification, pyrolysis or combustion. Wet and dry pyrolysis are two extremes. Other factors such as ash, alkali and trace components impact adversely on thermal conversion processes and cellulose contents influences on biochemical fermentation processes. There are three main reasons to use biomass as an energy source [McKendry, 2002]:

1- The technical advancement for suitable crop production implies the use of biomass at lower cost and higher conversion efficiency. For example, low cost biomass residues can be used instead of fossil fuels for the production of electricity. A cost effective use of energy crops for production of methanol and hydrogen looks promising.

2- The agricultural sector in Western Europe, US and Canada is producing food surpluses. This situation has led to a policy in which land is set aside in order to reduce surpluses. On these spared lands, energy crops can be grown without effecting food producing crops.

3- The major stimulus is no potential threat to climatic change. Biomass emits roughly the same amount of carbon during conversion as is taken up during plant growth. Therefore, use of biomass will not contribute to a buildup of $\mathrm{CO}_{2}$ in the atmosphere.

Table 1 shows the cellulose, hemicellulose and lignin contents of some of lignocellulosic materials. 


\section{Table 1: Average Composition of Various Biomass Materials}

[Fan et al., 1980; Sun and Cheng, 2002; Galbe and Zacchi, 2002; Kim and Dale, 2004]

\begin{tabular}{|l|l|l|l|}
\hline Materials & $\begin{array}{l}\text { Cellulose } \\
\mathbf{\%}\end{array}$ & $\begin{array}{l}\text { Hemicellulose } \\
\mathbf{\%}\end{array}$ & $\begin{array}{l}\text { Lignin } \\
\boldsymbol{\%}\end{array}$ \\
\hline Hard wood stems & $40-55$ & $24-40$ & $18-25$ \\
\hline Softwood stems & $45-50$ & $25-35$ & $25-35$ \\
\hline Nut shells & $25-30$ & $25-30$ & $30-40$ \\
\hline Corn cobs & 45 & 35 & 15 \\
\hline Corn stover & $35-41$ & $16-24$ & $15-17$ \\
\hline Coastal Bermuda grass & 25 & $35-7$ & 6.4 \\
\hline Leaves & $15-20$ & $80-85$ & 0.0 \\
\hline Cotton Seed Hairs & $80-95$ & $5-20$ & 0.0 \\
\hline Wheat straw & $40-50$ & $30-40$ & $16-25$ \\
\hline Barley straw & $34-38$ & $19-30$ & $9-15$ \\
\hline Newspaper & $40-55$ & $25-40$ & $18-30$ \\
\hline Waste papers from chemical pulps & $60-70$ & $10-20$ & $5-10$ \\
\hline Primary wastewater solid & $8-15$ & NA & $24-29$ \\
\hline Solid cattle manure & $2-5$ & $2-4$ & $2-6$ \\
\hline
\end{tabular}

Woody plant species have slow growth and are composed of tightly bound fibers. Herbaceous plants are more loosely bound fibers indicating lower portion of lignin. The relative proportion of cellulose and lignin is the determining factor of the suitable plant species.

\subsection{Components of lignocellulosic materials}

\section{Cellulose}

Cellulose is a polymer with an average molecular weight of around 100, 000. A single unit of glucose is shown in Figure 1. In the cellulose chain, the glucose units are in 6-membered rings, called 
pyranoses. They are joined by single oxygen atoms (acetal linkages) between the $\mathrm{C}-1$ of one pyranose ring and the $\mathrm{C}-4$ of the next ring.

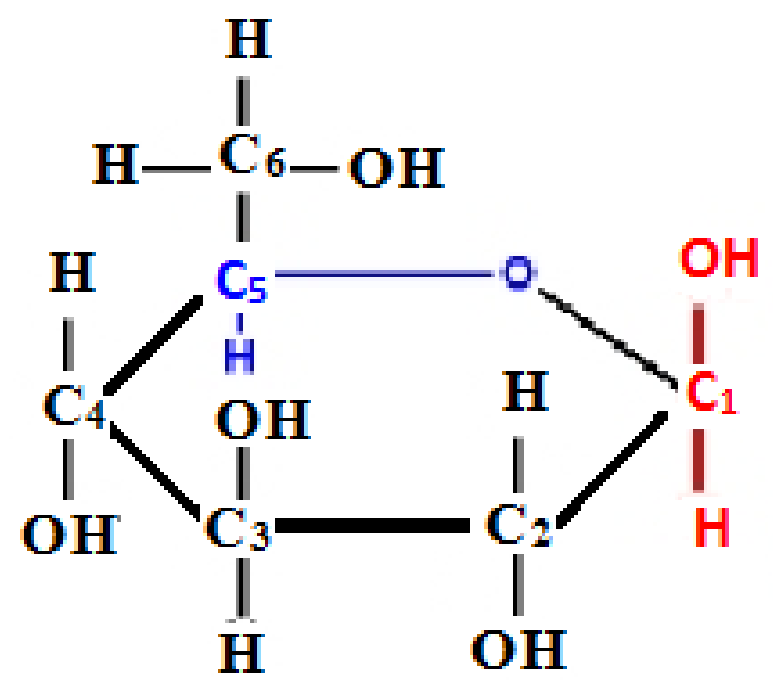

\section{Figure 1: A glucose unit in cellulose chain}

[Adapted from: Klemm et al., 2005; Netrabukkana, 1996]

The ends of cellulose chain are named as reducing and non-reducing end. The end where there is a C-1 carbon atom which is not involved in a glycosidic bond is the reducing end, while the other end, where the $\mathrm{C}-1$ carbon atom is participating in a glycosidic bond, is called the non-reducing end as given in Figure 2. The approximate length of a cellulose molecule is about $50000 \AA$ (5000 nm) whereas the average size of each crystalline region determined by $x$-ray diffraction analysis was only $600 \AA$ in length, $50 \AA$ in width and $30 \AA$ in thickness. Approximately $36-42$ of cellulosic chains arrange together (as a bundle) by complex hydrogen bonds network to form elementary fibrils [O'Sullivan, 1997; Himmel et al., 2007; Habibi et al., 2007]. 


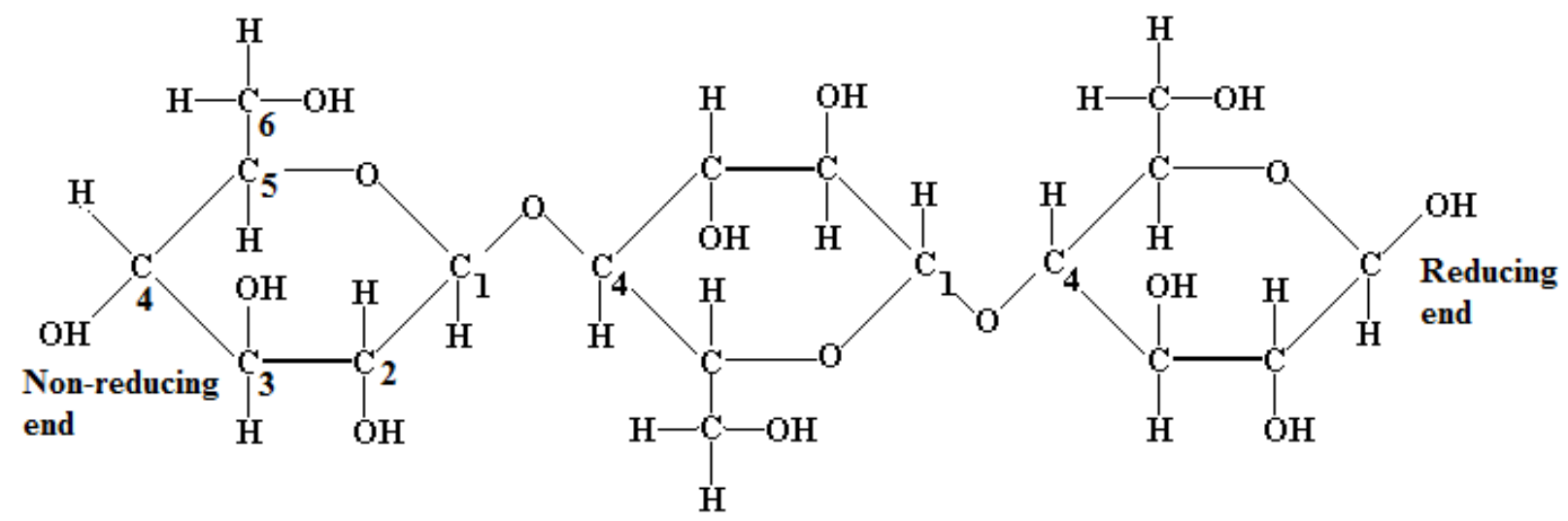

Figure 2: Glucose units in a cellulose chain ( $\beta-1,4-D-$ linkages)

[Adapted from Morrison and Boyd, 1992; Klemm et al., 2005; Carey and Sundberg, 2007]

The hydrogen bonding is possible due to the equatorial positions of the hydroxyls on the cellulose chain. These hydrogen bonds cause the chains to group together in highly ordered (crystal-like) structures. Since the chains are usually longer than the crystalline regions, they are thought to pass through several different crystalline regions, with areas of disorder in between (the "fringed-micelle" model). The inter-chain hydrogen bonds in the crystalline regions are strong, giving the resultant fibers good strength and insolubility in most solvents. They also prevent cellulose from melting (i.e., non-thermoplastic). In the less ordered regions, the chains are further apart and more available for hydrogen bonding to other molecules. There are six possible conformations of cellulose chains to be held in the elementary fibrils depending on the polymerization conditions [O'Sullivan, 1997]. Native cellulose is composed of a heterogeneous mixture of at least two conformations [O'Sullivan, 1997]. Cellulose is highly crystalline in the center of its elementary fibrils, and insoluble in water [Pauly and Keegstra, 2008]. The crystalline structure of cellulose is difficult to disrupt such as cellulose must be heated to $320^{\circ} \mathrm{C}$ at a pressure of $25 \mathrm{MPa}[1 \mathrm{MPa}=9.87 \mathrm{~atm}]$ to remove its crystallinity [O’Sullivan, 1997]. By the action of enzymes, cellulose was broken down to cellobiose and which 
was further broken down to glucose. Choi et al. (2002) has given the length and width of a glucose molecule as $5.6 \AA$ and $6.5 \AA$. [Kuhtreiber et al., 1999 has given a glucose unit of $4.75 \AA$ x $6.5 \AA$ x $3.4 \AA$ with $\beta(1,4)$ linkage based on the bond angle length. Cellobiose unit has dimensions of $9.0 \AA$ x $6.5 \AA$ x $3.4 \AA$ [Kuhtreiber et al., 1999]. Cellobiose unit measure by x-ray diffraction is $10.4 \AA \mathrm{x}$ $5.3 \AA$ x $3.4 \AA$ [Lynd and Zang, 2004]. A cellulose molecule is a polytrihydric alcohol, containing one primary and two different secondary hydroxyls per unit of polymerization. Reaction of cellulose may occur by disrupting the linkages holding the units together, or it may be any of the usual reactions of hydroxyl groups. In most reactions, the distribution of hydroxyl groups along the cellulose chain provide excellent binding (adsorption) sites for enzymes.

\section{Hemicellulose}

Hemicellulose $\left(\mathrm{C}_{31} \mathrm{H}_{34} \mathrm{O}_{11}\right)_{n}$ is a mixture of polysaccharides [Buchala and Wilkie, 1970] with an average molecular weight of $<30,000$. Hemicellulose is composed of sugars such as glucose, mannose, xylose and arabinose and methylglucuronic and galacturonic acids. Chemical structure of hemicellulose containing $\beta$-1, 3-D-linkage and $\beta$-1, 4-D-linkage are shown in Figure 3.

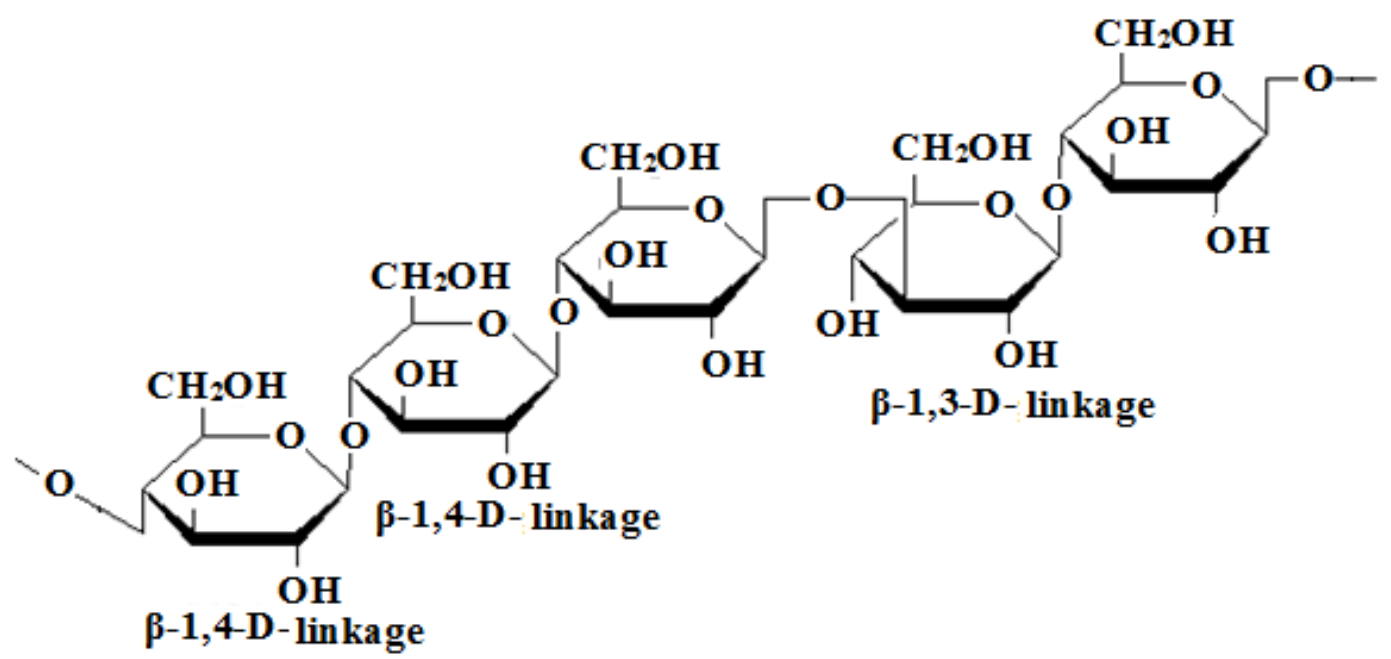

Figure 3: Chemical Structure of Hemicellulose

[Adapted from Klemm et al., 2005; Helmberger, 2009] 
In contrast to cellulose, hemicellulose is a heterogeneous branched polysaccharide that binds to the surface of each cellulosic micro fibril [Hopkins, 1999].Cellulose is generally the largest fraction about $40-50 \%$ by weight; and hemicellulose portion represents $20-40 \%$ of the material by weight [Brigham et al., 1996]. Hemicellulose differs from cellulose, in consisting primarily of xylose and other five-carbon monosaccharides.

\section{Lignin}

Lignin can be regarded as a group of high molecular weight amorphous compounds. Lignin is believed to be a three carbon chain attached to rings of six carbon atoms, called phenyl propanes. A polymeric form of these molecules is shown in the Figure 4.

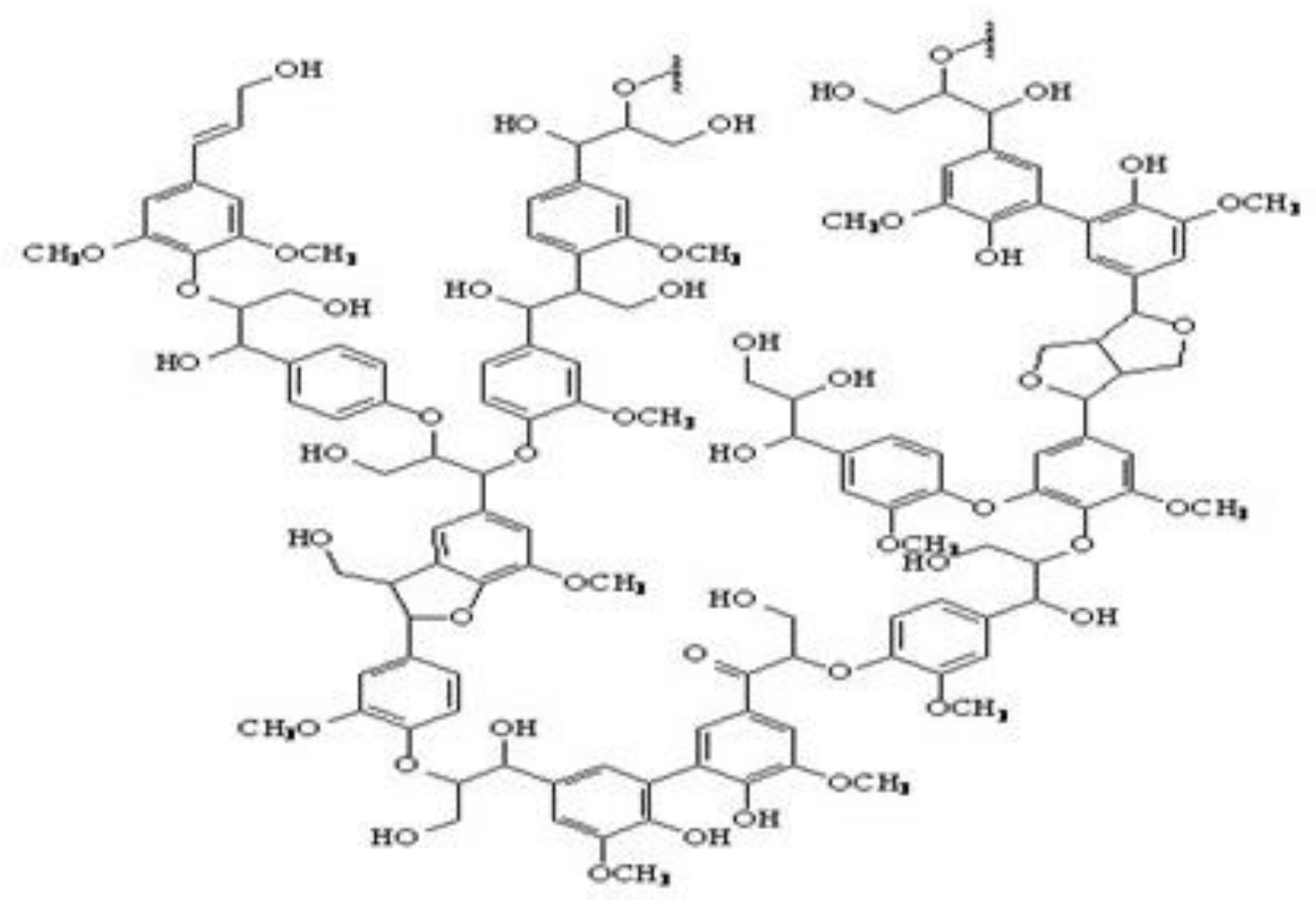

Figure 4: A lignin molecule

[Kirk et al., 1985] 
There may be zero, one or two methoxyl groups attached to the rings giving rise to three structures, termed as I, II and III respectively. The structure-I is found in plants such as grasses, structure II in the wood of conifers and structure III is found in deciduous woods. Lignin strengthens the cell structures by stiffening and holding the fibers of polysaccharides together [Fan et al., 1987]. Lignin contain several functional chemical groups, such as hydroxyl (phenolic or alcoholic), methoxyl, carbonyl and carboxyl, in various amounts, depending on origin and the applied isolation process [Gosselink et al., 2004; Sun et al., 2001].

Methoxyl groups $\left(-\mathrm{CH}_{3}\right)$ are found in lignin from all plants [Bykov, 2008]. The content of methoxyl groups found in softwood and hard wood are 0.92 and 0.94 per one phenyl propane unit respectively [Gosselink et al., 2004; Sun et al., 2001; Bykov, 2008]

Hydroxyl groups: There are aliphatic hydroxyl groups (bound to $\Upsilon$-carbon), secondary aliphatic hydroxyl groups (bound to $\alpha$-carbon) and phenolic groups (bound to 4-C atom of aromatic rings. On average, lignin contain 0.2 primary aliphatic hydroxyl groups per 1 phenyl propane unit, 0.84 secondary aliphatic hydroxyl groups per 1 phenyl propane unit, 0.3-0.35 phenolic hydroxyl groups per 1 phenyl propane unit.

Carboxyl groups: Natural lignin contain $0.05 \mathrm{COOH}$-groups per 1 phenyl propane units. Further carboxy groups are produced during delignification as a result of oxidization of hydroxal and carbonyl groups. After alkaline delignification carboxyl groups increased to 0.15 to 0.16 per 1 phenyl propane unit. The increase of $\mathrm{COOH}$ increase result in increased hydrophobicity of lignin. Carboxyl groups are able to connect to other functional groups via H-bonds. 
Carbonyl groups: The total carbonyl groups in lignin are 0.21 per 1 phenyl propane unit. However these can be of 4 different kinds, there are a few aldehyde groups at the $\Upsilon$-C atom ( 0.04 per 1 phenyl propane unit) and the rest of carbonyl groups are ( 0.17 per 1 phenyl propane unit) are ketone.

Hardwood lignin is easier to break down. The reason has to do with the monomers used for formation of lignin. Remember, hardwood lignins have sinapyl alcohol as a monomer. Since it has two methoxyl groups there is no site on the aryl ring where free radical coupling will occur. Therefore, hardwood lignin has more ether inter unit linkages than softwood lignin. Because of high reactivity of lignin, the presence of lignin is one of the major problems in bioethanol production [Dien et al., 2009].

Removal of lignin: In 1994, McMillan, recognized the importance of pretreatment of lignocellulosic materials. Problems in using lignocellulosic materials are: a) cellulose in nature is bound with lignin, b) lignin inhibit hydrolysis of cellulose. Pretreatment is not only necessary to remove lignin and hemicellulose but it also reduce cellulose crystallinity and increase the porosity of the materials. Pretreatment must meet the following requirements;

i. improve the formation of sugars

ii. avoid the degradation and loss of carbohydrate

iii. avoid byproduct formation which inhibit hydrolysis and fermentation processes iv. be cost effective.

Practical efforts to utilize lignocelluloses as a source for glucose and other sugars have led to many studies of the effect. These have resulted in the development of various pretreatment to increase hydrolysis susceptibility. Pretreatment of lignocellulosic materials has been carried out by physical, physico-chemical, chemical and biological processes. 


\subsection{Cellulases}

The term 'Cellulases' represents to a mixture of enzymes which contains CBHs, EGs and $\beta$ glucosidase (though in small quantity). Fungi and bacteria produce extracellular cellulases which degrade a number of wood and plants [Mandels and Weber, 1969]. A number of Trichoderma species such as T. reesei, T. viride, T. kongii and some other fungal species such as Penicillium funiculosum, A. wentii produce extracellular cellulases. Cellulomonas and Clostridium thermocellum are bacteria that produce extracellular species able to degrade cellulose. Literature review about the adsorption of cellulases onto cellulosic substrate is summarized in Table 2 where the type of enzyme (column 1) adsorbed on the type of substrate (column 2) is given.

Table 2: Summary of enzyme adsorption on cellulosic substrates

\begin{tabular}{|c|c|c|c|}
\hline Enzyme & Substrate & $\begin{array}{c}\text { Max Binding } \\
\mathrm{mg} / \mathrm{g}\end{array}$ & Reference \\
\hline \multicolumn{4}{|l|}{ Trichoderma reesei } \\
\hline $\mathrm{CBHI}, 4{ }^{\circ} \mathrm{C}$ & $\mathrm{BMCC}$ & 6.0 & Reinikainen et al., 1995 \\
\hline $\mathrm{CBHI}, 4{ }^{\circ} \mathrm{C}$ & Avicel & 48 & Medve et al., 1994 \\
\hline CBHI, $25^{\circ} \mathrm{C}$ & Avicel & 63 & Tomme et al., 1990 \\
\hline CBHII, $25^{\circ} \mathrm{C}$ & Avicel & 64 & Tomme et al., 1990 \\
\hline CBHI, $50^{\circ} \mathrm{C}$ & Avicel & 25 & Bothwell et al., 1997 \\
\hline \multicolumn{4}{|c|}{ Thermobifida fusca $50^{\circ} \mathrm{C}$} \\
\hline EG III & Avicel & 26 & Bothwell et al., 1997 \\
\hline EG III & $\mathrm{BMCC}$ & 741 & Bothwell et al., 1997 \\
\hline EG IV, V & Avicel & 31,31 & Bothwell et al., 1997 \\
\hline \multicolumn{4}{|c|}{ Trichoderma viride $30^{\circ} \mathrm{C}$} \\
\hline EG I & Avicel & 130 & Beldman et al., 1987 \\
\hline EG III & Avicel & 26 & Beldman et al., 1987 \\
\hline CBHI & Avicel & 6.6 & Beldman et al., 1987 \\
\hline
\end{tabular}




\begin{tabular}{|c|c|c|c|}
\hline Enzyme & Substrate & $\begin{array}{c}\text { Max Binding } \\
\mathrm{mg} / \mathrm{g}\end{array}$ & Reference \\
\hline EGs, $30^{\circ} \mathrm{C}$ & BMCC & 144 & Gilkes et al., 1992 \\
\hline $\mathrm{CBHs}, 30^{\circ} \mathrm{C}$ & BMCC & 184 & Gilkes et al., 1992 \\
\hline $\mathrm{CBH}, 22^{\circ} \mathrm{C}$ & Avicel & 3 & Ong et al., 1993 \\
\hline \multicolumn{4}{|l|}{ C. thermocellum $25^{\circ} \mathrm{C}$} \\
\hline CBHs & Avicel & 10 & Morag et al., 1995 \\
\hline CBHs & PSAC & 200 & Morag et al., 1995 \\
\hline \multicolumn{4}{|l|}{ C. cellulovorans } \\
\hline $\mathrm{CBH}, 37^{\circ} \mathrm{C}$ & Avicel & 2.1 & Goldstein et al., 1993 \\
\hline \multicolumn{4}{|l|}{ Cellulases mixture } \\
\hline T. reesei & Avicel & 95.2 & Lu et al., 2002 \\
\hline T. reesei & PSAC & 1224 & Lee et al., 1982 \\
\hline T. reesei, $4^{\circ} \mathrm{C}$ & Avicel & 34.9 & Zheng et al., 2013 \\
\hline T. reesei, $4^{\circ} \mathrm{C}$ & SPCL & 1.9 & Zheng et al., 2013 \\
\hline T.viride & Cotton & $78-89$ & Beltrame et al., 1982 \\
\hline T. reesei, $40^{\circ} \mathrm{C}$ & Avicel & 56 & Ooshima et al., 1983 \\
\hline T. reesei, $40^{\circ} \mathrm{C}$ & A.P. wood & 81 & Ooshima et al., 1990 \\
\hline T. reesei, $50^{\circ} \mathrm{C}$ & Avicel & 5.3 & Bommarius et al., 2008 \\
\hline T. reesei, $50^{\circ} \mathrm{C}$ & Avicel & 18.6 & Zheng et al., 2013 \\
\hline T. reesei, $50{ }^{\circ} \mathrm{C}$ & SPCL & 21.2 & Zheng et al., 2013 \\
\hline C. thermocellum $60^{\circ} \mathrm{C}$ & Avicel & 17.5 & Hayashi et al., 1997 \\
\hline
\end{tabular}

BMCC: Bacterial modified crystalline Cellulose; A.P. Wood: Dilute acid pretreated wood;

PSAC: Phosphoric acid-swollen cellulose: SPCL: Steam explosion pretreated corn stover lignin;

Max Binding: Maximum binding achieved

Table 2 indicates that cellulases produced from $T$. reesei complex have excellent adsorption on crystalline cellulose. Therefore, cellulases from $T$. reesei were selected to study adsorption and desorption. T. reesei complex secretes endoglucanases (EGs, such as Cel7B, Cel5A) and cellobiohydrolases (CBHI (Cel7A) and CBHII (Cel6A)) (Vinzant et al., 2001). In addition to the 
$\mathrm{CBH}$ and EG activity, T. reesei also produces $\beta$-glucosidase, BG (Chen et al., 1992). Table 3 represents main components of cellulases and their compositions in some available commercial enzyme complexes.

Table 3: Enzyme components from $T$, reesei cellulases complex

\begin{tabular}{|l|c|c|c|c|}
\hline Enzyme & $\begin{array}{l}\text { Lutzen } \text { et } \\
\text { al., 1983 }\end{array}$ & $\begin{array}{l}\text { Rosgaard } \text { et } \\
\text { al., 2007 }\end{array}$ & Kang, 2011 & $\begin{array}{l}\text { Hilden and } \\
\text { Johansson, 2004 }\end{array}$ \\
\cline { 2 - 5 } & Celluclast & Cellulases & Spezyme CP & NS 50013 \\
\hline $\begin{array}{l}\text { Cel 7B, } \\
\text { endoglucanase I }\end{array}$ & 10 & $5-10$ & 12 & 10 \\
\hline $\begin{array}{l}\text { Cel 5A, } \\
\text { endoglucanase II }\end{array}$ & 10 & $1-10$ & 9 & 10 \\
\hline $\begin{array}{l}\text { Cel 7A, } \\
\text { cellobiohydrolase I }\end{array}$ & 55 & $40-60$ & 50 & 60 \\
\hline $\begin{array}{l}\text { Cel 6A, } \\
\text { cellobiohydrolase II }\end{array}$ & 10 & $12-20$ & 14 & 15 \\
\hline$\beta$ - glucosidase & $1-2$ & N.D. & $<2$ & 2 \\
\hline
\end{tabular}

The modular structure of enzymes was deduced from the studies of T. reesei and Cellulomonas fimi. The modular structure features i) carbohydrate-binding domain (CBD), ii) catalytic domain (CD) or core, iii) linker which join CBD and CD [Srisodusk et al., 1993]. This structure has been confirmed by a number of researchers [Hefford et al., 1992; Ryu et al., 1991; Ramalingam et al., 1992; Wilson, 1992; Park et al., 1993]. Various instruments have been used in structure analysis such as Triple quadruple mass spectrometer with post-column splitter, reverse-phase HPLC on an Ultrafast Microprotein Analyzer, nuclear magnetic resonance, X-ray crystallography etc. Computer software's such as Multiview 1.0, DENZO, ROTAVATA and AGROVATA, RAVE, XPLOR and /or REFMAC can also help in structure analysis. CBD have shape like a wedge with dimensions approximately $30 \times 18 \times 10 \AA$ [Linder and Teeri, 1997]. CBDs are thought to have three primary functions i) proximity effects, ii) substrate targeting and, iii) microcrystallite disruption [Kuutti et 
al., 1991; Linder and Teeri, 1997; Boraston et al., 2004). CBMs promotes the association of the enzyme with the substrate (proximity effect) (Reinikainen et al., 1991; 1992].

CBDs are selective for substrates including crystalline and amorphous celluloses, and various soluble and non-soluble polysaccharides (substrate targeting) [Lamed et al., 1994; Tomme et al., 1995; Creagh et al., 1996; Tormo et al., 1996; Linder and Teeri, 1997; Henshaw et al., 2004]. In addition, CBDs disrupt the structures of the carbohydrate ligands to make the substrate more susceptible to enzymatic attack (microcrystalline disruption) [Din et al., 1994]. For the purpose of biomass conversion the CBDs with the function of substrate targeting (cellulose) are of interest [Phelps et al., 1995; Teeri, 1997; Boraston et al., 2004. The full catalytic domain consists of 89 to 450 amino acid residues. The active site of Cel6A (CBH II), as for the T. reesei $\mathrm{CBH}$ II, is enclosed by two extended surface loops (residues 174-196 and 407-435). This results in the formation of a long substratebinding tunnel, over $20 \AA$ long. The active-site tunnel of the $H$. insolens Cel6A (CBH II) constricts to a minimum dimension of approximately $3.5 \AA$. Both of these loops are stabilized by disulphide bridges (Cys181-Cys240, Cys372-Cys419. Two aspartic acid residues, located in the center of the tunnel are the probable catalytic residues [Rouvinen et al., 1990]. A mechanism outlined by Koshland (1953) requires the presence of two catalytic carboxylate groups: a proton donor to protonate the glycosidic bond and promote leaving-group departure, and a catalytic base to activate the hydrolytic water molecule for nucleophilic attack at the anomeric center.

Comparison of the primary structures of $T$. reesei cellulases revealed that a large catalytic domain joined by a flexible, 0-glycosylated linker peptide to a smaller cellulose-binding domain (CBD) [Penttila et al., 1986, Stahlberg et al.,1991]. The linkers identified in T. reesei cellulases may contain 30-44 amino acids in length [Fagerstam et al., 1984; Tomme et al., 1988; Claeyssens and Tomme, 
1989; Srisodsuk et al., 1993]. Linkers are rich in proline, serine, threonine (Teeri et al., 1987) and they are negatively charged. The proline and hydroxyl amino acid content is different among the linkers. The length of linker from CBH I and CBH II observed was 5-15 nm [Lee and Brown, 1997; Liu et al., 2011]. Cellulase linkers represent extended, flexible hinges between the two domains facilitating their independent function (Burton, 1989; Bushuev et al., 1989). Figure 5 represents how CBHs, EGs and $\beta$ Gs approach cellulose. CBHs attack on the reducing $(\mathrm{R})$ and nonreducing (NR) ends. Endoglucanase II (EG II) from T. reesei is able to hydrolyze the internal $\beta$-1,4-glycosidic bonds of soluble celluloses and amorphous regions of cellulose $\beta$ Gs converts tetrose, triose, cellobiose.

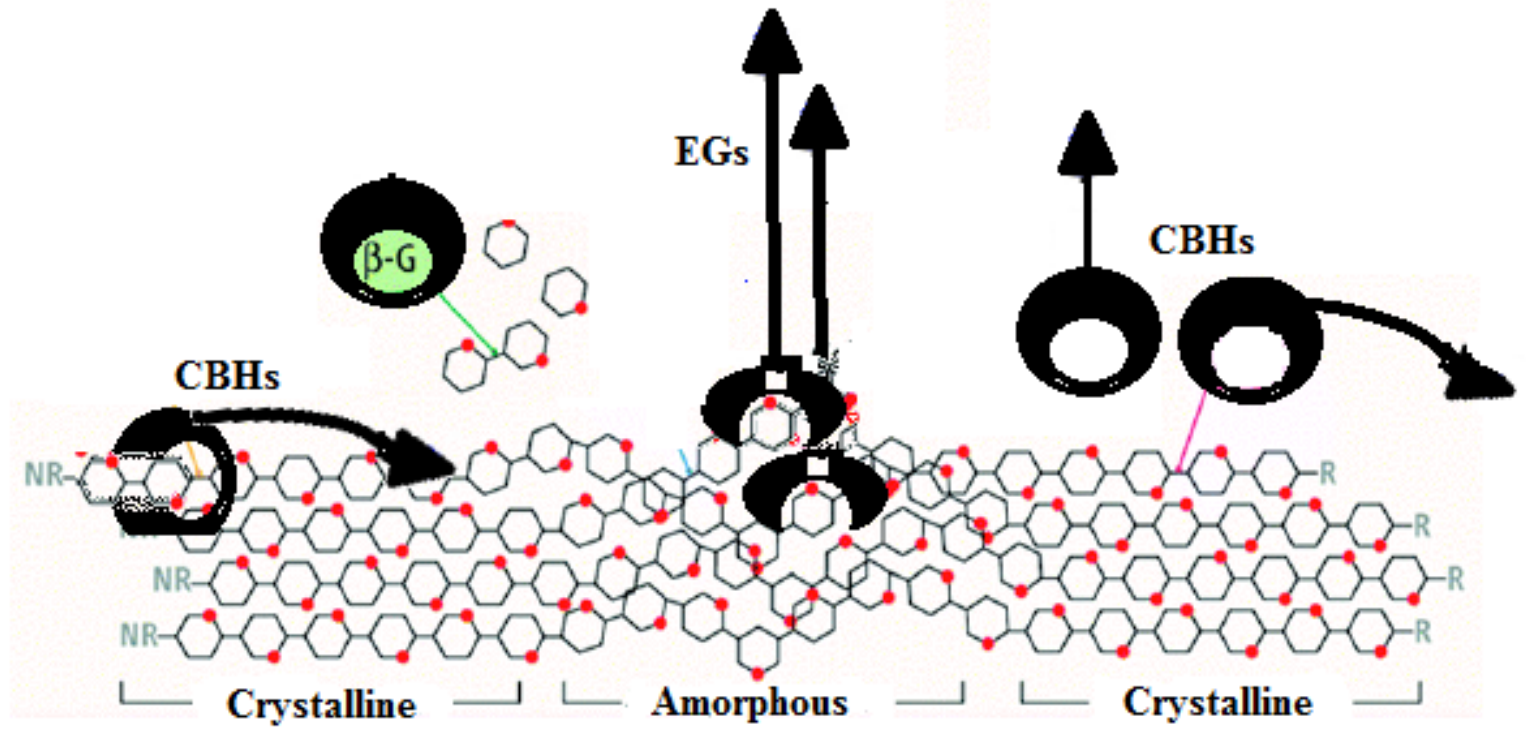

Figure 5: A conceptual diagram on functioning of cellulases onto cellulose

Structural difference between the EGs and CBHs is at the two loops which contains the active sites in the CBHs are absent in EGs. The one loop (407-435) present in Cel6A (CBH II) is absent from EGs while the other surface loop (174-196) is 'pulled up' in the EG structure in a way to expose the active site [Divne et al., 1994; Henriksson et al., 1996]. This results in an active-site tunnel for Cel6A (CBH II) and an open a cleft in EGs. The work pattern in both the enzymes is almost the same. The enzymes CBH I and CBH II have different structure and hydrolyze the cellulose from the reducing 
end and the non-reducing end. They have tunnel shaped active sites. The enzymes CBH I, CBH II, EG I, and EG II shared a region of 36 amino acids well conserved [Terri et al., 1987; Divine et al. 1994]. From a structural point of view, adsorption of cellulase is through CBD [Creagh et al., 1996; Carrard et al., 2000; Fox et al., 2013]. Several papers have reviewed the roles and function of these binding domains [Shoseyov et al., 2006]. See further discussion on CBDs under the heading 'Cellulases adsorption'.

\section{Cellulases dimensions}

Depending upon the substrates and the fermentation conditions, cellulases obtained from different sources are quite different in size and molecular weight. Using gel filtration Cowling (1975) estimated dimensions of cellulases complexes in two possible scenarios: 1) as hydrodynamic spheres, from $24 \AA$ to $77 \AA$ A. 2) as ellipsoids, from 13 X $79 \AA$ to 42 X $79 \AA$ in width and length. Cel7A from T. reesei is composed of long loops, on one face of the sandwich, that form a cellulose-binding tunnel of $\approx 50 \AA$. The catalytic residues are glutamate 212 and 217 , which are located on opposite sides of the active site, separated by an intervening distance consistent with a double-displacement retaining mechanism [Kleywegt et al., 1997]. Enzyme binding sites are regions on the surface of an enzyme specially designed to interact with other molecules. The binding site has the task of specifically recognizing the molecule upon which the enzyme acts [Shevelev and Hubscher, 2002] and develop binding. CBH I, II and EG I, II are two domain components of cellulases, consisting of a large catalytic core linked to a small cellulose-binding domain by a heavily glycosylated linked region [Abuja et al., 1988]. The catalytic domain of CBH (Cel7A) consists overall dimensions of

approximately $60 \AA ̊$ x $40 \AA ̊$ x $50 \AA$ [Grassic et al., 2004]. The third type of enzyme present in cellulases is $\beta$-glucosidase and it is a single domain enzyme. All the three type of enzymes act in synergy to convert cellulose to glucose. 


\section{Cellulases adsorption}

EG II from Trichoderma reesei is able to hydrolyze: i) the internal $\beta$-1,4-glycosidic bonds of soluble celluloses and, ii) the amorphous regions of cellulose [Fukuda et al., 2006]. When EG II approach celluloses, its $\mathrm{CBD}$ binds to cellulose and its catalytic domain breaks the glycosidic bonds of cellulose (Nam et al., 2002; Ito et al., 2004; Linder et al., 1995). EG moves progressively along a crystalline cellulose chain, its $\mathrm{CBD}$ arranges the chain to feed to the catalytic domain where cellobiose is produced by hydrolyzing $\beta-(1,4)$ glycosidic linkages. CBD had a flat face composed of asparagine 29 (N29) and glutamine 34 (Q34) and three aromatic amino acid residues (W5), (Y31), and (Y32) on the flat face (Linder et al., 1995). The aromatic amino acid residues are the main part for the binding to crystalline cellulose, as shown by the alanine-substitution experiment of each aromatic amino acid residue (Linder et al., 1995). The conceptual diagram in Figure 6 is design by adapting published literature.

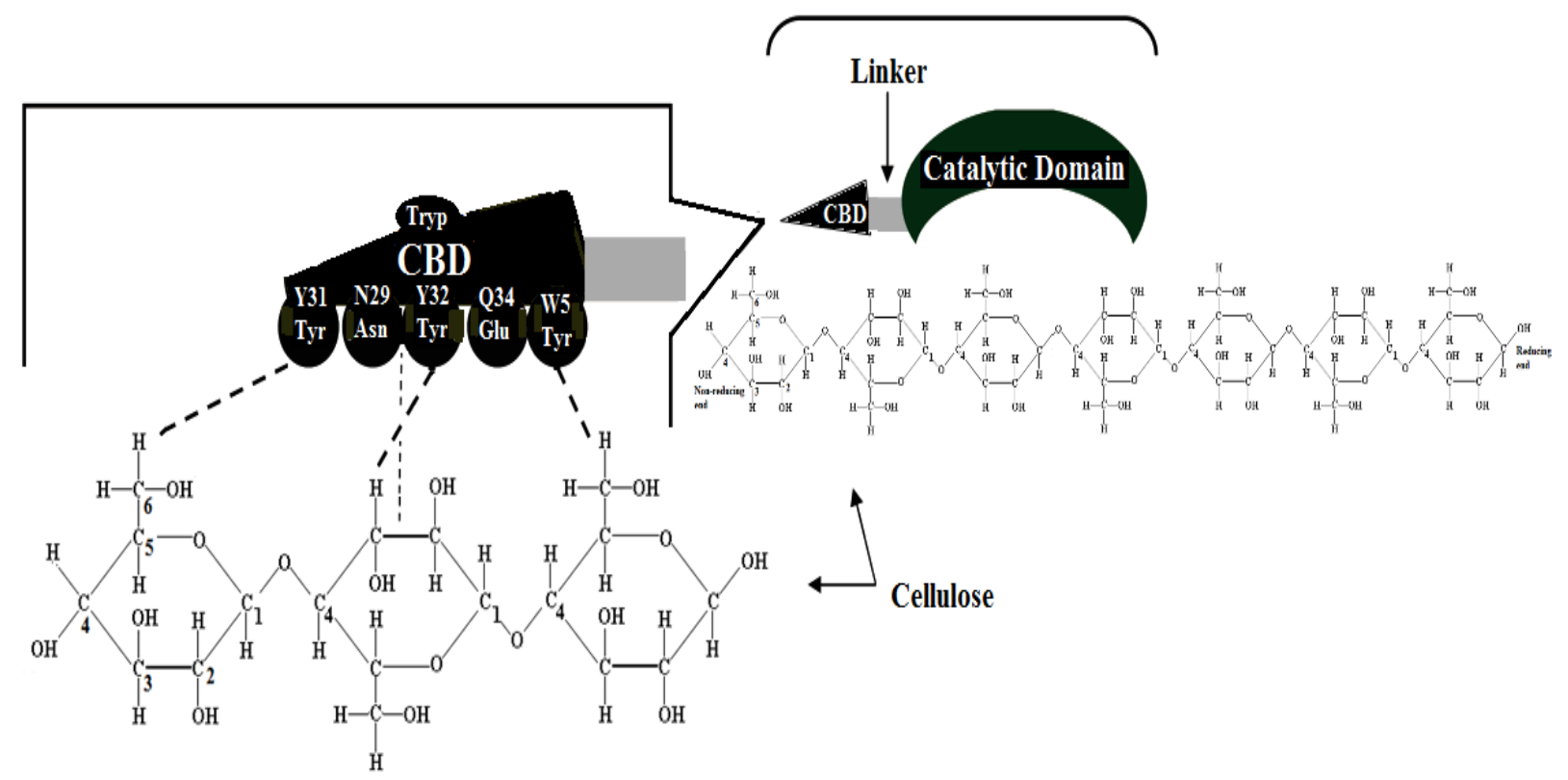

Figure 6: A conceptual diagram on action of CBDs on cellulose for adsorption

[Adapted from: Linder et al., 1995; Nam et al., 2002; Ito et al., 2004; Fukuda et al., 2006; Nimlos et al., 2007] 
The distance between the groups is about the same as a cellobiose unit in the cellulose i.e. $11 \AA$ [Humphrey et al., 1996]. The $4^{\text {th }}$ tyrosine residue in the CBD (Y13) moves from its internal position to form van der Waals interactions with the cellulose surface [Nimlos et al., 2007]. CBD because of the presence of aromatic residues behaves as hydrophobic and interact with the surface structure of crystalline cellulose [Lehtio et al., 2003]. In this conformation either 2 or 3 axial hydrogen atoms are exposed, while hydroxyl groups at the ring are in the equatorial position. As a result, the hydrophobic surfaces of CBDs bind to the hydrophobic surface of crystalline cellulose.

There are two hypotheses to explain adsorption of cellulases [Coughlan, 1989; Tomme et al., 1988; Zagursky et al., 1986]: i) the CBD simply binds to cellulose i.e. riding over the cellulose surface [Teeri, et al., 1992], ii) the CBD plays more active role in liberating cellulose chains from the crystal bundle [Knowles et al., 1987; Mulakala and Reilly, 2005]. The 3D structure of binding domain of CBH I was determined earlier [Kraulis et al., 1989]. The domain folds into a wedge-like structure with one face flat and hydrophilic and the other face is more hydrophobic. The flat face of CBD most probably adsorbs on the substrate. The amino acid sequences of the four cellulose-binding domains of T. reesei cellulases have similar $70 \%$ amino acid character. The tyrosines Y492 and Y493 are strictly conserved in all $T$. reesei cellulases and the Y474 is substituted by tryptophan in CBH II and EG II. The spacing between the tyrosines (and the tryptophans) are almost the same as that the spacing between every second glucose unit in the cellulose crystal [Reinikainen et al., 1992].

\section{Enzymes to substrate ratio}

The number of studies that speak directly to this point is, however, limited, and thus extensive data are not available with respect to variables such as sources of enzymes, substrates, enzyme preparation method, enzyme/substrate ratios, and extent of reaction. In the Table 4 column 1 is for the enzymes 
adsorbed on substrate (column 2), column 3 gives enzyme to substrate and column 4 shows enzyme concentration used in adsorption.

Table 4: Enzymes used for adsorption onto substrates

\begin{tabular}{|c|c|c|c|c|}
\hline Enzyme & Substrate & $\mathrm{E} / \mathrm{S}$ & $\begin{array}{l}\text { [Enzyme] } \\
\mu \mathrm{g} \mathrm{mL}-1\end{array}$ & Reference \\
\hline $\begin{array}{l}\text { Meicelase CEPB- } \\
5041 \text { (T. viride })\end{array}$ & MCC 2330 & $5.7-4.5$ & $160-230$ & Converse et al., 1988 \\
\hline CBHI, CBHII & $\begin{array}{l}\text { Avicel } \\
(\mathrm{M} 2331)\end{array}$ & $0.01,0.03$ & N.D. & Medve et al., 1994 \\
\hline $\begin{array}{l}\text { Cellulases } \\
\text { T. viride, T. reesei }\end{array}$ & Avicel PH 101 & 0.02 & $40-500$ & Wang et al., 2011 \\
\hline $\begin{array}{l}\text { cellulases QM } \\
9414 \text { (T.uiride) }\end{array}$ & Solkafloc 40 & $\begin{array}{l}0.11,0.22,0.011 \\
0.022,0.044\end{array}$ & $1100-2200$ & Peitersen et al., 1977 \\
\hline CBHI, CBHII & Avicel PH 101 & 0.008 & 100 & Kim et al., 2001 \\
\hline CBHI, EG II & $\begin{array}{l}\text { Avicel } \\
\text { (M2331) }\end{array}$ & $0.005,0.01,0.16$ & N.D. & Medve et al., 1998 \\
\hline $\begin{array}{l}\beta \text {-d-glucosidase, } \\
\text { Mannanase, EGs, } \\
\text { CBHs }\end{array}$ & $\begin{array}{l}\text { Shirakamba } \\
\text { wood }\end{array}$ & $1,0.1,0.02$ & N.D. & Ishihara et al., 1991 \\
\hline $\begin{array}{l}\text { Tyrosine, } \\
\text { Phenylalanine }\end{array}$ & Corn Cobs & $0.01-0.002$ & $20-100$ & Alves et al., 2013 \\
\hline
\end{tabular}

According to Lee and Fan (1982) a linear correlation exist between adsorption/hydrolysis rate and enzyme to substrate ratio. Bernardez et al. (1993) adsorbed cellulases (obtained from Clostridium thermocellum) on Avicel 105 and on pretreated mixed wood (90\% Birch wood, $10 \%$ Maple) and examined the effect of enzyme to substrate ratio on adsorption. They concluded that at low E/S ratios, there was a linear trend of adsorbed enzyme with respect to the initial enzyme concentration. At higher E/S ratios, the results of their experiments showed that adsorbed enzyme leveled off due to the saturation of the cellulosic substrate with enzyme. A very crucial parameter is an enzyme/substrate (E/S) ratio, since a limitation of cellulase adsorption by substrate surface area may occur at high E/S ratios. Use as low a concentration of cellulase as possible in the experiments. High enzyme concentration may result in distorted inhibition patterns because of a possible lack of 
cellulose surface area to bind the enzyme. For the same reason, our study used low cellulose concentrations and worked a fixed substrate concentrations, in other words, at low enzyme/substrate ratios.

\section{Interactions of cellulases with cellulose}

Cellulase adsorption onto crystalline cellulose was widely studied with a focus on CBD-cellulose interactions, CBDs adsorb more to cellulosic surfaces [Palonen et al., 1999]. The $\alpha$ - and $\beta$-structures of cellulose have hydrophilic and hydrophobic faces. The hydrophobic faces are only $38 \%$ of surface area in crystals of 36 parallel cellulose chains [Nimlos et al., 2012]. Lehtio et al. (2003) reported that

CBDs of family 1 and family 3 cellulases was preferentially adsorbed on the hydrophobic planes of Valonia cellulose. Enzymes interact with carbohydrates through charged and aromatic amino-acid residues and enzymes may form hydrogen bonds or van der Waals interactions with carbohydrates [Vyas, 1991]. There are contradicting results reported about the effect of $\mathrm{pH}$ on cellulase adsorption. For example, Reinikainen et al. (1995) showed that $\mathrm{pH}$ only had a modest effect on T. reesei Cel7A adsorption onto BMCC, while binding onto catalytic domain was unaffected by $\mathrm{pH}$. Some other report suggested that at high substrate concentration the CBDs becomes less important for substrate recognition [Le Costaouec et al., 2013; Varnai et al., 2013].

\section{Interactions of cellulases with lignin}

Non-productive enzyme adsorption onto the lignin-rich components of biomass prevents efficient hydrolysis of feedstock [Chernoglazov et al., 1988; Sutcliffe and Saddler, 1986]. Adsorption onto lignin is disadvantageous for process economics: i) higher enzyme loadings are required to overcome the inhibitory effect, and ii) enzyme recycling is hindered after a completed reaction (Lee et al., 1995). Three types of interactions are involved in enzyme binding onto lignin: i) hydrophobic 
(Eriksson et al., 2002), ii) electrostatic (Nakagame et al., 2011b), and iii) hydrogen-bonding interactions (Berlin et al., 2005). The CBDs of T. reesei cellulases, Cel7A and Cel5A were adsorbed onto lignin in significantly high amount [Palonen et al., 2004] due to hydrophobic interaction. Some isolated lignin have shown carboxylic acid, phenolic and aliphatic hydroxyl groups [Berlin et al., 2006]. Phenolic hydroxyls in lignin model compounds were found to be deprotonated in the $\mathrm{pH}$ range 6.2-11.3 [Ragnar et al., 2000]. Enzymatic hydrolysis of lignocellulosic materials is usually carried out at $\mathrm{pH} 5$, when carboxylic acid groups present in lignin are deprotonated. Nakagame et al. (2011b) reported that at $\mathrm{pH} 4.8$ the isolated lignin showed a negative charge, and T. reesei enzymes (Cel6A and Cel5A) were positively charged, resulting in better adsorption. Adsorption onto lignin was reduced at elevated $\mathrm{pH}$ values due to increased repulsive electrostatic forces between the enzymes and lignin (Lou et al., 2013). This finding has more practical value from adsorption and desorption point of view. Enzyme-substrate interactions are non-covalent type and the driving forces involve are hydrophobic and electrostatic interactions, with minor contribution from hydrogen bonding and dipolar interactions [Claesson et al., 1995; Norde, 1996].

\section{Degradation of substrates during adsorption}

Most of the reported results showed that the adsorbed cellulase reached a constant value in less than $90 \mathrm{~min}$, and among these many were in less than 30 min whereas complete hydrolysis of cellulose took a day or more [Ooshima et al., 1983; Chernoglazov et al., 1988; Lee and Woodward, 1989; Singh et al., 1991; Boussaid and Saddler, 1999]. Andersen and co-workers reported that Avicel PH101 was hydrolyzed up to $7 \%$ in 24 hours by using a commercial enzyme mixture (EGs, CBHs and $\beta$-glucosidase). Most of this hydrolysis (5\%) was completed after 5 hours of the adsorption. Kyriacou et al. (1988) studied adsorption of EG I, EG II, EG III and CBH I components of cellulases on Solkafloc (purified wood cellulose) at temperature $5{ }^{\circ} \mathrm{C}, 30^{\circ} \mathrm{C}$ and $50^{\circ} \mathrm{C}$. The degree of hydrolysis 
of Solkafloc was examined by each cellulases component during the adsorption process by monitoring the reducing sugars produced. At $5.0^{\circ} \mathrm{C}$, cellulases EG I, EG II, and EG III hydrolyzed less than $1.0 \%$ of Solkafloc and CBH I did $1.5 \%$. At $50.0{ }^{\circ} \mathrm{C}$, EG I could degrade $2.0 \%$, EG II and EG III, did by $2.4 \%$, while CBHI degraded Solkafloc by $3.3 \%$. In our cellulases system there were $10 \%$ EG I, $10 \%$ EG II and $60 \%$ CBH I, therefore the expected degradation could be $2.24 \%$, which is negligible and we were not working with Solkafloc also. Hu et al. (2011) adsorbed Celluclast 1.5L on steam pretreated corn stover and found that the substrate was $5 \%$ hydrolysed after 24 hours. Lee and Woodward (1989) adsorbed cellulases T. reesei C30 on Avicel at pH 5, 5.6 and 9.6. Adsorption equilibrium was achieved in 30 minutes and after 4 hours hydrolysis just started. Similarly, Gao et al. (2014) studied hydrolysis of Avicel by using a mixture of cellulases and $\beta$-glucosidase and $0.4 \%$ hydrolysis occurred at 24 hours. Notice another point here that Gao et al. (2004) were also using $\beta$ glucosidase which helps hydrolysis. Therefore, during the period of adsorption/desorption no hydrolysis of Avicel was expected by using cellulases NS50013 alone.

Sahoo et al. (2011) reported that the thermal degradation onset temperature for Protobind 1000 was $155^{\circ} \mathrm{C}$. Onset temperature is the temperature at which the weight loss begins. The initial (small) degradation in Protobind 1000 was observed at $55{ }^{\circ} \mathrm{C}$ which was negligible because it was due to dehydration of xylose. Protobind 1000 contains $<4 \%$ xylose which degrade around $200-270{ }^{\circ} \mathrm{C}$. The thermal decomposition reactions of polysaccharides occur through: i) dehydration, decarboxylation, decarbonylation, ii) cleavage of glucoside bonds, C-H, C-O and C-C bonds [Hoareau et al., 2004]. Xylose undergoes dehydration during the initial stage of heating $\left(55^{\circ} \mathrm{C}\right)$ and depolymerization of xylose take place on increasing the temperature above $200{ }^{\circ} \mathrm{C}$ [Lappalainen $e t$ al., 2006]. The major degradation (52.7\%) occurs between temperatures 200 to $600{ }^{\circ} \mathrm{C}$. At $800{ }^{\circ} \mathrm{C}$ 
char residues obtained were about $38 \%$. Therefore, in this study the degradation of Protobind during adsorption/desorption studies was not expected.

\subsubsection{Cellulases adsorption isotherms}

The first step in cellulolysis is binding (adsorption) of the cellulase onto the substrate. Equilibrium relationships between cellulases and substrates are described by adsorption isotherms. Adsorption isotherms give the capacity of the adsorbent based on the ratio between the quantity adsorbed and the remaining in solution at fixed temperature at equilibrium [Dhir and Kumar, 2010]. The adsorption isotherms have history for being used in representing adsorption of gases on liquids [Wilkins, 1934; Wylie, 1952; Dabarowski, 2001] and liquids on solid surfaces [Lee, 1999; Berti, et al., 2000]. Paper pulp, silica or mica were used to model the behaviour of cellulose due to the presence of hydroxyl groups [Bogdanovic et al., 2001; Lingstrom et al., 2007], but the mineral surfaces cannot be considered as very good representatives of cellulosic surfaces. Therefore various ultrathin films have instead been developed to represent more precisely surface of cellulosic fibres. They were introduced in detail in a review article (Kontturi et al., 2006) and were considered for studies of adsorption and swelling of materials (Falt et al., 2003; Tammelin et al., 2006) or direct surface force measurements (Notley and Wagberg, 2005). Recently, some reports were available on cellulases adsorption on various lignocellulosic substrates, such as microcrystalline cellulose [Medve et al., 1994; Hong et al., 2007], newspaper pulp, bagasse, and treated wood chips [Yu et al., 1995; Goel and Ramchandran, 1983], corn stover [Xu et al., 2008], steam-exploded Douglas fir [Lu et al., 2002], pretreated hardwood [Bernardez et al., 1993], isolated lignin from softwood [Palonen et al., 2004] and lignin preparations from Lodgepole pine [Tu et al., 2009]. 
The information about adsorption of cellulases onto lignin is very rare and for wheat straw lignin none could be found. Adsorption of cellulases on cellulose and lignin under similar experimental conditions was never studied although both remained present on lignocellulosic substrate at the same time. The aim of the present work was to investigate the adsorption of cellulases on cellulose (Avicel PH 101) and wheat straw lignin (Protobind 1000) under similar experimental conditions.

Peitersen et al. (1977) and Kim et al. (1995a; 1998) determined that adsorption of cellulases onto microcrystalline cellulose could be represented by Langmuir model. Some of the researchers have suggested Freundlich isotherm for adsorption of cellulases [Carrard and Linder, 1999; Tu et al., 2009; Sun et al., 2011;]. Few reports used both Langmuir and Freundlich isotherms to represent adsorption of cellulases [Kanchagar, 2003; Vadi et al., 2010; Singh and Kaur, 2014]. The present work will elucidate adsorption pattern of cellulases whether it follow Langmuir or Freundlich or another type of isotherm. Furthermore, this is the first report on the study of cellulases adsorption on Protobind 1000.

\section{Linear adsorption isotherm}

Linear adsorption isotherm is also known as Nernst adsorption isotherm. According to Nernst isotherm equation an enzyme (cellulases) irrespective of its total amount, distributes itself between two layers (adsorbed or bulk) in a constant concentration ratio, at constant temperature; the ratio, equal to the constant in Equation 2.4, is referred to as the distribution or partition ratio/coefficient $\left(K_{N}\right)$ [Oscik and Cooper, 1982]:

$$
P_{e}=K_{N}\left[P_{f}\right] \quad \ldots \quad 2.4
$$

where, $P_{e}=$ specific amount of cellulases adsorbed on substrate, $\mu \mathrm{g} \mathrm{mg}^{-1},\left[P_{f}\right]=$ concentration of cellulases present in the solution, $\mu \mathrm{g} \mathrm{mL}^{-1}, K_{N}=$ Partition coefficient given by the slope, $\left(\mathrm{mL} \mathrm{mg}^{-1}\right)$. 


\section{Langmuir adsorption isotherm}

The Langmuir adsorption model assumes:1) The substrate is composed of uniform binding sites and, 2) There is no interaction between the adsorbing molecules. A monolayer of adsorbents is formed and that the free energy of adsorption remains constant. The amount of adsorbed cellulases were obtained by the following Equation 2.5 [Langmuir, 1918]:

$$
P_{e}=\left[P_{f}\right] \frac{K_{a} P_{a m}}{\left(1+K_{a}\left[P_{f}\right]\right)} \quad \ldots \quad 2.5
$$

where,

$P_{a m}=$ maximum cellulases adsorbed $(\mu \mathrm{g}$ of cellulases $/ \mathrm{mg}$ of substrate $), K_{a}=$ constant $(\mathrm{mL} / \mu \mathrm{g})^{-1}$

Equation 2.5 can be rearranged to get a linear form:

$$
\frac{\left[P_{f}\right]}{P_{e}}=\frac{1}{K_{a} P_{a m}}+\frac{1}{P_{a m}}\left[P_{f}\right] \quad \ldots \quad 2.6
$$

Pietersen et al. (1977) used equation 2.6 for the first time. The Equation 2.5 can also be rearranged in another way called 'Scatchard' type, used for the first time in 1949:

$$
\frac{P_{e}}{\left[P_{f}\right]}=K_{a} P_{a m}-K_{a} P_{e} \quad \ldots \quad 2.7
$$

\section{Freundlich adsorption isotherm}

The Freundlich isotherm has a place in colloid chemistry for characterising the adsorption of molecules onto an interface [Reed and Matsumoto 1993; Proctor and Toro-Vazquez, 1996]. Freundlich isotherm was used to describe adsorption of $\alpha$-amylase to starch granules. Freundlich isotherm for adsorption to heterogeneous surfaces is given as follows [Freundlich, 1906]: 


$$
P_{e}=K_{f}\left[P_{f}\right]^{\frac{1}{m}}
$$

Where, $K_{f}=$ Freundlich constant for cellulases-substrate complex, distribution constant, $\mu \mathrm{g} \mathrm{mg}^{-1}, \mathrm{~m}$ $\left(\mu \mathrm{g} \mathrm{mg}^{-1}\right)$, power term of the Freundlich isotherm $(m>1), m$ and $K_{f}$ are empirical parameters.

The linear form of Equation 2.8 can be written as:

$$
\ln P_{e}=\frac{1}{m} \ln \left[P_{f]}+\ln K_{f} \quad \ldots \quad 2.9\right.
$$

Cellulases adsorption on cellulose is a prerequisite to desorption. Adsorption of cellulases generally reached to its equilibrium within a short time. The adsorption pattern was commonly explained using Langmuir isotherm [Hong et al., 2007; Zhang and Lynd, 2004]. The Langmuir isotherm assumed that the adsorption was a single layer phenomenon and it maintained a balance between rates of adsorption and desorption, binding affinity and adsorption capacity. The values of parameters in Langmuir isotherms are available through a number of reports. However, the reported data have a wide variation, due to different methods and experimental conditions used. Some studies reported contrasting hypothesis [Zhang and Lynd, 2004] such as cellulases bound reversibly to cellulosic materials while some claimed partially irreversible [Kyriacou et al., 1989; Palonen et al., 2004]. Cellulases have different binding preferences (Pinto et al., 2004; Boraston, 2005; Ding et al., 2006). Therefore, a dedicated study on the adsorption of cellulases on cellulose and lignin was required and present study fulfill these needs. Adsorption is the ability of cellulases to stay on a substrate. The more tightly adsorbed cellulases to a substrate, the less likely cellulases will desorb [Azevedo et al., 2000]. The adsorption studies also provide insight about the structure of adsorbed layers and the type of interaction of cellulases with the substrates hence about desorption because desorption is dependent on surface coverage [Wang et al., 2013] and adsorption pattern. 


\subsubsection{Adsorption of mixtures of endoglucanases and exoglucanases}

Kanchagar (2003) studied adsorption of mixtures of endoglucanase or exoglucanases in different combinations. Some components of endoglucanase and exoglucanases showed synergism in hydrolytic action while others do not show any synergism $\mathrm{CBH}$ II showed synergistic action in the presence of EG II but in presence of EG I, CBH II showed preferential adsorption on microcrystalline cellulose. $\mathrm{CBH}$ II was found to be inactive on microcrystalline cellulose when used alone [Kanchagar, 2003]. Some other research groups reported that CBH II showed synergistic action when present in the ratio of 1:1 (w/w) with EG I or EG II [Kim et al., 1995a, Kim et al., 1995b, Kim et al., $1995 c]$.

Beldman (1987) studied adsorption of endoglucanase and exoglucanases from Tricoderma viride and reported that some enzymes adsorbed strongly (EG I, III and CBH I) and the others adsorbed moderately on crystalline cellulose (EG II, IV, CBH II) and Ryu et al. (1984) observed that a part of endoglucanase do not adsorbed at all. The competitive adsorption of CBH I (Cel7A, an exoglucanase and endoglucanase I (Cel7B) from T. longibrachiatum was studied by Maurer et al. (2012) on cellulose and it was observed that Cel7A (CBH I) has a higher adsorptive affinity for cellulose than does Cel7B (EG I). The rate at which each surface enzyme bound (when they are present alone) was identical. Because of the higher affinity of Cel7A for the cellulose surface, when Cel7A and Cel7B compete for surface sites. A significantly higher bulk concentration of Cel7B is required to achieve comparable surface enzyme concentrations. The choice of bulk composition (initial composition) of enzymes would be designed by considering nature (composition) of substrate. According to Linder et al. (1995) the cellulose binding modules of CBH I and EG I show single amino acid substitutions leading to differences in binding affinity. In addition, catalytic domains of cellulases are known to specifically adsorb to cellulose binding sites independently of 
cellulose binding modules [Lynd et al., 2002]. The maximum cellulase adsorption at equilibrium was higher for EG I than for $\mathrm{CBH}$ I, indicating more accessible cellulose binding sites for EG I, which was also observed by other researchers [Beldman et al., 1987, Nidetzky et al., 1994]. Besides the aforesaid differences in cellulases structure and binding affinity, these maximum adsorption differences could be explained by the lower molecular mass of EG I and, therefore, a better access to internal binding sites (pores) as described for other proteins and materials [Hunter and Carta, 2002; Oberholzer and Lenhoff, 1999].

On the other hand, it was suggested that the substrate to enzyme ratio may not be maintained because of a decrease in number of sites for endoglucanases and increase in number of sites for exoglucanases and individual nature of adsorption of endoglucanases and exoglucanases [Ooshima et al., 1983; Kim et al., 1992]. Under various tested conditions the results obtained by the mixed enzymes exceeds the sum of the individual enzymes [Qi et al., 2007; Zhang et al., 2010; Boutard et al., 2014]. Therefore, the adsorption of cellulases mixture (as planned in this study) could be a representative adsorption of a complete enzyme system. Some contrasting results were presented by researchers about cellulases adsorption and optimal activity because these researches were conducted under different temperatures, $\mathrm{pH}$ and with enzymes obtained from various sources. Therefore, our study is using a commercial mixture of cellulases on wide range of temperature (same conditions for both cellulose and lignin) to help estimate adsorption and desorption on/from lignocellulosic substrates

\section{Time taken for adsorption of cellulases}

The adsorption profile of cellulases on microcrystalline cellulose (Avicel), and potato pulp was determined by Singh et al. (1991). It was observed that most of the enzymes were rapidly adsorbed onto Avicel and pulp within the first $10 \mathrm{~min}$ of contact at $30^{\circ} \mathrm{C}$. No significant adsorption was 
observed thereafter. Steiner et al. (1988) reported that half of the maximally adsorbed enzyme was bound within 1-2 min of contact with microcrystalline cellulose, however, adsorption equilibrium was established less than $30 \mathrm{~min}$. Pulp exhibited higher enzyme adsorption than Avicel. An appreciable amount (about 18\%) of cellulase was also found to be adsorbed onto xylan substrate within 10-20 min of contact. Jager et al. (2010) reported that cellulase adsorption on $\alpha$-cellulose was rapid, cellobiohydrolase $\mathrm{CBH}$ I reached equilibrium in 20 minutes and endoglucanase EG I in 30 min. Pareek et al. (2013) adsorbed cellulases on spruce lignin (SP) and black cotton wood lignin (BCWL) and found that more than $60 \%$ of the protein had adsorbed within 30 min of incubation, while it took more than $2 \mathrm{~h}$ for the BCWL to reach the same value. Tu et al. (2009) reported that the time taken by cellulases to adsorb on ethanol pretreated lodgepole pine wood and steam exploded Lodgepole Pine was 30-60 minutes. These examples indicated that adsorption of cellulases onto cellulose was considerably different from that of lignin.

\section{Effect of temperature on adsorption of cellulases}

Controversial results were reported for the effect of temperature on cellulase adsorption process. Some of the researchers suggested that cellulases adsorption on lignocellulose was an exothermic and enthalpy-controlled reaction. They found that the amount of cellulases adsorption decreased as the temperature increased [Medve et al., 1994; Kim et al., 2000 and Ooshima et al., 1983]. On the contrary, Hoshino et al. (1992) and Creagh et al. (1996) proposed that cellulases adsorption on cellulose was an endothermic and entropy-driven reaction, means increased with temperature. Tu, et al. [2009] investigated reaction of cellulases on a soft wood Lodgepole pine, Pinus contorta, (cellulose, $47.6 \%$; hemicellulose, $22.9 \%$; lignin, $26.3 \%$; and extractives, $4.7 \%$ ). The lignin derived from steam exploded Lodgepole pine (L-SELP), and lignin derived from ethanol pretreated Lodgepole pine (L-EPLP) was used for the experiments. The results showed a higher level of 
cellulase adsorption onto lignin at $45^{\circ} \mathrm{C}$ than at 4 and $25^{\circ} \mathrm{C}$, indicating that cellulases adsorption on L-SELP and L-EPLP probably was an endothermic reaction [Eriksson et al., 2002; Tu et al., 2009; Zheng et al., 2013]. This most likely is true for the cellulases adsorption onto lignin, because hydrophobic interaction is the main force between lignin and cellulase enzymes [Eriksson et al., 2002; Tu et al., 2007], and the entropy could be the predominant driving force in the adsorption process through hydrophobic interactions [Eriksson et al., 2002; Tu et al., 2009; Wang et al., 2010]. The adsorption process which is entropy-driven was established by experimental data obtained from titration micro calorimetry [Creagh et al., 1996]. It means that lignin adsorbs more cellulases and with increase in temperature the adsorption on lignin increased. The results also implied that delignification of lignocellulosic substrates for cellulases desorption was necessary. Through literature survey it was observed that effect of temperature is a complex phenomenon because at one hand it influence adsorption, desorption and on the other hand it affect activity of cellulases.

\section{Denaturation and loss of activity of cellulases with temperatures}

There could be two ways to determine feasible/optimal temperatures for enzymes to work with, where enzyme do not lose activity or do not denature:

i- Considering denaturing temperature of each fundamental component of an enzyme

ii- Searching examples from literature

Table 5 presents the temperatures at which amino acids in a cellulase enzyme denatured. The fundamental amino acids in enzymes are listed in first column and their denaturing temperature are given in the second column. 
Table 5: Denaturing temperatures of amino acids present in cellulases

\begin{tabular}{|l|c|l|}
\hline Amino acid & $\begin{array}{c}\text { Temperature } \\
{ }^{\circ} \mathbf{C}\end{array}$ & \multicolumn{1}{|c|}{ Reference } \\
\hline Aspartate & 60 & Eze and Echetebu, 1979 \\
\hline Glutamate & 70 & Kang et al., 1981; Consalavi et al., 1991 \\
\hline Arginine & 60 & "Brenda", 2016 \\
\hline Lysine & 60 & "Brenda", 2016 \\
\hline Tryptophan & $50-60$ & Neurath et al., 1944 \\
\hline Tyrosine & 55 & Lazar et al., 1981 \\
\hline Isoleucine & 60 & "Brenda", 2016 \\
\hline Histidine & 50,60 & $\begin{array}{l}\text { Westmoreland and Matthews, 1973; } \\
\text { Savany and Cronenberger, 1982 }\end{array}$ \\
\hline Phenylalanine & 55 & "Brenda", 2016 \\
\hline Alanine & 60 & Eze and Echetebu, 1979 \\
\hline Cysteine & 65 & "Brenda", 2016 \\
\hline Leucine & 60 & Berman and Boyer, 1969 \\
\hline
\end{tabular}

Arginine is one of the amino acids which perform anionic bonding with the substrate, other one is lysine. Phenylalanine starts denaturing at $55{ }^{\circ} \mathrm{C}$ but this amino acid is located in the inner core of enzymes therefore temperature around $55^{\circ} \mathrm{C}$ start affecting on cellulases structure. Srinivas and Balasubramanian (1995) have reported that the presence of proline delays the thermal unfolding of the enzymes by approximately $10^{\circ} \mathrm{C}$. It means that over all denaturing temperature of enzymes have higher values than that of individual participating amino acid.

Literature provided examples of activities of cellulases components as a function of temperature such as Baker et al. (1992) investigated thermal denaturation of four purified Trichoderma reesei cellulase components, cellobiohydrolases CBH I, CBH II, endoglucanase EG I, and EG II. The cellulases components were monitored using a combination of differential scanning calorimetric (DSC), and 
thermal scanning fluorescence emission spectrometry. The substrates studied were cellulose (Avicel), carboxymethyl cellulose (CMC). In Table 6 first column contains cellulase components and the second column comments on their interaction with substrate under the influence of temperature.

Table 6: Denaturing temperatures of the components of the cellulases system

\begin{tabular}{|l|l|}
\hline Cellulase & Influence on temperature on enzyme activity \\
\hline CBH I & $\begin{array}{l}\text { Increases with increase in temperature from } 20 \text { to } 55^{\circ} \mathrm{C} \text {, maintains up to } 60{ }^{\circ} \mathrm{C} \text { and } \\
\text { had a rapid fall and completely denatured at } 70{ }^{\circ} \mathrm{C}\end{array}$ \\
\hline EG I & $\begin{array}{l}\text { Increases with increase in temperature from } 20 \text { to } 50{ }^{\circ} \mathrm{C} \text {, maintains up to } 60{ }^{\circ} \mathrm{C} \text { and } \\
\text { had a rapid fall and had complete denatured at } 70{ }^{\circ} \mathrm{C}\end{array}$ \\
\hline EG II & $\begin{array}{l}\text { For CMC, Increases with increase in temperature from } 20 \text { to } 50{ }^{\circ} \mathrm{C}, \text { maintains up to } \\
65{ }^{\circ} \mathrm{C} \text { and had a rapid fall and had complete denatured at } 70{ }^{\circ} \mathrm{C} \\
\text { For Avicel max was achieved at } 60{ }^{\circ} \mathrm{C} \text { and complete denaturing at } 75{ }^{\circ} \mathrm{C}\end{array}$ \\
\hline $\mathrm{CBH}$ II & $\begin{array}{l}\text { Increases with increase in temperature from } 20 \text { to } 50{ }^{\circ} \mathrm{C} \text {, maintains up to } 60{ }^{\circ} \mathrm{C} \text { and } \\
\text { had a rapid fall and had complete denatured at } 70{ }^{\circ} \mathrm{C}\end{array}$ \\
\hline
\end{tabular}

Both Differential Scanning Calorimetry (DSC) and the activity measurements showed that EG II had maximum temperature $75^{\circ} \mathrm{C}$ to be denatured. It means that EG II to be the most stable by $10-11{ }^{\circ} \mathrm{C}$ than the other three enzymes (Table 6). Few example will explain complexity of the influence of temperature. T. versicolor laccase, was adsorbed on pre-silanized silica beads by Dehghanifard et al. (2013). The results demonstrated that the maximum activity for both free and adsorbed lassase was at $40{ }^{\circ} \mathrm{C}$. At $60{ }^{\circ} \mathrm{C} 70 \%$ of the activity of adsorbed laccase was retained while free laccase were completely inactive. Because inactivation of a protein on a surface is a slower process and it is dependent on temperature. Andreaus et al. (1999) during studying adsorption of cellulases on Avicel found that the activity of the enzymes, was not affected until $37^{\circ} \mathrm{C}$, it was slightly reduced $(-20 \%)$ between 37 and $50{ }^{\circ} \mathrm{C}$ and it decreased sharply above $50{ }^{\circ} \mathrm{C}$. Above $70{ }^{\circ} \mathrm{C}$ almost no activity was 
found. Rahikainen et al. (2011) worked on lignins prepared from softwood and reported that activity of endoglucanases was reduced to $16 \%$ and that of exoglucanases to $35 \%$ of the original activity at $45^{\circ} \mathrm{C}$. It could be that enzymes with less compact structure are more likely to undergo structural changes during binding (Billsten et al., 1995; Haynes and Norde, 1995). The loss in activity could be due to conformational changes (or denaturing) in enzymes. Possible means to prevent enzyme denaturation on lignin surfaces would be to decrease the process temperature.

Other reported activities of endoglucanase and exoglucanase (Cel7A) after adsorption to enzymatic residual lignin (EnzHR). Such as, at $45^{\circ} \mathrm{C}, 29 \%$ of the initially added TeCel7A-CBM3 enzymes were free in solution, whereas at $55^{\circ} \mathrm{C}$ only $9 \%$ were free after $4 \mathrm{~h}$ of incubation. Furthermore, at high temperature TeCel7A-CBM3 was found to bind stronger on spruce EnzHR lignin, indicated by a steeper decrease in the amount of bound enzyme at $55^{\circ} \mathrm{C}$ than at $45^{\circ} \mathrm{C}$ [Rahikainen $e t$ al., 2011]. Increased enzyme binding onto lignin and increased surface denaturation are possible explanations for the negative effect of lignin at elevated temperatures [Rahikainen et al., 2011; Borjesson et al., 2007; Viikari et al., 2007]. Bonomo et al. (2006) investigated stability in the temperature range of $10-40{ }^{\circ} \mathrm{C}$ for Bovine serum albumin (BSA) and $\beta$-lactoglobulin $(\beta$-lg)/Hydrophobic adsorbent (Streamline Phenyl, packed in a column HR 5/5) and suggested that over $30{ }^{\circ} \mathrm{C}$ a great conformational change occur. Cellulases from T. reesei (Celluclast 1.5 L, Spezyme CP), cellulases from Penicillium sp. (MSUBC) on cellulolytic enzyme lignin (CEL) from steam-exploded Lodgepole pine (SELP) and on ethanol (organosolv)-pretreated Lodgepole pine (EPLP) showed that the activity of Celluclast $1.5 \mathrm{~L}$ increased from $25{ }^{\circ} \mathrm{C}$ to $45^{\circ} \mathrm{C}$ and enzymes got denatured from $55^{\circ} \mathrm{C}$ to $75^{\circ} \mathrm{C}$ [Tu et al., 2009b]. Therefore, in order to find the optimum desorption temperature it is quite tempting to the study of desorption of cellulases from substrate at temperatures $40{ }^{\circ} \mathrm{C}, 50{ }^{\circ} \mathrm{C}$, and 60 ${ }^{\circ} \mathrm{C}$, though $70^{\circ} \mathrm{C}$ was added in desorption studies but it was not promising. 


\section{Accessibility of surface area for adsorption}

A specific surface area (SSA) may play a great role in accessibility of substrate to cellulases. Fan et al. (1980) investigated the influence of surface type on hydrolysis by using Sigmacell $50(50 \mu \mathrm{m})$, Avicel $101(50 \mu \mathrm{m})$, and Avicel $105(20 \mu \mathrm{m})$ as substrate. Through literature survey, it was known that the rate of hydrolysis was proportional to the concentration of the active adsorbed enzymes [Converse et al., 1988; Ucar et al., 1989], and rate limiting step is adsorption. It was expected that the adsorption of cellulases would increase with an increasing surface area. However, the published data showed that the specific surface area may not significantly affect the adsorption rate. It appeared that the extent of adsorption was determined by specific surface area (SSA) and the surface area showed no clear correlation with the adsorption in these reports and created a confusion. The effect of the SSA of cellulose to enzymatic hydrolysis was discussed in some other researches (Cowling, 1975; Gharpuray et al., 1983; Stone et al., 1967; Burns et al., 1989) as well. Shewale and Sadana (1979) found no difference between the adsorption rates for two samples of microcrystalline cellulose with average particle size 38 and $90 \mu \mathrm{m}$. Similarly, Rivers and Emert (1988) also reported that the particle size was not the major factor for determining accessibility of lignocellulosics to cellulolytic enzymes. Some researchers [Welmer and Weston, 1985; Lin et al., 1985; Burns et al., 1989] developed a relationship between pore size (pore volume) distribution and hydrolysis rate. It was shown that the rate-limiting size of pores was equal or greater than the size of cellulase, which was estimated to be 40-90 ^ [Welmer and Weston, 1985; Stone et al., 1967; Burns et al., 1989]. Therefore, in the determination of surface area accessible to cellulases a molecular probes with similar size must be used. Clementi and Palade (1969) used peroxidase or chymotrypsin because of their inertness to cellulose and fairly close molecular sizes and weights to the cellulases. The diameter of peroxidase molecule was estimated to be $50 \AA$ [Clementi and Palade, 1969], the size of 
chymotrypsin was estimated as 40 x 40 x $50 \AA$ [Squire and Himmel, 1979]. SSA measured by peroxidase was $0.30 \mathrm{~m}^{2} / \mathrm{g}$. The SSA of cellulose measured by Fan et al. using nitrogen adsorption gave a value of $2.2 \mathrm{~m}^{2} / \mathrm{g}$. This discrepancy resulted from structural non-uniformity of cellulose in respect to adsorption of low-mol-wt gases, and of high-mol-wt proteins. In the present work, the effect of surface area of Avicel PH 101 and Protobind 1000 on adsorption of cellulases was discussed.

\subsection{Thermodynamics of enzymatic adsorption and desorption}

Thermodynamics study could indicate feasibility of the adsorption and desorption from the obtained values of the thermodynamic parameters. The van't Hoff equation can be adapted to represent the adsorption and desorption processes of cellulases to/from adsorbents like Avicel PH 101 and Protobind 1000. It relates the main thermodynamics parameters such as enthalpy $(\Delta H)$ and entropy $(\Delta \mathrm{S})$ to the equilibrium distribution coefficient $(\mathrm{K})$ of the adsorbed or desorbed species between an aqueous solution and an adsorbent, as shown in Equation 2.10:

$$
\ln K=-\frac{\Delta H}{R T}+\frac{\Delta S}{R}
$$

$\mathrm{K}$ is the ratio of cellulases adsorbed in equilibrium to the cellulases present in supernatant in equilibrium, $\mathrm{R}$ is the universal gas constant $\left(8.314 \mathrm{JK}^{-1} \mathrm{~mol}^{-1}\right)$, and $\mathrm{T}$ is the absolute temperature. The other thermodynamic parameter Gibbs free energy $(\Delta \mathrm{G})$ is given by Equation 2.11:

$$
\Delta \mathrm{G}=\Delta \mathrm{H}-\mathrm{T} \Delta \mathrm{S} \quad \ldots \quad \ldots \quad 2.11
$$

The values of $\Delta \mathrm{H}$ and $\Delta \mathrm{S}$ were calculated from slope and intercept of the plot of $\operatorname{lnK}$ vs $1 / \mathrm{T}$ and $\Delta \mathrm{G}$ was calculated from the obtained of $\Delta \mathrm{H}$ and $\Delta \mathrm{S}$ values. 


\section{Enthalpy}

There were conflicting reports in literature on the effect of temperature on the adsorption of cellulases and hence calculated $\Delta \mathrm{H}$ values both decreased and increased (positive or negative) with increasing temperature were observed. For one system of an enzyme and a substrate it can have a positive and negative value depending upon experimental conditions. For example, Ooshima et al. (1985) studied thermodynamic parameters for adsorption of EGs and $\mathrm{CBHs}$ on cellulose for a temperature range of $5{ }^{\circ} \mathrm{C}$ to $50{ }^{\circ} \mathrm{C} . \Delta \mathrm{H}$ values obtained at $10{ }^{\circ} \mathrm{C}$ were positive due to endothermic adsorption process. It was suggested that the increase in $\Delta \mathrm{H}$ may be produced by the release of the water molecules which was structurally adjusted on the surface of cellulose and/or around the cellulases. The adsorption was entropy driven. On the other hand, the $\Delta \mathrm{H}$ values reported at $40{ }^{\circ} \mathrm{C}$ were negative. At $40{ }^{\circ} \mathrm{C}$ the adsorption process was exothermic and enthalpy-driven. It was observed through literature survey that $\Delta \mathrm{H}$ values also changed with the structure of substrates, for more porous structure (activated carbon and AFEX treated wheat straw) there was more $\Delta \mathrm{H}$. Table 7 is a brief presentation of $\Delta \mathrm{H}$ values, reported in literature for various sets of enzymes and substrates, measured at given temperature ranges.

$\Delta \mathrm{H}$ values reported in Table 7 for Avicel up to $30^{\circ} \mathrm{C}$ were positive and for the cases when it was reported for temp $30-50{ }^{\circ} \mathrm{C}$ and it was negative. $\Delta \mathrm{H}$ values reported for activated carbon were positive. $\Delta \mathrm{H}$ is a state function. Being a state function means that $\Delta \mathrm{H}$ is independent of the processes between initial and final states. In other words, it does not matter what steps we take to get from initial reactants to final products - the $\Delta \mathrm{H}$ will always be the same. $\Delta \mathrm{H}$ can have a positive value and a negative value. A positive sign means that the adsorption system (cellulases solution + substrate) uses heat and is endothermic. 
Table 7: $\Delta H$ values for adsorption for various enzyme and substrate systems

\begin{tabular}{|c|c|c|c|c|}
\hline Enzyme & Substrate & $\Delta \mathrm{H}, \mathrm{kJ} \mathrm{mol}^{-\mathrm{I}}$ & Conditions & Reference \\
\hline $\begin{array}{l}\text { CBH I from } \\
\text { I. lacteus }\end{array}$ & $\begin{array}{l}\text { Avicel } \\
\text { Cotton }\end{array}$ & $\begin{array}{l}0.18 \\
0.267\end{array}$ & $5^{\circ} \mathrm{C}$ to $15^{\circ} \mathrm{C}$ & Hoshino et al., 1992 \\
\hline $\begin{array}{l}\text { Endo } 1 \text { from } \\
\text { I. lacteus }\end{array}$ & $\begin{array}{l}\text { Avicel } \\
\text { Cotton }\end{array}$ & $\begin{array}{l}0.467 \\
0.2\end{array}$ & $5{ }^{\circ} \mathrm{C}$ to $15^{\circ} \mathrm{C}$ & Hoshino et al., 1992 \\
\hline $\begin{array}{l}\text { d-glucono- } \xi- \\
\text { lactone } \\
\text { hydrolase }\end{array}$ & lignocellulosic & -5.1 & $25^{\circ} \mathrm{C}$ & Murphy, 2010 \\
\hline T. reesei $\operatorname{mix}$ & $\begin{array}{l}\text { AFEX-treated } \\
\text { wheat straw. }\end{array}$ & -118 & $35^{\circ} \mathrm{C}$ to $49^{\circ} \mathrm{C}$ & Brown et al., 2010 \\
\hline $\begin{array}{l}\text { Trichoderma } \\
\text { viride mix }\end{array}$ & $\begin{array}{l}\text { Sigmacell 20, } 50 \\
(20 \mu \mathrm{m}, 50 \mu \mathrm{m})\end{array}$ & $\begin{array}{l}-29.930 \\
-24.942\end{array}$ & $5^{\circ} \mathrm{C}$ to $50^{\circ} \mathrm{C}$ & Kim et al., 1988 \\
\hline $\begin{array}{l}\text { CBHs from } \\
\text { C. fimi }\end{array}$ & $\mathrm{BMCC}$ & -5.6 & $25,30,35{ }^{\circ} \mathrm{C}$ & Creagh et al., 1996 \\
\hline EGs & Avicel & $\begin{array}{l}8.20 \\
-0.142\end{array}$ & $\begin{array}{l}5{ }^{\circ} \mathrm{C} \text { to } 30^{\circ} \mathrm{C} \\
30{ }^{\circ} \mathrm{C} \text { to } 50^{\circ} \mathrm{C}\end{array}$ & Ooshima et al., 1983 \\
\hline $\begin{array}{l}\text { CBHI , CBHII: } \\
\text { T. reesei }\end{array}$ & Avicel & $-16.71,-3.35$ & $20^{\circ} \mathrm{C}$ to $35^{\circ} \mathrm{C}$ & Kim and Hong, 2000 \\
\hline CBHI, CBHII & Avicel & $-18.0,-6.2$ & $15^{\circ} \mathrm{C}$ to $30^{\circ} \mathrm{C}$ & Kim et al., 2001 \\
\hline $\mathrm{Cr}(\mathrm{VI})$ & Kraft lignin & -20.68 & $20^{\circ} \mathrm{C}$ to $40^{\circ} \mathrm{C}$ & $\begin{array}{l}\text { Tazrouti and Amrani, } \\
2009\end{array}$ \\
\hline Malachite green & Lignin sulfonate & 131.58 & $10^{\circ} \mathrm{C}$ to $60^{\circ} \mathrm{C}$ & Tang et al., 2015 \\
\hline Rhodamine B & $\begin{array}{l}\text { Aerobic granular } \\
\text { wastewater } \\
\text { sludge }\end{array}$ & -2.20 & $5{ }^{\circ} \mathrm{C}$ to $45^{\circ} \mathrm{C}$ & Zheng et al., 2005 \\
\hline T viride (EGs) & Cotton fibers & -48.9 & & Beltram et al., 1984 \\
\hline $\begin{array}{l}\text { Malachite Green } \\
\mathrm{C}_{50} \mathrm{H}_{52} \mathrm{~N}_{4} \mathrm{O}_{8}, \mathrm{FW} \\
=927.03 \mathrm{~g} / \mathrm{mol}\end{array}$ & $\begin{array}{l}\text { Aerobic granules } \\
\text { wastewater } \\
\text { sludge }\end{array}$ & 0.03 & $30{ }^{\circ} \mathrm{C}$ to $50^{\circ} \mathrm{C}$ & Sun et al., 2008 \\
\hline $\mathrm{Cr}$ (III) & PAm-g-RWF & 105.6 & $30,50,70{ }^{\circ} \mathrm{C}$ & Mahdavi et al., 2011 \\
\hline $\begin{array}{l}\text { Aspergillus } \\
\text { niger cellulase }\end{array}$ & $\begin{array}{l}\text { Activated carbon } \\
\text { powder }\end{array}$ & 11.12 & $20{ }^{\circ} \mathrm{C}$ to $60^{\circ} \mathrm{C}$ & Daoud et al., 2010 \\
\hline Cadmium & Goethite & 12.6 & $10^{\circ} \mathrm{C}$ to $70^{\circ} \mathrm{C}$ & Johnson, 1990 \\
\hline Safranin & $\begin{array}{l}\mathrm{NaOH} \text { treated } \\
\text { rice husk }\end{array}$ & 40.92 & $30{ }^{\circ} \mathrm{C}$ to $50^{\circ} \mathrm{C}$ & $\begin{array}{l}\text { Chowdhury et al., } \\
2010\end{array}$ \\
\hline
\end{tabular}

1= considering Avicel has a CrI of 0.64; PAm-g-RWF: Acrylamide grafted on Rubberwood fibers; ITC: isothermal titration calorimetry was used to measure the thermodynamics of the binding

The negative $\Delta \mathrm{H}$ value means that the reactants have greater enthalpy than the products, or there is a removal of energy from the reaction (and addition into the surroundings). 


\section{Entropy}

Some examples of $\Delta \mathrm{S}$ values for adsorption of enzymes and big molecules on lignocellulosic, activated carbon and rubber are given in Table 8.

Table 8: $\Delta \mathrm{S}$ values for various adsorption systems

\begin{tabular}{|c|c|c|c|c|}
\hline Enzyme & Substrate & $\Delta \mathrm{S}, \mathrm{Jmol}^{-1} \mathrm{~K}^{-1}$ & Conditions & Reference \\
\hline $\begin{array}{l}\text { CBH I } \\
\text { from I. lacteus }\end{array}$ & $\begin{array}{l}\text { Avicel } \\
\text { Cotton }\end{array}$ & $0.01,0.02$ & $5-15^{\circ} \mathrm{C}$ & Hoshino et al., 1992 \\
\hline $\begin{array}{l}\text { EG I } \\
\text { from I. lacteus }\end{array}$ & $\begin{array}{l}\text { Avicel } \\
\text { Cotton }\end{array}$ & $\begin{array}{l}0.011 \\
0.013\end{array}$ & $5-15^{\circ} \mathrm{C}$ & Hoshino et al., 1992 \\
\hline EGs & Avicel & $\begin{array}{l}167.36 \\
-21.34\end{array}$ & $\begin{array}{l}5-30{ }^{\circ} \mathrm{C} \\
30-50^{\circ} \mathrm{C}\end{array}$ & Ooshima et al., 1983 \\
\hline Safranin & $\begin{array}{l}\mathrm{NaOH} \text { treated } \\
\text { rice husk }\end{array}$ & 153.95 & $30{ }^{\circ} \mathrm{C}$ to $50^{\circ} \mathrm{C}$ & $\begin{array}{l}\text { Chowdhury et al., } \\
2010\end{array}$ \\
\hline $\begin{array}{l}\text { CBH I, CBH II: } \\
\text { T. reesei }\end{array}$ & Avicel & $54.4,86.2$ & $20-35^{\circ} \mathrm{C}$ & $\begin{array}{l}\text { Kim and Hong, } \\
2000\end{array}$ \\
\hline $\begin{array}{l}\text { Trichoderma } \\
\text { viride cellulase }\end{array}$ & $\begin{array}{l}\text { Sigmacell } 20,50 \\
(20 \mu \mathrm{m}, 50 \mu \mathrm{m})\end{array}$ & $\begin{array}{l}16.731 \\
31.236\end{array}$ & $5-50^{\circ} \mathrm{C}$ & Kim et al., 1988 \\
\hline Trypsin & $\begin{array}{l}\mathrm{CuS} \\
\text { nanoparticles }\end{array}$ & -137.1 & $10-40{ }^{\circ} \mathrm{C}$ & Saha et al., 2014 \\
\hline $\mathrm{Cr}(\mathrm{VI})$ & Kraft lignin & 86.0 & $20^{\circ} \mathrm{C}$ to $40^{\circ} \mathrm{C}$ & $\begin{array}{l}\text { Tazrouti and } \\
\text { Amrani, } 2009\end{array}$ \\
\hline Malachite green & lignin sulfonate & 131.58 & $10^{\circ} \mathrm{C}$ to $60^{\circ} \mathrm{C}$ & Tang et al., 2015 \\
\hline $\begin{array}{l}\text { Aspergillus } \\
\text { niger cellulase }\end{array}$ & $\begin{array}{l}\text { activated carbon } \\
\text { powder }\end{array}$ & 84.0 & $20{ }^{\circ} \mathrm{C}$ to $60^{\circ} \mathrm{C}$ & Daoud et al., 2010 \\
\hline $\begin{array}{l}\text { EGs from } \\
\text { Bacillus species }\end{array}$ & $\begin{array}{l}\text { regenerated } \\
\text { cellulose }\end{array}$ & $\begin{array}{l}15^{\circ} \mathrm{C}=-174.47 \\
25^{\circ} \mathrm{C}=-119.66\end{array}$ & $\begin{array}{l}\text { Measured by } \\
\text { ITC }\end{array}$ & Boraston, 2005 \\
\hline $\begin{array}{l}\text { Glucoamylase } \\
\text { from } A \text {. niger }\end{array}$ & acarbose & -11.67 & $\begin{array}{l}\text { Measured by } \\
\text { ITC, } 27^{\circ} \mathrm{C}\end{array}$ & $\begin{array}{l}\text { Christensen } \text { et al., } \\
1999\end{array}$ \\
\hline $\begin{array}{l}\text { Glucoamylase } \\
\text { from A. niger }\end{array}$ & $\beta$-cyclodextrin & -68.0 & $\begin{array}{l}\text { Measured by } \\
\text { ITC, } 27{ }^{\circ} \mathrm{C}\end{array}$ & $\begin{array}{l}\text { Christensen } \text { et al., } \\
1999\end{array}$ \\
\hline Rhodamine B & $\begin{array}{l}\text { aerobic granules } \\
\text { wastewater } \\
\text { sludge }\end{array}$ & 100 & $5^{\circ} \mathrm{C}$ to $45^{\circ} \mathrm{C}$ & Zheng et al., 2005 \\
\hline $\begin{array}{l}\text { Malachite Green } \\
\mathrm{C}_{50} \mathrm{H}_{52} \mathrm{~N}_{4} \mathrm{O}_{8}, \mathrm{FW} \\
=927.03 \mathrm{~g} / \mathrm{mol} \\
\end{array}$ & $\begin{array}{l}\text { aerobic granules } \\
\text { wastewater } \\
\text { sludge }\end{array}$ & 110 & $30^{\circ} \mathrm{C}$ to $50^{\circ} \mathrm{C}$ & Sun et al., 2008 \\
\hline $\mathrm{Cr}$ (III) & PAm-g-RWF & 12.64 & $30,50,70{ }^{\circ} \mathrm{C}$ & Mahdavi et al., 2011 \\
\hline
\end{tabular}




\begin{tabular}{|c|c|c|c|c|}
\hline Enzyme & Substrate & $\Delta \mathrm{S}, \mathrm{Jmol}^{-1} \mathrm{~K}^{-1}$ & Conditions & Reference \\
\hline $\begin{array}{l}\text { EGs from } \\
\text { Clostridium } \\
\text { cellulovorans } \\
\end{array}$ & $\begin{array}{l}\text { regenerated } \\
\text { cellulose }\end{array}$ & $\begin{array}{l}15^{\circ} \mathrm{C}=-198.74 \\
25^{\circ} \mathrm{C}=-230 \\
35^{\circ} \mathrm{C}=-181.59\end{array}$ & $\begin{array}{l}\text { Measured by } \\
\text { ITC }\end{array}$ & Boraston, 2005 \\
\hline $\mathrm{Cu}(\mathrm{II})$ & $\begin{array}{l}\text { Rubber (Hevea } \\
\text { brasiliensis) leaf } \\
\text { powder }\end{array}$ & -95.94 & $27^{\circ} \mathrm{C}$ to $47^{\circ} \mathrm{C}$ & $\begin{array}{l}\text { Ngah and } \\
\text { Hanafiah, } 2008\end{array}$ \\
\hline $\mathrm{Cd}(\mathrm{II})$ & $\begin{array}{l}\text { Red algae } \\
\text { (Ceramium } \\
\text { virgatum) }\end{array}$ & -42.4 & $20{ }^{\circ} \mathrm{C}$ to $50{ }^{\circ} \mathrm{C}$ & $\begin{array}{l}\text { Sari and Tuzen, } \\
2008\end{array}$ \\
\hline $\mathrm{Ni}(\mathrm{II})$ & Baker's yeast & -23.66 & $27^{\circ} \mathrm{C}$ to $60^{\circ} \mathrm{C}$ & $\begin{array}{l}\text { Padmavathy, } \\
2008\end{array}$ \\
\hline$N i(I I), P b(I I)$ & $\begin{array}{l}\text { Lichen } \\
\text { (Cladonia } \\
\text { furcata) } \\
\text { biomass }\end{array}$ & $-71.5,-57.6$ & $20{ }^{\circ} \mathrm{C}$ to $50{ }^{\circ} \mathrm{C}$ & Sari et al., 2007 \\
\hline $\begin{array}{l}\text { Malachite } \\
\text { Green }\end{array}$ & Neem sawdust & -169.57 & $25^{\circ} \mathrm{C}$ to $45^{\circ} \mathrm{C}$ & $\begin{array}{l}\text { Khattri and Singh, } \\
2009\end{array}$ \\
\hline $\begin{array}{l}\text { Acid Yellow } \\
17\end{array}$ & $\begin{array}{l}\text { Non-living } \\
\text { aerobic } \\
\text { granular sludge }\end{array}$ & -15.79 & $20^{\circ} \mathrm{C}$ to $50^{\circ} \mathrm{C}$ & Gao et al., 2010 \\
\hline $\begin{array}{l}\text { Acid Orange } \\
52\end{array}$ & $\begin{array}{l}\text { Paulownia } \\
\text { tomentosa } \\
\text { Steud. leaf } \\
\text { powder } \\
\end{array}$ & -17.00 & $25^{\circ} \mathrm{C}$ to $45^{\circ} \mathrm{C}$ & $\begin{array}{l}\text { Deniz and } \\
\text { Saygideger, } \\
2010\end{array}$ \\
\hline Benzoic Acid & $\begin{array}{l}\text { Amberlite XAD- } \\
4\end{array}$ & $\begin{array}{l}18^{\circ} \mathrm{C}=-77.99 \\
32^{\circ} \mathrm{C}=-74.44 \\
46^{\circ} \mathrm{C}=-70.63\end{array}$ & $\begin{array}{l}\text { Decreased with } \\
\text { increasing } \\
\text { temperature }\end{array}$ & Liu et al., 2003 \\
\hline
\end{tabular}

l= considering Avicel has a CrI of 0.64., PAm-g-RWF: Acrylamide grafted on Rubberwood fibers;

ITC: isothermal titration calorimetry was used to measure the thermodynamics of the binding

$\Delta \mathrm{S}$ values reported for lignin, activated carbon, aerobic granule and rubber was positive for all range of temperatures. For other lignocellulosic materials it was negative. For cellulose $\Delta \mathrm{S}$ values were positive for low temperatures $\left(5^{\circ} \mathrm{C}\right.$ to $\left.30^{\circ} \mathrm{C}\right)$ and negative when reported for temperatures $30^{\circ} \mathrm{C}$ and above. It is considered that the reason which holds for positive value its opposite would be a reason for negative value, in fact, this is not true.

The positive $\Delta \mathrm{S}$ value could be due to one or more indicated reasons: i) increased randomness at the solid/solution interface with some structural changes in the adsorbate and the adsorbent [RinconSilva et al., 2015 ], ii) The adsorbed solvent molecules, which are displaced by the adsorbate species, 
gain more translational entropy than is lost by the adsorbate ions/molecules, thus allowing for the prevalence of randomness in the system [Ateya et al., 2010], iii) an increase in the degree of freedom of the adsorbed species [Zhao et al., 2012], vi) the total entropy change of the adsorption process $(\Delta S)$ is the sum of the above entropy increase and the entropy reduction and the net $\Delta \mathrm{S}$ is positive [Shalabi et al., 2014]. v) Substrate is degrading, releasing small molecules. A negative value of $\Delta \mathrm{S}$ suggests that the process is enthalpy driven and it could be due to: i) a decreased disorder at the solid/liquid [Liu et al., 2003]. ii) The mobility of the adsorbate was more restricted on the adsorbent surface than in solution [Freundlich, 1906], iii) structural changes during adsorbate-adsorbent interaction [Srivasta et al., 2011].

In this study $\Delta \mathrm{H}$ and $\Delta \mathrm{S}$ values for adsorption onto cellulose and lignin were calculated under similar experimental conditions and reported for the first time. For desorption investigations, $\Delta \mathrm{H}$ and $\Delta \mathrm{S}$ values were calculated for a wide range of temperature $\left(25^{\circ} \mathrm{C}\right.$ to $\left.70^{\circ} \mathrm{C}\right)$ and $\mathrm{pH}(6$ to 9$)$ under similar experimental conditions.

\subsection{Desorption of cellulases from substrates}

In contrast to adsorption, attempts to desorb cellulases from substrate and recycle it in active form were not successful. Otter et al. (1984) studied desorption of cellulase on Avicel at $50-55^{\circ} \mathrm{C}$ at two $\mathrm{pH}$ values of 5 and 10 . At $\mathrm{pH} 5$, the desorbed amount was $40 \%$ of initial amount and $90 \%$ of this $40 \%$ was active only while at $\mathrm{pH} 10$ desorption was $45 \%$ with $0 \%$ activity of the cellulase recovered. Deshpande and Eriksson (1984) investigated desorption of cellulases from Avicel and steam exploded wheat straw (SEWS). The enzymes were recovered by suspending the residues (3\% suspensions) in a number of eluents at $40{ }^{\circ} \mathrm{C}$ for 15 minutes. The most effective elution was, obtained with phosphate buffer which gave $40 \%$ endo, $38 \%$ exo and $30 \% \beta$-glucosidase of the original amount of the cellulases used. Jackson et al. (1996) studied desorption of cellulase from hardwood 
and soft wood samples they could desorb $40 \%$ and $55 \%$ of cellulases, respectively, at $25{ }^{\circ} \mathrm{C}$ by using a surfactant, Tween 80, and the cellulase activity reported for both the substrates was $27 \%$. They pointed out that all the cellulase became inactive under the alkaline washing conditions. Therefore, high alkaline condition deactivates cellulases.

Other attempts to desorb cellulases include the use of surfactants, alkali, urea and buffers of varying pH. Otter et al. (1989) used variety of surfactants to study desorption of cellulase from Avicel and steam exploded aspen wood (SEAW). The amount desorbed from SEAW and Avicel at pH 10 and $50{ }^{\circ} \mathrm{C}$ by using Triton $\mathrm{X}-100$ was $25 \%$ and $69 \%$ respectively but the activity of the enzymes was not reported. Yang et al. (2010) investigated on the desorbed cellulases from filter paper Whatman No.1, in the presence of a surfactant Tween 80 and found that the activity of the enzymes was declined. The compounds like Tween 80 , Triton X-100 and urea react with enzymes and may instigate conformational changes in their structures which may cause denaturing of enzymes [Horton et al., 1996]. Therefore, choice of surfactants to help desorption should be made with care.

Some researchers reported desorption of cellulases from solid residues by contact with fresh substrate [Vallander and Eriksson, 1987; Lee et al., 1995; Qi et al., 2011]. But they could not prove, i) how much enzymes were desorbed and, ii) how much transferred to the fresh substrate surface. Even, due to the repeated recycling, the solid residue became lignin-rich. Girard and Converse (1993) and Lee et al. (1995) used similar technique of desorbing by fresh substrate and reported that the hydrolytic ability of the recovered cellulase was decreases.

There is a lack of specific research on cellulases desorption from lignin rich substrates or lignin [Tu et al., 2009]. Berlin et al. (2005) worked on delignified Douglas fir (Pseudotsuga menziesii) they could desorb $50 \%$ of cellulases with $35 \%$ of activity. Rahikainen et al. (2011) prepared lignin rich substrate from steam treated spruce wood chips to estimate capacity of lignin to interact with 
cellulases and reported that the cellulases were not desorbed due to the strong interaction. The studies, in general, on desorption of cellulases (though they are few) and reuse for the production of ethanol have shown the following limitations:

1- The number of tested samples were small, reducing the predictive ability of the conducted tests.

2- A narrow spectrum of controlling factors was studied. A detailed strategic study of the effects of $\mathrm{pH}$, temperature was not conducted, for example working only on two temperatures or $\mathrm{pH}$ values and then generalizing results.

3- Cellulases desorption and activity was not investigated systematically.

4- Most of the studied were based on action of cellulases from the pure substrates such as crystalline cellulose or filter paper, a few studies have covered forestry lignocellulosic materials and the study on agricultural material is extremely rare.

Our work is planned on predicted range of $\mathrm{pH}$ and temperature to find optimum active desorption. Desorption of cellulases is difficult to represent by Langmuir though Langmuir equation provides a good data fitting in most cases. Because, Langmuir assumed that there will be a reversible desorption of cellulases. Actually, more complicated situation exists, such as partially irreversible adsorption occur due to entrapment by substrate matrix (Lee et al., 1983; Palonen et al., 1999), and/or inactivity of enzymes.

\subsubsection{Time taken for desorption of cellulases}

Reese (1982), demonstrated that $90 \%$ of cellulase with $60 \%$ activity could be recovered (desorbed) using $6 \mathrm{M}$ urea at $\mathrm{pH} 4.9$ and $40{ }^{\circ} \mathrm{C}$ for $30 \mathrm{~min}$. The research showed that activity of the desorbed cellulases could be increased to $72 \%$ when desorption time was shortened to 5 min. It was also 
reported a combination of high $\mathrm{pH}$ and urea was ineffective for desorption. Nutor and Converse (1991) studied the hydrolysis of pretreated poplar wood with GC123 Trichoderma reesei cellulase at $\mathrm{pH} 4.8$ and $40{ }^{\circ} \mathrm{C}$. The enzyme rapidly adsorbed initially, reaching a maximum in about $30 \mathrm{~min}$ and about $50 \%$ of the cellulase desorbed. Zhu et al. (2009) studied adsorption of cellulase on Avicel and dilute acid (DA)-pretreated corn stover at $4{ }^{\circ} \mathrm{C}$. The adsorption time was taken 10 minutes and with no desorption time, desorption was 55-57 \% at pH 8 and $\mathrm{pH}$ 9. Otter et al. (1984) demonstrated that desorption by $\mathrm{NaOH}$ was essentially complete within 30 seconds and was not affected by increases in desorption time to $15 \mathrm{~min}$. A desorption step in a cellulose hydrolysis process can therefore be designed with a short contact time from 30 second to $15 \mathrm{~min}$.

\subsubsection{Effect of temperature on desorption}

The only one direct example for desorption found from literature was given by Otter et al. (1984). They discovered that desorption of cellulase from Avicel was effective in the range of $22-55^{\circ} \mathrm{C}$, and a further increase of temperature reduced enzyme stability. The other examples provided indirect information for desorption temperature because they were discussing feasibility of reaction temperature in terms of activity and stability of cellulases. Some researchers studied interaction of laccase and/or tyrosinase on different substrates (porous glass beads, aqueous phenol and bisphenols). Though glass beads are different from cellulose yet they provide analogy to design a study. Their results demonstrate that the activity of adsorbed enzyme at $60{ }^{\circ} \mathrm{C}$ retained about $70 \%$ of its maximal activity, while the free enzyme were inactivated [Lante et al., 2000; Champagne et al., 2007; Nicolucci et al., 2011]. Pardo and Forchiassin (1999) investigated influence of temperature on cellulase activity and stability in Nectria catalinensis and found that optimal temperature for the activity of the cellulase system ranged from 50 to $55^{\circ} \mathrm{C}$. Fungsin et al. (2007) carried out bioconversion of cassava waste into sugar by using microbial enzyme. The fungal cellulase was 
produced from Trichoderma reesei. The optimum temperature found for bioconversion was $60{ }^{\circ} \mathrm{C}$. Acharya (2010) studied saccharification of wheat bran by cellulases and concluded that endoglucanase and $\beta$-glucosidase retained 55 and $65 \%$ activity at $60{ }^{\circ} \mathrm{C}$. Increase in the temperature more than $60{ }^{\circ} \mathrm{C}$ resulted in a sharp decrease in the activity which can be attributed to thermal inactivation of the enzymes. Getting maximum activity at $60{ }^{\circ} \mathrm{C}$ at saccharification provided information that enzymes were performing their maximum during adsorption, desorption and hydrolysis at $60^{\circ} \mathrm{C}$. The stability of cellulases reported as the activity of cellulases which starts falling after $55{ }^{\circ} \mathrm{C}$ [Otter et al., 1984, Andreaus et al., 1999 and Tu et al., 2009]. The loss of activity of enzymes was due to thermal denaturation of the enzymes [Peterson et al., 2007; Daniel et al., 2013]. Heat can disrupt hydrogen bonds and non-polar hydrophobic interactions between amino acids in cellulases. Hydrogen bonding is very important in cellulosic structure. Hydrogen bonding occurs between amide groups in the secondary chain structure. Hydrogen bonding between "side chains" occurs in tertiary protein structure in a variety of amino acid combinations. This occurs because the increase in heat increases the kinetic energy which makes the molecules to vibrate so speedily and intensely that the bonds are disrupted [Ophardt, 2003; Velisek, 2014]. There is a lack of documentation in reporting of desorption temperatures.

\subsubsection{Effect of $\mathrm{pH}$ on desorption}

There are some examples of desorption of cellulases demonstrating effect of $\mathrm{pH}$ on desorption from various materials. Otter et al. (1989) achieved maximum desorption from Avicel at $\mathrm{pH} 11.5$, and $\mathrm{pH}$ 12 but the cellulase activity was $9 \%$ and $6 \%$ of the original activity. In another study they used cellulases on steam exploded Aspen and Lucerne wood at $\mathrm{pH} 10$ and achieved desorption of $50 \%$ and $70 \%$ respectively. In the discussion they reported that at alkaline $\mathrm{pH}$ cellulases were probably inactivated. Andreaus et al. (1999) studied desorption of cellulases on cotton fabric for $\mathrm{pH} 5$ to $\mathrm{pH}$ 
10. They discovered that desorption of cellulases from cotton fabrics increased from $\mathrm{pH} 5$ to $\mathrm{pH} 10$, and only $11 \%$ of protein were desorbed at $\mathrm{pH} 10$. During desorption experiments the activity of desorbed cellulases was determined by measuring reducing soluble sugars. The amounts of reducing soluble sugars found in desorption supernatant might be ascribed to enzymatic degradation of cotton fabric during preparation and storage of the cellulase adsorbed fabrics. The adsorption and desorption time was 7 hours while storage time was not reported. The amount of reducing sugars formed at $\mathrm{pH}$ 10 was the least of all $\mathrm{pH}$ values. Therefore, alkaline $\mathrm{pH}$ destroyed enzymes. Seo et al. (2011) reported that desorption of cellulases from delignified pine wood chips were almost doubled by increasing $\mathrm{pH}$ from 4.8 to $\mathrm{pH} 7.2$ but the presented data was not telling about activity of desorbed cellulases. Du et al., 2012 examined the adsorption and stabilities of cellulase at various pH values. The acidic condition ( $\mathrm{pH} 4.8$ ) favored adsorption, whereas alkaline condition ( $\mathrm{pH} 7$ and 10) favored desorption. It was found that the influence of $\mathrm{pH}$ on the activity of cellulases was reliant on temperature such as under severe conditions $\left(\mathrm{pH} \mathrm{10,50}{ }^{\circ} \mathrm{C}\right)$, irreversible inactivation took place. Alkaline $\mathrm{pH}$ value affects the activity of cellulases and $\mathrm{pH}$ also effects on desorption of cellulases. Since this research is on the reuse of cellulases, therefore, the effect of $\mathrm{pH}$ on desorption as well as on the activity of cellulases (desorption of active cellulases) was studied.

Table 9 shows the effect of $\mathrm{pH}$ on amino acids. The first column in Table 9 displays amino acids which are components of cellulases as indicated by Kleywegt et al. (1997). The second column is for optimum working $\mathrm{pH}$ values for amino acids and third column is dedicated for the $\mathrm{pH}$ at which an amino acid denatured. Data for second and third columns are taken from Brenda's website. From Table 9 it is clear that most of the amino acids denatured above $\mathrm{pH} 9$ while most of the desorption studies reported at pH 10 and above. Therefore, desorption of deactivated cellulases is quite evident. Hence, a detailed strategic study of $\mathrm{pH}$ is required to get desorption of active cellulases from lignocellulosic substrate because desorption of cellulase has never been studied with a complete plan. 
Table 9: Denaturing pH of component amino acids

\begin{tabular}{|c|c|c|}
\hline Amino acid & Optimum pH & Denaturing pH \\
\hline Aspartate & N.A. & $>9.5$ \\
\hline Glutamate & $9-9.5$ & 9.5 \\
\hline Arginine & $5.2-9.5$ & 9.5 \\
\hline Leucine & $6-9.5$ & 10 \\
\hline Tyrosine & $6-9.5$ & 9.5 \\
\hline Tryptophan & $6-9.5$ & $7.0-9.5$ \\
\hline Phenylalanine & $8.4-10.1$ & N/A \\
\hline Histidine & $8-9.5$ & N/A \\
\hline Methionine & $8.9-11.5$ & N/A \\
\hline Lysine & 9.59 & 10 \\
\hline Valine & $6-8$ & 9 \\
\hline Serine & $7-10$ & N/A \\
\hline Threonine & $7-10.3$ & 10.5 \\
\hline Alanine & $6.4-9.0$ & 10.0 \\
\hline
\end{tabular}

[“Brenda", 2016]

The interaction between amino acids is changed as $\mathrm{pH}$ alters as given in Table 10. The change in interaction in amino acids inside enzymes change the structure of enzyme. The change in structure results in the change in behavior of enzyme i.e. a change in interaction with substrate. The change in the charges of amino acids as a change in $\mathrm{pH}$ is given in Table 10. The contents for Table 10 are retrieved from: Amino acids available in cellulases, [Divne et al., 1994; Kleywegt et al., 1997; Abuja et al., 1988; Belaich et al.,1992. ; Mackenzie et al., 1998]; charges on cellulases are from the work of Cameselle et al. (1986); functions of amino acids are taken from Molecular Biology [Horton et al., 1996]. As pH increases from 5 to 10 the negativity of charges on aspartate (Asp) and glutamate (Glu) increases 2.5 and 5 times respectively, positive charge on arginine and lysine decreases. Tryptophan and Tyrosine have positive charge and they hold substrate in the active sites so that Asp 
and Glu can act on substrate [Linder et al., 1995: Fukuda et al., 2006], also a decrease in positive charge will decrease their capability to make hydrogen bonds with substrate. Alanine, leucine, isoleucine, valine, methionine, phenylaline and proline are non-polar. At $\mathrm{pH} \mathrm{10,} \mathrm{all} \mathrm{of} \mathrm{the} \mathrm{amino}$ acids are negatively charged, this situation brings structural problems and the enzyme goes through conformational changes. From Table 10 glutamate, arginine, methionine, tyrosine, and tryptophan start denaturing above $\mathrm{pH} 9$.

Table 10: Charges on component amino acids at various $\mathrm{pH}$ levels of desorption system

\begin{tabular}{|l|c|c|c|c|c|c|}
\hline \multicolumn{1}{|c|}{ Amino Acid Residues } & \multicolumn{5}{c|}{ pH } \\
\cline { 2 - 7 } & $\mathbf{5}$ & $\mathbf{6}$ & $\mathbf{7}$ & $\mathbf{8}$ & $\mathbf{9}$ & $\mathbf{1 0}$ \\
\hline $\begin{array}{l}\text { Aspartate (Asp) } \\
\text { Cation binding, } \mathrm{H}^{+} \text {transfer, }\end{array}$ & -0.96 & -1 & -1 & -1.02 & -1.2, & -1.72 \\
\hline $\begin{array}{l}\text { Glutamate (Glu) } \\
\text { Cation binding, } \mathrm{H}^{+} \text {transfer, }\end{array}$ & -0.85 & -0.98 & -1 & -1.02 & -1.18 & -1.68 \\
\hline $\begin{array}{l}\text { Arginine (Arg) } \\
\text { Anionic binding, }\end{array}$ & 1 & 1 & 0.99 & 0.91 & 0.49 & 0.09 \\
\hline $\begin{array}{l}\text { Lysine (Lys) } \\
\text { Anionic binding, }\end{array}$ & 1 & 1 & 0.99 & 0.94 & 0.59 & -0.01 \\
\hline $\begin{array}{l}\text { Tryptophan (Trp) } \\
\text { H-bond with ligands }{ }^{\mathrm{a}},\end{array}$ & 0 & 0 & 0 & -0.04 & -0.27 & -0.78 \\
\hline $\begin{array}{l}\text { Tyrosine (Tyr) } \\
\text { H-bond with ligands }\end{array}$ & 0 & 0 & 0 & -0.08 & -0.51 & -1.31 \\
\hline $\begin{array}{l}\text { Threonine (Thr) } \\
\text { bb }\end{array}$ & 0 & 0 & 0 & -0.07 & -0.44 & -0.89 \\
\hline $\begin{array}{l}\text { Serine (Ser) } \\
\text { bb } \\
\text { Covalent bond with acyl-, }\end{array}$ & 0 & 0 & 0 & -0.06 & -0.38 & -0.98 \\
\hline $\begin{array}{l}\text { Histidine (His) } \\
\mathrm{H}^{+} \text {transfer }\end{array}$ & 0.91 & 0.5 & 0.08 & -0.05 & -0.4 & -0.87 \\
\hline
\end{tabular}




\begin{tabular}{|l|c|c|c|c|c|c|}
\hline Amino Acid Residues & $\mathbf{5}$ & $\mathbf{6}$ & $\mathbf{7}$ & $\mathbf{8}$ & $\mathbf{9}$ & $\mathbf{1 0}$ \\
\hline Cysteine (Cys) & 0 & 0 & -0 & -0.31 & -0.85 & -1.24 \\
\hline Alanine (Ala) & 0 & 0 & 0 & -0.2 & -0.17 & -0.67 \\
\hline Leucine (Leu) & 0 & 0 & 0 & -0.02 & -0.2 & -0.72 \\
\hline Isoleucine (Ile) & 0 & 0 & 0 & -0.02 & -0.17 & -0.68 \\
\hline Valine (Val) & 0 & 0 & 0 & -0.02 & -0.19 & -0.71 \\
\hline Methionine (Met) & 0 & 0 & -0 & -0.06 & -0.38 & -0.86 \\
\hline Phenylalanine (Phe) & 0 & 0 & -0 & -0.06 & -0.4 & -0.87 \\
\hline Proline (Pro) & 0 & 0 & 0 & 0 & -0.02 & -0.19 \\
\hline
\end{tabular}

$\mathrm{a}=$ hydrophobic; $\mathrm{b}=$ hydrophillic, polar; $\mathrm{bb}=$ hydrophillic no charge

[Cameselle et al., 1986; Horton et al., 1996]

Therefore, reading Table 9 and Table 10 together gave information that the $\mathrm{pH}$ suitable for desorption is 6-9. From this literature survey and the discussion given above, it was decided to use pH of 6, 7, 8 and 9 to get desorption of active cellulases where $\mathrm{pH} 8$ and $\mathrm{pH} 9$ look more promising.

\subsubsection{Decrease in desorption due to entrapment of cellulases}

Jung et al. (2002) found that the cellulases were entrapped in the pores of substrate during adsorption of enzymes from T. fusca Cel5A, Cel6B, Cel48A onto BMCC and resulted in irreversible desorption. Tanaka et al. (1988) found that one cause of the rapid decrease in the hydrolysis rate was the diffusion of cellulases into small pores of cellulose. When cellulases enter the small pores they get trapped and reduce the rate of hydrolysis.

There were certain requirements of the internal geometry of a substrate if high enzyme activity retention was to be achieved. That is, the enzyme should be able to enter into pore to be adsorbed. 
The pore size of the selected substrate should meet three requirements.

i. $\quad$ pore size should be at least of the same order as enzyme size [Ferreira et al., 2002]

ii. enzyme-conformation mobility should be not significantly reduced compared with that of the free enzyme, thus necessitating the presence of larger pore size than the size of the enzyme molecules [Hwang et al., 2004].

iii. diffusion constraints should be mitigated to retain high apparent activity [Tischer and Kasche, 1999]

Hwang et al. (2004) investigated on adsorption of papain on porous silica with pores in the range 30-90 nm, through the series of experimentation they concluded that pore size should be 5-10 times the size of the enzyme regarding the high retention of activity. If the pore sizes are less than suggested enzymes size there are 60 to $70 \%$ chances of entrapment of enzymes which will result in reduction in desorption. The average pore size of Avicel is around 30 [Rodriguez, 1997] and the average size of CBDs of CBHs and EGs is around 28.5 $\AA$ [Gilkes et al., 1992]. CBD can get trapped in the pore, resulting in a decrease of desorption of cellulases.

\subsection{Enhancement of Desorption}

After strategic use of $\mathrm{pH}$ and temperature, the question that remains is: can this desorption be enhanced to get new maxima, if at all possible? Chemical such as glycerol, polyethylene glycol and enzyme $\beta$-glucosidase were selected to be used for the reasons given in the respective sections below. Simplicity and cost effectiveness are among the key strengths of this enzyme recycling strategy. 


\section{Glycerol}

Glycerol was observed as an effective desorbent [Otter et al., 1989]. The maximum desorption (67 $\%$ with $56 \%$ activity) of cellulases from Avicel was achieved at pH 10 with $10 \%$ glycerol while 57 $\%$ desorption with $88 \%$ activity was achieved at pH 5 and $60 \%$ glycerol [Otter et al., 1989]. Similarly, Wang et al. (2012) used $40 \%$ glycerol to desorb endoglucanases from sulfite treated poplar and they could desorb $10 \%$ endoglucanases and activity was not reported. Therefore, I noticed that high concentrations for glycerol $(>40 \%)$ can help in desorption. Literature survey gave me insight that high concentration of glycerol denature enzymes [Wenbin et al., 2002] and low concentration of glycerol $(<20 \%)$ increase stability of proteins. Therefore, I decided to use glycerol in low concentration mixtures with distilled water to enhance stability of enzymes and desorption. Moreover, in aqueous medium, the amino acid chains on the surface of cellulases preferentially excluded glycerol from the core of cellulases and made it more compact thus forming a thermodynamically unfavorable situation [Gekko and Timasheff, 1981b]. To minimize the effect of glycerol, the cellulases fold themselves more and became more compact, hence, stability was increased [Gekko and Timasheff, 1981a]. Glycerol could increase cellulases stability during desorption at high $\mathrm{pH}$. Glycerol competed with the enzyme for hydrogen bond at sites on the cellulose and as the glycerol concentration increased cellulases was desorbed [Gekko and Timasheff, 1981b]. In most cases, binding of proteins to insoluble substrates is weakened at high temperatures because of increased kinetic energy. Therefore it helped desorption. At elevated $\mathrm{pH}$ values due to increased repulsive electrostatic forces between the enzyme and lignin [Lou et al., 2013]. Enzyme-lignin interaction are non-covalent type and the driving forces involve are hydrophobic and electrostatic interaction, with minor contribution from hydrogen bonding and dipolar interactions [Claesson et al., 1995; Norde, 1996]. Therefore, I expect that elevated temperature and $\mathrm{pH}$ will help desorbing 
cellulases from wheat straw (lignocellulosic materials) and glycerol will stabilize cellulases at elevated temperature and alkaline $\mathrm{pH}$. A concentration larger than $10 \%$ was resulted in instability of cellulases [Nagayama et al., 2012] either by cellulases precipitation or by the penetration of glycerol into core of the cellulases which result in conformational changes of cellulases. Hence, decrease in activity of cellulases.

\section{Ethylene glycol}

Ethylene glycol was used to pre-treat substrates to prevent substrates from adsorption of enzymes [Alstine et al., 1996; Borjesson et al., 2007; Hofs et al., 2008]. The mechanism of ethylene glycol in rejection of enzymes is that steric repulsion where surface attached ethylene glycol competes with the hydrophobic interaction between the enzymes and the surface [Jeon et al., 1991]. I used the same property of ethylene glycol to remove adsorbed enzymes (cellulases) from the substrates.

The electrons within O-H bonds in ethylene glycol have a higher probability of appearance around the Oxygen atom than their probability of appearance around the Hydrogen atom, which makes the Hydrogen atom slightly electropositive. The electropositive hydrogen atom develop an affinity with the substrate-cellulase complex, providing $\mathrm{H}^{+}$to cellulases attached with cellulose and let it desorb from the substrate (cellulose, lignin, wheat straw). Ethylene glycol is oxidized by the enzymes [Eder et al., 1998]. The cellulases-ethylene glycol complex is not stable because $\mathrm{H}$-bond of ethylene glycol molecule have strong affinity with $\mathrm{H}-\mathrm{O}-\mathrm{H}$. Ethylene glycol satisfy its charges from water molecule and release/ desorb cellulases. Elevated temperatures increase cellulases desorption from the surface of Protobind. Ethylene glycol may attach to the lignin in one of two ways (1) terminally; or (2) by interaction between the Protobind and ethylene glycol. The first interaction with the surface of 
Protobind require high EG dosage to cover the whole surface, while the latter require a low concentration to make a very thin ethylene glycol layer on the surface.

It can suggest that the interaction is formed between ethylene glycol and the phenolic hydroxyl groups [Matsushita, 2015] of Protobind. The importance of phenolic hydroxyl groups in lignin and cellulase interaction has already been hypothesized [Sewalt et al., 1997]. Phenolic hydroxyl groups exposed on the lignin surface can easily form hydrogen bonds with the oxygen atoms of the ethylene glycol polymer. This would mean that ethylene glycol is accepting a hydrogen bond, and free phenolic hydroxyl group of lignin is donating the hydrogen bond [Borjesson et al., 2007]. The accepted hydrogen bond balance the charge requirement of cellulases and cellulases desorbed from the substrate (cellulose, lignin wheat straw).

\section{$\beta$-glucosidase}

Cellulases are a family of enzymes having three members endoglucanase (EC 3.2.1.4), cellobiohydrolase (CBH) (EC 3.2.1.91), and $\beta$-Glucosidase (EC 3.2.1.21). End-product inhibition has shown to play a major role in hindering a continuously fast desorption/hydrolysis rate. In the cellulase family of multiple enzymes, endoglucanases (EG) act on amorphous regions or regions of low crystallinity in the cellulose. Exoglucanases (CBH I; Cel7A) progressively adsorb and hydrolyze the cellulose chain from the reducing end through a retaining mechanism to produce $\beta$-cellobiose, whereas exoglucanases (CBH II; Ce16A) preferentially acts from the nonreducing end of the chain via an inverting mechanism to produce $\alpha$-cellobiose. After the action of endoglucanase and exoglucanases, cellobiose, cellotriose and cellotetraose are formed. Cellulases (EGs and CBHs) adsorbed on cellobiose/cellotriose/ cellotetraose cannot desorb [Xiao et al., 2004; Gruno et al., 2004], called fixation of cellulases. Working dimensions of a cellulases were studied on Cel45. Cel45 are 
endoglucanases (EC 3.2.1.4) from Humicola insolens endoglucanase V. Cel45 have a (maximum stretch of a molecule) $D_{\max }$ of $125 \AA$ which results in a maximum distance between the centers of the constitutive modules of $85 \pm 10 \AA$ (CBM and $\mathrm{CM}$ or $\mathrm{CD}$ ). From this, one can conclude that from a fixed binding site of the CBM onto a cellulose chain, Cel45 has a maximum operation range of about $40 \AA$ A, e.g. may operate only a maximum of four glycosidic bonds of similar orientation on a single chain. [Receveur et al., 2002]. That is why some times cellobiose/cellotriose/ cellotetraose are obtained in products. The presence of $\beta$-glucosidase decrease the chances of fixation of cellulases with adsorption products of EGs and CBHs [Levine et al., 2010; Manara, 2012]. To decrease the chances of fixation of cellulases $\beta$-glucosidase for desorption enhancement were used. There is also a lack of information on whether $\beta$-glucosidase favor desorption and effects on cellulase activity during cellulose conversion, hence it is need to be addressed. 
3.0 objectives 


\section{Objectives of thesis}

Bioethanol has received a tremendous interest of research community as an alternative fuel because of the climate change effect and the fear of depletion of fossil fuels. My extensive literature survey identified huge gaps in the previously reported studies on bioethanol production. The detected gaps may be the reasons for non-commercialization of enzymatic hydrolysis in the bioethanol producing industry. The gaps are summarized as: i) narrow spectrum of factors influencing desorption was studied. A detailed strategic study of the effects of $\mathrm{pH}$, temperature was not conducted, for example working only on two temperatures or $\mathrm{pH}$ values and then results were generalized, ii) cellulases desorption and activity was not investigated systematically, iii) most of the studies were based on action of cellulases from the pure chemicals such as crystalline cellulose or filter paper, a few studies have covered forestry lignocellulosic materials and the study on agricultural material was very rare.

This $\mathrm{Ph}$. D. thesis deals with the active desorption of cellulases from the lignocellulosic materials being used in producing bioethanol in a cost-effective and environmental friendly way. It is hypothesized that: i) the poor desorption of cellulase from lignocellulosic substrates would be enhanced by using a high pH (weakening of H-bonding). Similarly, the use of high temperature may give more desorbed cellulases but the desorbed cellulases may not be active cellulases (thermal denaturing), ii) desorption of cellulases can be enhanced by competing adsorption of glycerol, ethylene glycol and controlling entrapment of cellulases by reaction by-products (fixation of cellulases) by using $\beta$-glucosidase, iii) the techniques used for desorption of cellulases from the components of lignocellulosic materials can be used for lignocellulosic materials used in bioethanol producing industry.

The main objective of this work has been to gain a better understanding of adsorption and desorption of cellulases from a lignocellulosic material, more specifically: 
1. Determine adsorption isotherms for adsorption onto Avicel PH 101 to resolve the conflicts in literature about adsorption patterns of cellulases and determine adsorption pattern of cellulases on Protobind 1000 for the first time.

2. Determine adsorption capacity of Avicel PH 101 and Protobind 1000 under similar experimental conditions such as temperature, $\mathrm{pH}$, dynamics and type of enzymes. Quantify the adsorption for a range of initial cellulases concentration. Determine the changes in enthalpy $\left(\Delta \mathrm{H}_{\mathrm{a}}\right)$ and entropy $\left(\Delta \mathrm{S}_{\mathrm{a}}\right)$ for adsorption of cellulases on Avicel PH 101 and Protobind 1000 to predict the feasibility of adsorption and the optimum adsorption conditions.

3. Determine active desorption of cellulases from adsorbed cellulases from both substrates, Avicel PH 101 and Protobind 1000. Determine the feasibility of desorption through changes in enthalpy $\left(\Delta \mathrm{H}_{\mathrm{d}}\right)$ and entropy $\left(\Delta \mathrm{S}_{\mathrm{d}}\right)$ for desorption of cellulases from Avicel pH 101 and Protobind 1000. Estimate optimum conditions for active desorption of cellulases, using a wide range of temperature and $\mathrm{pH}$, to fill the gaps in literature.

4. Enhance the active desorption of cellulases by strategic use of $\mathrm{pH}$, temperatures, as suggested by last 3 steps. Clarify the use of additives (such as desorbing agents) to enhance desorption of active cellulases. Quantify desorption of cellulases for a range of initial cellulases concentration, temperature, $\mathrm{pH}$ and additives to patch the holes in the fundamental knowledge of desorbing cellulases from lignocellulosic materials in the biofuel business.

5. Apply the strategy developed till the step 4 for desorption of active cellulases from wheat straw and delignified wheat straw and make recommendations for the bioethanol producing industry. 
4.0 Material and Methods 


\subsection{Materials}

\section{Avicel PH 101}

Avicel PH 101 (analytical grade, 100\% solids, Sigma-Aldrich Corp., Missouri, and USA) is a white powder cotton-source microcrystalline cellulose of approximately $50 \mu \mathrm{m}$ particle size, $78 \%$ porosity, and $56.7 \%$ crystallinity. Avicel was purchased from Sigma-Aldrich Corp. It has a molecular weight $370.35 \mathrm{~g} / \mathrm{mol}$ and density $0.600 \mathrm{~kg} \mathrm{~L}^{-1}$. The functional groups of Avicel PH 101 participating in adsorption are $-\mathrm{OH}$ group, the $-\mathrm{C}-\mathrm{O}-\mathrm{C}-$ group of the $\beta-1,4-$ glycosidic linkage. Stored at room temperature.

\section{Protobind 1000}

Protobind 1000 (analytical grade, 100\% solid) is an aromatic polyphenolic material derived from wheat straw lignin during its soda pulping is generously donated by Dr. J. Lora from Green Value Enterprises LLC. It is a dark brown solid with an average particle size of $200 \mu \mathrm{m}$, and $64 \%$ crystallinity. Its molecular weight 3000 and density of $0.550 \mathrm{~kg} \mathrm{~L}^{-1}$. The Protobind 1000 was found to be composed of $p$-coumaric and ferulic acid, acetosyringone, syringaldehyde and vanillin types of lignin. Stored at room temperature.

\section{Wheat straw}

Wheat straw (Tritium sativum) is an agricultural waste. For this study two bales of wheat straw were gifted from a farm north of Toronto. The straw was dedusted by gentle tapping and milled by a machine (Type SM100 Comfort, Retsch Inc. Philadelphia, USA). The milled wheat straw was sieved separately to the required sizes $(0.5 \mathrm{~mm})$, wheat straw has cellulose $46.81 \%$, and lignin $18-22 \%$ and the crystallinity of the cellulose is $55.57 \%$. Wheat straw used was $30 \%$ and $60 \%$ delignified for studies while delignification was conducted by ozonation. 


\section{Chemicals}

Cellulases, a commercial cellulase mixture, brown liquid, (NS50013, batch \# CCN03129) from Trichoderma reesei was generously donated by Novozymes (Denmark). According to the manufacturer, the solution mostly contains exocellulases (cellobiohydrolases: CBHI and CBHII). $\mathrm{CBHI}$ is responsible for hydrolysis of both amorphous and crystalline cellulose. Endocellulases (Endoglucanases: EGI and EGII), are known to attack and adsorb preferentially on amorphous cellulose. The approximately composition of commercial enzyme mixture was: CBH I (60 \%), CBH II (15\%), EG I and II (20\%), and BG (2\%) [Wenger, 2006]. Molecular weights estimated were 52000 for EGs [Li et al 1965], 23000-58000 for EGs [Beldman et al., 1985], and 60500 - 62000 for CBHs [Beldman et al., 1985]. To simplify calculations the molecular weight of cellulases was taken as 60000. It was stored at $4{ }^{\circ} \mathrm{C}$ until used. Every time before use mother solutions (varying concentrations) of cellulases were prepared form the original stock solution. Protein concentration as well as total activity (FPU) of the mixtures were determined according the procedures described in Analyses. It was used as additive to desorption studies.

A commercial $\beta$-glucosidase (BG, NS50010, batch \# DCN00218) from Trichoderma reesei was generously donated by Novozymes (Denmark). The $\beta$-glucosidase has a molecular weight of 76000 [Beldman et al., 1985].

Glycerol (G, electrophoresis reagent grade; $99 \%$ pure) was a product of Sigma-Aldrich. It has molecular formula $\mathrm{C}_{3} \mathrm{H}_{8} \mathrm{O}_{3}$ with a formula weight of 92.09. It was stored at room temperature, and used as specified.

Ethylene glycol (EG, Analyzed reagent grade; $99.7 \%$ pure) was a product of J.T. Baker. It has molecular formula $\mathrm{C}_{2} \mathrm{H}_{6} \mathrm{O}_{2}$ with a formula weight of 62.07 . It was stored at room temperature 


\subsection{Instruments}

\section{Delignification}

Ozone at concentration of ca. 6.5 to $65.5 \mathrm{mg} / \mathrm{L}$ was produced from pure oxygen using an ozone generator (PC1-WEDCO, Model GL-1, USA) as shown in part A of Figure 7. Oxygen was supplied in cylinders by Linde Canada Limited. Ozone is made by passing pure oxygen gas through a tube though which energy is directed. The energy breaks apart the molecules as described above, and what emerges from the other side is ozone.

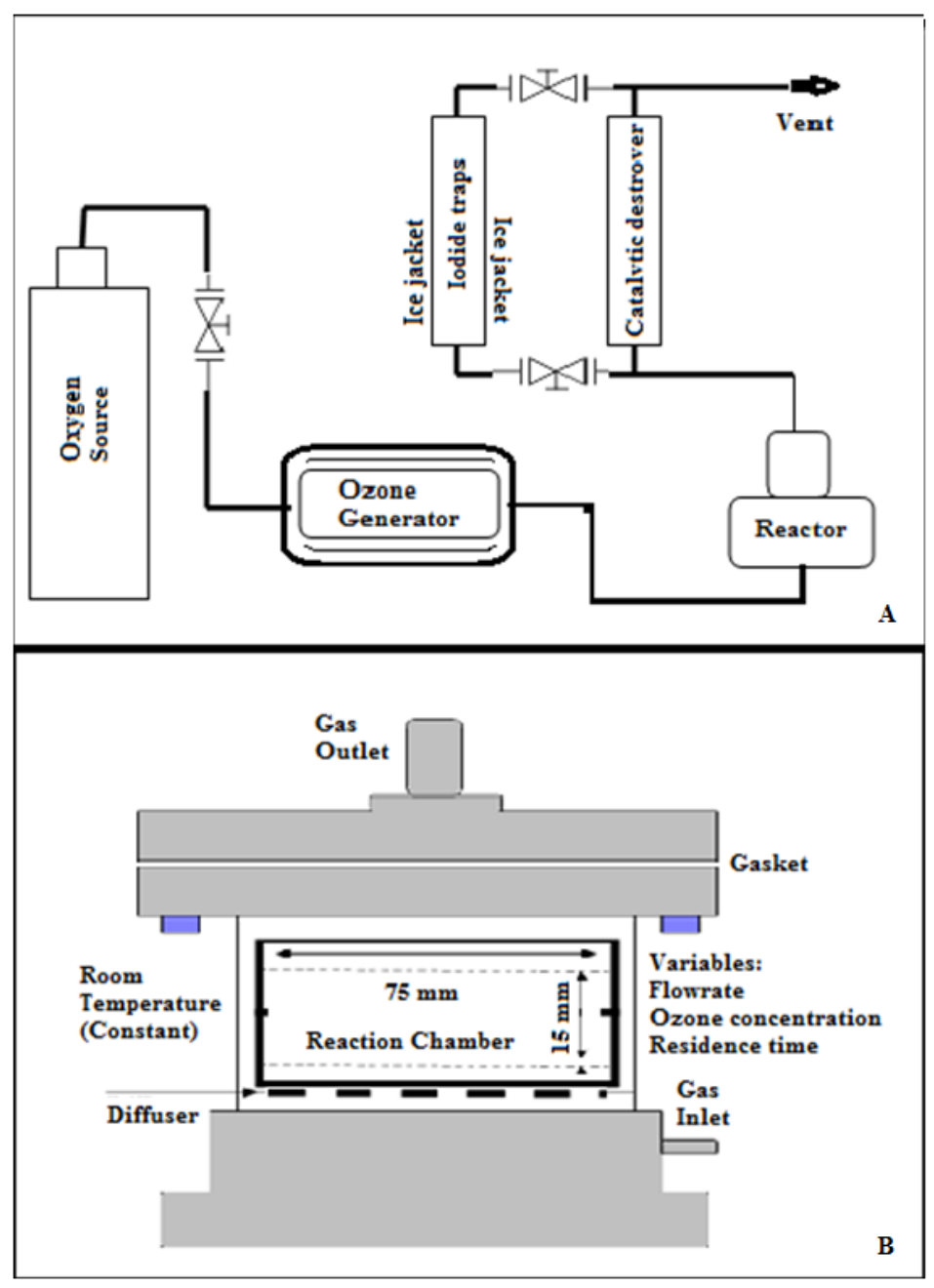

[Baig et al. 2015]

Figure 7: Delignification by ozone. Figure A) Experimental set up for delignification, B) Delignification reactor 
Wheat straw samples were exposed to the flowing ozone streams using a 2 phase solid-gas fluidization reactor as shown in Figure 7 (b), which had a stainless steel reaction chamber. At the entrance and exit of reactor ozone flow is maintained and controlled by control valves. The concentration of ozone entering was measured automatically by an online spectrophotometer (at 257 $\mathrm{nm})$. After entering in the reactor, ozone passed through a diffuser which distribute ozone homogenously in the reaction chamber to react with wheat straw. The unreacted ozone left the reactor from an outlet located at the top and a catalytic destroyer convert it to oxygen before it was sent to the vent.

\section{Incubation for Adsorption and Desorption}

New Brunswick Shakers Innova 40 (Figure 8) was used for adsorption and desorption studies for incubation of samples. It's an orbital shaker with controllable rpm and temperature. Its temperature was monitored by a glass thermometer for the temperatures of $25^{\circ} \mathrm{C}$ and $60{ }^{\circ} \mathrm{C}$ and no difference in temperature readings were found.

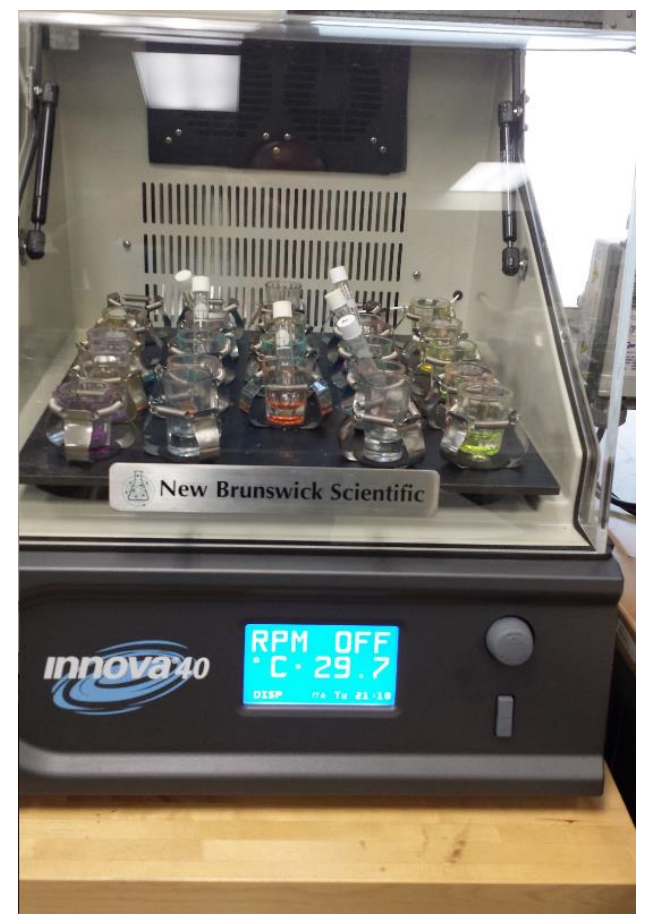

Figure 8: Incubator used for Adsorption and desorption studies 


\section{Spectrophotometer for measurement of activity and concentration of enzymes}

The Biochrom Libra S50 model is a low maintenance UV/Visible spectrophotometry. Spectrophotometers use a monochromator containing a diffraction grating to produce the analytical spectrum. The grating can either be movable or fixed. The Biochrom Libra S50 model, the grating is fixed and the intensity of each wavelength of light is measured by a different detector in the array. After amplification of the energy received the display gives out the readings as shown in Figure 9.

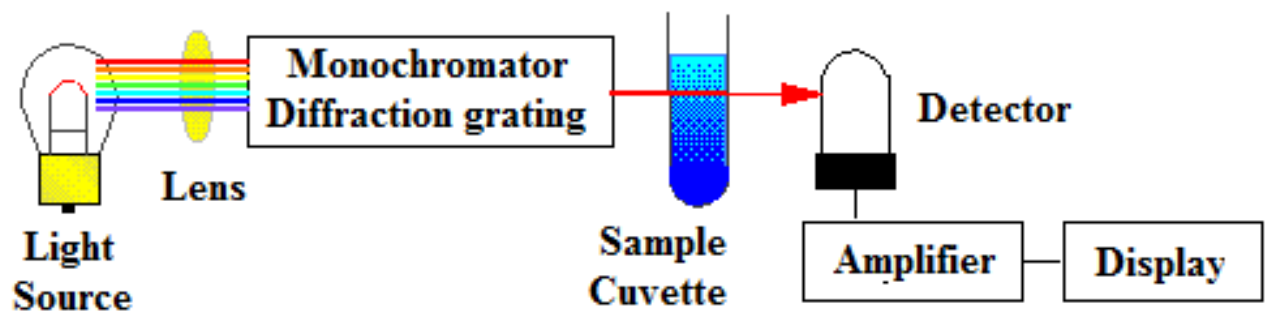

Figure 9: Detection mechanism of a spectrophotometer

Spectrophotometry is an important technique used in enzymology experiments that involve protein isolation, enzyme kinetics and biochemical analyses. [Trumbo et al., 2013]. A brief explanation of the procedure of spectrophotometry includes comparing the absorbance of a blank sample that contain everything of the enzyme solution but not the substance (or enzyme) of interest to a sample that contains the substance. The spectrophotometer is used to measure colored compounds in the visible region of light (between $350 \mathrm{~nm}$ and $800 \mathrm{~nm}$ ), [Ninfa et al., 2010]. In enzymology experiments, a chemical and/or physical property is chosen and the procedure that is used is specific to that property in order to derive more information about the sample, such as the enzyme purity, enzyme quantity, enzyme activity, etc. Because a spectrophotometer measures the wavelength of a compound through its color, an enzyme binding substance can be added so that it can undergo a color change and be measured. Spectrophotometers have been developed and improved over decades and 
have been widely used among chemists. It is considered to be a highly accurate instrument that is also very sensitive and therefore extremely precise, especially in determining color change. [Mavrodineanu et al., 1973]

\subsection{Procedures}

\section{Proposed treatment for delignification}

The novel proposed pretreatment for delignification of wheat straw by using ozone is a three-step procedure:

Step 1: Wheat straw was oven dried and soaked in $1 \% \mathrm{NaOH}$ for 12 hours. The resulting aqueous mixture was filtered using binder-free, glass micro fiber filter grade 691, $9.0 \mathrm{~cm}$ diameter with pore size of $1.5 \mu \mathrm{m}$. The filtered residues were washed with deionized water until the $\mathrm{pH}$ value was around 7.0. The washed residue were dried at $105^{\circ} \mathrm{C}$ in an oven (Catalogue No. 3605, 1200watts, Labline Inc., USA) until a constant weight of dry wheat straw was obtained.

Step 2: The dried sample was sprayed with 3 times of the dry weight of wheat straw by a spray bottle. Then, the moistened sample was wrapped in aluminum foil, placed in covered Petri-dishes, further wrapped in cellophane and placed in a fridge at $4{ }^{\circ} \mathrm{C}$ to avoid water loss for 24 hours. The time was provided to let the water absorb in the wheat straw sample completely.

Step 3: The moistened sample was unwrapped and quickly subjected to ozonation.

\section{Adsorption and desorption}

An initial concentration of commercial cellulases $\left[P_{0}\right]$ was added to substrate. The concentration of free cellulases present in the supernatant after adsorption was labelled $\left[P_{f a}\right]$. The concentration which remained adsorbed $\left[P_{a}\right]$ calculated by the difference between initial concentration and free nonadsorbed cellulases. Figure 10 shows that the supernatant obtained from the centrifugation of 
adsorption sample after incubation were used for estimation of cellulases concentration and activity. The solid residues obtained from the adsorption step was used for desorption studies. Similarly, supernatant obtained from desorption sample after the centrifugation was used for the concentration of the cellulases desorbed and activity of the cellulases desorbed. The solid residues obtained from desorption were discarded.

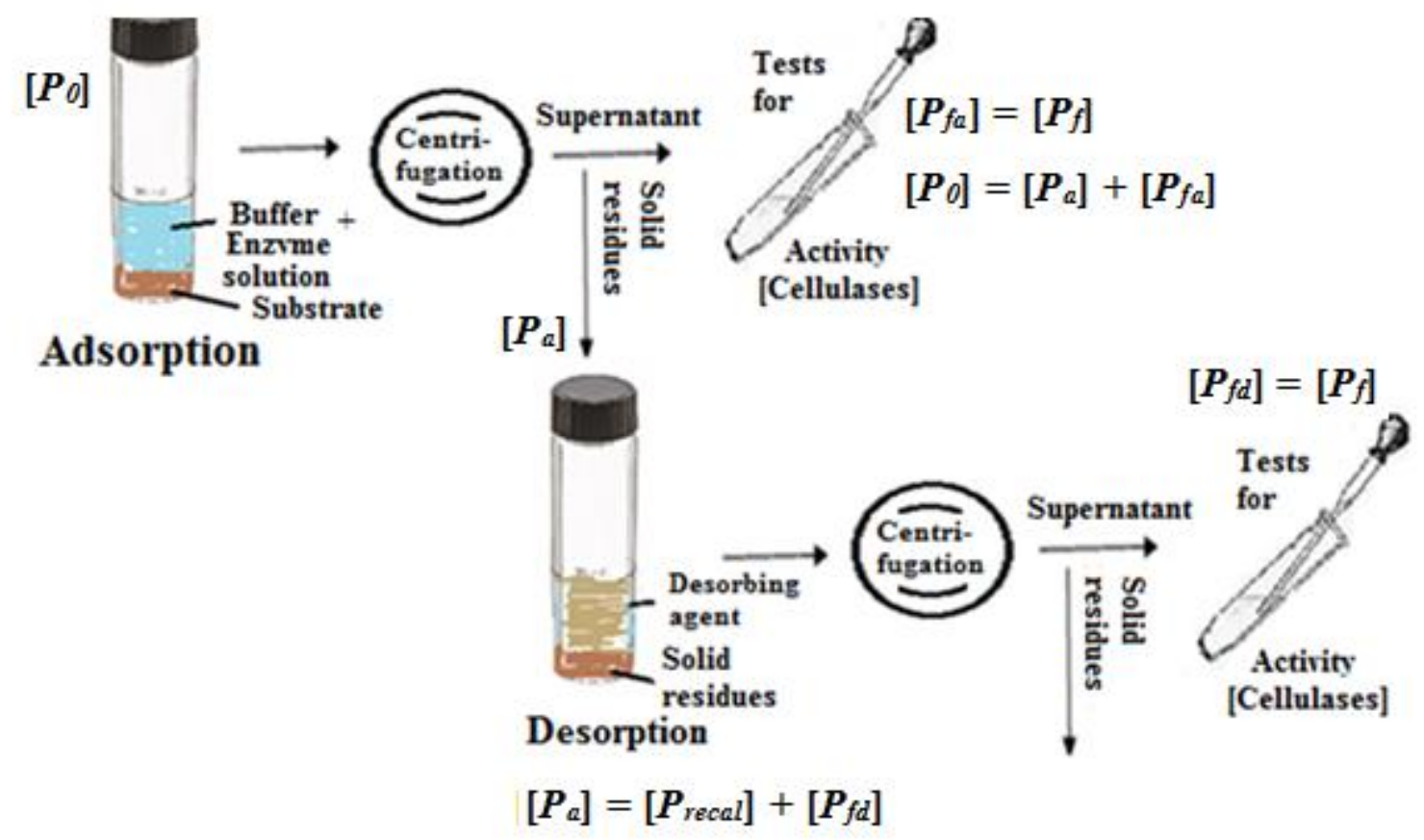

Figure 10: Procedure for adsorption and desorption

The concentration of cellulases that could not desorbed from substrates was $\left[P_{\text {recal }}\right]$.

\section{Adsorption of cellulases onto substrates}

Thirty milliliters of distilled water were placed in a $250-\mathrm{mL}$ Erlenmeyer flask. Then $70 \mathrm{~mL}$ of $0.05 \mathrm{mM}$ sodium citrate buffer at $\mathrm{pH} 5$ was added followed by addition of the brownish commercial cellulases mixture NS50013 (in predefined amounts). The solution was hand mixed to uniformly disperse the cellulases (observed by dispersion of color). The $\mathrm{pH}$ was adjusted to 5 using distilled water or $\mathrm{NaOH} 0.1 \mathrm{M}$. The solution was hand-mixed again, and placed at $25^{\circ} \mathrm{C}$ in an Innova 40 
Incubator Shaker (New Brunswick Scientific, USA) at $100 \mathrm{rpm}$ for 2 hours (values chosen by literature survey). Performed this step to get a homogenous mixture. Five 1-mL samples of the solution were drawn to measure the initial concentration of cellulases, $\left[P_{0}\right]$, as described in the section Analyses, and $5 \mathrm{~mL}$ of the solution were added into each of $10-\mathrm{mL}$ screw cap glass test tubes already containing $100 \mathrm{mg}$ of Avicel PH 101. The test tubes were placed in the incubator shaker at $25{ }^{\circ} \mathrm{C}$ and $100 \mathrm{rpm}$ for $5,10,20,30,40,50,60$, and $90 \mathrm{~min}$ of contact time (as pre-designed through literature survey). The experiment was triplicated. Each test tube was centrifuged in a Clinical 100 centrifuge (VWR USA) at $4000 \mathrm{rpm}$ for 4 minutes. The concentration of non-adsorbed free cellulases, $\left[P_{f}\right]$, in the supernatant was determined in triplicate, and the solid residue of adsorbed cellulases on Avicel was discarded. The concentration of adsorbed cellulases on Avicel was calculated as $\left[P_{a}\right]=\left[P_{0}\right]-$ $\left[P_{f}\right]$. This procedure was repeated using $0.077,0.096,0.107,0.123,0.138,0.169,0.192$, and 0.199 $\mu \mathrm{L}$ of commercial cellulase mixture, resulting in initial $\left[P_{0}\right]$ of about $100,125,140,160,180,220$, 250 and $260 \mu \mathrm{g}$ of protein per $\mathrm{mL}$ of solution.

Using about $180 \mu \mathrm{g}$ protein per mL of solution $^{-1}$ on $100 \mathrm{mg}$ of Avicel with a contact time of up to 60 minutes, the temperature of the experiment was maintained at $25,40,50,60$ or $70{ }^{\circ} \mathrm{C}$, and the concentration of non-adsorbed free cellulases was determined as before. Experiments were done in triplicate.

The above procedure for adsorption and for effect of $\mathrm{T}$ was repeated in the Protobind 1000, also in the triplicate.

Wheat straw $(0.5 \mathrm{~mm})$ was used as substrate for adsorption at $25^{\circ} \mathrm{C}, \mathrm{pH} 5$, and $100 \mathrm{rpm}$ over 120 minutes of contact time. 


\section{Desorption of cellulases from substrate}

Adsorption with an initial cellulase concentration protein per $\mathrm{ml}$ of solution, at $25^{\circ} \mathrm{C}, \mathrm{pH} 5$ and after 30 minutes of contact, the supernatant was discarded after measurement of its concentration of nonadsorbed free cellulases, which was transformed into amount of adsorbed cellulases available on Avicel for future release by desorption. The centrifuged solid residue, with its adsorbed cellulases, was immediately re-suspended in $5 \mathrm{~mL}$ of distilled water already equilibrated at $25^{\circ} \mathrm{C}$ and at $\mathrm{pH} 5$. Preliminary desorption studies were conducted for Avicel for a time range of 5 minutes to 60 minutes by placing 11 pre-adsorbed reaction tubes, (including water blank, substrate blank) in the incubator. Fresh reaction tubes were used as data points for each of the taken out supernatant initially at 5 minute interval for first 40 minutes and then after 10 minutes for 50 to 60 minutes. Each experiment was conducted in triplicate. Triplicates of results were obtained in this fashion. Each test tube was centrifuged in the same manner as for adsorption samples. The concentration of the desorbed and activity of desorbed free cellulases in supernatants were determined as before. The activity of the desorbed enzymes was determined using filter paper assay described in the analysis section. Solid residues were discarded.

To investigate the effect of temperature and of $\mathrm{pH}$, the same initial cellulase concentration as above was used. Through literature survey it was decided to conduct desorption at temperatures of 40, 50, 60 and $70{ }^{\circ} \mathrm{C}$ while desorption at $25^{\circ} \mathrm{C}$ was taken as a reference. For a similar reason desorption was evaluated at a pH of 6, 7, 8 and 9, along with the 40, 50, 60 and $70{ }^{\circ} \mathrm{C}$. All experiments were in triplicates.

To enhance desorption, glycerol or ethylene glycol were added to the distilled water used to resuspend the solid residues with their adsorbed cellulases, at 1,5 , and $10 \mathrm{v} / \mathrm{v} \%$. Another additive $\beta$ glucosidase, was also used in distilled water 5, 10 and $18 \mathrm{v} / \mathrm{v} \%$. After 20 minutes of contact time at 
40, 50 and $60{ }^{\circ} \mathrm{C}$, at $\mathrm{pH} 8$ and 9 , the concentration and activity of desorbed free cellulases in supernatants were determined as before while the solid residues were discarded.

The whole desorption process was repeated using Protobind 1000 within an adsorption time of 45 minutes and desorption time of 20 minutes, as determined by preliminary adsorption and desorption profiles. Similarly, desorption of cellulases from wheat straw $(0.5 \mathrm{~mm})$ was performed at $25^{\circ} \mathrm{C}, \mathrm{pH}$ 5, $100 \mathrm{rpm}$ for up to 100 minutes of contact (adsorption) time, after adsorption in conditions similar to those of Avicel PH 101, in triplicates. Conditions at $60{ }^{\circ} \mathrm{C}, \mathrm{pH} 9$ and 40 minutes of desorption were compared to those of Avicel PH 101 and Protobind 1000.

Wheat straw (30\% and $60 \%$ delignified) triplicate experiment were also performed at $60{ }^{\circ} \mathrm{C}, \mathrm{pH} 9$ and 40 min. They were compared with glycerol (G) added and with conditions of $25^{\circ} \mathrm{C}$ and $\mathrm{pH} 5$.

\subsection{Analyses}

\section{Detection of Lignin}

The contents of lignin in lignocellulosic material (Wheat Straw, WS) can be analyzed gravimetrically after hydrolyzing the cellulose and hemicellulose fractions with sulfuric acid. Acid insoluble lignin present in test samples of WS were measured as Laboratory Analytical Procedure \#003 entitled as Determination of Acid-Insoluble Lignin in Biomass used by the National Renewable Energy Laboratory (NREL), which is operated by the Midwest Research Institute (MRI) for the Department Of Energy, USA. The procedure is following:

A pretreated sample of $1.0 \mathrm{~g}$ was weight and placed in a $20 \times 150 \mathrm{~mm}$ test tube. Record as $\mathrm{W}_{1}$, the initial sample weight. Each sample was ran in triplicate. For reference the sample taken was natural wheat straw. Added $15.00 \mathrm{~mL}$ of $72 \% \mathrm{H}_{2} \mathrm{SO}_{4}$, chilled to $4{ }^{\circ} \mathrm{C}$ in the refrigerator. Used a glass stirring 
rod to mix for 1 minute, or until the sample was thoroughly wetted. Hydrolyzed the sample for 2 hours at room temperature (approximately $23^{\circ} \mathrm{C}$ ), stirred every 15 minutes to assure complete mixing and wetting. Transferred the hydrolysate to a $1000 \mathrm{~mL}$ Erlenmeyer flask and dilute to a $3 \%$ acid concentration with $560 \mathrm{~mL}$ of deionized water. Placed the flask on the heating manifold and attach to the reflux condenser as shown in Figure 11 for hydrolysis of wheat straw for measurement of acid insoluble lignin.

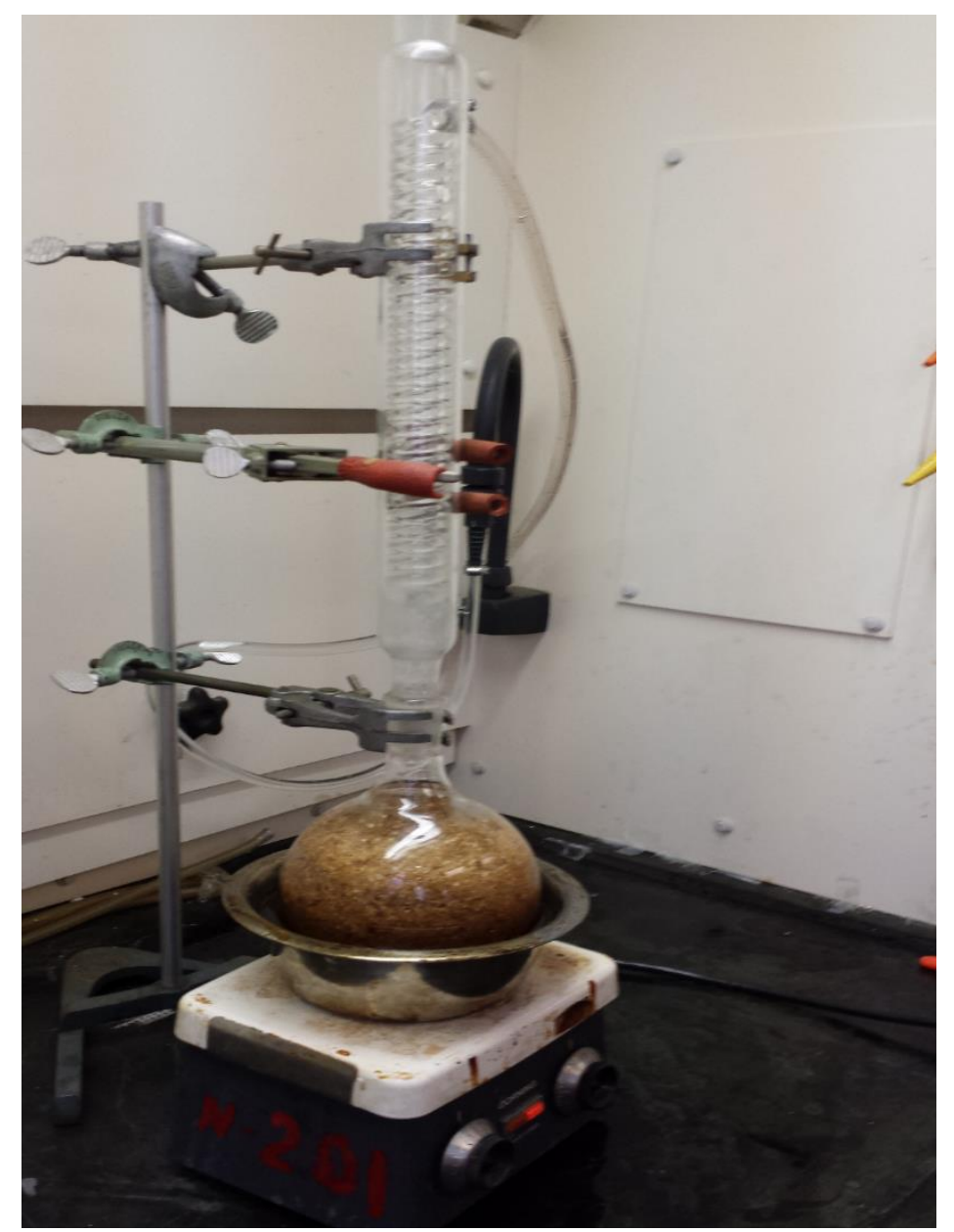

Figure 11: Hydrolysis of wheat straw for measurement of acid insoluble lignin

Heated the liquid to a gentle boil. Started timing at the onset of boiling, and set on reflux for 4 hours minutes. At the end of 4 hours, rinse the condenser with a small amount of deionized water before 
disassembling reflux apparatus. Vacuum filtered the hydrolysis solution through one of the previously ignited filtering crucibles. To determine acid-soluble lignin determination (LAP-004), recorded the weight of the collected filtrate. Decanted $15-25 \mathrm{~mL}$ of filtrate into a resealable container, aliquot was store in refrigerator at $4{ }^{\circ} \mathrm{C}$ for further analysis. Used hot deionized water to wash any particles clinging to the glass bottle into the crucible and to wash the filtered residue free of acid using vacuum filtration. Dried the crucible and contents at $105^{\circ} \mathrm{C}$ for 2 hours or until constant weight was achieved. Cooled in desiccator and record the weight, $\mathrm{W}_{2}$, the weight of the crucible, acidinsoluble lignin, and acid-insoluble ash. Placed the crucible and contents in the muffle furnace and ignite at $575^{\circ} \mathrm{C}$ for a minimum of 3 hours, or until all the carbon is eliminated. Heat at a rate of 10 ${ }^{\circ} \mathrm{C} / \mathrm{min}$ to avoid flaming. If the sample tends to flare up, the container should be partially covered during this step. Avoid heating above the maximum stated temperature. Cooled in desiccator and record the weight, $\mathrm{W}_{3}$, the weight of the crucible and acid insoluble

\section{Ash Contents of WS for delignification}

The ash contents are approximate measure of the mineral content and other inorganic matter in lignocellulosic material. The ash contents are used with other assays to determine the total composition of lignocellulosic samples. It proceeded was adapted from Laboratory Analytical Procedure \#005 of NREL, as:

A crucible was marked with a unique identification using a porcelain marker, placed it in the muffle furnace, and brought to constant weight by igniting at $575^{\circ} \mathrm{C}$. The crucible was removed from the furnace, cooled to room temperature in a desiccator, weighed and recorded this weight as the tare weight. The test sample taken into the tared crucible was 1.0 gram. The initial weight (container plus sample minus tare weight of container) of the test specimen, $\mathrm{W}_{2}$, was recorded. The container and contents were placed in the muffle furnace and ignite at $575^{\circ} \mathrm{C}$ for a minimum of three hours. At the 
start to avoid flaming, heat slowly, and to avoid flare up of WS samples, the container was partially covered during this step. The crucible was placed in a desiccator, cooled to room and the final weight of the ash, $\mathrm{W}_{1}$ was recorded, as the container plus ash weight minus container tare weight.

\section{Reducing sugars formed during adsorption}

The reducing sugars formed during adsorption process were detected by DNS method. A standard curve of the absorbance at $540 \mathrm{~nm}$ was developed by using 50 to $800 \mu \mathrm{g} \mathrm{mL}$ glucose standard $/ \mathrm{mL}$ solution in triplicates, shown in Figure 12.

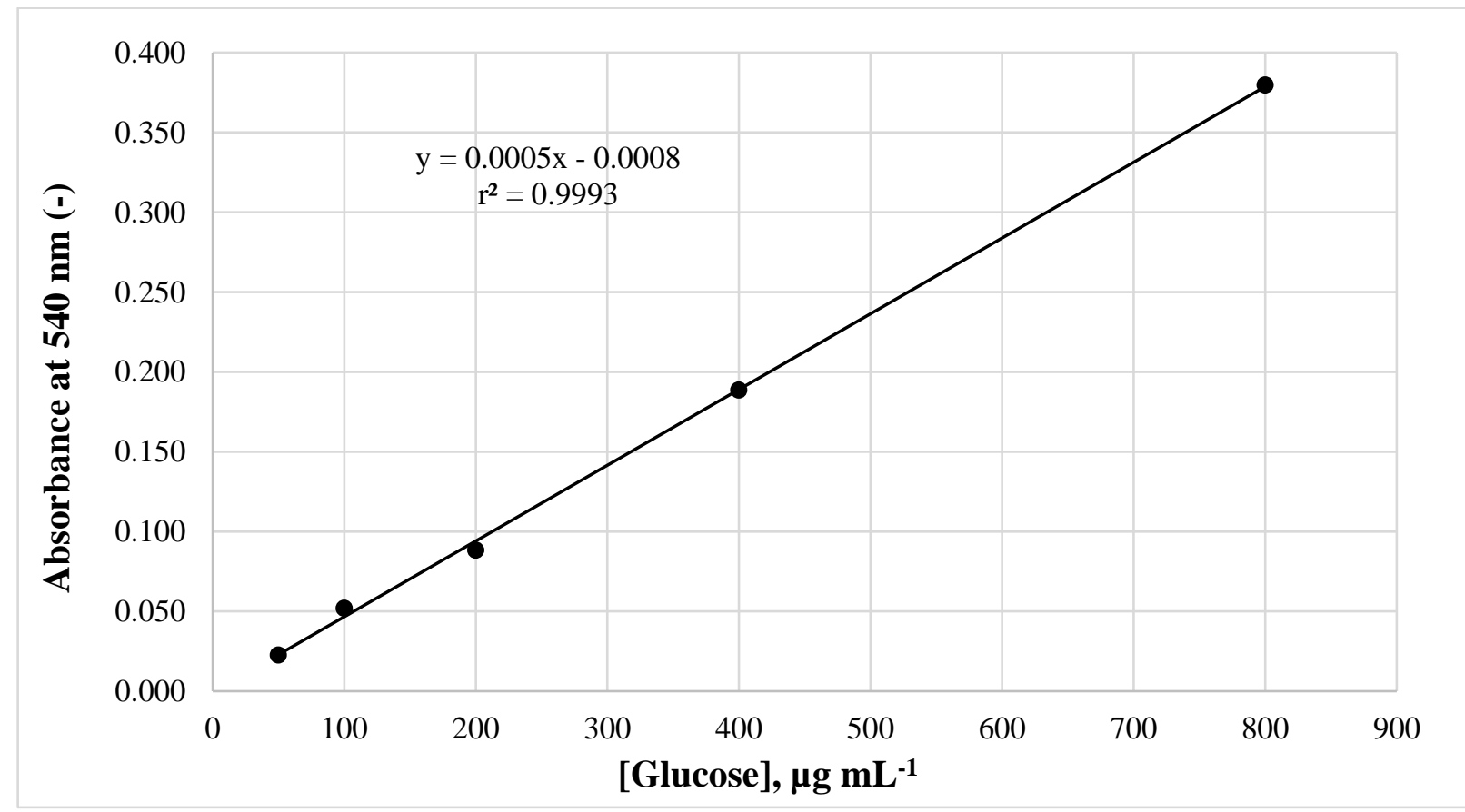

Figure 12: Glucose calibration curve (DNS method) used for the measurement of reducing sugars formed during adsorption process.

The supernatants obtained after adsorption of $180 \mu \mathrm{g} \mathrm{mL}^{-1}$ of cellulases NS 50013 on Avicel, at 25 ${ }^{\circ} \mathrm{C}, \mathrm{pH} 5$, for 60 minutes was used to determine the concentration of any reducing sugar formed during the process. After adding buffer to the supernatant as given in the 'Activity of cellulases solutions (Filter Paper Assay)', the mixture was placed in boiling water for 5 minutes in a water bath. The least squares regression line resulted in an $r^{2}$ value of 0.9993 was: 


$$
\text { A } 540 \mathrm{~nm}=0.0005[\text { Glucose }]-0.0008 .
$$

\section{Protein concentration of cellulases solutions}

The concentration of cellulases in solution (commercial mixture; $P_{0} ; P_{f}$ ) for adsorption and desorption was determined according to the Lowry method [Waterberg, 2002] using Bovine Serum Albumin (BSA) as the reference protein. One test tube for water blank and one other was a substrate control added the samples to the appropriately labeled test tube. One milliliter of the Lowry Reagent Solution to control, blank, and each samples $(0.5 \mathrm{~mL})$ tubes. Mix well. Allow solutions to stand at room temperature for 20 minutes. With rapid and immediate mixing, add $0.5 \mathrm{ml}$ of the Folin and Ciocalteu's Phenol Reagent Working solution to each tube. Allow color to develop for 30 minutes. Transfer solutions to cuvette and measure the absorbance of the control and sample tubes vs. blank and control at a wavelength of $750 \mathrm{~nm}$. The absorbance of the color developed for triplicate solutions of 0 to $400 \mu \mathrm{g} \mathrm{BSA} \mathrm{mL} \mathrm{mL}^{-1}$ as shown as a standard curve in Figure 13.

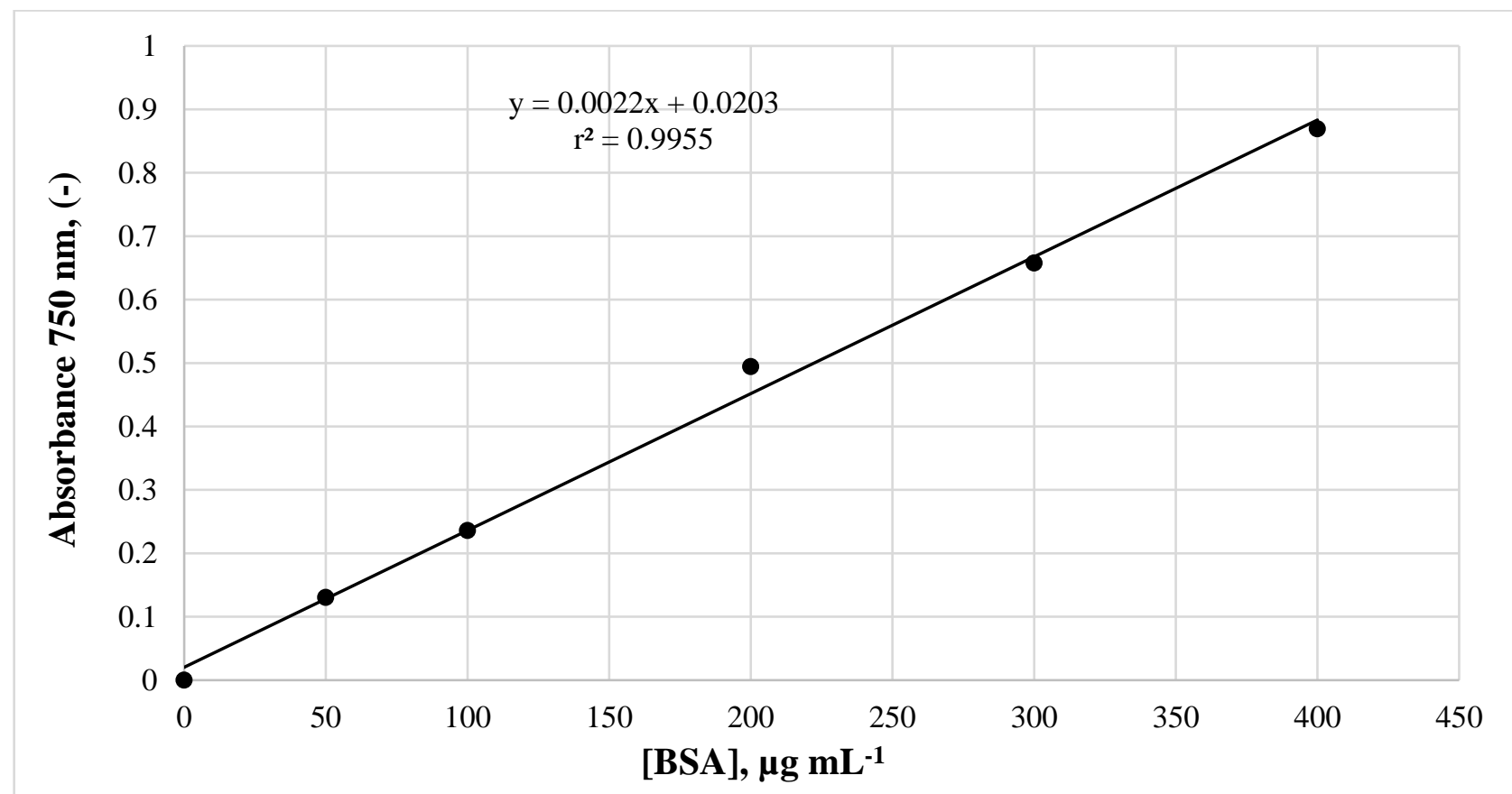

Figure 13: Calibration curve for the determination of cellulases concentration 
A least squares regression line with an $\mathrm{r}^{2}$ value of 0.9955 was obtained:

$$
\mathrm{A}_{750 \mathrm{~nm}}=0.0022[\mathrm{BSA}]+0.0203
$$

The concentration of an approximately diluted enzyme solution (commercial mixture, $\mathrm{P}_{0}$,) will be read off the regression line, including error in the standard data. The procedure for measuring this error is shown in Appendix B. Sample calculation for activity of cellulases from supernatants (i.e. $\left[P_{f a},\left[P_{f d}\right]\right)$ is also given in Appendix D.

\section{Activity measurement procedure (Filter Paper Assay)}

The Filter Paper Activity (FPA) of cellulases was determined by the National Renewable Energy Laboratory Analytical Procedure (Technical Report NREL/TP-510-42628 2008. Measurement of Cellulase Activities (Adney and Baker, 1996). Strips of 50-mg Whatman No. 1 filter paper (1.0 x 6.0 $\mathrm{cm})$ were placed in contact with appropriately diluted cellulase solutions for 60 minutes at $50^{\circ} \mathrm{C}$. Reducing sugars released from this limited hydrolysis reaction (due to activity of enzymes on filter paper) were quantified using dinitrosalicylic (DNS) method. In this method, the enzyme action is immediately stopped adding 3.0 ml DNS reagent and mixing. Blanks, controls and glucose standards should be incubated at $50^{\circ} \mathrm{C}$ along with the enzyme assay tubes. Boil all tubes for exactly 5.0 minutes in a vigorously boiling water bath containing sufficient water to cover the portions of the tubes occupied by the reaction mixture plus reagent. All samples, controls, blanks, and glucose standards should be boiled together. After boiling, transfer to a cold ice-water bath. Let the tubes sit until any suspension was settled. Prepared dilution of $0.2 \mathrm{~mL}$ into $2.5 \mathrm{~mL}$ of distilled water, homogenized the mixture. Transfer each dilution (from all blanks and samples) into the cuvettes to read from the standard curve as shown in Figure 14. This procedure was repeated in triplicate. 


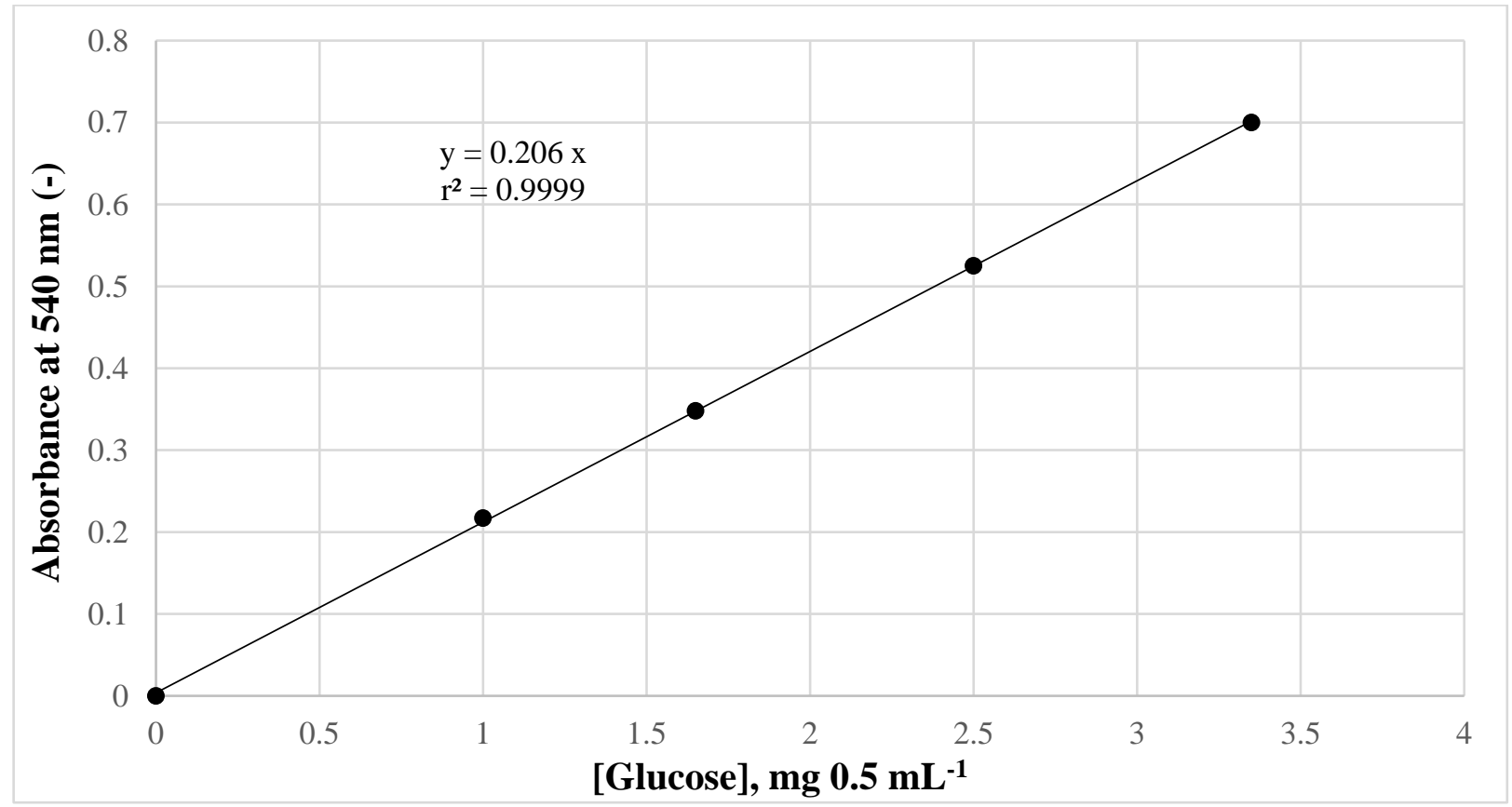

Figure 14: Glucose calibration curve (DNS method) used for cellulase enzyme activity measurement

The least squares regression line resulted in an $\mathrm{r}^{2}$ value of 0.9999 was obtained: $\mathrm{A}_{540 \mathrm{~nm}}=0.206$ [Glucose]. The unknown samples were transferred in cuvettes to read at $540 \mathrm{~nm}$ using UV/Visible Spectrophotometer Biochrome 50 which gives an absorbance reading in comparison with the standard curve. A set of sample calculations for cellulases NS 50013 enzyme activity is given in Appendix A.

Activity of unknown enzymes from the supernatant of adsorption which contain non-adsorbed cellulases $\left[P_{f a}\right]$ and similarly from the supernatant of desorption which contain desorbed enzymes $\left[P_{f d}\right]$ can be found from by using Figure 14. All other sample calculations for cellulases adsorbed, $\%$ desorbed, $\ln K_{a}$ and $\ln K_{d}$ and the calculation for activity of cellulases from supernatants are given in Appendix D. 
5. $0_{\text {Results and Discussion }}$ 


\subsection{Delignification}

The goal of delignification of wheat straw was to degrade and remove lignin that was an obstacle to get the best accessibility to cellulose of wheat straw. To evaluate lignin degradation/removal Klason lignin determination method was applied. It was well known that ozone remove lignin by degrading carbon-carbon double bonds present in lignin [Kratzl et al., 1974; Kaneko et al., 1981]. In preliminary experiments, no reaction was observed between wheat straw brought in contact with low concentration of ozone. On the other hand, only 11- $13 \%$ of lignin was removed at vigorous conditions of ozone flow rate of $4 \mathrm{~L} \mathrm{~min}^{-1}$ with a concentration of $40 \mathrm{mg} \mathrm{L}^{-1}$ for 120 minutes. Next thought was to introduce a reaction medium, hence, water was used as a reaction medium which increased the lignin removal up to $30 \%$ of the original lignin present in the wheat straw. Now we can share our best results and used techniques for delignification.

\section{Effect of water contents on delignification}

The removal of lignin by using ozone from wheat straw was strongly influenced by the water contents. Wetting of the wheat straw surface causes water to absorb into the pores of wheat straw resulting in the swelling of pores and increasing the surface area for reaction with ozone. A range of water contents from 0 to $300 \%$ (3 times the weight of dry wheat straw) was tried. Various water absorption times, and the styles of applying water (dropping water on surface, spraying, spraying and mixing) were attempted. The pretreatment where water was sprayed on wheat straw and then mixed with it until homogeneity, gave the best results. When the water contents were $30 \%$ the dry mass of wheat straw, the lignin removed was $73 \%$. As water contents were raised to $100 \%(1: 1)$, amount of lignin removal obtained was also increased to $85 \%$. Further increase in the ratio of water contents to dry weight of wheat straw from 1:1 to $1: 3$, could only increase 3-6\% lignin removal. The 
effect of water contents on lignin removal was given in Figure 15 while other experimental conditions were fixed as: ozone flow rate $4 \mathrm{~L} \mathrm{~min}^{-1}$, ozone concentration in ozone-oxygen gas stream was $2 \%$ $\mathrm{wt} / \mathrm{wt}$, and reaction time as mentioned by each experimental value i.e., $120 \mathrm{~min}$. Each data point was measured independently and it was an average of triplicate results. The optimum amount of water contents observed was $300 \%$ ( 3 times) of the amount of dry mass of wheat straw; hence, this amount was used in this study. It was noticed that increase of water contents beyond 1:3 resulted in decrease of lignin removal. For example in the slurry of wheat straw in water (1:100) the amount of lignin removed was $30.1 \%$ only [Baig et al., 2015]. .

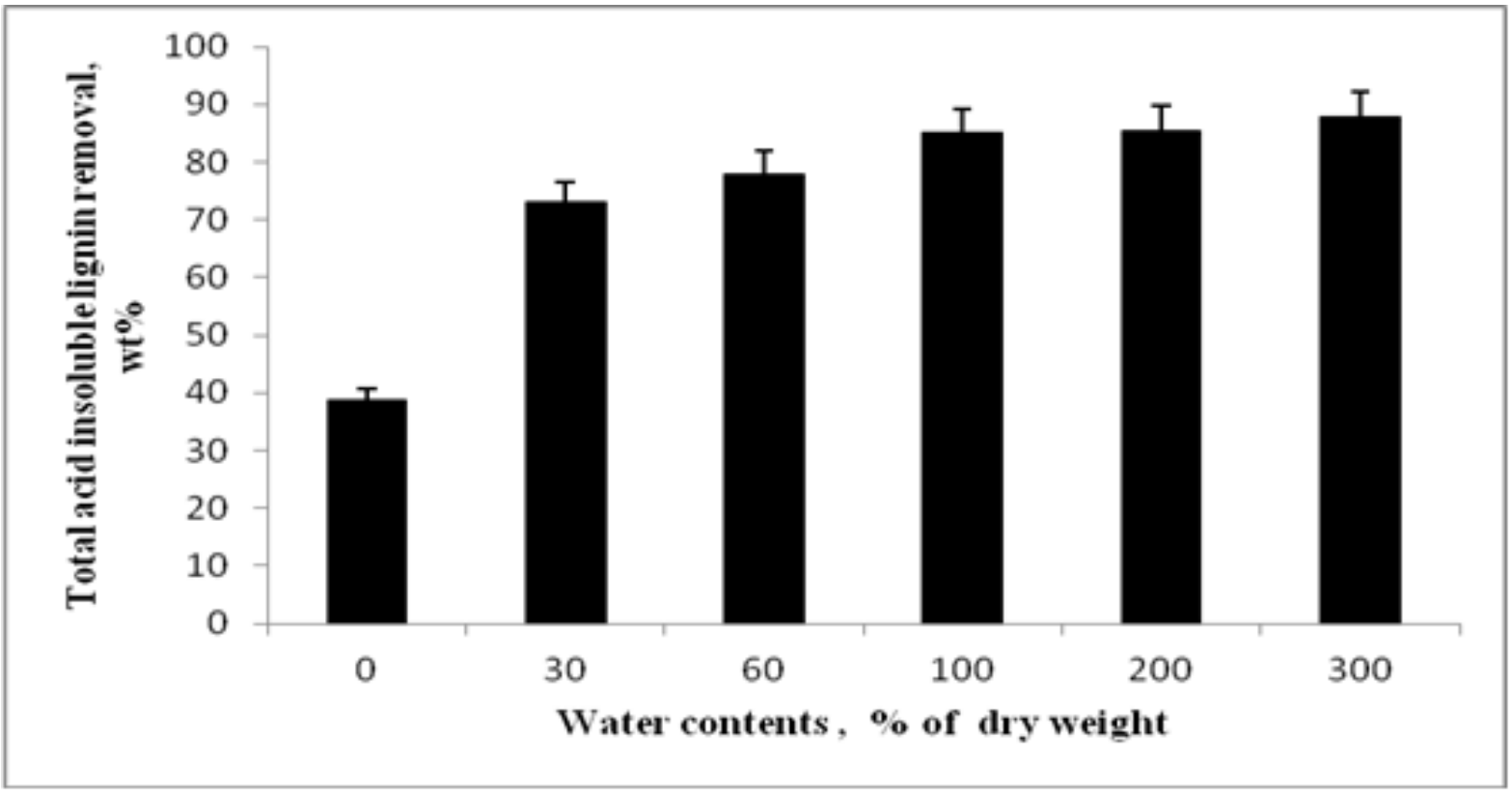

Figure 15: Effect of water contents on lignin removal. Ozone flow rate $4 \mathrm{~L} \mathrm{~min}{ }^{-1}$, ozone concentration in ozone-oxygen gas stream was $2 \% \mathrm{wt} / \mathrm{wt}$

[Baig et al., 2015]

At $300 \%$ water content and spraying and mixing, the amount of lignin removed was increased from $84 \%$ to $88 \%$ for a 60 minute of reaction time while all other reaction conditions remained the same. 
Effect of flow rate of ozone through the sample, the concentration of ozone in the flowing ozone stream and the particle size of wheat straw was also investigated. The range of flow rates investigated the experiments was 1 - $6 \mathrm{~L} \mathrm{minutes}^{-1}$. Percent of lignin removal increased with increasing flow rate of ozone up to $4 \mathrm{~L} \mathrm{~min}^{-1}$. Further increase in ozone flow rate showed no increase in percent of lignin removed. In fact, the percent of lignin removal was decreased while going beyond $4 \mathrm{~L} \mathrm{~min}^{-1}$ to $6 \mathrm{~L}$ $\min ^{-1}$ which was attributed to the lignin condensation. It was expected that ozone will react more with wheat straw if the concentration of ozone in the supplied ozone-oxygen gas mixture stream was increased. The effect of concentration of ozone was studied over a range from the $0.5 \%$ wt/wt to 5 $\% \mathrm{wt} / \mathrm{wt}\left(6.55\right.$ to $\left.65.5 \mathrm{mg} \mathrm{L}^{-1}\right)$ with a reaction time of 60 minute. The increase in concentration from 13.1 to $52.4 \mathrm{mg} \mathrm{L}^{-1}$, gave an increase in the acid insoluble lignin (AIL) removed which was $77.3 \%$ to $89.6 \%$ and further increase in concentration from $52.4 \mathrm{mg} \mathrm{L}^{-1}$ to $65.5 \mathrm{mg} \mathrm{L}^{-1}$, AIL remained unchanged. For the higher concentrations $\left(52.4 \mathrm{mg} \mathrm{L}^{-1}\right.$ and above) all available lignin was consumed quickly and an equilibrium is established between depolymerized and repolymerized lignin radicals hence, no significant change in lignin removal was observed [Baig et al., 2015].

The particle size of wheat straw could affect the reaction due to the contact and diffusion of ozone into the complex internal structure of lignocellulosic materials. It was observed that with the increase in particle size the AIL removed was decreased. The AIL removed was $35 \%$ less when the particle size was increased to 20 times (i.e. from $0.5 \mathrm{~mm}$ to $10 \mathrm{~mm}$ ). It was observed that reducing the particle size less than 500 microns resulted in loss of $20 \%$ of material during handling, reaction, and filtration and drying [Baig et al., 2015]. Through the course of our experiments $0.5 \mathrm{~mm}$ particle size, $52.4 \mathrm{mg}$ $\mathrm{L}^{-1}$ ozone concentration and $300 \%$ water contents were selected as optimum parameter values for the delignification and the contact time was evaluated in next step. 


\section{Effect of reaction time}

In Figure16, AIL removed during delignification of wheat straw was plotted against time of reaction with ozone. Three flow rates of ozone $4 \mathrm{~L} \min ^{-1}, 2 \mathrm{~L} \mathrm{~min} \operatorname{mon}^{-1}, 1 \mathrm{~L} \mathrm{~min}^{-1}$, containing $2 \%$ ozone by weight, at room temperature were studied for $1 \mathrm{~min}$ to 180 minutes. Each data point was an average of triplicate of the percent of acid insoluble lignin removed and each data point was measured independently. In the start the lignin removal was fast because it was easy for ozone to access lignin freely. For example at the flow rate of $4 \mathrm{~L} \mathrm{~min}^{-1}$ around $86 \%$ of lignin was removed at $60 \mathrm{~min}$. There was only 4-8 \% change in \% lignin removed from $60 \mathrm{~min}$ to $120 \mathrm{~min}$ [Baig et al., 2015]. At 90 minutes of reaction with ozone, the AIL removed was $90 \%$ of the total lignin present in untreated wheat straw.

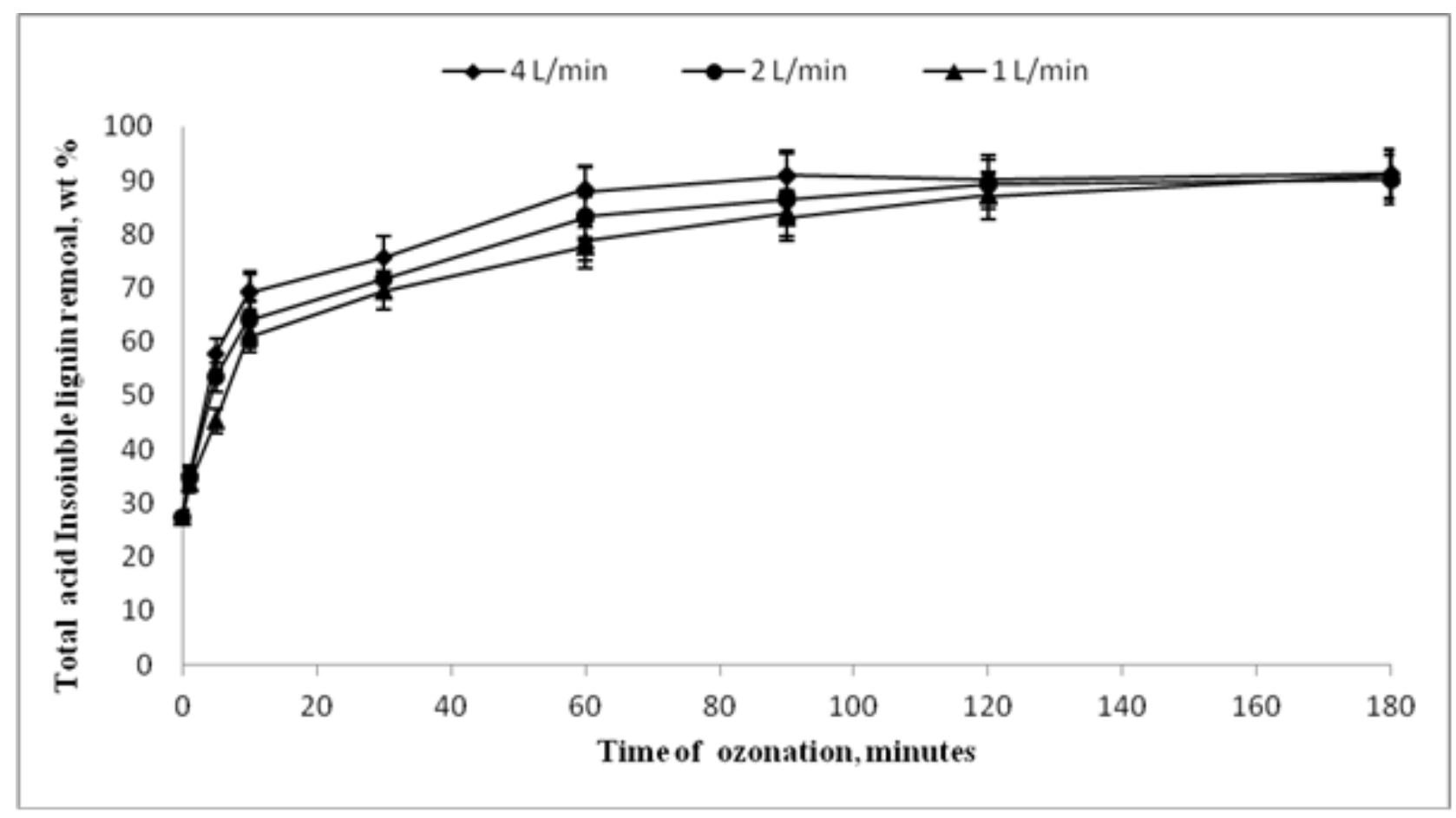

Figure 16: Lignin removal with various ozone flow rates, containing 2 wt $\%$ of ozone in ozone-oxygen gas stream, at $22^{\circ} \mathrm{C}$

[Baig et al., 2015] 
Samples treated with $4 \mathrm{~L} \mathrm{~min}^{-1}$ maintained more or less the same AIL value which they have attained at $90 \mathrm{~min}$. Samples treated with ozone at flow rates of $2 \mathrm{~L} \mathrm{~min}^{-1}$ showed the same AIL value at about 120 minutes as that of $4 \mathrm{~L} \mathrm{~min}^{-1}$ at 90 minutes of ozonation. It was also observed that all flow rates ( $1 \mathrm{~L} \mathrm{~min}^{-1}$ to $4 \mathrm{~L} \mathrm{~min}^{-1}$ ) showed almost the same value for AIL removed at 180 minutes of ozonation. Tock et al. (1982) could only remove $40 \%$ of lignin from Mesquite wood with ozone for a reaction time of 300 minute. Vidal and Molinier (1988) ozonated popular saw dust and $66 \%$ of lignin was removed for a 360 minute of reaction time in $45 \%$ acetic acid as reaction medium while our proposed technique removed $90 \%$ of AIL with 90 minutes of ozonation. It is worth mentioning here that 88.3\% AIL was removed at 60 minutes of ozonation. García-Cubero et al. (2009) reported AIL content decreased from $22.1 \%(\mathrm{w} / \mathrm{w}$ ) for non-ozonated material to $12.3 \%$ which is only $43.96 \%$ removal of lignin for $150 \mathrm{~min}$ of ozonation reaction. They also observed that the lignin removed remained constant for reaction times above 150 minute. Similar observation was also noticed in our study where no change in the amount of lignin removed after 120 minutes. It can be explained as that there was no accessible lignin available for ozone to react.

It has been demonstrated that the novel proposed technique was suitable for lignin removal from wheat straw. Since the proposed technique was used at room temperature and ambient pressure, therefore, fabrication of reactor would not need expensive construction material. Ozone can be generated on site hence no stock of chemicals would be required for industrial scale production of ozone. Excessive ozone can be decomposed to oxygen before sending it into the atmosphere; therefore, the technique results in no environmental impact. Treatment of wheat straw needs surface preparation for an effective pretreatment with ozone. It was found that soaking in $1 \% \mathrm{NaOH}$ and then washing to neutral $\mathrm{pH}$ was sufficient to proceed for reaction with ozone. The highest value of lignin removal was achieved when the water content was 3 times of the weight of oven dried wheat 
straw, ozone concentration was $2 \mathrm{~L} \mathrm{~min}^{-1}$, with ozone concentration $52.4 \mathrm{mg} \mathrm{L}^{-1}$ and particle size of wheat straw was $0.5 \mathrm{~mm} .30 \%$ and $60 \%$ delignified wheat straw samples were prepared for the evaluation of novel active desorption strategy in coming experiments.

\subsection{Adsorption of cellulases}

\subsubsection{Adsorption of cellulases on Avicel and Protobind}

For the study of desorption, adsorption was a prerequisite. In Figure 17 amount of cellulases adsorbed $\left[P_{f a}\right]$ on Avicel at room temperature, $100 \mathrm{rpm}$, was for various contact times, for eight initial cellulases concentration $\left[P_{0}\right]$ was studied for a time range between 0-90 minutes. Each data point was measured separately in triplicate except for $163 \mu \mathrm{g} \mathrm{mL} \mathrm{m}^{-1}$ when 9 replicates were done. Hence, the plots in Figure 17 are obtained by 189 experiments. Entries given in the legend bar are initial concentrations of cellulases $\mathrm{P}_{0} \mathrm{~s}^{\prime}$ with the units' $\mu \mathrm{g} \mathrm{mL}^{-1}$.

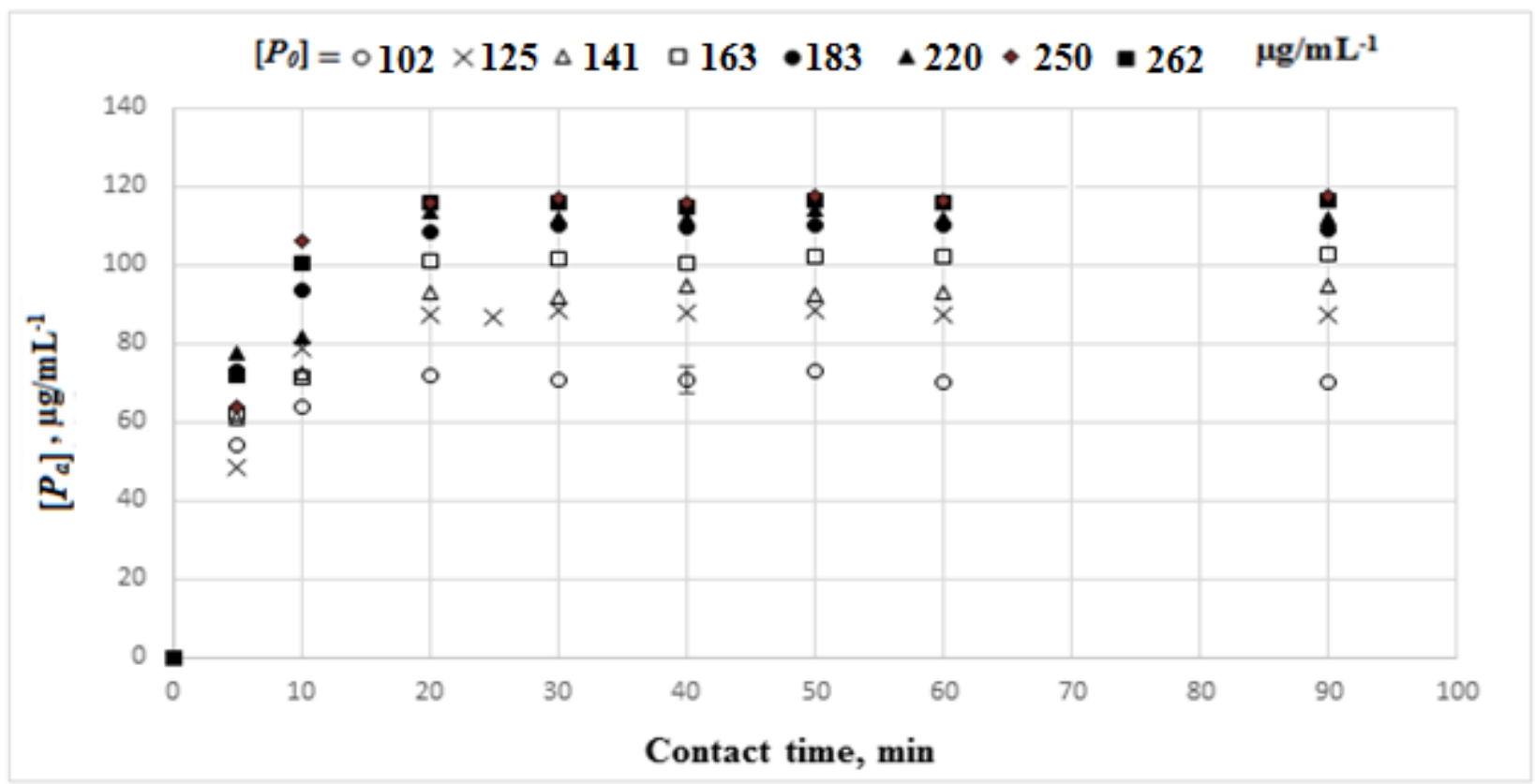

Figure 17: Adsorption of cellulases on Avicel PH 101 at $100 \mathrm{rpm}, \mathrm{pH} 5,25^{\circ} \mathrm{C},\left[P_{0}\right]$ varied from $102,125,141,163,183,220,250$, to $262 \mu \mathrm{g} \mathrm{mL} \mathrm{m}^{-1}$ with error bars at $95 \%$ probability [Baig et al., 2016] 
In the start increasing contact time increased the cellulases adsorbed and adsorption achieved its maximum almost at 20 minutes after of contact time, then it seemed to level off. Therefore, the time used for adsorption studies was set 30 minutes. In the study of enzymatic adsorption/hydrolysis, it was a tradition that the enzyme contents in the supernatant were determined for the free cellulases $\left[P_{f}\right]$ and the adsorbed cellulases $\left[P_{a}\right]$ were calculated from the difference between the initial cellulases concentration and the free cellulases [Stuart and Ristroph, 1984; Tu et al., 2009] which was carried out. In this set experiments it was found that increasing initial cellulases concentration $\left[P_{0}\right]$ from 100 $\mu \mathrm{g} \mathrm{mL} L^{-1}$ to $183 \mu \mathrm{g} \mathrm{mL}^{-1}$, adsorption increased from $68.45 \mu \mathrm{g} \mathrm{mL}^{-1}$ to $109.3 \mu \mathrm{g} \mathrm{mL}^{-1}$ for $100 \mathrm{mg}$ of Avicel. Further increase in $\left[P_{0}\right]$ from $183 \mu \mathrm{g} \mathrm{mL}^{-1}$ to $262 \mu \mathrm{g} \mathrm{mL}^{-1}$ cannot bring any significant change in $\left[P_{a}\right]$ as shown in Figure 11 (i.e. from $109.3 \mu \mathrm{g} \mathrm{mL}^{-1}$ to $116.2 \mu \mathrm{g} \mathrm{mL} \mathrm{L}^{-1}$ ). The value of maximum cellulases adsorbed was similar to that determined by other researches on various lignocellulosic substrates. [Singh et al., 1991, Nutor and Converse, 1991, Nidetzky and Steiner, 1993]. The supernatant obtained after adsorption of $183 \mu \mathrm{g} \mathrm{mL}-1$, at $25^{\circ} \mathrm{C}, \mathrm{pH} 5$ for a contact time of 60 minutes showed no reducing sugars were formed. So, no noticeable hydrolysis took place during any of the adsorption experiments. This was expected since, Andersen and co-workers reported that Avicel PH101 was only hydrolyzed up to $7 \%$ in 24 hours and that most of this hydrolysis (5\%) was occurred after 5 hours of contact [Anderson et al., 2008].

Similarly adsorption of cellulases on Protobind 1000 was studied for seven initial concentrations of cellulases NS 50013 as given in the legend bar of Figure 18, the units of $\left[P_{0}\right] \mathrm{s}^{\prime}$ were $\mu \mathrm{g} \mathrm{mL} \mathrm{m}^{-1}$. Increasing $\left[P_{0}\right]$ from $100 \mu \mathrm{g} \mathrm{mL}^{-1}$ to $263 \mu \mathrm{g} \mathrm{mL} \mathrm{L}^{-1}$ adsorption increased from $45.62 \mu \mathrm{g} \mathrm{mL}^{-1}$ to 199.0 $\mu \mathrm{g} \mathrm{mL} \mathrm{L}^{-1}$ for $100 \mathrm{mg}$ of Protobind as shown in Figure 18 as well. The adsorption profiles were in agreement with that of published literature [Lu et al., 2002; Chen et al., 2006; Jagar et al., 2010; Li et al., 2011; Das et al., 2012; Zheng et al., 2013; Machado et al., 2014; Karmakar and Ray, 2015] 
for adsorption of enzymes on various substrates.

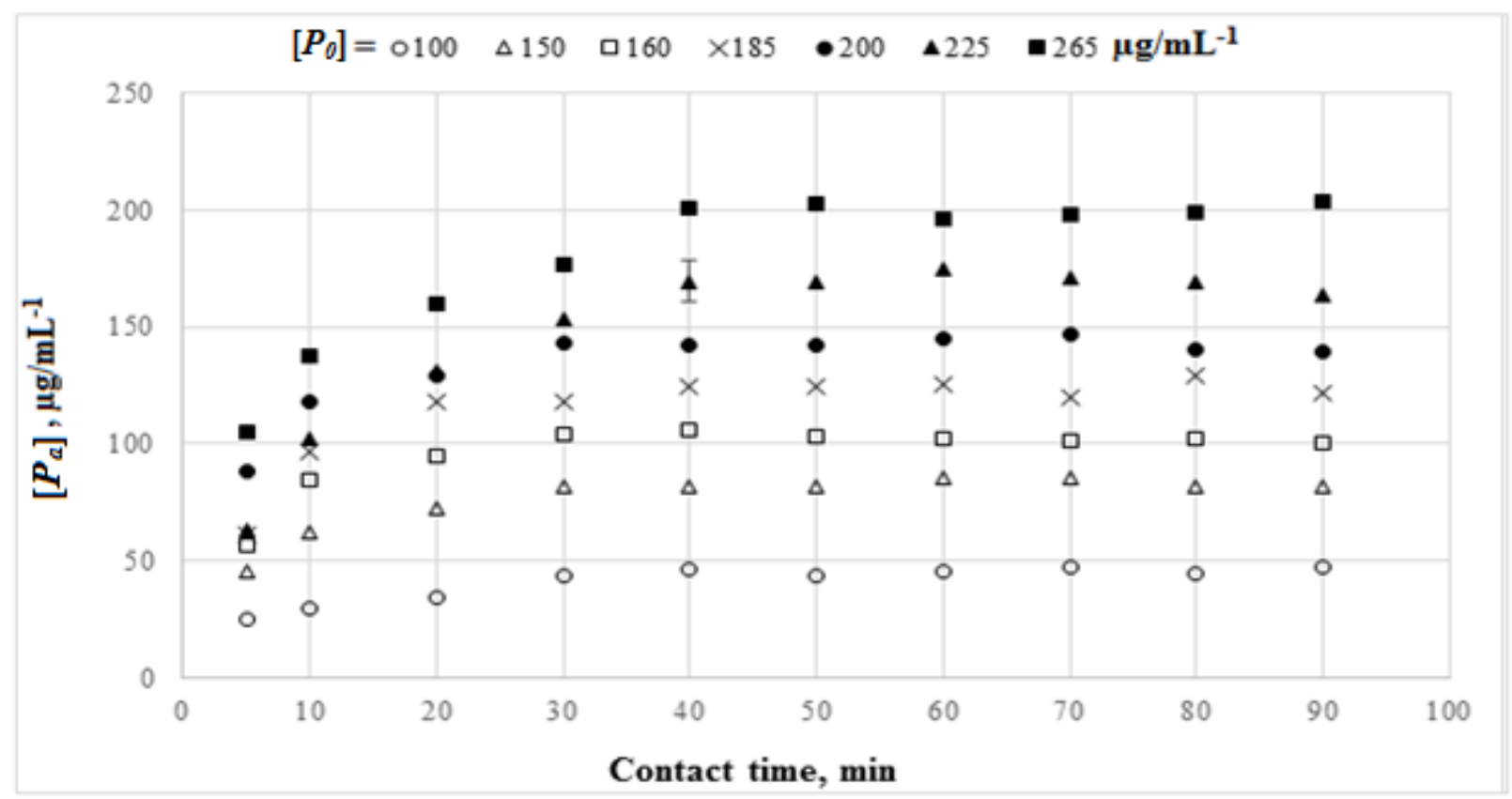

Figure 18: Adsorption of cellulases on Protobind 1000 at $100 \mathrm{rpm}, \mathrm{pH} 5,25{ }^{\circ} \mathrm{C},\left[P_{0}\right]$ varied from $100,150,160,185,200,225$, to $265 \mu \mathrm{g} \mathrm{mL}^{-1}$ with error bars at $95 \%$ probability [Baig et al., 2016]

The maximum adsorption was achieved at 40 minutes of contact time. Therefore, future adsorption experiments were done at 45 minutes of contact time. Long adsorption time of cellulases experienced for lignins versus cellulose can be explained by considering the functional groups taking part in this interaction. Cellulose contains a large number of hydroxyl groups [Sjostrom, 1993] to interact with cellulases. Cellulases adsorption on lignin is affected by functional groups, such as carboxylic, carbonyl, aliphatic hydroxyl, and phenolic hydroxyl groups [Berlin et al., 2006; Pan, 2008; Pareek et al., 2013; Rahikainen et al., 2013].

The cellulase adsorption ability of lignin involved more complex factors other than just the interaction with the hydroxyl groups as in case of cellulose [Kawamoto et al., 1992; Berlin et al., 2006]. More functional groups in lignin offers more attraction to cellulases. When a number of 
cellulases approaches to lignin molecule, electrostatic repulsion [Norde, 1986; Nakagame, 2010] came into play between the cellulases themselves and they need time to rearrange themselves for adsorption. Another cause of delayed interaction could be a repulsion between amino acids tyrosine and histamine from cellulases and carbonyl from lignin may allow cellulase to rearrange in order to adsorb on lignin. Therefore, involvement of a number of positive and negative functional groups make adsorption on lignin complex phenomena which takes longer time. Detection of reducing sugars from the contact of cellulases with Protobind was not evaluated since lignin does not contain any polymeric sugars.

\subsubsection{Effect of temperature on adsorption of cellulases}

Adsorption of cellulases on Avicel PH 101 and Protobind 1000 under the influence of temperature is shown in Figure 19 and Figure 20 respectively.

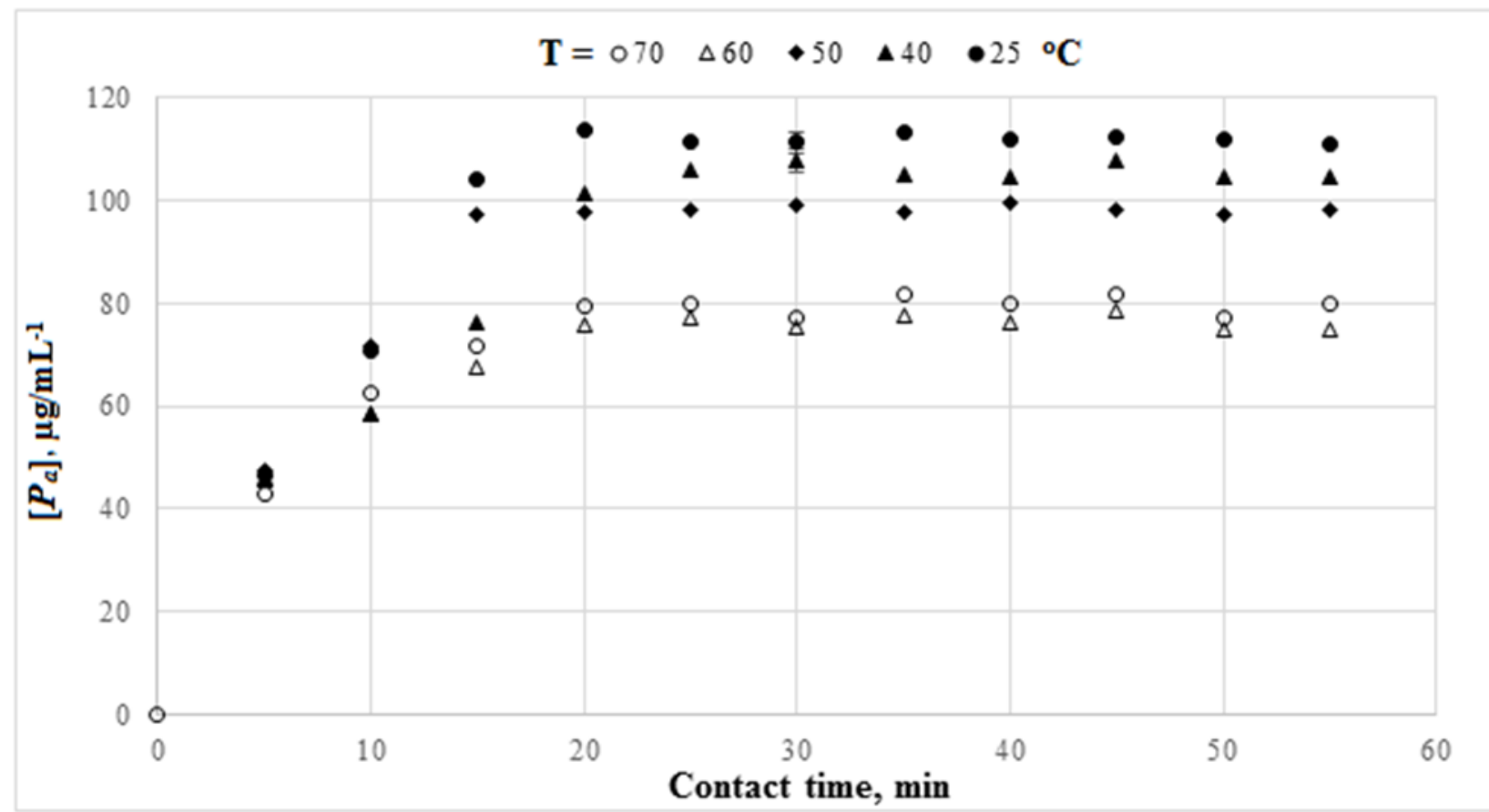

Figure 19: Adsorption of cellulases on Avicel PH 101 at varying temperature at pH 5, 100 rpm and maximum error bar at $95 \%$ probability 
Adsorption of cellulases varied with varying temperatures from 25 to $60{ }^{\circ} \mathrm{C}$ and adsorption decreased with further increase in temperature. Lee et al. (1982) studied adsorption of cellulases on pure cellulosic materials (absorbent cotton, Avicel PH 102, Solkafloc SW-40 hammer milled, Solkafloc BW-200 ball milled, and hammer-milled newspaper which passed through a 40-mesh) at only two temperatures $4{ }^{\circ} \mathrm{C}$ and $50{ }^{\circ} \mathrm{C}$ and concluded that the cellulases adsorbed at $4{ }^{\circ} \mathrm{C}$ was more than $50{ }^{\circ} \mathrm{C}$ though the difference was very small. Tomme et al. (1990) reported only a small effect on the adsorption by varying the temperature from 4 to $50{ }^{\circ} \mathrm{C}$. Our results for adsorption of cellulases on Avicel PH 101 for temperature range of 25 to $50{ }^{\circ} \mathrm{C}$ were in agreement with the results of Lee (1999) and Tomme et al. (1990). For example, Tomme et al. (1990) reported that the fall in adsorption was less than $10 \%$. Our adsorption on Avicel at $25{ }^{\circ} \mathrm{C}$ was $59.67 \%$, it was fallen to $52.94 \%$ at $50{ }^{\circ} \mathrm{C}$, which is also less than $10 \%$.

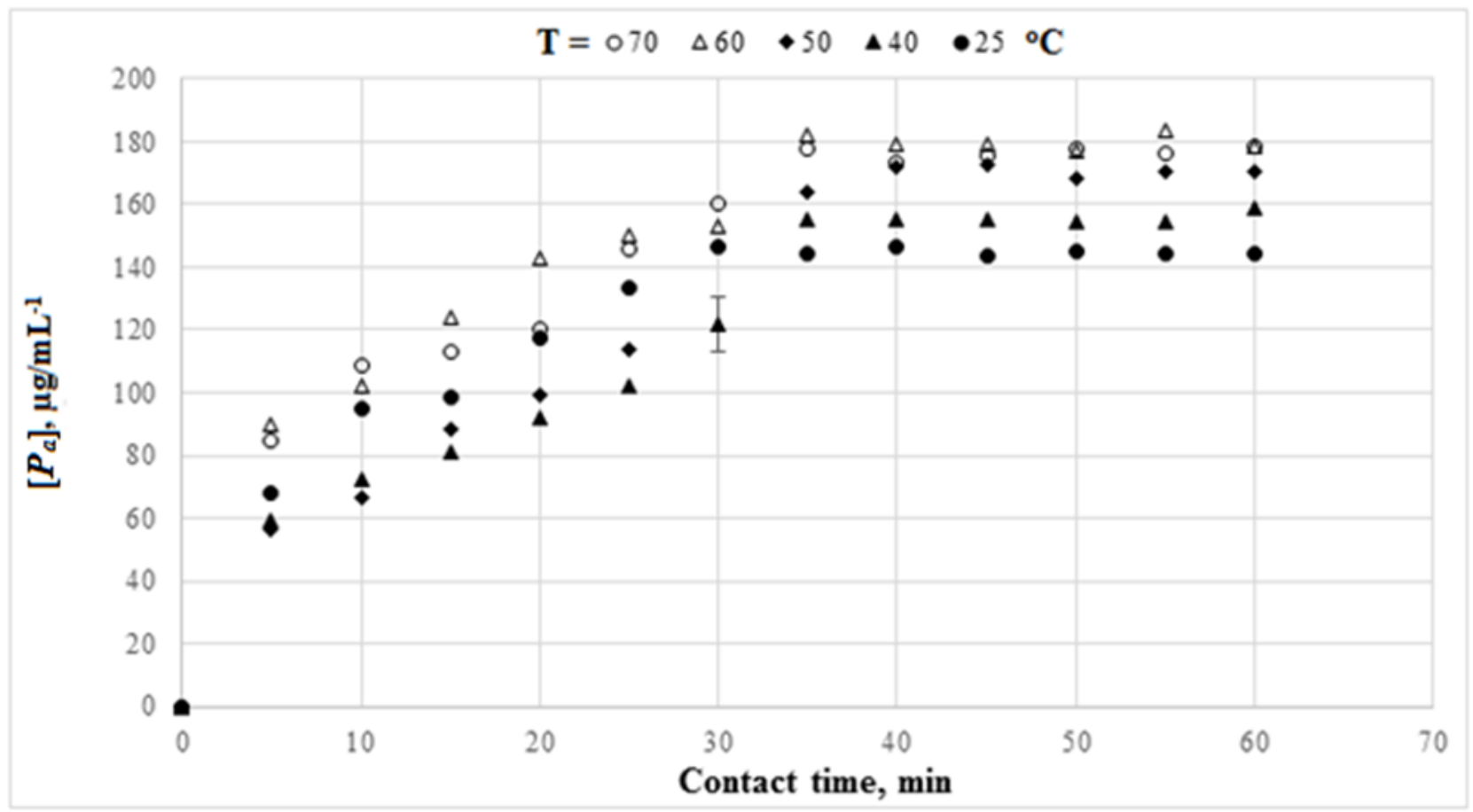

Figure 20: Adsorption of cellulases on Protobind 1000 at varying temperature at pH 5, $100 \mathrm{rpm}$ and maximum error bar at $95 \%$ probability 
The most of researchers investigated adsorption of metal ions, dyes and enzymes on various lignocellulosic substrates at varying temperatures and found that by increasing temperature, the amount adsorbed increased but the time to reach equilibrium remains the same [Medve, 1994; Sethi et al., 1998; Kim et al., 2001; Qadeer, 2005; Alzaydien and Manasreh, 2009; Daoud et al., 2010; Zheng et al., 2013; Du et al., 2014]. Our results are in agreement with their findings.

Both the substrates (Avicel PH 101 and Protobind 1000) behave almost opposite to each other. For Protobind $E_{a} \%$ increased up to $60{ }^{\circ} \mathrm{C}$ and further increase in temperature it was almost the same. Our hypothesis was that the increase in temperature increase adsorption of cellulases onto Protobind for a temperature range of $25^{\circ} \mathrm{C}$ to $60{ }^{\circ} \mathrm{C}$, which proved right. Tu et al. (2009) studied adsorption of cellulase on isolated lignins from Enzyme pretreated Lodgepole pine (EPLP) and steam pretreated Lodgepole pine (SELP) for temperatures 4,25 and $45^{\circ} \mathrm{C}$ and concluded that increase in temperature from $4{ }^{\circ} \mathrm{C}$ to $45{ }^{\circ} \mathrm{C}$ increased the adsorption, i.e. for EPLP adsorption raised from $1.85 \mu \mathrm{g} \mathrm{mg}^{-1}$ to $2.99 \mu \mathrm{g} \mathrm{mg}^{-1}$ and for SELP from $4.25 \mu \mathrm{g} \mathrm{mg}^{-1}$ to $6.10 \mu \mathrm{g} \mathrm{mg}^{-1}$. Rahikainen (2013) stated similar results of adsorption of cellulases on two types of lignin (enzymatic mild acidolysis lignin: EMAL and lignin-rich hydrolysis residues: EnzHR) for 4 and $45{ }^{\circ} \mathrm{C}$. Our results on adsorption of cellulases on Protobind for temperature 25 to $50{ }^{\circ} \mathrm{C}$ were in agreement with those from Rahikainen (2013) and Tu et al. (2009). Increase in temperature beyond $50{ }^{\circ} \mathrm{C}$ create some chemical changes in lignin due to dissociation of lignin phenolic groups [Evstigneev, 2011] and expose more substrate for cellulases. These changes could result in increasing adsorption on lignin [Kawamoto et al., 1992]. The adsorption of cellulases NS 50013 onto Protobind 1000 was conducted and reported for the first time in our study. It is also for the first time that the study was conducted systematically and reported for the temperature range of $25^{\circ} \mathrm{C}$ to $70{ }^{\circ} \mathrm{C}$. On the other hand this increase in temperature brings no changes in chemical structure of cellulose and the increased temperature create conformational 
changes in cellulases folding, consequently, cellulases cannot remained adsorbed due to these conformational changes on the Avicel PH 101 and the adsorption decreased. Therefore, it can be concluded that the increase in temperature effects on adsorption one way or other.

In an adsorption process, $\left[P_{a}\right]$ is a function of time. The equilibrium quantity of cellulases adsorbed on the substrates (cellulose, lignin) are described by adsorption isotherms at constant temperature. The adsorption isotherm also explains adsorption pattern of cellulases and adsorption capacity of substrates.

\subsection{Cellulases Adsorption Isotherms}

In this study, four isotherms (Nernst, Langmuir (2 linear types), and Freundlich) were evaluated for Avicel PH 101 and Protobind 1000.

\subsubsection{Nernst adsorption isotherm}

In Figure 21, amount of cellulases adsorbed per unit mass of Avicel PH $101 P_{e}$ is plotted against the concentration of free cellulases $\left[P_{f a}\right]$ according to Equation 2.4. Every data points is an average of at least triplicate experiment conducted with initial enzyme concentration $\left[P_{0}\right]$ at $102 \mu \mathrm{g} \mathrm{mL} \mathrm{m}^{-1}$ to 262

$\mu \mathrm{g} \mathrm{mL} L^{-1}$. First data point on right had side is at $\left[P_{0}\right]=262 \mu \mathrm{g} \mathrm{mL} L^{-1}$ where $\left[P_{f a}\right]$ was $135 \mu \mathrm{g} \mathrm{mL}^{-1}$. $\left[P_{0}\right]$ and $\left[P_{f a}\right]$ were measured, $P_{e}$ was calculated. The concentration of adsorbed $\left[P_{a}\right]$ is equal to the total enzyme concentration $\left[\mathrm{P}_{0}\right]$ minus the concentration of the enzymes in the solution $\left[\mathrm{Pfa}_{\mathrm{f}}\right]$ [Stuart and Ristroph, 1984; Tu et al., 2009]. Error bars were obtained for $95 \%$ probability and reside within the points being so small. Each data point was measured separately. According to the Nernst theory, irrespective of the initial (total) cellulases concentration $\left[P_{0}\right]$, cellulases distribute themselves in $P_{e}$ and $\left[P_{f a}\right]$ in a constant ratio. 


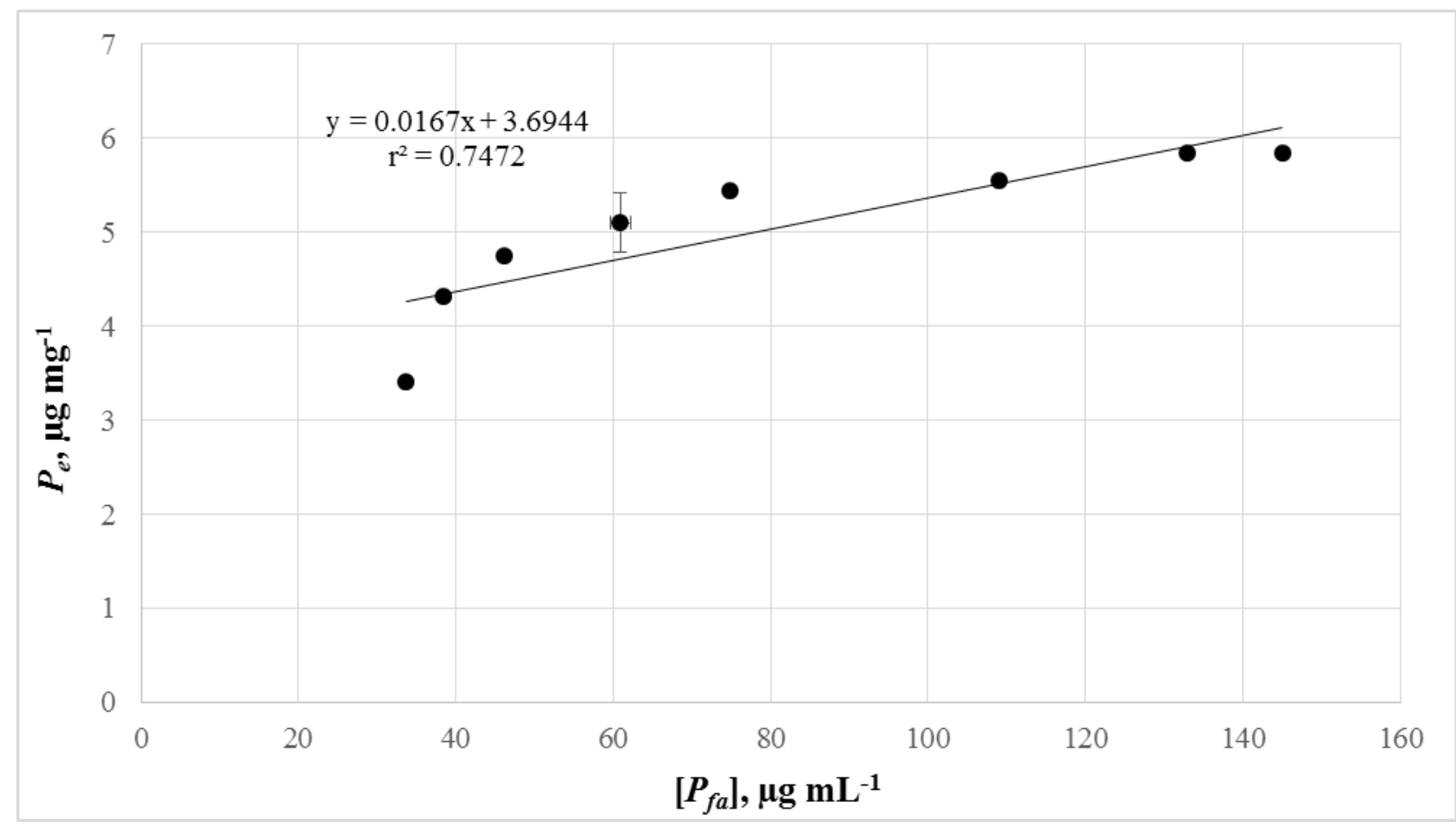

Figure 21: Adsorption of cellulases on Avicel PH 101 according to Nernst isotherm model, at pH 5, $25^{\circ} \mathrm{C}$, and $100 \mathrm{rpm}$ also shown with maximum error bar at $95 \%$ probability

[Baig et al., 2016]

Apparently the average of data point do not flows a straight line but with considering error. The model equation obtained by plotting $P_{e}$ against $P_{f a}$ according to the Nernst theory was: $P_{e}=0.016$ $\left(P_{f a}\right)+3.694$ with an $\mathrm{r}^{2}$ of 0.7472 . In contrary to expectations, the linear curve did not pass through origin. Therefore, Nernst isotherm will not be able to represent adsorption of cellulases on Avicel PH 101.

Nernst isotherm for Protobind 1000 is shown in Figure 22. All data points are obtained by conducting experiments under same experimental conditions as Avicel PH 101. The data is clustered between $50 \mu \mathrm{g} / \mathrm{mL}$ to $70 \mu \mathrm{g} \mathrm{mL}{ }^{-1}$ indicated that the increase in specific adsorption $P_{e}$ is much more than the corresponding increase in $\left[P_{f a}\right]$. The $\mathrm{r}^{2}$ value obtained was 0.210 which suggest that Nernst adsorption model was not a good representation of adsorption of cellulases on Protobind 1000. 


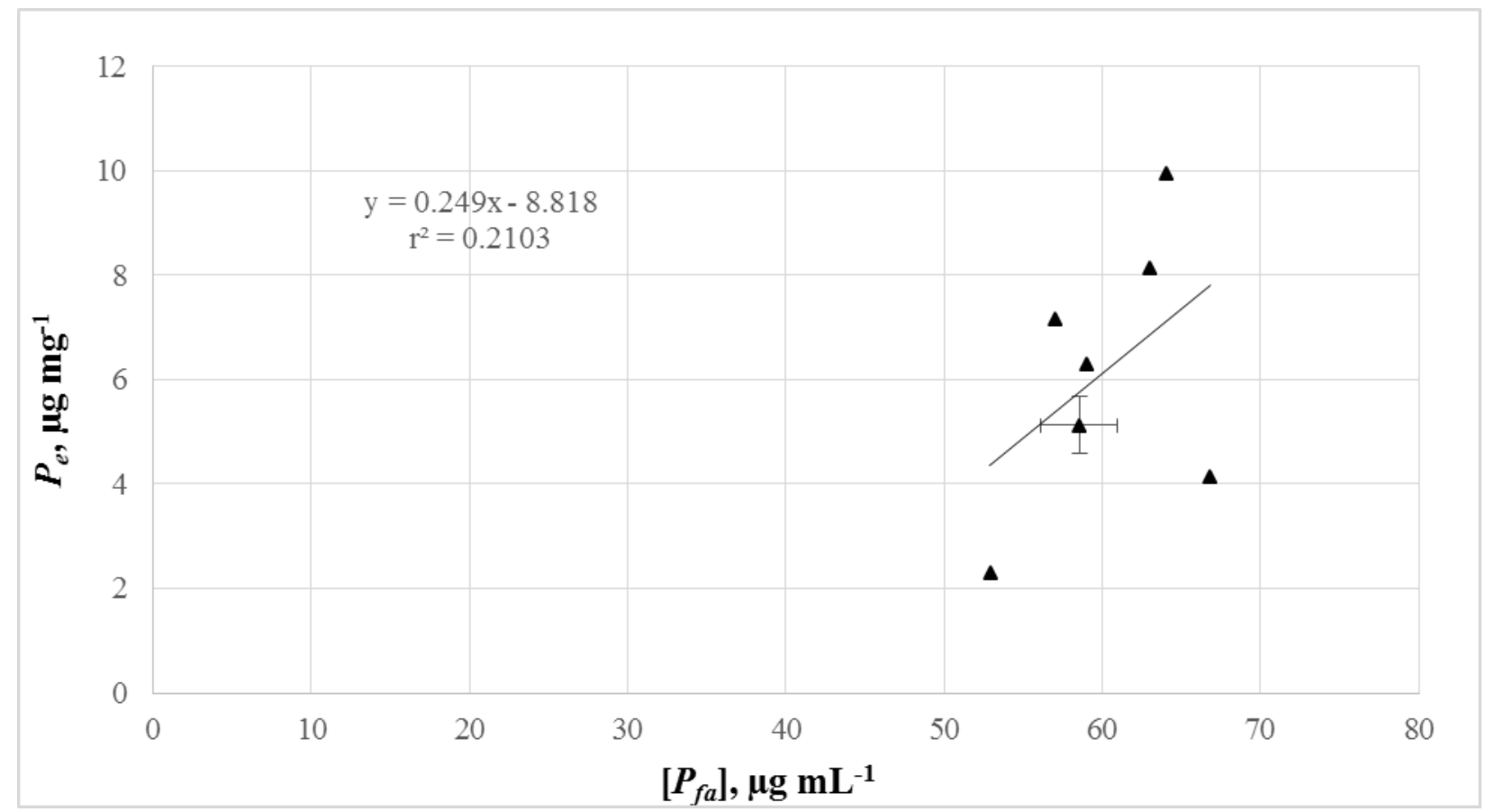

Figure 22: Adsorption of cellulases on Protobind 1000 according to Nernst adsorption, data was obtained at $\mathrm{pH} \mathrm{5,25}{ }^{\circ} \mathrm{C}$, and $100 \mathrm{rpm}$ with maximum error bar at $95 \%$ probability

[Baig et al., 2016]

\subsubsection{Langmuir, adsorption isotherm}

Adsorption data for Avicel according to Langmuir isotherm is shown in Figure 23. The ratio of specific adsorbed cellulases to non-adsorbed cellulases (y-axis) versus the specific adsorbed cellulases (x-axis).

The plot gave a straight line with a slope of $\left(\mathrm{K}_{\mathrm{a}},(\mu \mathrm{g} / \mathrm{mL})^{-1}\right)$ and an intercept of $\left(\mathrm{K}_{\mathrm{a}} \mathrm{P}_{\mathrm{am}},\left((\mu \mathrm{g} / \mathrm{mL})^{-1 *}\right.\right.$ $\left(\mu \mathrm{g} / \mathrm{mg}\right.$ of substrate)). As $\left[P_{e}\right]$ increased the corresponding $\left(P_{e} /\left[P_{f}\right]\right)$ decreased. Eliminating one outlier, rest of the seven data points gave the existing plot with $\mathrm{r}^{2}$ value equal to 0.9572 . Thus, $96 \%$ of the specific adsorbed cellulases were directly accounted for specific adsorbed cellulases per cellulases present in the bulk of solution. The model equation obtained from the plotted data was: $P_{e} /\left[P_{f}\right]=-0.049 E_{e}+0.3302$ 


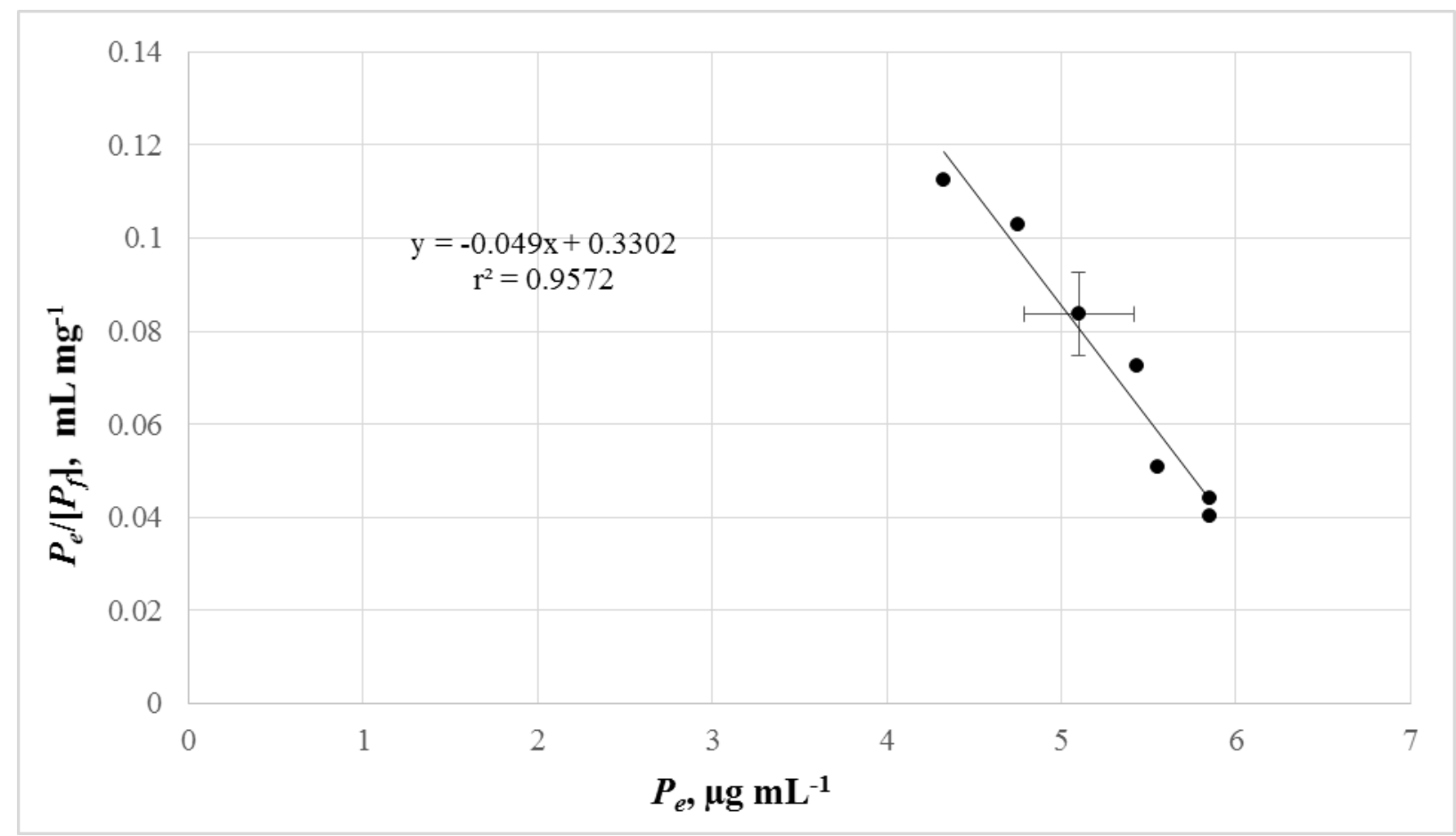

Figure 23: Langmuir adsorption isotherm (linear form as Equation 2.7) for Avicel PH 101 data was obtained at $\mathrm{pH} 5,25^{\circ} \mathrm{C}$, and $100 \mathrm{rpm}$ and maximum error bar at $95 \%$ probability [Baig et al., 2016]

The non-adsorbed cellulases $\left[P_{f}\right]$ was found to be directly proportional to the initial cellulases concentration $\left[P_{0}\right]$. The results also indicated that the cellulases adsorbed on the surface of Avicel PH 101 homogenously and all adsorption is monolayer type. Similar results were observed by other researchers as well [Hoshino et al., 1992; Kim et al., 2001].

Langmuir adsorption isotherm for adsorption of cellulases on Protobind 1000 is shown in Figure 24. The ratio of specific adsorbed cellulases to non-adsorbed cellulases ( $y$-axis) versus the specific adsorbed cellulases structures this plot. The plot gave a straight line with a slope of $\left(0.0151, K_{a}\right)$ and an intercept of $\left(K_{a} P_{a m}\right)$. 


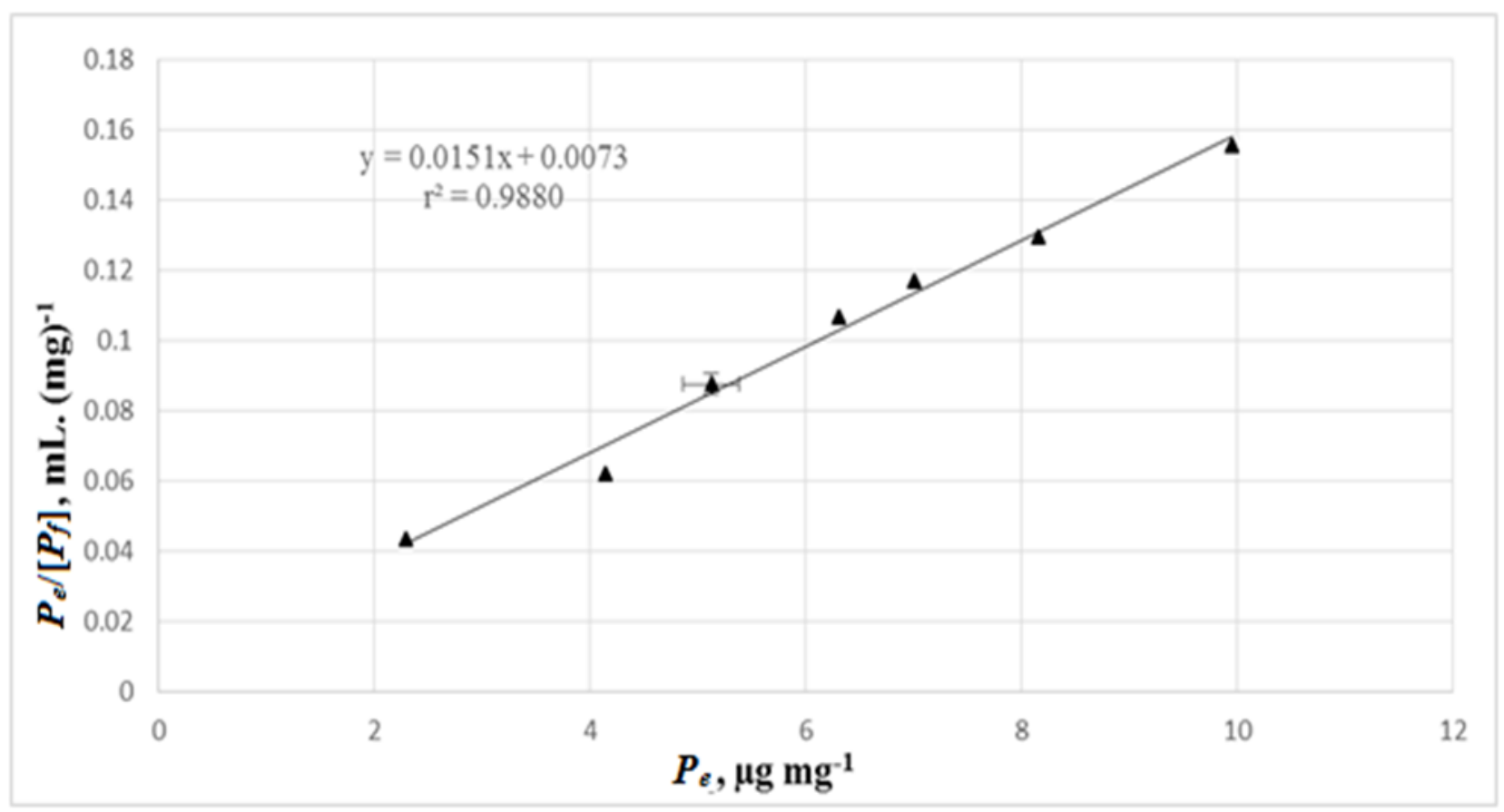

Figure 24: Langmuir isotherm (linear form as Equation 2.7) for adsorption on Protobind 1000 data was obtained at $\mathrm{pH} 5,25^{\circ} \mathrm{C}, 100 \mathrm{rpm}$ and error bar at $95 \%$ Probability

[Baig et al., 2016]

The curve line obtained from the plotted data-points follow a model equation as $P_{e} / P_{f a}=0.015\left(P_{e}\right)$ +0.007 with an $r^{2}$ value of 0.9880 . The plotted data showed a positive correlation between $P_{e}$ vs $P_{e} /\left[P_{f a}\right]$. It was indicated that ratio of specific amount of cellulases adsorbed on Protobind to the concentration of cellulases in the solution follow a smooth increase with the increase in $P_{e}$. The Scatchard plot with a positive slope is contrary to generally accepted wisdom derived from studies of cellulases on lignocellulosic materials. In life sciences, the positive slope was recognized by a number of researchers while studying, binding of DNA to ligands, binding of oxygen to hemoglobin or drugs to nucleic acids etc. [Dahlquist, 1978; Nesbitt et al., 1982; Elmore et al., 1988; Ofek and Doyle, 1994; Gupta, 2011]. The positive slopes cooperative adsorption. Cooperative adsorption is adsorption where an adsorbed cellulases has a positive effect on the adsorption of "new" adsorbing cellulases. Positive cooperative binding of enzymes was never noticed before. This study noticed 
this positive cooperative adsorption because it is first thorough study of adsorption of cellulases (enzymes) to Protobind (Protobind 1000).

\subsubsection{Freundlich adsorption isotherm}

Freundlich adsorption isotherm of cellulases on Avicel is shown in Figure 25, it was obtained by plotting natural logarithm of specific adsorbed cellulases $\left(\ln P_{e}\right)$ against natural $\operatorname{logarithm}$ of cellulases present in the bulk of solution $\ln \mathrm{P}_{f}$.

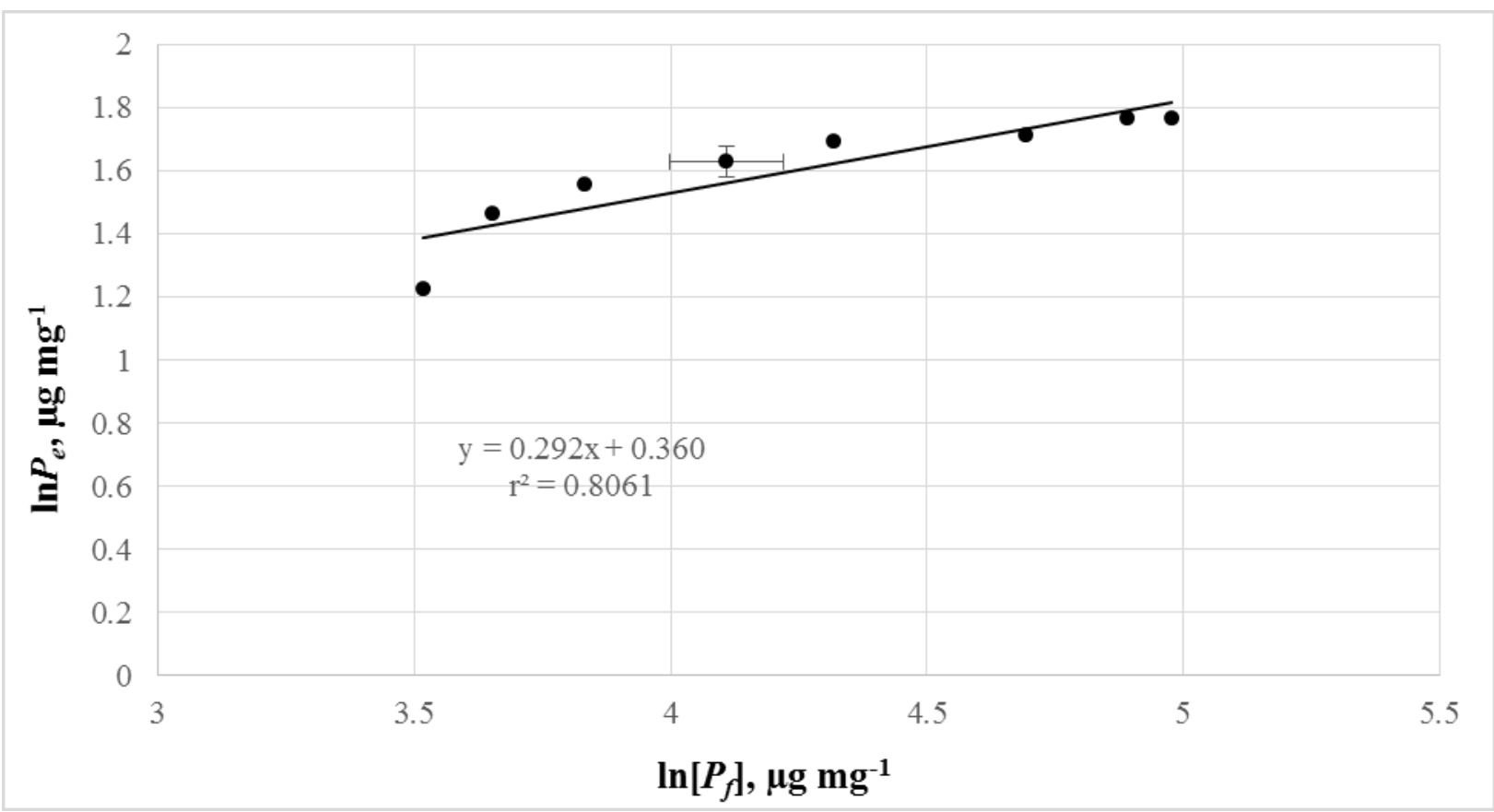

Figure 25 : Freundlich isotherm for adsorption of cellulases on Avicel PH 101, data was obtained at pH 5, $25^{\circ} \mathrm{C}, 100 \mathrm{rpm}$ and maximum error bar at $95 \%$ probability [Baig et al., 2016]

The model equation obtained after plotting the experimental data was: $\ln P_{e}=0.292\left(\ln P_{f a}\right)+0.360$.

Plotting the graph a straight line with value of slope $(1 / \mathrm{m})$ equal to 0.292 and $\ln K_{f}$ as $y$-axis intercept was 0.360 . The $\mathrm{K}_{\mathrm{f}}$ value obtained was $1.43 \mu \mathrm{g} \mathrm{mg}^{-1}$. According to Freundlich isotherm this intercept was expected. The slope is called heterogeneity factor and ranges between 0 and 1 . A system is considered to be more heterogeneous when slope is closer to 0 . The slope value 1.43 is closer to 1 , 
indicated that adsorption of cellulases on Avicel showed some uneven distribution of cellulases on the adsorbent surface. Freundlich isotherm was used for adsorption on heterogeneous surfaces or surface supporting sites of varied affinities [Dabrowski, 2001]. Since $r^{2}$ value is equal to 0.8061 which means that Avicel surface was not having different affinities and we cannot expect any multilayer adsorption. The $\left[P_{e}\right]$ value predicted was in around $3.0 \%$ error with respect to the corresponding experimental value.

Figure 26 shows Freundlich adsorption isotherm for adsorption of cellulases on Protobind 1000. The plot was obtained by plotting of $\ln P_{e}$ (y-axis) vs $\ln P_{f a}$ was a straight line with $\mathrm{r}^{2}=0.2813$ and its intercept giving $\ln K_{f} .(-11.71)$.

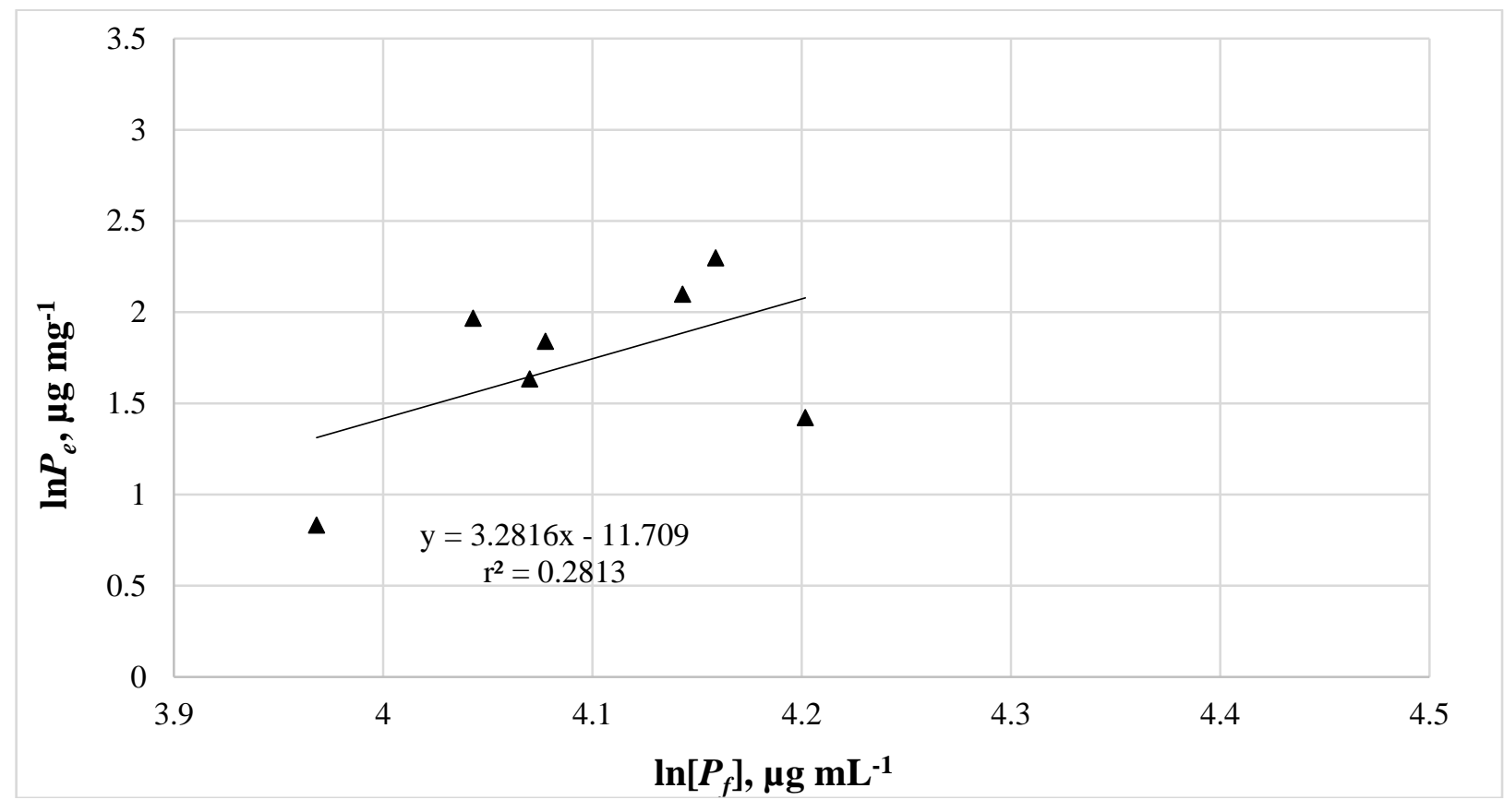

Figure 26: Freundlich isotherm for adsorption of cellulases on Protobind 1000, data was obtained at $\mathrm{pH} 5,25^{\circ} \mathrm{C}$, and $100 \mathrm{rpm}$ and with maximum error bar at $95 \%$ probability [Baig et al., 2016]

The $K_{f}$ calculated for wheat straw lignin (Protobind 1000) was $8.21 \times 10-6 \mu \mathrm{g} \mathrm{mg}^{-1}$ while $K_{f}$ for Avicel PH 101 was $1.43 \mu \mathrm{g} \mathrm{mg}^{-1}$. Reading the value of $K_{f}$ with $\mathrm{r}^{2}$ value showed not to use Freundlich 
isotherm as representative for adsorption on Protobind 1000. The correlation factor obtained for Freundlich adsorption isotherms from Avicel and Protobind were 0.8679 and 0.2813 respectively. By removing one outlier at $\ln P_{f a}=4.2 \mu \mathrm{g} / \mathrm{mg}$ (Figure 22), the shape of the trend line obtained was: $\ln P_{e}=6.683\left(\ln P_{f a}\right)-25.46$, with $\mathrm{r}^{2}$ became equal to 0.8120 with remaining 6 data points. The $\mathrm{r}^{2}=$ 0.8120 (for 6 data points) was still not better than $r^{2}=0.9880$ (for 7 data point for Langmuir isotherms as shown in Figure 24).Hence Freundlich isotherm was not a good representative of cellulases adsorption on the studied substrates. Therefore, it can be stated that during adsorption, cellulases did not make multilayers adsorption on Avicel as well as on Protobind.

\subsubsection{Choice of a model}

The plots in Figure 21 and 22 were used to test whether the linear model was a good fit for the adsorption data of the cellulases. Plots in Figure 23 and Figure 24 were used to determine whether the adsorption data of the cellulases onto Avicel PH 101 and Protobind 100 was explained by Langmuir adsorption isotherm. The plot in Figures 25 and 26 tested the goodness of fit for the Freundlich model. Langmuir adsorption isotherm appear to be a good selection for the representation of adsorption of cellulases on Avicel PH 101 as well as for Protobind. Among other adsorption methods it stand out because of correlation coefficient for both substrates.

Therefore, adsorption of cellulases on Avicel PH 101 and Protobind 1000 followed Langmuir's adsorption pattern. This adsorption pattern suggested that the adsorption of cellulases in monolayer and interaction between cellulases do not form multilayer of enzymes as suggested by some others [Vadi et al., 2010; Sun et al., 2011]. The amount of cellulases distributed on substrate and in bulk solution is not directly proportional. The amount adsorbed increased and decreased with increase in or decrease in cellulases taken as initial amount but not in the same proportion. For maximum concentration of initial cellulases taken $\left(265 \mu \mathrm{g} \mathrm{mL}^{-1}\right)$ the maximum amount of cellulases adsorbed 
on same mass (100 mg) of Avicel and Protobind was 108-115 $\mu \mathrm{g} \mathrm{mL}^{-1}$ and $180-199 \mu \mathrm{g} \mathrm{mL} \mathrm{mhich}^{-1}$ means Protobind showed almost 1.5 to 1.8 times more adsorption capacity than that of Avicel. Amount of cellulases need for the conversion of wheat straw to ethanol can be adjusted accordingly by the cellulose and lignin contents in the wheat straw. Lignin adsorbed almost twice the amount of cellulases as that of cellulose and adsorption of cellulases was faster on lignin that on cellulose. Disagreement of data with Freundlich isotherm indicated that cellulases do not interacts to form multilayer on the substrates. Therefore all cellulases adsorbed was on the surface of substrates. Langmuir isotherm give us maximum amount of cellulases adsorbed, $P_{a m}$, which can be a lead to find accessible surface area of a substrate. The equilibrium concentrations of cellulases adsorbed on the substrate $\left[P_{a}\right]$ and remaining in the bulk $\left[P_{f}\right]$ can be used for the study of enthalpy and entropy. The study of adsorption isotherms told us that cellulases adsorb on the substrate in monolayer. Monolayers (cellulases-substrate) are stronger than the multilayer (cellulases-cellulases) [Qin, et al., 2014]. Since this study is about desorption strategies, therefore studying desorption from a monolayer adsorption system would be the real job.

\subsubsection{Pore diffusion of cellulases}

In general, the quantity of an adsorbed enzyme on to a substrates to a large extent related to the pore size rather than the surface [Dong et al., 2012; Du et al., 2013]. For example, in a study of adsorption of papain in porous glass it was found that little or no protein was adsorbed in the pores when glass pores approached the molecular dimensions of the protein. Thus, it was suggested to achieve maximum adsorption, the pores in substrates should be 3-9 times larger than the size of the enzymes [Stone et al., 1969]. It means that the pore sizes play an important role in the enzyme adsorption [Deere et al., 2002; Li et al., 2010; Bayne et al., 2013]. Bayne et al. (2013) reported that for an enzyme of $5 \mathrm{~nm}$ to adsorb on a substrate having pore diameters less than $10 \mathrm{~nm}$ in general there will 
be a decrease in enzyme adsorption because of the physical restrictions faced by enzymes in accessing surface offered. For substrates pore sizes above $100 \mathrm{~nm}$ the adsorption of enzymes $(5 \mathrm{~nm})$ increased due to an associated increase in available surface area. For the pores sizes of 10-100 nm a decrease in protein adsorption level was expected with increasing pore diameter. It was observed that the enzymes adsorption in this range of pore diameter remained almost constant. Bayne et al. (2013) concluded that decrease in pore diameter restricted access to the available surface area. Monsan (1978) found that the adsorption of trypsin (an enzyme) on amino silica was strong due to the pore size but not due to the surface area [Datta et al., 2013]. It suggested that the pore size usually dictated the loading of the enzymes. Similarly, it was found that penicillin G acylase was $0.01 \mathrm{mg} \mathrm{g}^{-1}$ adsorbed on triacrylate substrate having surface area $245 \mathrm{~m}^{2} \mathrm{~g}^{-1}$ and pore diameter $12.64 \mathrm{~nm}$. The amount of penicillin $\mathrm{G}$ acylase adsorbed on the Eupergit $\mathrm{C}$ was one tenth $(\sim 0.1)$ which has almost similar surface area $\left(180 \mathrm{~m}^{2} \mathrm{~g}^{-1}\right)$ but much greater pore diameter size $(20-40 \mathrm{~nm})$. As expected in the former example the enzyme faced restriction to enter the pores of triacrylate ( $5 \mathrm{~nm}$ was the size of) and apparently, all the adsorption was on the external surface [Thygesen et al., 2010]. From this discussion it was derived that cellulases not only adsorb on the external surface area, they may adsorb on the pores of substrates. Again, not at all the pores but the pores with diameter more than 10 times of the enzymes diameter.

The experimental adsorption data of cellulases adsorbed onto test substrates was modeled by using Bangham's Equation 5.2 to evaluate pore diffusion [Aharoni and Ungarish, 1977]. Bangham model studied to uncover the mechanism of cellulases adsorption/binding onto the surfaces of Avicel and Protobind. The goodness of fit will be used to estimate the role of pore diffusion of cellulases in the adsorption process. 


$$
\log \left[\log \left\{\frac{P_{0}}{\left(P_{0}-P_{e} M\right)}\right\}\right]=\log \left[\frac{k_{0}}{2.303 V}\right]+\propto \log (t)
$$

Where, $\mathrm{E}_{0}$ is the initial concentration of the cellulases in solution $\left(\mathrm{mg} \mathrm{L}^{-1}\right)$,

$\mathrm{V}$ is the volume of the solution $(\mathrm{mL})$,

$\mathrm{M}$ is the mass of substrate ( $\mathrm{g}$ ),

$\propto$ is the constant of Bangham Model

$P_{e}\left(\mathrm{mg} \mathrm{g}^{-1}\right)$ is the amount of adsorbate retained at time $\mathrm{t}$ and $\alpha$ (less than 1$)$ and $\mathrm{k}_{0}$ are the constants.

As such $\log \left[\log \left\{P_{0} /\left(P_{0}-P_{e} \mathrm{M}\right)\right\}\right]$ was plotted against $\log (\mathrm{t})$ in Figures 27 , and 28 the two substrates. The plot was found to be linear for each adsorbent with good correlation co-efficient, such as 0.9034 , and 0.9027 , for Avicel, Protobind respectively. Since $r^{2}$ value $(>0.90)$ which was a positive linear association indicated that experimental data confirmed to Bangham's equation and therefore it can be deduced that pore diffusion has some control on the adsorption of cellulases on the substrates.

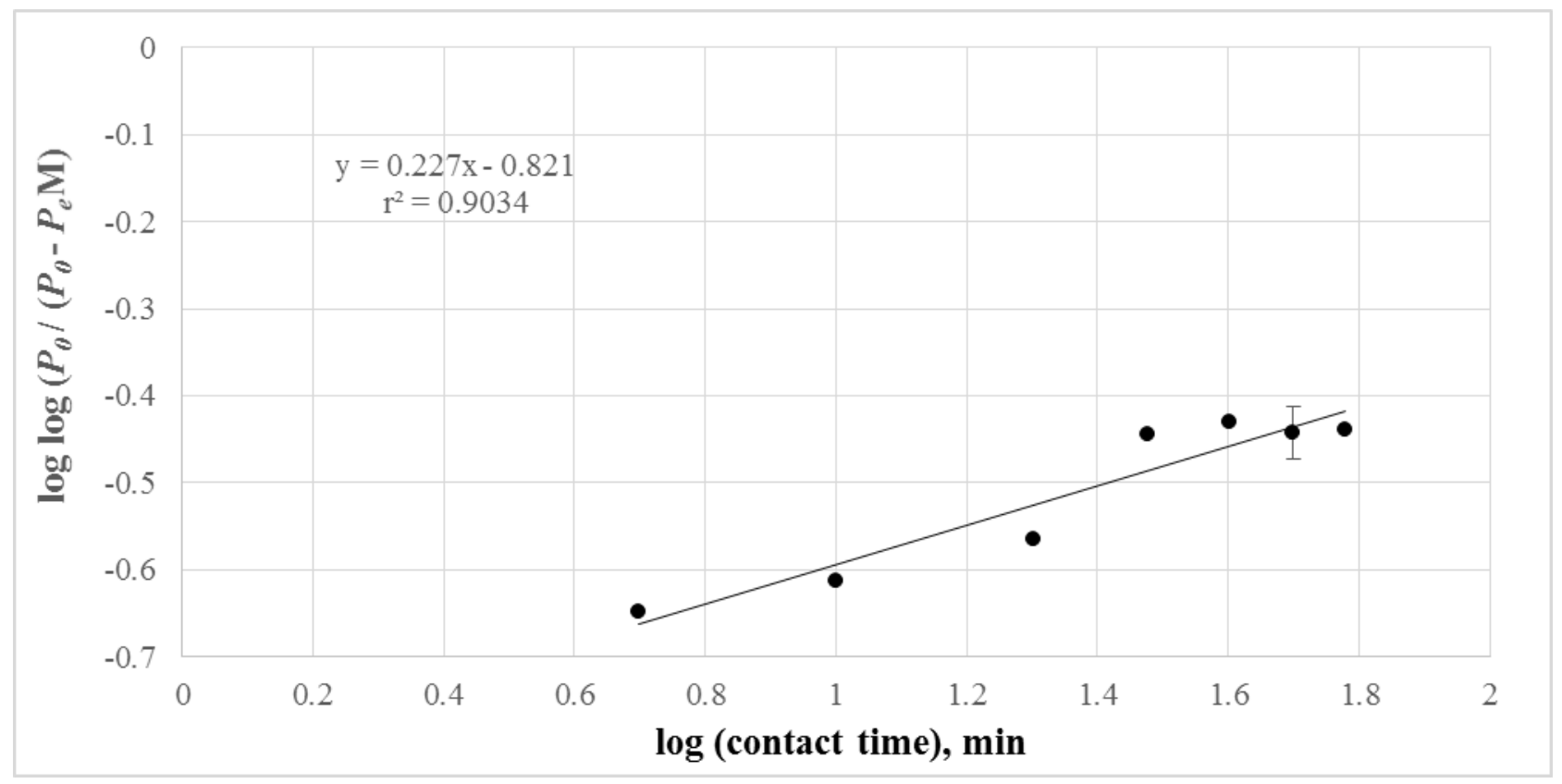

Figure 27 : Pore diffusion plot for Avicel PH 101, with maximum error bar at $95 \%$ probability 
The plots for Avicel and Protobind obtained by Bangham model have almost same intercepts, i.e. 0.821 and 0.972 respectively. In the case of slopes, the slope of Avicel (0.227) was almost two times of the slope of Protobind (0.401). As, it could be noticed that $\log \left[\log \left\{\mathrm{P}_{0} /\left(\mathrm{P}_{0}-\mathrm{P}_{\mathrm{e}} \mathrm{M}\right)\right\}\right]$ was increasing with $\log (\mathrm{t})$, it indicated that $\left\{\mathrm{P}_{0} /\left(\mathrm{P}_{0}-\mathrm{Pe} \mathrm{M}\right)\right\}$ is increasing with contact time. If $\mathrm{P}_{0}$ is consistent, then $\left(\mathrm{P}_{0}-\mathrm{Pe} \mathrm{M}\right)$ is decreasing to make this term large, hence adsorption is increasing. Therefore, adsorption in the pores of Protobind was 2 times of that of Avicel.

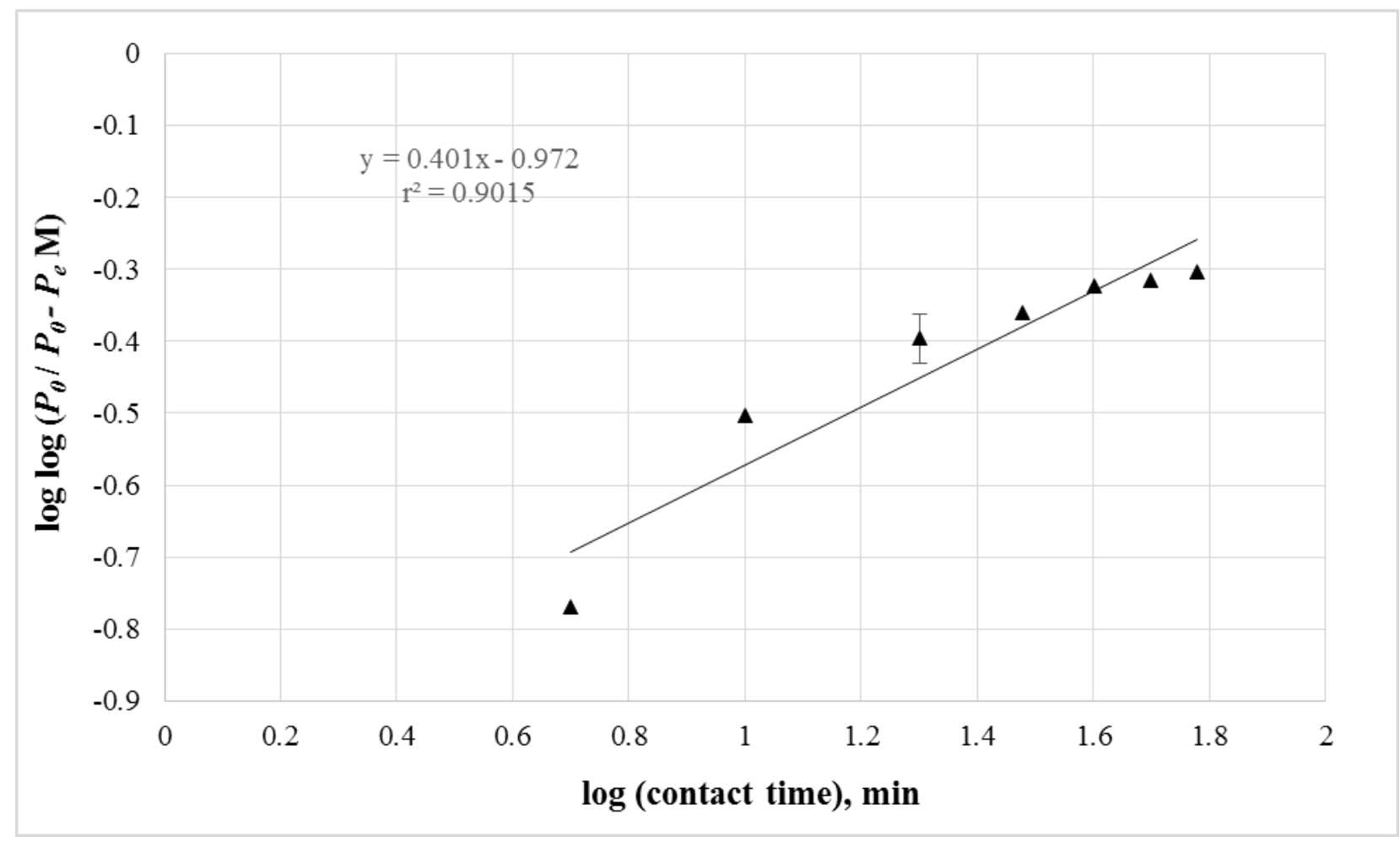

Figure 28 : Pore diffusion for Protobind 1000, with maximum error bar at $95 \%$ probability

Pore diffusion may have share in adsorption of cellulases on to Protobind 1000 as the correlation coefficient $r^{2}$ was 0.9015 . This indicated that the adsorption is dependent on surface area which in turn is dependent on the pore size because pores increase surface area. 


\subsection{Enthalpic and entropic changes for adsorption under the influence of temperature}

The temperature dependency and thermodynamics of desorption, however, was rarely reported in the literature. The van't Hoff equation was adapted to represent the adsorption processes of cellulases to Avicel PH 101 and Protobind 1000. Plotting the equilibrium adsorption results for both solid substrates as a van't Hoff relation (Equation 2.10) linearity of adsorption is observed over the temperature range of $298 \mathrm{~K}\left(1 / \mathrm{T}=3.35 \times 10^{-3} \mathrm{~K}^{-1}\right)$ to $343 \mathrm{~K}\left(1 / \mathrm{T}=2.92 \times 10^{-3} \mathrm{~K}^{-1}\right)$ (Figure 29). The left side of the plot represents higher temperature.

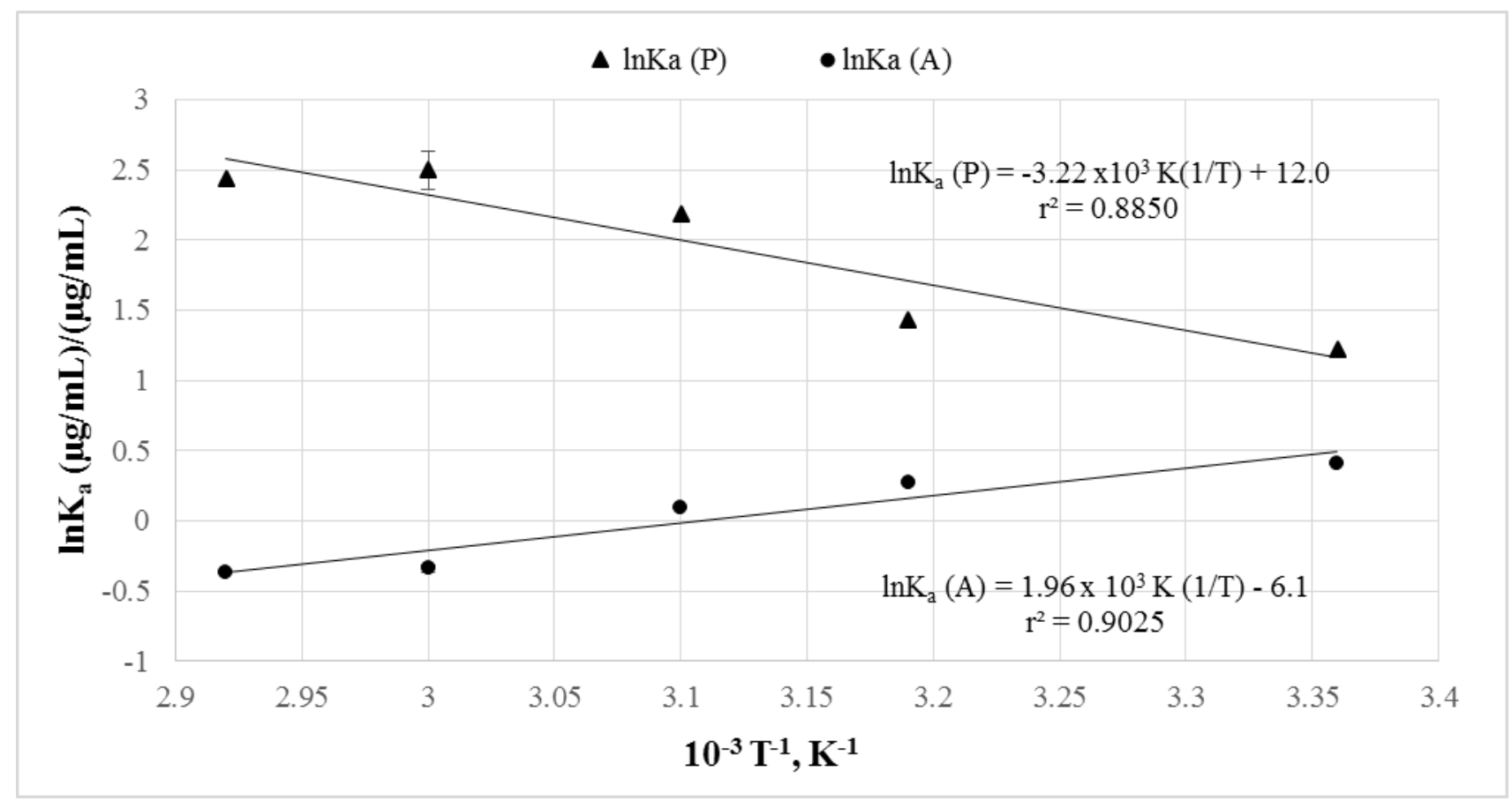

Figure 29: Van't Hoff plots for adsorption on Avicel PH 101 and on Protobind 1000 at pH 5 with maximum error bar at $95 \%$ probability

[Baig, 2016]

For Avicel, $\ln K_{a}$ decreased with an increase in temperature, there was a small decrease (10-12\%) in adsorption at $323 \mathrm{~K}$ compared to $298 \mathrm{~K}$, and at $343 \mathrm{~K}$ the adsorption decreased by $33 \%$, as was expected from published literature [Andreaus et al., 1999; Kim et al., 2001; Tu et al., 2009b; Rahikainen et al., 2013]. Other research groups reported that some cellulases started denaturing 
around $323 \mathrm{~K}$ [Otter et al., 1984; Andreaus et al., 1999; Tu et al., 2009a; Rahikainen et al., 2011$].$ The Novozymes cellulases used in this study surpassed this limit by $10 \mathrm{~K}$. On the other hand, Baker's group [Baker et al., 1992] proved that individual cellulases maintain their activities up to $333 \mathrm{~K}$. The observed $\ln \mathrm{K}_{\mathrm{a}}$ at lower temperature may be associated to a reduced translational energy and rotational energy (vibrational energy is negligible) of cellulases and cellulose allowing opposite charges on the cellulose-binding domain (CBD) of cellulases and on the Avicel to align themselves. The van't Hoff model gave $\ln \mathrm{K}_{\mathrm{a}}=1.96 \times 10^{3}(1 / \mathrm{T})-6.10$. The change in enthalpy $\left(\Delta \mathrm{H}_{\mathrm{a}}\right)$ value obtained from the slope of the equation was found to be $15.95 \mathrm{kJmol}^{-1}$. The adsorption process sometimes is a arrangement of two processes: (a) desorption of the solvent (water) molecules formerly adsorbed on it or a neighbor molecule, and (b) the adsorption of the cellulases. In an endothermic process, the cellulases has to displace more than one water molecule for their adsorption and this result in the endothermicity of the adsorption process. Therefore, $\Delta \mathrm{H}_{0}$ will be positive. The positive $\Delta \mathrm{H}_{\mathrm{a}}$ of adsorption means that non-covalent interactions (such as electrostatic, van der Waals, hydrogen bonding, etc.) are significant [Ooshima et al., 1983; Hoshino et al., 1992] between cellulases and Avicel. The $\Delta \mathrm{S}_{\mathrm{a}}$ value obtained from intercept of the plot was $-50 \mathrm{Jmol}^{-1} \mathrm{~K}^{-1}$. The negative entropy indicated that the mobility of the adsorbed cellulases on the surface of Avicel was restricted. Negative values of $\Delta \mathrm{S}_{\mathrm{a}}$ were also observed for adsorbed enzymes during other studies [Ooshima et al., 1983; Boraston, 2005; Saha et al., 2014] and for ionic adsorption [Ngah and Hanafiah, 2008; Padmavathy, 2008; Ramdane et al., 2014]. Another reason for negative $\Delta \mathrm{S}_{\mathrm{a}}$ value could be unfolding (conformational changes) of cellulases. The unfolding of endoglucanases from Aspergillus niger and $\alpha$-amylase from Bacillus licheniformis, DNA ligase and xylanase were reported where the $\Delta \mathrm{S}$ value was negative [Violet and Meunier, 1989; D’Amico et al., 2003; Collins et al., 2003]. Violet and Meunier (1989) presented the formation of an intermediate (X) on the pathway between the native (N) and the denatured (D) enzyme forms (i.e. $\quad N \rightarrow X \rightarrow D$ ). They noticed that the intermediate state 
(adsorption of enzymes on substrate) is more ordered structure than the starting state i.e. $\Delta \mathrm{S}_{\mathrm{a}}$ is negative.

According to the second law of thermodynamics for any spontaneous process, the overall $\Delta \mathrm{S} \geq 0$. The negative change in entropy does not contradict the second law, because the adsorption of cellulases on Avicel have a sufficiently large negative $\Delta \mathrm{H}_{\mathrm{a}}$ (over 320 times of that of $\Delta \mathrm{S}_{\mathrm{a}}$ ) results in a sufficiently large increase in entropy that overall the change in entropy is positive. That is, the $\Delta S$ of the liquid increases enough because of the exothermicity of the reaction that it overcompensates for the negative $\Delta \mathrm{S}$ of the solid-liquid interface, and since the overall $\Delta \mathrm{S}_{\mathrm{a}}=\Delta \mathrm{S}_{\text {surroundings }}+\Delta \mathrm{S}_{\text {system, }}$ the overall change in entropy is still positive. The Gibbs free energy $\left(\Delta \mathrm{G}_{\mathrm{a}}\right)$ value increased from $1170 \mathrm{Jmol}^{-1}$ to $1080 \mathrm{Jmol}^{-1}$ as temperature increased from $298 \mathrm{~K}$ to $343 \mathrm{~K}$. A negative $\Delta \mathrm{G}_{\mathrm{a}}$, expected for spontaneous adsorption occurred only from $298 \mathrm{~K}$ to $323 \mathrm{~K}$. Consequently, only this temperature range is recommended for adsorption of cellulases on Avicel PH 101. For bioethanol producing industries, using wheat straw where cellulose is a component, adsorption can be performed on delignified wheat straw between the temperature ranges of $298 \mathrm{~K}$ to $323 \mathrm{~K}$. Since fermentations are conducted in most of the industries around $313 \mathrm{~K}$ therefore, adsorption can also be performed at the same temperature for the ease of process.

In the case of Protobind, the experimental data points plotted between $298 \mathrm{~K}$ and $343 \mathrm{~K}$ showed $\ln \mathrm{K}_{\mathrm{a}}$ increased with an increase in temperature. The trend line equation (regression equation) was $\ln K_{a}=$ $-3.22 \times 10^{3}(1 / \mathrm{T})+12.0$. Therefore, $\Delta \mathrm{Ha}_{\mathrm{a}}$ was $26 \mathrm{kJmol}^{-1}$, which indicates an endothermic reaction. The amount of cellulases adsorbed increased from $75 \%$ to $94 \%$ of the initial cellulases concentration when temperature increased from $298 \mathrm{~K}$ to $333 \mathrm{~K}$. The $\Delta \mathrm{S}_{\mathrm{a}}$ for the adsorption of cellulases on Protobind 1000 was positive $\left(100 \mathrm{jmol}^{-1} \mathrm{~K}^{-1}\right)$ which means that disorder of the system was increased [Saha and Chowdhury, 2011]. In accordance with the second law of thermodynamics since $\Delta \mathrm{S}_{\mathrm{a}}>0$, 
the adsorption of cellulases on lignin appears to be an irreversible process. The $\Delta \mathrm{G}_{\mathrm{a}}$ decreased from $-2.90 \times 10^{3} \mathrm{Jmol}^{-1}$ to $-7.40 \times 10^{3} \mathrm{Jmol}^{-1}$ as temperature increased from $298 \mathrm{~K}$ to $343 \mathrm{~K}$, which becomes the suitable adsorption temperature range for Protobind 1000. By choosing 298 K, $20 \%$ less cellulase would be adsorb on ligneous component than at $343 \mathrm{~K}$ and $30 \%$ more cellulases will adsorb [delignified wheat straw].

The negative $\Delta \mathrm{H}_{\mathrm{a}}, \Delta \mathrm{S}_{\mathrm{a}}$ and $\Delta \mathrm{G}_{\mathrm{a}}$ indicated that maximum temperature suitable for adsorption is 298 $\mathrm{K}$ to $320 \mathrm{~K}$. In depth study showed that maximum adsorption on Avicel was between temperatures $298 \mathrm{~K}$ to $313 \mathrm{~K}$ and maximum adsorption on Protobind was on temperature $323 \mathrm{~K}$ to $343 \mathrm{~K}$. To avoid adsorption on lignin (in addition to optimum removal of lignin) low temperatures such as $298 \mathrm{~K}$ to $313 \mathrm{~K}$ should be used for adsorption because at these temperature thermodynamic conditions give less support for adsorption on lignin. Therefore, a temperature closer to $298 \mathrm{~K}$ is recommended for adsorption part of bioethanol production process. Reuse of adsorbed enzymes to save cost of enzymatic hydrolysis is important, therefore, entropy and enthalpy of desorbed cellulases from was studied next. 


\subsection{Desorption of cellulases}

Desorption of adsorbed cellulases (adsorbed on Avicel PH 101) remaining on the solids residues after centrifugation is shown Figure 30. Desorption was conducted with distilled water at $25^{\circ} \mathrm{C}$. Cellulase desorbed over time, found their way in the supernatant and reported as a percentage of the concentration. Half of the $\%$ desorbed was obtained in first 5 minutes then desorption progressed slowly till it reached to its equilibrium around at 20 minutes. Variance in measurement were estimated by error propagation technique and finalized to get $95 \%$ probability of desorption. Therefore, desorption time in further studies for Avicel was taken as 20 minutes.

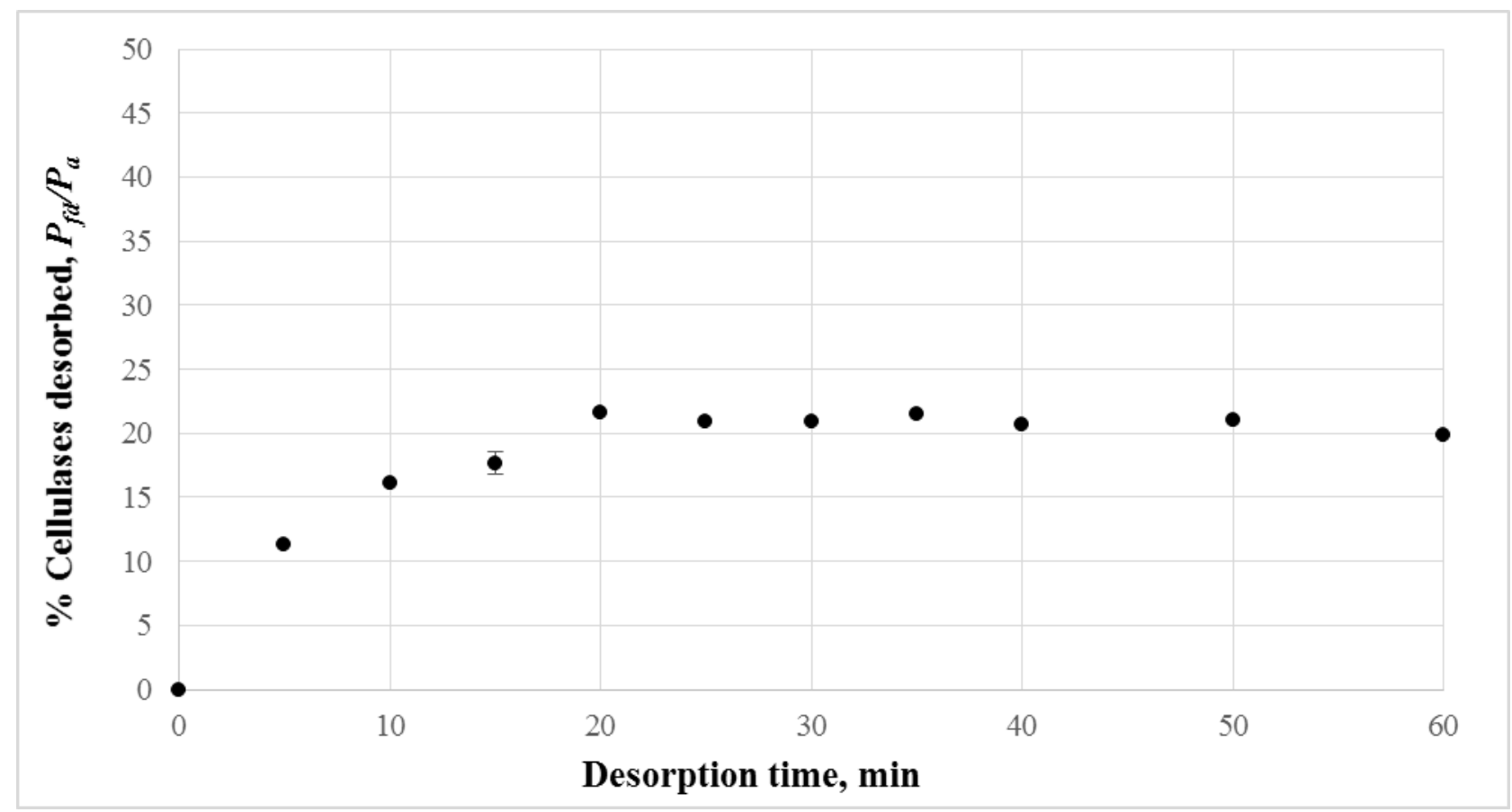

Figure 30: Desorption of cellulases from Avicel PH 101 using distilled water, at pH 5, $25{ }^{\circ} \mathrm{C}, \mathrm{E}_{0}$ at $165.2 \mu \mathrm{g} \mathrm{mL}^{-1}$ and maximum error bar at $95 \%$ probability

Desorption time 20 minutes is closer to the reported time in literature. For example Otter et al. (1984) demonstrated that desorption from steam exploded aspen was completed in 30 seconds and was not affected by increases in desorption time to $15 \mathrm{~min}$. Similarly, Nidetzky and Steiner (1993) 
reported achievement of desorption from microcrystalline cellulose within 15 minutes, which is closer to 20 minutes. The existing hypothesis was evaluated and found that desorption from Avicel by using distilled water was only $22 \%$ which means that adsorption was not completely reversible.

The plots in Figure 31 showed $\%$ of cellulases desorbed at temperatures varying from 25 to $70{ }^{\circ} \mathrm{C}$ at $\mathrm{pH}$ from 6 to 9 . Every data point was measured individually for an average of 5 replicates. All the curves seem to follow a similar trend leading to a maximum concentration of desorbed enzymes at $60{ }^{\circ} \mathrm{C}$. Maximum desorption of cellulases from Avicel achieved was $74 \%$ at $\mathrm{pH} 9$ and $60{ }^{\circ} \mathrm{C}$. The second maximum cellulases desorbed achieved was $62 \%$ at $\mathrm{pH} 8$ and $60{ }^{\circ} \mathrm{C}$. At $\mathrm{pH} 9,50{ }^{\circ} \mathrm{C}$ desorption was around $52 \%$. Increasing temperature over $60{ }^{\circ} \mathrm{C}$ decreased desorption.

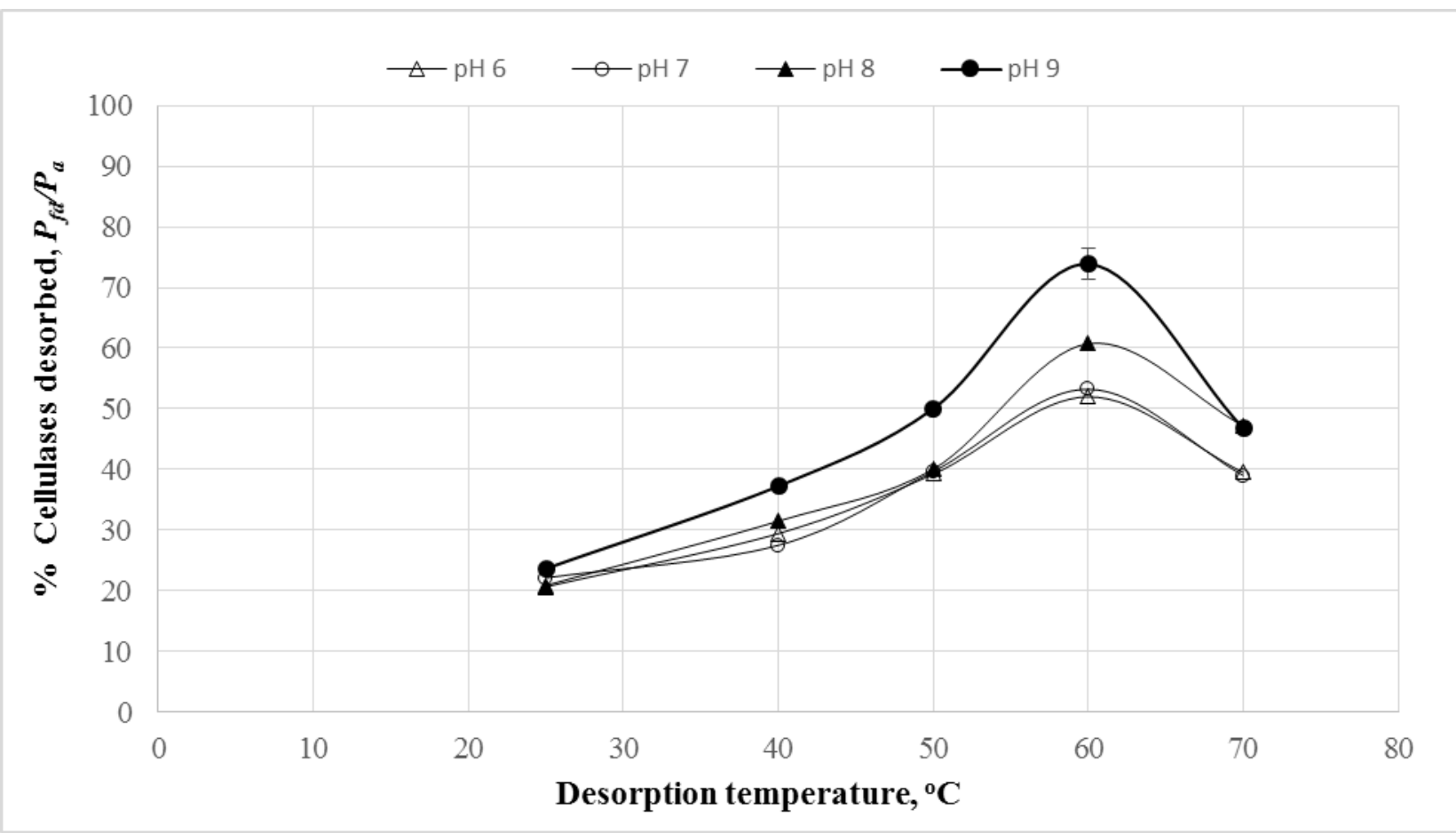

Figure 31 : Desorption of cellulases from Avicel with varying temperature (from $25^{\circ} \mathrm{C}$ to 70 ${ }^{\circ} \mathrm{C}$ ) and $\mathrm{pH}$ (from $\mathrm{pH} 6$ to $\mathrm{pH} 7$ ), $100 \mathrm{rpm}$ and maximum error bar at $95 \%$ probability [Baig et al., 2013]

Ye (2012) studied desorption of cellobiohydrolases (CBH I) at $0{ }^{\circ} \mathrm{C}$ and $50{ }^{\circ} \mathrm{C}$ from Avicel and reported that $25 \%$ of total enzymes desorbed at $50{ }^{\circ} \mathrm{C}$ while desorption at $0{ }^{\circ} \mathrm{C}$ was less than $10 \%$. 
Implied that increase in temperature from $0{ }^{\circ} \mathrm{C}$ to $50{ }^{\circ} \mathrm{C}$ increased desorption. Our results showed that desorption of Avicel was increased from $20 \%$ to $75 \%$ with respect to the initial cellulases concentration when temperature was increased from $25{ }^{\circ} \mathrm{C}$ to $60{ }^{\circ} \mathrm{C}$ at $\mathrm{pH}$. Hong et al. (2007) reported that increase in $\mathrm{pH}$ from 5 to 10 increased desorption to $61 \%$. Our results have similar trends as presented in literature and have better values while increasing from $\mathrm{pH} 6$ to $\mathrm{pH} 9$ at $60{ }^{\circ} \mathrm{C}$, desorption increased from $51 \%$ to $75 \%$. Hong et al. (2007) also reported that desorption was $84 \%$ from Avicel and $94 \%$ from dilute acid pretreated corn stover at $\mathrm{pH} 13$ but desorbed enzymes were not active. Desorption of all non-active enzymes was useless as enzymes could not be reused.

The relative activities of the cellulases desorbed are shown in Figure 32. All the data points were measured separately and were averages of 5 replicates.

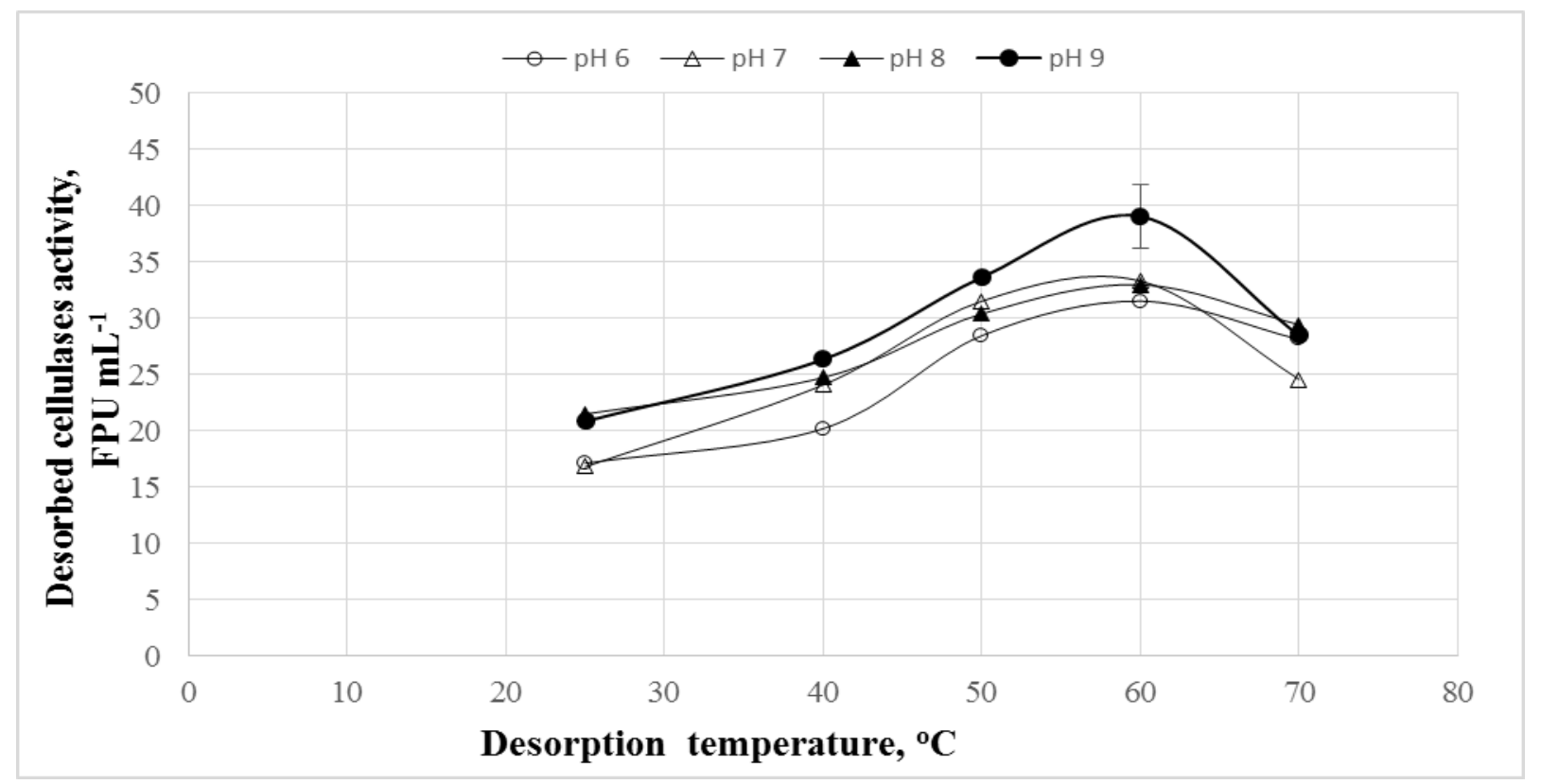

Figure 32 : Activity of desorbed cellulases from Avicel with varying temperature (from $25^{\circ} \mathrm{C}$ to $70{ }^{\circ} \mathrm{C}$ ) and $\mathrm{pH}$ (from pH 6 to $\mathrm{pH} 9$ ), $100 \mathrm{rpm}$ and maximum error bar shown at $95 \%$ probability

All curves seem to follow a similar trend and obtained their maximum at $60{ }^{\circ} \mathrm{C}$. At $\mathrm{pH} 9$, beyond 60 ${ }^{\circ} \mathrm{C}$ cellulases lost around $30 \%$ of their activity which may be an attribute of denaturing. The 
maximum activity achieved at $\mathrm{pH} 8$ and 9 at $60{ }^{\circ} \mathrm{C}$ were 33.01 and $39.07 \mathrm{FPU} \mathrm{ml}^{-1}$ respectively. The activity values obtained at $\mathrm{pH} 8$ and $\mathrm{pH} 9$ are almost the same up to $50^{\circ} \mathrm{C}$. Otter et al. (1989) desorbed $68 \%$ of cellulases at $\mathrm{pH} 10$ with zero activity, the amount was there maximum reported. Our result indicated that $\mathrm{pH} 8$ and $\mathrm{pH} 9$ are suitable to desorb active cellulases from cellulosic substrates. We achieved maximum active desorption at $\mathrm{pH} 9$ at $60{ }^{\circ} \mathrm{C}$ from Avicel. Another test was also conducted by heating Avicel PH 101 at $70{ }^{\circ} \mathrm{C}, \mathrm{pH}$ 9, and $100 \mathrm{rpm}$ for 60 minutes which showed that no reducing sugars were formed. Therefore no degradation or self-hydrolysis of Avicel occurred at the conditions of desorption. In Figure 33 each data point plotted was measured individually and was an average of triplicates. The desorption trend is similar to that of Avicel desorption.

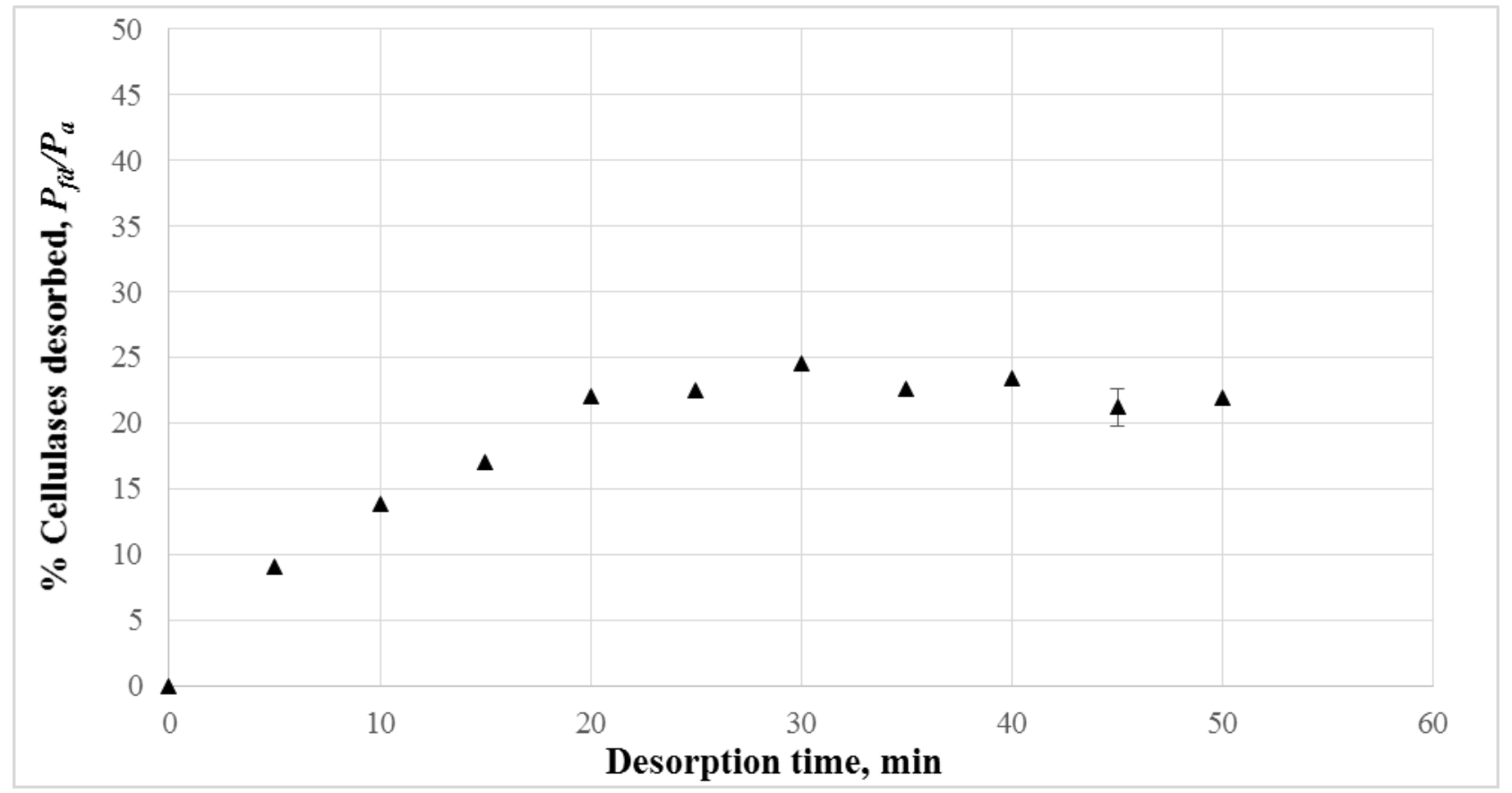

Figure 33 : Desorption of cellulases from Protobind 1000 using distilled water, at pH 5, $25{ }^{\circ} \mathrm{C}$, $E_{0}$ at $182.7 \mu \mathrm{gL}^{-1}$ and maximum error bar at $95 \%$ probability

It was surprizing to experience that desorption equilibrium for Protobind was established around 20 min which is the same as that of Avicel. It needs further research to determine why desorption time from Protobind and Avicel is the same. For further desorption experiments desorption time was 
selected as 20 minutes. The existing hypothesis was evaluated for desorption from Protobind by using distilled water and $25 \%$ cellulases were desorbed which means that adsorption was not completely irreversible. Therefore, existing hypothesis that adsorption on lignin is irreversible was proven wrong.

Figure 34 contain plots of cellulases desorbed from Protobind 1000 under similar conditions as studied during desorption from Avicel.

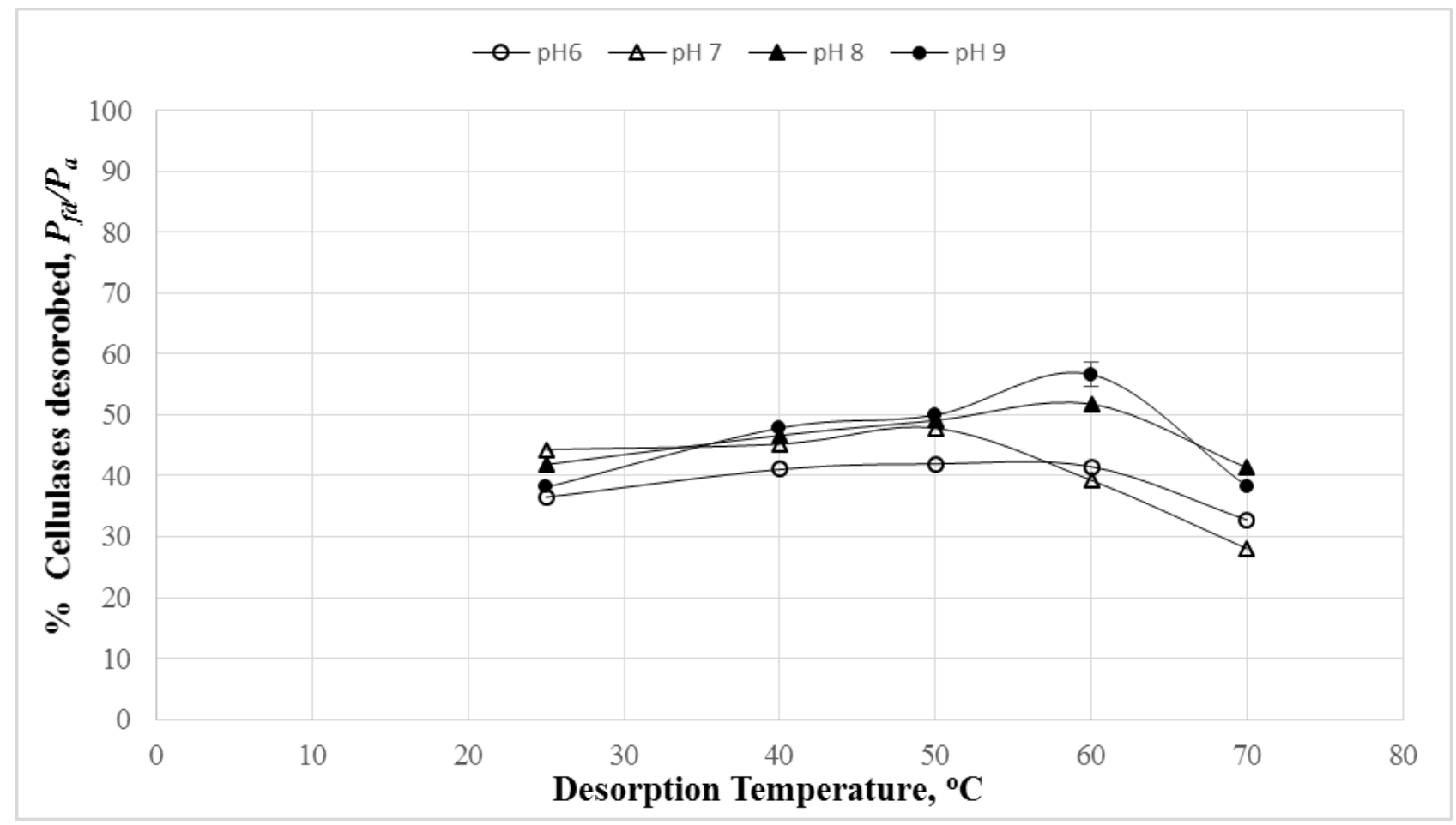

Figure 34 : Desorption of cellulases from Protobind with varying temperature from $\left(25^{\circ} \mathrm{C}\right.$ to $70{ }^{\circ} \mathrm{C}$ ), $\mathrm{pH}$ (from pH 6 to $\mathrm{pH} 9$ ), $100 \mathrm{rpm}$ and maximum error bar at $95 \%$ probability [Baig et al., 2013]

For $\mathrm{pH} 9$, the maximum desorption $(55 \%)$ was achieved at $60{ }^{\circ} \mathrm{C}$. Desorption at $\mathrm{pH} 9$ and $50{ }^{\circ} \mathrm{C}$ was around $50 \%$. Desorption increased from $42 \%$ to $55 \%$ with increase in temperature from $25{ }^{\circ} \mathrm{C}$ to $60{ }^{\circ} \mathrm{C}$ at $\mathrm{pH} 9$. Beyond $60^{\circ} \mathrm{C}$, a fall in activity was observed. At $70{ }^{\circ} \mathrm{C}$ there was almost $15 \%$ decrease in desorption than of $60{ }^{\circ} \mathrm{C}$. A pH 8 has shown similar $\%$ cellulases desorbed at $50{ }^{\circ} \mathrm{C}$ and $60{ }^{\circ} \mathrm{C}$ as that of $\mathrm{pH}$ 9. Results of Protobind also supported that $\mathrm{pH} 8$ and $\mathrm{pH} 9$ with $50{ }^{\circ} \mathrm{C}$ and $60{ }^{\circ} \mathrm{C}$ are good 
desorption conditions. The $\%$ of cellulases desorbed from Protobind were less than $\%$ of cellulases desorbed from Avicel. The presence of multiple functional groups on the surface of lignin make the strong interactions between lignin and cellulases and hence make it difficult for cellulases to desorb. Wang et al. (2012) prepared artificial lignocellulosic substrates with lignin concentration of $29.6 \%$ and $29.1 \%$ of lignin by mass. These percentages of lignin were closer to the concentration of lignin in wheat straw (i.e. $23 \%$ ). Figure 35 showed activity of the cellulases desorbed plotted along y-axis with varying desorption temperatures plotted along $\mathrm{x}$-axis. All the data points were measured separately and were average of 5 replicates.

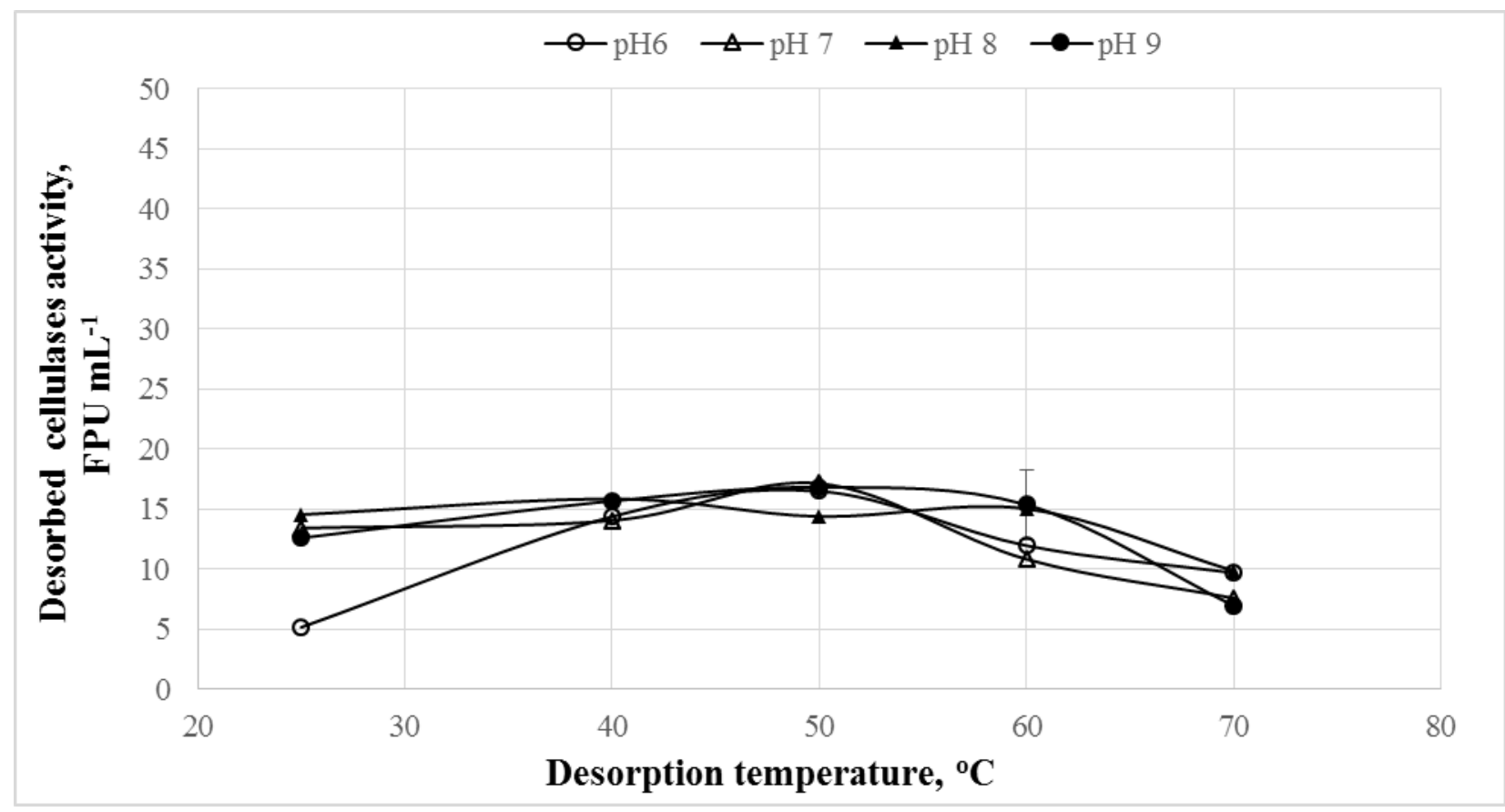

Figure 35 : Activity of desorbed cellulases from Protobind 1000 with varying temperature (from $25^{\circ} \mathrm{C}$ to $70{ }^{\circ} \mathrm{C}$ ), $\mathrm{pH}$ (from $\mathrm{pH} 6$ to $\mathrm{pH} \mathrm{9),} 100 \mathrm{rpm}$ and maximum error bar at $95 \%$ probability

Contrary to results with Avicel, activity of cellulases after desorption from Protobind reached to its maximum at temperature $50{ }^{\circ} \mathrm{C}$ and $\mathrm{pH} 9$ around $17 \mathrm{FPU}$. The activity measured at $\mathrm{pH} 9$ and $60{ }^{\circ} \mathrm{C}$ was around $17 \mathrm{FPU}$ (close to $50^{\circ} \mathrm{C}$ ). At $70^{\circ} \mathrm{C}$ the activity of the desorbed cellulases decreased to 65 
$\%$ of their value at $60{ }^{\circ} \mathrm{C}$ for $\mathrm{PH} 8$ and $45 \%$ to their value at $\mathrm{pH} 9$ (almost to its half than its value at $60{ }^{\circ} \mathrm{C}$ ). The activities at $\mathrm{pH} 8$ and $\mathrm{pH} 9$ were almost the same at $40{ }^{\circ} \mathrm{C}$ to $60{ }^{\circ} \mathrm{C}$. The thermo-stability of enzymes was studied by Rodrigues et al. (2012) at temperatures 30, 37, 40, 45 and $50{ }^{\circ} \mathrm{C}$ for one artificially prepared substrate, 4-methylumbelliferyl- $\beta$-D-cellobioside (not a lignin). They found that at $45^{\circ} \mathrm{C}$ the desorbed cellulases was $89.7 \%$ active while at $50{ }^{\circ} \mathrm{C}$ there was a sharp decline in activity i.e. only $37.5 \%$ active and at $\mathrm{pH} 10$ the structure was partially lost. These results were almost the same as ours. For the substrates containing cellulose and lignin $\mathrm{pH} 8$ and pH 9 with temperatures 50 ${ }^{\circ} \mathrm{C}$ and $60{ }^{\circ} \mathrm{C}$ are suitable for desorption of cellulases. Through literature survey we hypothesized that alkaline $\mathrm{pH}$ and elevated temperature can desorb active cellulases in significant amount. The change in temperature dictate the change in enthalpy and entropy of the system.

\subsection{Enthalpic and entropic changes for desorption under the influence of temperature}

The temperature dependency of desorption, however is reported and discussed here. The results could indicate feasibility of the desorption reactions from the obtained values of the thermodynamic parameters. It also give insight whether desorption is enthalpy driven or entropy driven. The equilibrium adsorption results for both solid substrates (Avicel PH 101 and Protobind 1000) were plotted as a van't Hoff relation (Equation 2.10) for linearity of adsorption over the temperature range of $298 \mathrm{~K}$ to $343 \mathrm{~K}$ (Figure 30 ).

\subsubsection{Desorption from Avicel PH 101 and from Protobind 1000}

Van't Hoff plots were constructed for the desorption of cellulases from Avicel over a temperature range of $298 \mathrm{~K}$ to $343 \mathrm{~K}$ and a $\mathrm{pH}$ range of 6 to 9 (Figure 36) for desorption time 20 minutes (data not shown). The curves were drawn up to $\mathrm{T} \leq 333 \mathrm{~K}$ because there appears to be denaturing of 
cellulases occurring after $333 \mathrm{~K}$ [Dehghanifard et al., 2013; Tavares et al., 2013]. The denaturing of cellulases was similar to what happened for adsorption but was much more pronounced.

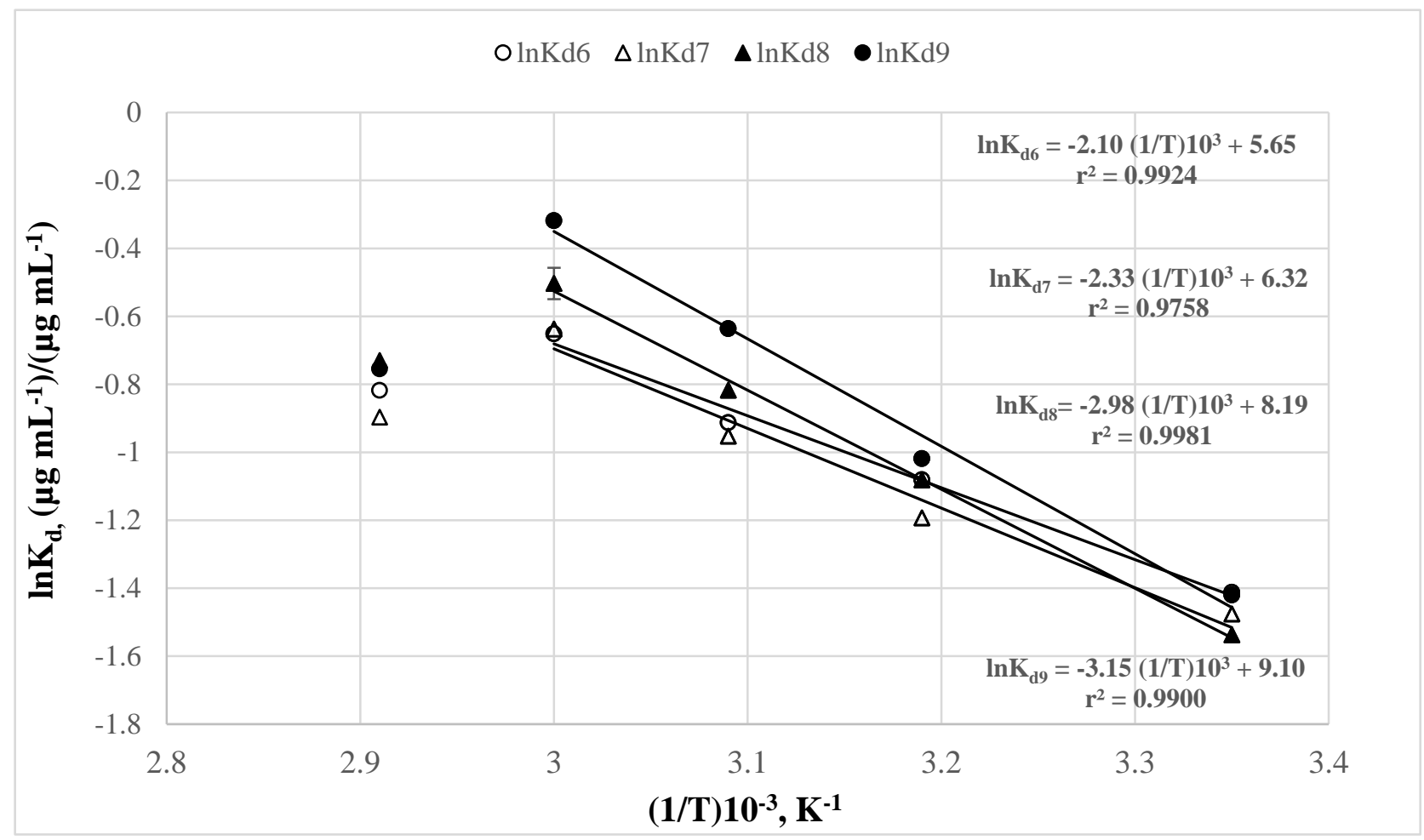

Figure 36: Desorption of cellulases NS 50013 from Avicel PH101 at varying pH (from pH 6 to pH 9), temperature (from $298 \mathrm{~K}$ to $343 \mathrm{~K}$ ), $100 \mathrm{rpm}$ and maximum error bar at $95 \%$ probability

Desorption regression equations are given below:

$$
\begin{array}{lll}
\ln K_{d 6}=(-2.10) \frac{1}{T} 10^{3}+5.65 & \ldots & 5.3 \\
\ln K_{d 7}=(-2.33) \frac{1}{T} 10^{3}+6.32 & \ldots & 5.4 \\
\ln K_{d 8}=(-2.98) \frac{1}{T} 10^{3}+8.19 & \ldots & 5.5 \\
\ln K_{d 9}=(-3.15) \frac{1}{T} 10^{3}+9.10 & \ldots & 5.6
\end{array}
$$


Since all slopes of the van't Hoff equations were negative, all $\Delta \mathrm{H}_{\mathrm{d}}$ values were positive. There was a slight increasing trend in $\Delta \mathrm{H}_{\mathrm{d}}$ from $\mathrm{pH} 6$ to $\mathrm{pH} 9: 17.5,19.4,24.1,26.2 \mathrm{kJmol}^{-1}$, respectively. This meant that heat energy was gained by the cellulases desorption system, which resulted in the decrease in van der Waals interactions and hydrogen bonding between cellulases and cellulose. The $\Delta \mathrm{H}_{\mathrm{d}}$ values obtained from the last two point $333 \mathrm{~K}$ to $343 \mathrm{~K}$ for all $\mathrm{pH}$ values were negative as -15.8, $24.6,-21.5$, and $-41.5 \mathrm{kJmol}^{-1}$ respectively. The negative signs of enthalpy usually mean that the heat is being released by the occurring reaction. The changes in entropy, $\Delta \mathrm{S}_{\mathrm{d}}$, for all $\mathrm{pH}$ values were (46 to $75 \mathrm{Jmol}^{-1} \mathrm{~K}^{-1}$ ) positive. [Entropy of adsorption was $\Delta \mathrm{S}_{\mathrm{a}}$ was -50 ] This indicated decreased randomness which favored desorption. At $333 \mathrm{~K}$ to $343 \mathrm{~K}$ the $\Delta \mathrm{S}_{\mathrm{d}}$ was $-52,-79,-68$, and $-127 \mathrm{Jmol}^{-}$ ${ }^{1} \mathrm{~K}^{-1}$ for $\mathrm{pH} 6$ to $\mathrm{pH} 9$ which indicated further decreased desorption. The values of $\Delta \mathrm{G}_{\mathrm{d}}$ obtained from Equation 2.11 are given in Table 11.

Table 11: $\Delta \mathrm{G}_{\mathrm{d}}$ obtained for desorption of cellulases from Avicel PH 101 for $\mathrm{pH} 6$ to $\mathrm{pH} 9$ at temperatures $298 \mathrm{~K}$ to $343 \mathrm{~K}$

\begin{tabular}{|c|c|c|c|c|}
\hline \multirow{2}{*}{$\begin{array}{c}\text { Temperature } \\
\text { K }\end{array}$} & \multicolumn{4}{|c|}{$\Delta \mathbf{G}_{\mathbf{d}}$} \\
\hline & $\begin{array}{c}\text { pH } 6 \\
\text { Jmol }^{-1} \mathbf{K}^{-1}\end{array}$ & $\begin{array}{c}\text { pH } 7 \\
\text { Jmol }^{-1} \mathbf{K}^{-1}\end{array}$ & $\begin{array}{c}\mathbf{p H ~} 8 \\
\mathbf{J m o l}^{-1} \mathbf{K}^{-1}\end{array}$ & $\begin{array}{c}\text { pH } 9 \\
\text { Jmol-1 }^{-1} \mathbf{K}^{-1}\end{array}$ \\
\hline 298 & $3.54 \times 10^{3}$ & $3.77 \times 10^{3}$ & $3.80 \times 10^{3}$ & $3.60 \times 10^{3}$ \\
\hline 313 & $2.84 \times 10^{3}$ & $2.98 \times 10^{3}$ & $2.80 \times 10^{3}$ & $2.48 \times 10^{3}$ \\
\hline 323 & $2.37 \times 10^{3}$ & $2.12 \times 10^{3}$ & $2.10 \times 10^{3}$ & $1.72 \times 10^{3}$ \\
\hline 333 & $1.90 \times 10^{3}$ & $1.94 \times 10^{3}$ & $1.45 \times 10^{3}$ & $0.970 \times 10^{3}$ \\
\hline 343 & $2.31 \times 10^{3}$ & $2.52 \times 10^{3}$ & $2.05 \times 10^{3}$ & $2.10 \times 10^{3}$ \\
\hline
\end{tabular}

$\Delta \mathrm{G}_{\mathrm{d}}$ values were all positive and decreased with increase in temperature. Gibbs free energy $\left(\Delta \mathrm{G}_{\mathrm{d}}\right)$ decreased with the increase in temperature which means at $\mathrm{pH} 9$ and $333 \mathrm{~K}$ the cellulases showed minimum affinity (adsorption interest) for the substrate. The maximum desorption of cellulases was 
achieved at almost $333 \mathrm{~K}$ for all $\mathrm{pH}$ values. Theoretically, the maximum desorption achieved should be at $343 \mathrm{~K}$ since high temperature support desorption. The decrease in desorption while moving from $333 \mathrm{~K}$ to $343 \mathrm{~K}$ can be attributed to the configurational changes of cellulases which render the cellulases to desorb. The $\Delta \mathrm{G}_{\mathrm{d}}$ values calculated for temperature $343 \mathrm{~K}$ were large and positive as compare to the values at $333 \mathrm{~K}$ represented a less desorption the temperature (last row of Table 12 ). The positive and large $\Delta \mathrm{H}_{\mathrm{d}}$, small $\Delta \mathrm{S}_{\mathrm{d}}$ value, with positive $\Delta \mathrm{G}_{\mathrm{d}}$ values indicated that desorption process was favorable for $\mathrm{pH}$ ranging from 6 to 9 and the temperature ranging from $298 \mathrm{~K}$ to $333 \mathrm{~K}$ only. Beyond $\mathrm{T} \geq 333 \mathrm{~K}, \Delta \mathrm{H}_{\mathrm{d}}$ was negative $\Delta \mathrm{S}_{\mathrm{d}}$ was negative and $\Delta \mathrm{G}_{\mathrm{d}}$ was very large which resulted in decrease in desorption due to denaturing of cellulases.

Desorption of cellulases NS 500013 from Protobind, in similar conditions as that for Avicel is shown in Figure 36. The maximum error bar of all individualized experiments is at $\mathrm{pH} 8$ and $313 \mathrm{~K}(3.19 \mathrm{x}$ $\left.10^{-3} \mathrm{~K}^{-1}\right)$. Again data for $\mathrm{T} \geq 333 \mathrm{~K}$ showed incompatibility with rest of the data because of very low $\ln K_{d}$ values observed (low desorption from the Protobind surface). The $\ln K_{d}$ increased with an increase in temperature from $298 \mathrm{~K}$ to $333 \mathrm{~K}$ and the corresponding regression equations are given below:

$$
\begin{array}{lll}
\ln K_{d 6}=(-1.17) \frac{1}{T} 10^{3}+2.60 & \ldots & 5.7 \\
\ln K_{d 7}=(-0.610) \frac{1}{T} 10^{3}+1.00 & \ldots & 5.8 \\
\ln K_{d 8}=(-0.830) \frac{1}{T} 10^{3}+1.80 & \ldots & 5.9 \\
\ln K_{d 9}=(-0.920) \frac{1}{T} 10^{3}+2.20 & \ldots & 5.10
\end{array}
$$




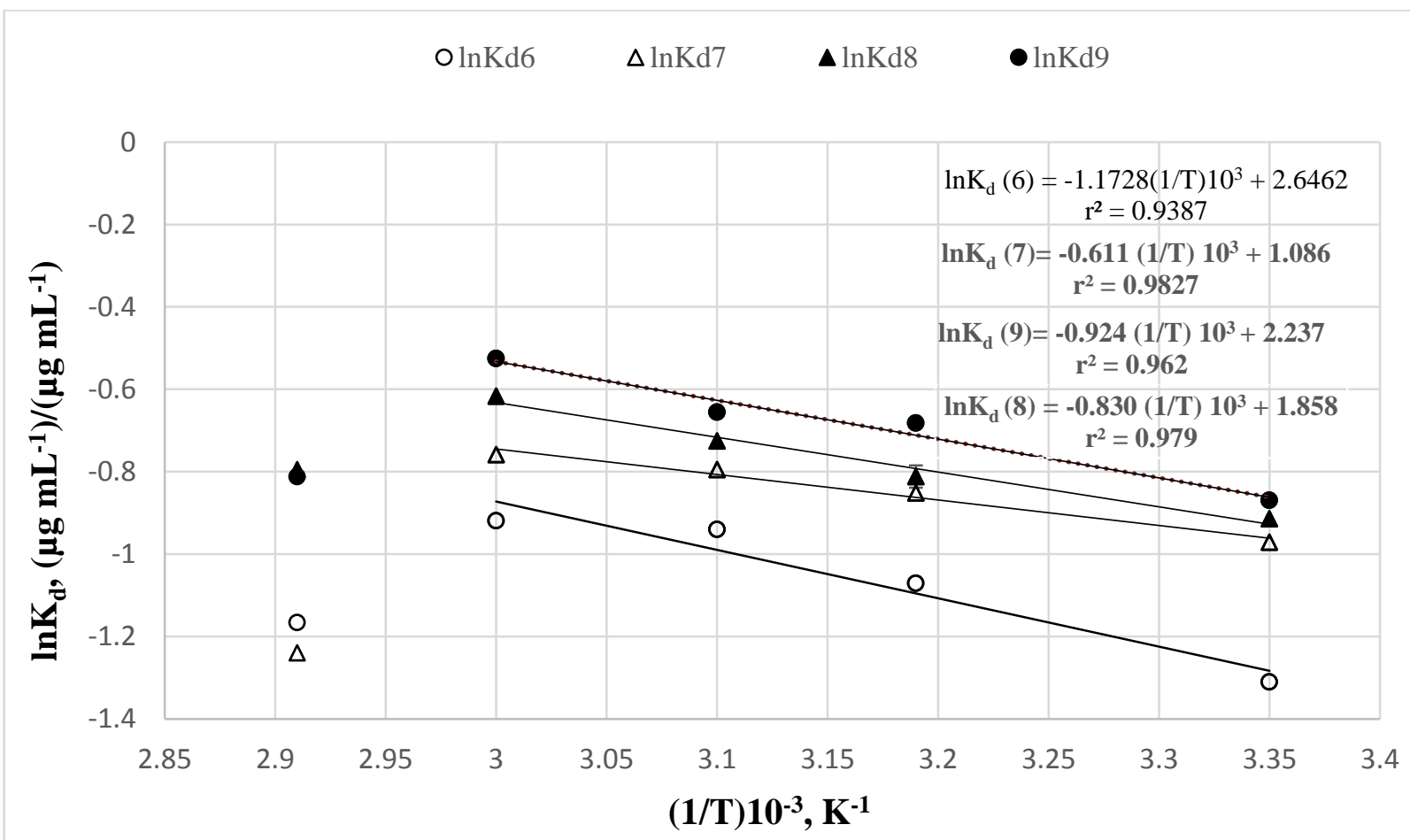

Figure 37: Desorption of cellulases NS 50013 from Protobind 1000 at varying pH (from pH 6 to pH 9), temperature (from $298 \mathrm{~K}$ to $343 \mathrm{~K}$ ), $100 \mathrm{rpm}$ and maximum error bar at $95 \%$ probability.

As with Avicel, all slopes for desorption from Protobind had negative values, although their values for Protobind were in the range of $0.610 \mathrm{~K}$ to $1.160 \mathrm{~K}, 2-4$ times less than Avicel at the respective $\mathrm{pH}$ values, leading to positive $\Delta \mathrm{H}_{\mathrm{d}}$ values of $9.60,5.10,6.90$ and $7.70 \mathrm{kJmol}^{-1}$ respectively. The positive $\Delta \mathrm{H}_{\mathrm{d}}$ values indicated that the supplied heat energy was consumed in weakening the interactions between cellulases and Protobind. The large negative $\Delta \mathrm{H}$ values were observed between $333 \mathrm{~K}$ to $343 \mathrm{~K}$ and was attributed to a conformational change in enzymes. The small positive $\Delta \mathrm{S}_{\mathrm{d}}$ values of $21.70,9.00,15.40$, and $18.60 \mathrm{Jmol}^{-1} \mathrm{~K}^{-1}$ for all desorption from Protobind signify that all reactions are not entropy driven rather enthalpy-driven. This small $\Delta \mathrm{S}_{\mathrm{d}}$ in case of desorption could be the result of an indirect decrease in entropy due to the influence of water molecules in the vicinity of non-polar cellulases residues which are broken down at higher temperatures [Rezus and Bakker, 2007; Mukhergee and Gupta, 2015]. The decrease in the entropy of desorption may be due to the decrease in the conformational flexibility of cellulases [Privalov, and Gil, 1988]. The small $\Delta \mathrm{S}_{\mathrm{d}}$ 
implying that the cellulases-substrate complex has restricted flexibility (highly ordered), therefore less desorption. For a process that involves a decrease in entropy and a small change in enthalpy, a positive free energy change, $\Delta \mathrm{G}$, means that will not occur spontaneously [Rout et al., 2003]. $\Delta \mathrm{G}_{\mathrm{d}}$ values calculated for $\mathrm{pH} 6,7,8$ and 9 over the range of temperature $298 \mathrm{~K}$ to $333 \mathrm{~K}$ are presented in Table 12. They remained positive and almost the same throughout the range of temperature and $\mathrm{pH}$.

Table 12: $\Delta \mathrm{G}_{\mathrm{d}}$ obtained for desorption of cellulases from Protobind 1000 for $\mathrm{pH} 6$ to $\mathrm{pH} 9$ at temperatures $298 \mathrm{~K}$ to $343 \mathrm{~K}$

\begin{tabular}{|c|l|l|l|l|}
\hline \multirow{2}{*}{$\begin{array}{c}\text { Temperature } \\
\text { K }\end{array}$} & \multicolumn{4}{|c|}{$\Delta \mathbf{G}_{\mathbf{d}}$} \\
\cline { 2 - 5 } & $\begin{array}{l}\mathbf{p H ~ 6} \\
\mathbf{J m o l}^{-1} \mathbf{K}^{-1}\end{array}$ & $\begin{array}{l}\mathbf{p H ~ 7} \\
\mathbf{J m o l}^{-1} \mathbf{K}^{-1}\end{array}$ & $\begin{array}{l}\mathbf{p H ~ 8} \\
\mathbf{J m o l}^{-1} \mathbf{K}^{-1}\end{array}$ & $\begin{array}{l}\mathbf{p H ~ 9} \\
\mathbf{J m o l}^{-1} \mathbf{K}^{-1}\end{array}$ \\
\hline 298 & $3.18 \times 10^{3}$ & $2.38 \times 10^{3}$ & $2.30 \times 10^{3}$ & $2.14 \times 10^{3}$ \\
\hline 313 & $2.86 \times 10^{3}$ & $2.25 \times 10^{3}$ & $2.08 \times 10^{3}$ & $1.86 \times 10^{3}$ \\
\hline 323 & $2.64 \times 10^{3}$ & $2.16 \times 10^{3}$ & $1.93 \times 10^{3}$ & $1.67 \times 10^{3}$ \\
\hline 333 & $2.40 \times 10^{3}$ & $2.07 \times 10^{3}$ & $1.78 \times 10^{3}$ & $1.48 \times 10^{3}$ \\
\hline 343 & $3.29 \times 10^{3}$ & $3.47 \times 10^{3}$ & $2.24 \times 10^{3}$ & $2.28 \times 10^{3}$ \\
\hline
\end{tabular}

$\Delta \mathrm{G}_{\mathrm{d}}$ values decreased from $2.40,2.07,1.78$ and $1.48 \mathrm{kJmol}^{-1} \mathrm{~K}^{-1}$ as $\mathrm{pH}$ increased from $\mathrm{pH} 6,7,8$, and 9 at $333 \mathrm{~K}$ and it also decreased with increase in temperature up to $333 \mathrm{~K}$. Minimum energy is required to desorb at $\mathrm{pH} 9$ and $333 \mathrm{~K} . \Delta \mathrm{G}_{\mathrm{d}}$ was increased for all $\mathrm{pH}$ at $343 \mathrm{~K}$. The $\Delta \mathrm{G}_{\mathrm{d}}$ values calculated for temperature $343 \mathrm{~K}$ were very large and positive as compare to the values at $333 \mathrm{~K}$ represented a less desorption the temperature (last row of Table 12). The maximum energy to desorb cellulases from Protobind was obtained at $343 \mathrm{~K}$ for all $\mathrm{pH}$ values as given in the last row of Table 12. Desorption from the cellulases-substrate complex was restricted due to unfolding of cellulases. The positive $\Delta \mathrm{H}_{\mathrm{d}}$ for both Avicel and Protobind meant that heat energy was gained by the system by 
increasing temperature from $298 \mathrm{~K}$ to $333 \mathrm{~K}$ favored desorption. The positive $\Delta \mathrm{S}_{\mathrm{d}}$ for both Avicel and Protobind indicated that the increased randomness also favored desorption for $298 \mathrm{~K}$ to $333 \mathrm{~K}$. The minimum $\Delta \mathrm{G}_{\mathrm{d}}$ obtained at $\mathrm{pH} 9$ and $333 \mathrm{~K}$ indicated that cellulases have less affinity for substrate at this point in another words cellulases are maximum on desorption. Since wheat straw is a combination of cellulose and lignin, the thermodynamic study offers a strategy for using wheat starw for ethanol production. For desorption of cellulases from wheat straw, the positive $\Delta \mathrm{H}_{\mathrm{d}}, \Delta \mathrm{S}_{\mathrm{d}}$ and $\Delta \mathrm{G}_{\mathrm{d}}$ indicated favored desorption at $\mathrm{pH} 9$ temperatures $323 \mathrm{~K}$ and $333 \mathrm{~K}$.

\subsubsection{Effect of pore diameter of substrates on desorption of cellulases}

Average pore diameter in the mesopore and macropore ranges using Barrett-Joyner-Halenda analysis (BJH) was measured. The model was based on the assumption that pores had a cylindrical shape and that pore radius was equal to the sum of the radius and the thickness of the film adsorbed on the pore wall [Barrett, 1951; Kalliopi, 2005]. The pore diameter measured by a single set of experiment (average diameter from mesopores and macropores) for Avicel PH 101 was $47.93 \mathrm{~nm}$ and for

Protobind 1000 was $28.89 \mathrm{~nm}$. The reported diameter size of cellulases was $6 \mathrm{~nm}(60 \AA)$ [Grassick et al., 2004]. Stone et al. (1969) suggested to achieve maximum adsorption, the pores in substrates should be 5-9 times larger than the size of the enzymes [Stone et al., 1969]. Since the pore diameter of Protobind 1000 was smaller than the 5 times of the size of cellulases (i.e., $30 \mathrm{~nm}$ ). The cellulases enter into the pores, get adsorbed and then, they get trapped. The cellulases those are entrapped are unable to function, cannot get desorbed. Therefore, one of the reasons that desorption from Protobind is less than that of Avicel is entrapment of cellulases into the pores. 


\subsection{Enhancement of desorption of cellulases}

Temperature facilitates in desorption but at $70{ }^{\circ} \mathrm{C}$ and beyond temperature participated in deactivation of cellulases which was resulted in less desorption. Through desorption studies, it was concluded that maximum concentration of the cellulases were desorbed at $\mathrm{pH} 60^{\circ} \mathrm{C}$ from both Avicel and Protobind. The maximum activities of desorbed cellulases from Avicel were obtained at $60{ }^{\circ} \mathrm{C}$ and Protobind have almost the same activities at 40,50 and $60^{\circ} \mathrm{C}$. It was also observed that desorbed cellulases behaved similar at $\mathrm{pH} 8$ and $\mathrm{pH}$ 9. Therefore, $\mathrm{pH}$ range from 8 to 9 and temperature $40{ }^{\circ} \mathrm{C}$ to $60^{\circ} \mathrm{C}$ were selected for enhancement studies. Some chemicals (Glycerol, Ethylene Glycol) and $\beta$ glucosidase were used in this enhancement studies.

\subsubsection{Glycerol}

The consequence of adding glycerol on desorption of cellulases from Avicel PH 101 was studied at $40,50,60^{\circ} \mathrm{C}$, and $\mathrm{pH} 8$ and $\mathrm{pH} 9$.

\section{Avicel PH 101}

In Figure 38, concentration of cellulases desorbed under various conditions of temperature and $\mathrm{pH}$ was plotted. All the data points were measured separately and were average of 5 replicates.

It seems from the plots that the maximum was achieved at $50{ }^{\circ} \mathrm{C}$ to $60{ }^{\circ} \mathrm{C}$. Maximum cellulases desorbed was at $\mathrm{pH} 9$ at $60{ }^{\circ} \mathrm{C}$ with $5 \%$ glycerol was around $96 \%$. The next closest values for same conditions with $10 \%$ glycerol were around $91 \%$ while the maximum desorbed at $\mathrm{pH} 9$ and $60{ }^{\circ} \mathrm{C}$ without glycerol was around $75 \%$. Therefore, there was a 16-26\% enhanced desorption of cellulases from Avicel using glycerol. It seems from the plots that the maximum was achieved at $50{ }^{\circ} \mathrm{C}$ to 60 ${ }^{\circ} \mathrm{C}$. Maximum cellulases desorbed was at $\mathrm{pH} 9$ at $60{ }^{\circ} \mathrm{C}$ with $5 \%$ glycerol was around $96 \%$. 


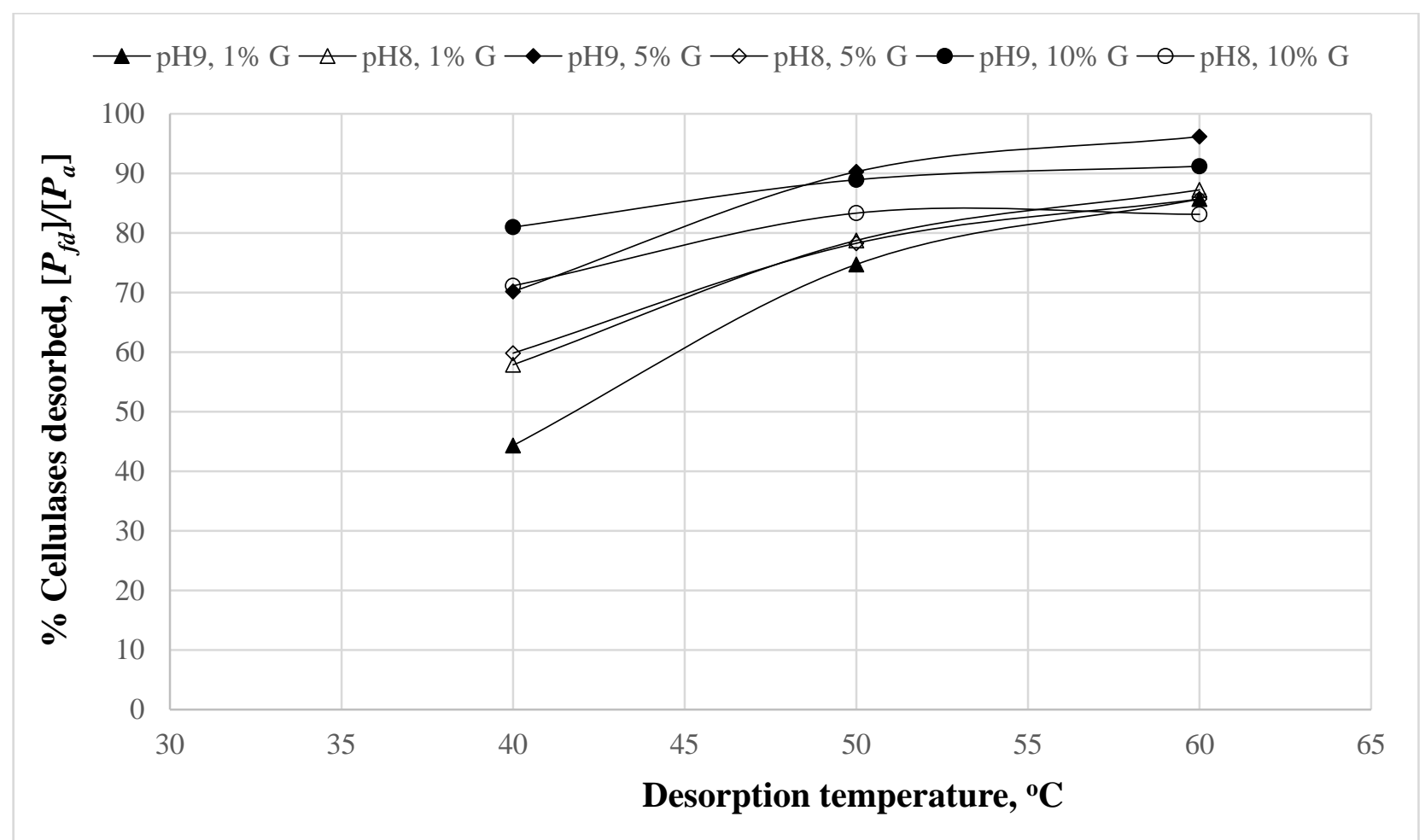

Figure 38 : Desorption of cellulases from Avicel by using glycerol (1\%, $5 \%$ and $10 \%)$, pH 8 and $\mathrm{pH} 9$, temperature $\left(40^{\circ} \mathrm{C}, 50^{\circ} \mathrm{C}\right.$ and $\left.60^{\circ} \mathrm{C}\right), 100 \mathrm{rpm}$ and maximum error shown at $95 \%$ probability

The next closest values for same conditions with $10 \%$ glycerol were around $91 \%$ while the maximum desorbed at $\mathrm{pH} 9$ and $60{ }^{\circ} \mathrm{C}$ without glycerol was around $75 \%$. Therefore, there was a 16$26 \%$ enhanced desorption of cellulases from Avicel using glycerol.

Activity of the cellulases desorbed are given in Figure 39. All data points were measured individually and were average of 5 replicates. The maximum activity was achieved was around $47 \mathrm{FPU} \mathrm{mL}^{-1}$ at $\mathrm{pH} 9$ with $5 \%$ and $10 \%$ glycerol $60{ }^{\circ} \mathrm{C}$ which is around $91 \%$ of the activity of the adsorbed cellulases. Otter et al. (1988) observed that glycerol was an effective desorbent to desorb cellulases. The maximum desorption (68\%) of cellulases from Avicel was achieved at pH 10 with $10 \%$ glycerol while $57 \%$ desorption was achieved at pH 5 and $60 \%$ glycerol [Otter et al., 1988]. 


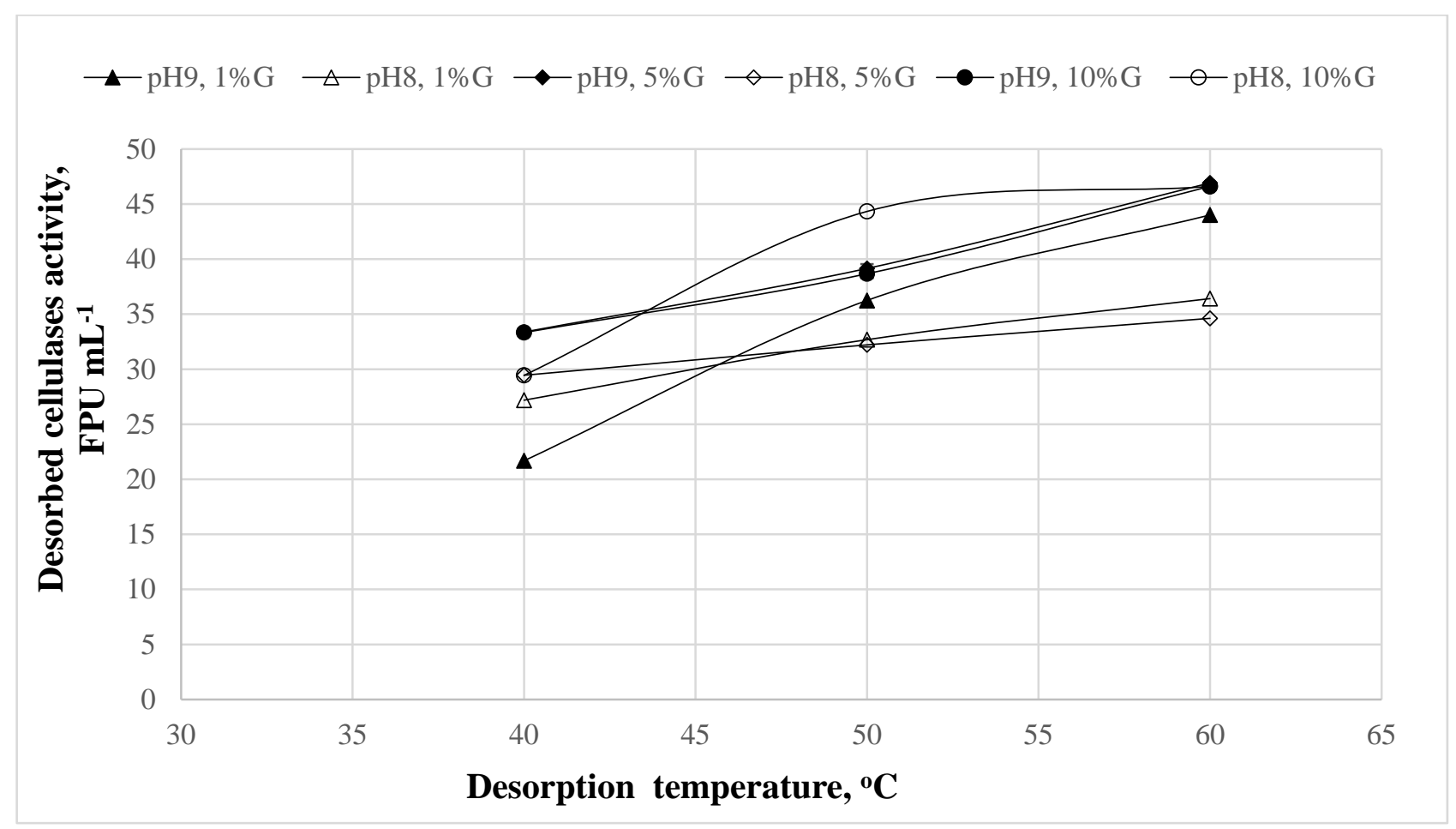

Figure 39 : Activity of cellulases desorbed from Avicel PH 101 by using glycerol (G $1 \%, 5 \%$ and $10 \%)$, pH 8 and $\mathrm{pH} 9$, temperature $\left(40{ }^{\circ} \mathrm{C}, 50{ }^{\circ} \mathrm{C}\right.$ and $\left.60^{\circ} \mathrm{C}\right), 100 \mathrm{rpm}$ and maximum error shown at $95 \%$ probability

Activities at $\mathrm{pH} 10$ and $\mathrm{pH} 5$ were not reported but it was stated that at $\mathrm{pH} 10.5$ all enzymes lost activity. Under vigorous industrial operational conditions it would be difficult to maintained the fine line $(\Delta \mathrm{pH}=0.5 \mathrm{pH})$ of $\mathrm{pH}$ control, therefore, our suggested technique is giving a safe $\mathrm{pH}$ to work with. This study also obtained more desorption than ever reported in literature, almost no loss of activity.

\section{Protobind 1000}

Figure 40 and Figure 41 shows desorption of cellulases from Protobind in the presence and varying concentrations of glycerol $(1 \%, 5 \%$, and $10 \%)$ and their activity, respectively. The maximum cellulases desorbed were around $66 \%$. Considering error bars it seems that at temperature $50{ }^{\circ} \mathrm{C}$ to $60{ }^{\circ} \mathrm{C}$ for both $\mathrm{pH} 8$ and $\mathrm{pH} 9$ almost similar '\% desorbed' of cellulases for all concentrations of glycerol. 


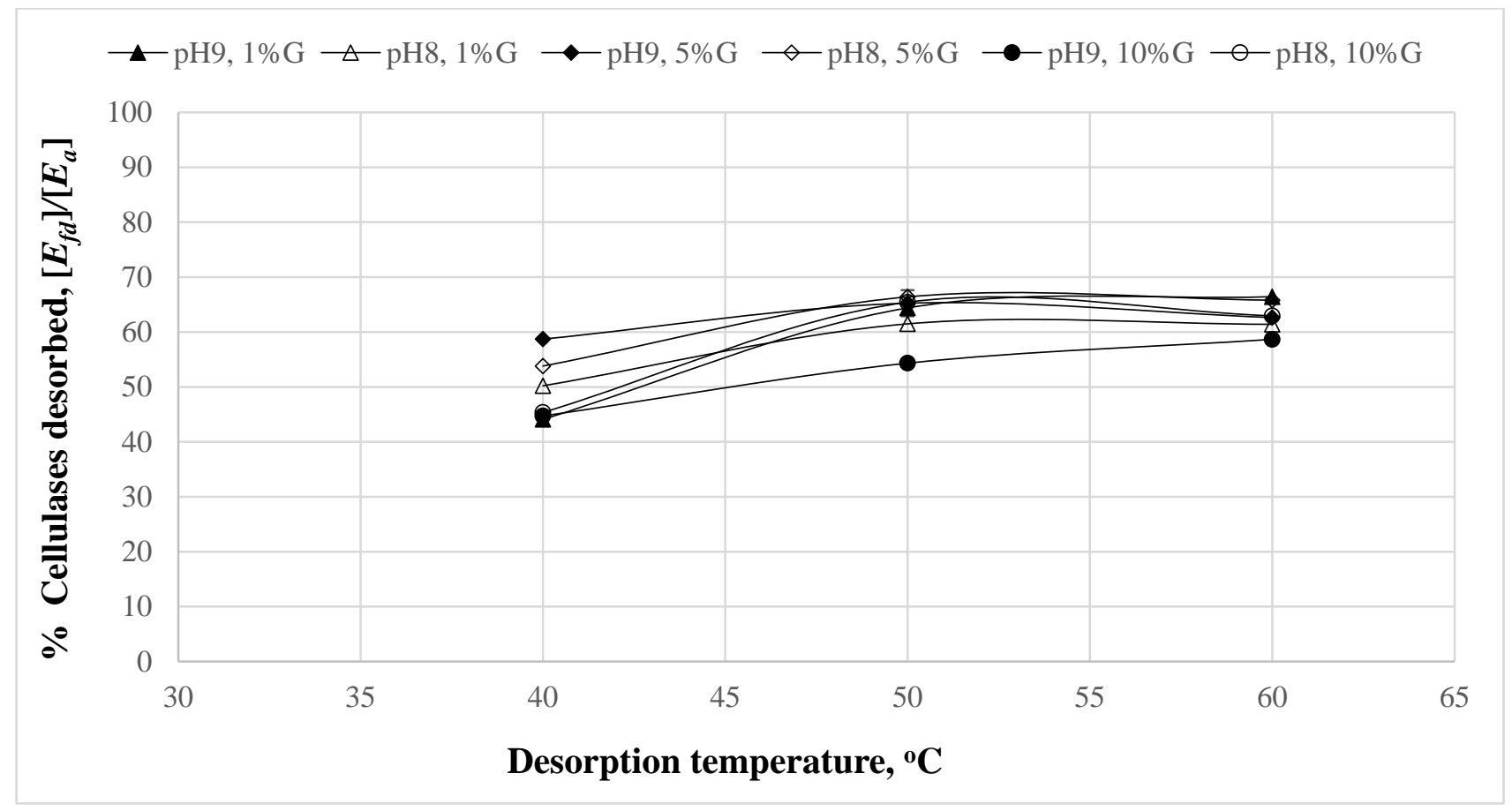

Figure 40 : Desorption of cellulases from Protobind 1000 by using glycerol (G $1 \%, 5 \%$ and $10 \%), \mathrm{pH} 8$ and $\mathrm{pH} 9$, temperature $\left(40^{\circ} \mathrm{C}, 50^{\circ} \mathrm{C}\right.$ and $\left.60^{\circ} \mathrm{C}\right), 100 \mathrm{rpm}$ and maximum error shown at $95 \%$ probability

Maximum \% desorption from Protobind without glycerol achieved in our studies was around $55 \%$, therefore a $10 \%$ more desorption was achieved with glycerol. Lu et al. (2002) reported that desorption of cellulases from lignin containing substrates were difficult. They could remove $30 \%$ and $65 \%$ of cellulases from steam exploded Douglas fir (lignin $46.1 \%$ ) hot alkali peroxide-treated Douglas fir ( $8.2 \%$ lignin) substrate. It is to be noted that the more lignin content $(46.1 \%)$ in a substrate the lesser was desorption (30\%) while Protobind 1000 has $100 \%$ lignin and with our techniques $65 \%$ lignin was desorbed. The maximum activity of \% desorbed cellulases achieved at $50{ }^{\circ} \mathrm{C}$ was $37 \mathrm{FPU} \mathrm{mL}^{-1}$ and $33 \mathrm{FPU} \mathrm{mL}^{-1}$ at $\mathrm{pH} 8$ (1\% glycerol) and $\mathrm{pH} 9$ (1\% glycerol) respectively. At $60{ }^{\circ} \mathrm{C}$ activity values was $33 \mathrm{FPU}$ at $\mathrm{pH} 9,5 \%$ glycerol which is almost the same as values reported for $50{ }^{\circ} \mathrm{C}$. 


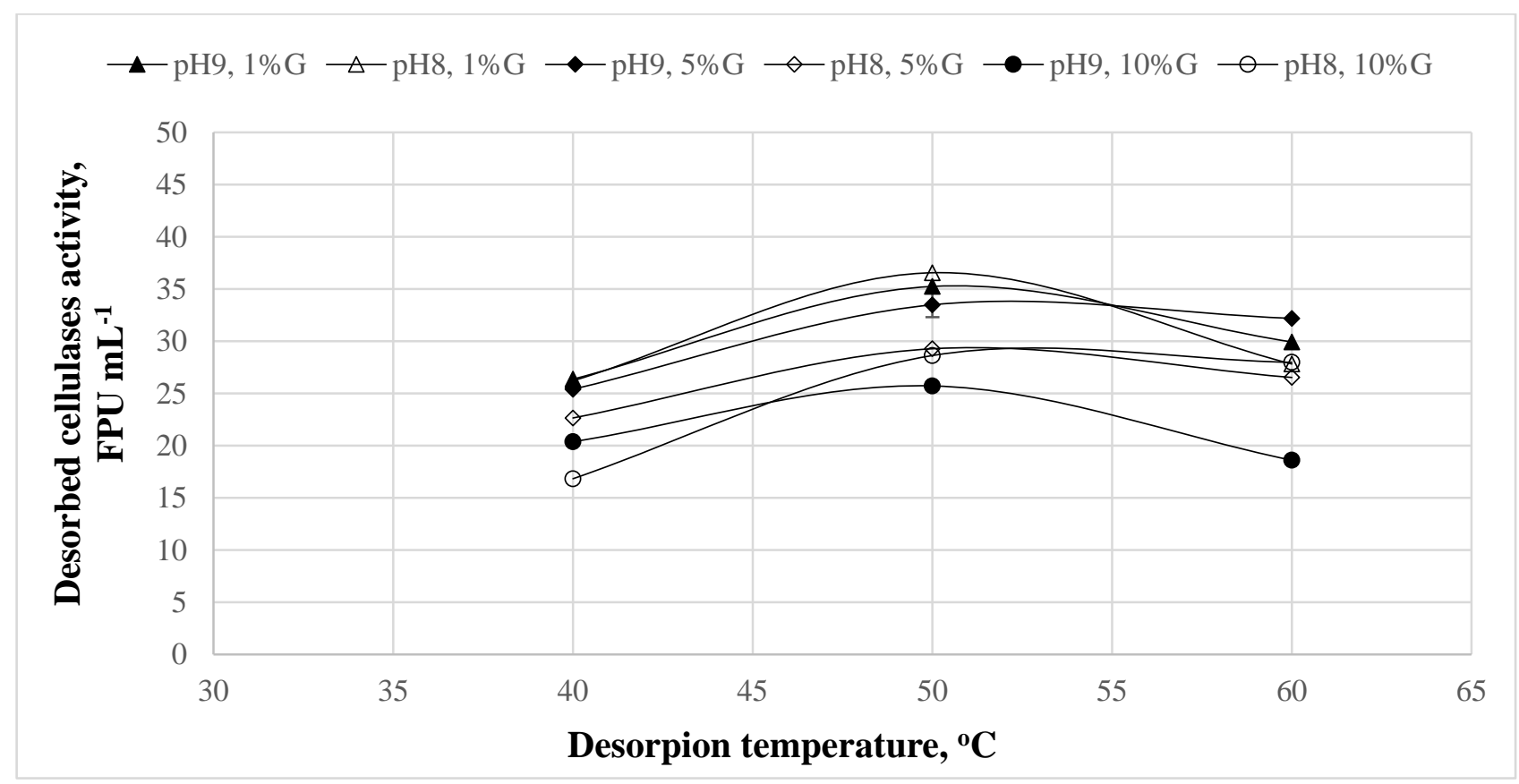

Figure 41 : Activity of desorbed of cellulases from Protobind 1000 by using glycerol (G $1 \%, 5$ $\%$ and $10 \%)$, pH 8 and $\mathrm{pH} 9$, temperature $\left(40{ }^{\circ} \mathrm{C}, 50^{\circ} \mathrm{C}\right.$ and $\left.60^{\circ} \mathrm{C}\right), 100 \mathrm{rpm}$ and maximum error shown at $95 \%$ probability

The maximum activity of desorbed cellulases achieved from Protobind without glycerol was around 17 FPU. It was also observed that $10 \%$ glycerol affect desorbed activity. Tu et al. (2007) find that the activity in the desorbed cellulases from ethanol-pretreated mixed softwood substrate (EPMS, $6 \%$ lignin) could not exceed from $35 \%$ even though they increased initial cellulases concentration from $25 \%$ to $51 \%$ (almost twice). The increased initial cellulases concentration to get better results were based on the assumption that there was product inhibition [Berlin et al., 2005] which did not worked. In our technique addition of $5 \%$ glycerol increased activity of desorbed cellulases from 17 FPU mL $\mathrm{mL}^{-1}$ to $37 \mathrm{FPUmL}^{-1}$ which is approximately double.

\subsubsection{Ethylene Glycol}

The impact of addition of ethylene glycol on desorption of cellulases from Avicel PH 101 and Protobind 1000 was studied. The concentration of glycerol used was $1 \%, 5 \%$, and $10 \%$ 


\section{Avicel PH 101}

Figure 42 shows amount of cellulases desorbed from Avicel PH 101 in the presence of ethylene glycol. All the data points were average of 5 replicates and measured separately.

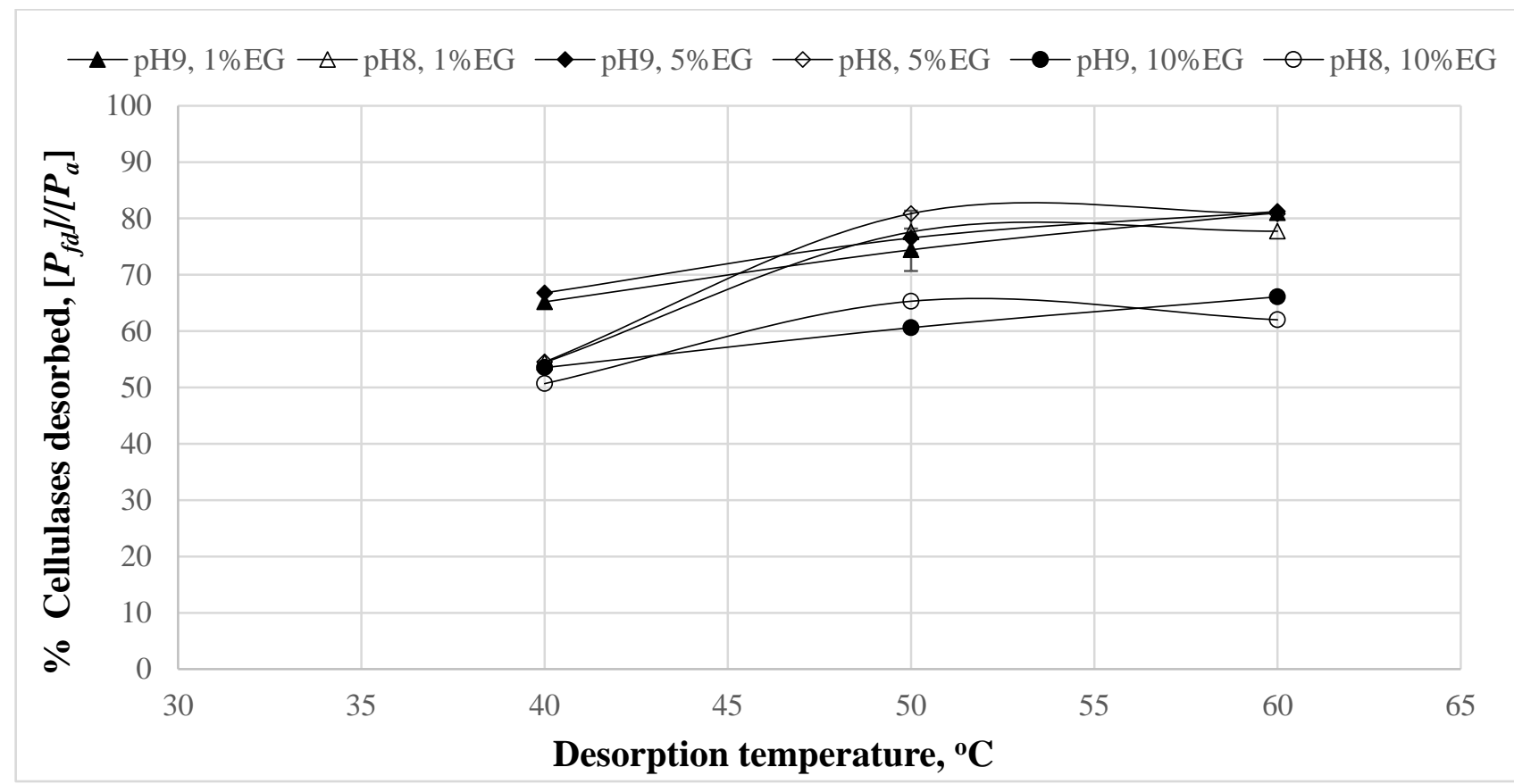

Figure 42: Desorption of cellulases from Avicel PH 101by using ethylene glycol (EG $1 \%, 5 \%$ and $10 \%)$, $\mathrm{pH} 8$ and $\mathrm{pH} 9$, temperature $\left(40{ }^{\circ} \mathrm{C}, 50^{\circ} \mathrm{C}\right.$ and $\left.60^{\circ} \mathrm{C}\right), 100 \mathrm{rpm}$ and maximum error shown at $95 \%$ probability

Maximum $\%$ desorbed cellulases were achieved at $60{ }^{\circ} \mathrm{C}$ for $\mathrm{pH} 9,1 \% \mathrm{EG}$ and $5 \% \mathrm{EG}$ and the increase in \% desorbed cellulases was $35 \%$ with no glycerol. Addition of $10 \%$ ethylene glycerol had a small increase of $15 \%$ desorption. The maximum \% desorbed from EG (80\%) was $10 \%$ less than maximum \% desorbed from glycerol. Figure 43 shows activity of cellulases desorbed from Avicel $\mathrm{PH}$. All the data points were average of 5 replicates and measured separately. At $60{ }^{\circ} \mathrm{C}$ with $\mathrm{pH} 8$, $1 \% \mathrm{EG}$ and $\mathrm{pH} 95 \% \mathrm{EG}$ have activity of $37 \mathrm{FPU} \mathrm{mL}^{-1}$ and $38 \mathrm{FPU} \mathrm{mL}^{-1}$ respectively. The activity values were which is $2-5 \%$ lower than the activity achieved without addition of EG. The minimum activity was achieved with $\mathrm{pH} 9$ with $10 \% \mathrm{EG}$ at $60{ }^{\circ} \mathrm{C}$ which is $34 \mathrm{FPU} \mathrm{mL} \mathrm{m}^{-1}$ which was about 12 
$\%$ less than the maximum activity achieved with the addition of glycerol. Therefore addition of EG did not produced any significant increase in activity for desorbed cellulases from Avicel.

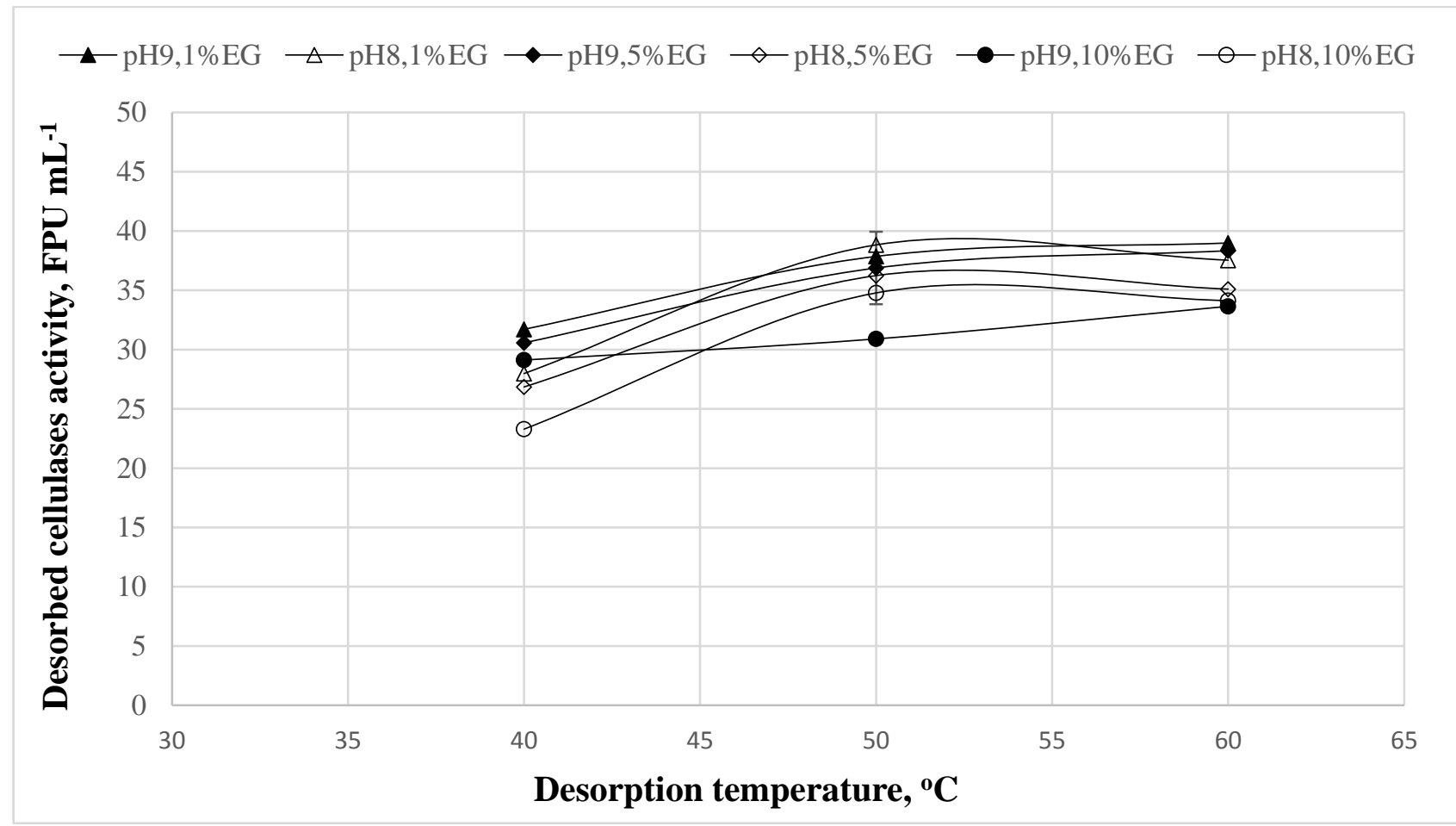

Figure 43 : Activity of desorbed cellulases from Avicel by using ethylene glycol (EG, $1 \%, 5 \%$ and $10 \%)$, $\mathrm{pH} 8$ and $\mathrm{pH} 9$, temperature $\left(40{ }^{\circ} \mathrm{C}, 50{ }^{\circ} \mathrm{C}\right.$ and $\left.60^{\circ} \mathrm{C}\right), 100 \mathrm{rpm}$ and maximum error shown at $95 \%$ probability

\section{Protobind 1000}

Figure 44 shows \% desorbed from Protobind in the presence of ethylene glycol. All the data points were average of 5 replicates and measured by separately conducted experiments. The maximum of $\%$ desorbed was achieved at $\mathrm{pH} 8$ and 9 at $50{ }^{\circ} \mathrm{C}$ to $60{ }^{\circ} \mathrm{C}$ with $1 \% \mathrm{EG}$ i.e. around $62 \%$ of the cellulases adsorbed on Protobind. In comparison with the cellulases desorbed from Protobind without use of EG it was $14 \%$ higher. 


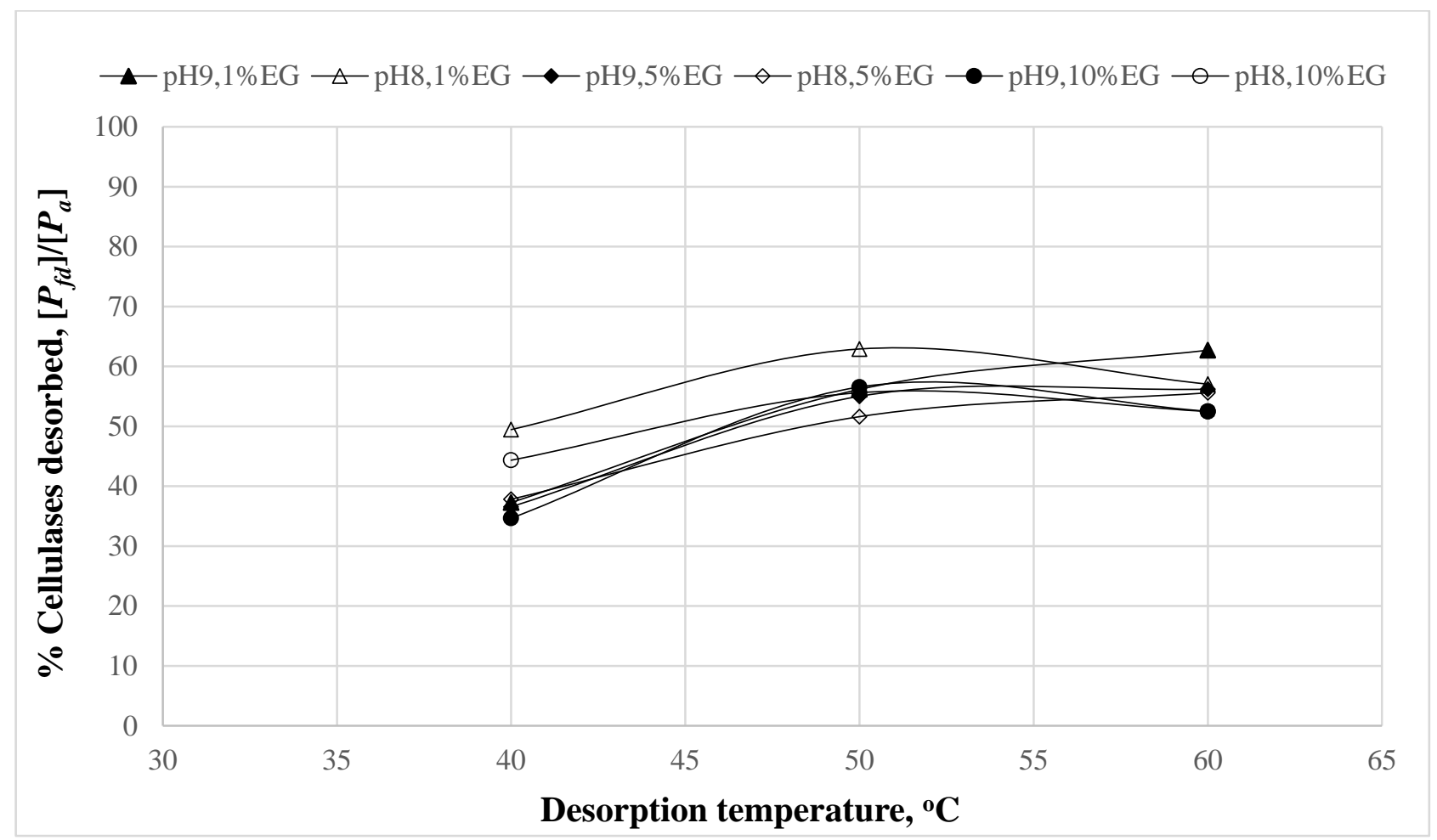

Figure 44 : Desorption of cellulases from Protobind 1000 by using ethylene glycol (EG $1 \%, 5$ $\%$ and $10 \%)$, pH 8 and $\mathrm{pH} 9$, temperature $\left(40{ }^{\circ} \mathrm{C}, 50^{\circ} \mathrm{C}\right.$ and $\left.60^{\circ} \mathrm{C}\right), 100 \mathrm{rpm}$ and maximum error shown at $95 \%$ probability

Zhu et al. (2009) reported desorption of cellulases (Spezyme CP) from Avicel and dilute acid treated corn stover as $81 \%$ and $74 \%$ respectively, with using $72 \%$ EG. The activity of the desorbed cellulases was not reported either. Since the aim of this research was to reuse active desorbed cellulase economically, the use of $72 \%$ of EG was not feasible. In Figure 45 activity of the cellulases desorbed from Protobind is given. Maximum desorption was achieved at $50{ }^{\circ} \mathrm{C}$ than other temperatures with $5 \%$ glycerol at $\mathrm{pH} 9$ i.e., $24 \mathrm{FPU} \mathrm{mL}^{-1}$ which is $48 \%$ of the activity of the cellulases adsorbed. The activity of the maximum desorbed was only 7 units higher than the activity archived without using EG. 


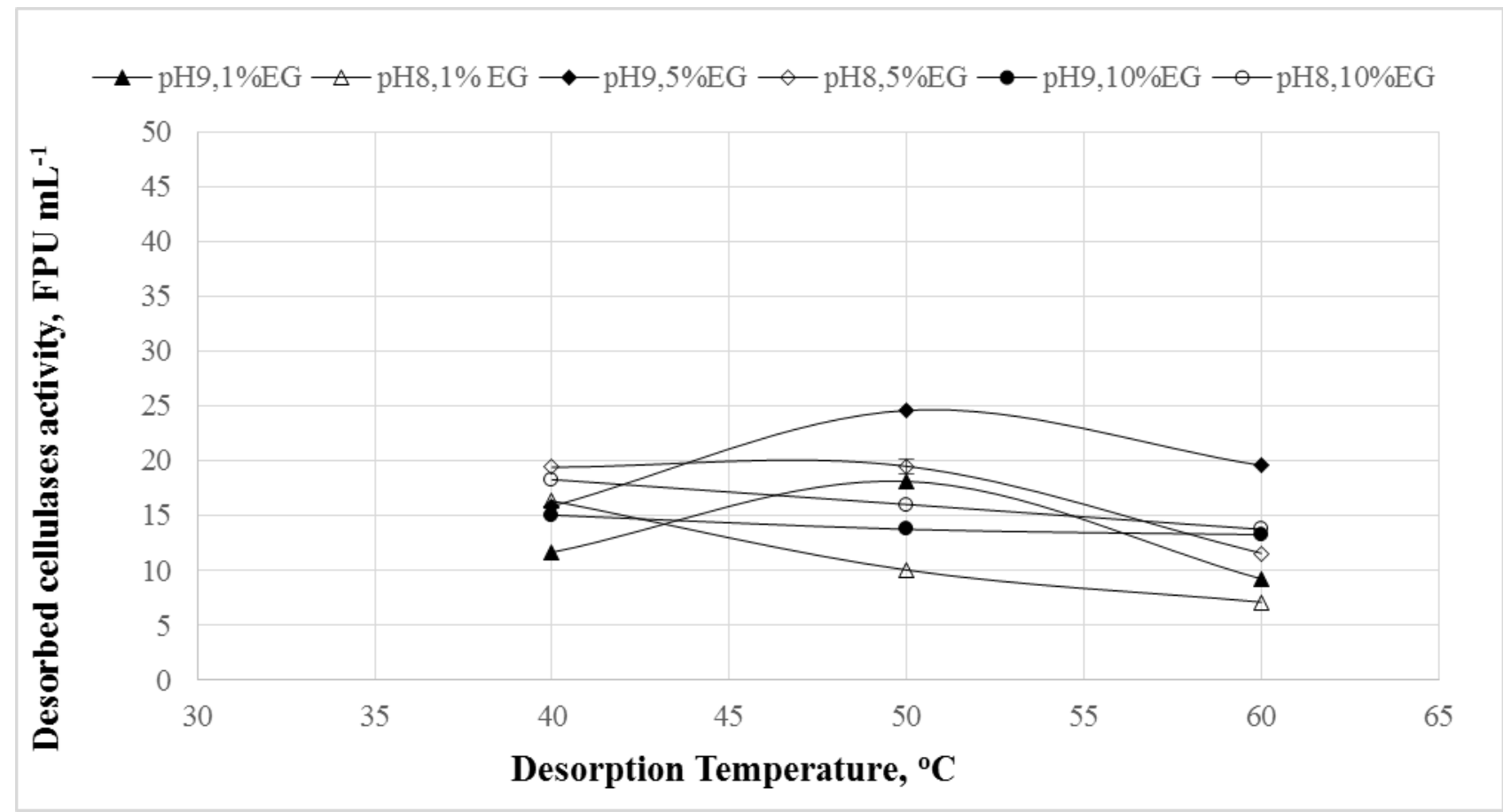

Figure 45: Activity of desorbed cellulases from Protobind 1000 by using ethylene glycol (EG 1 $\%, 5 \%$ and $10 \%), \mathrm{pH} 8$ and $\mathrm{pH} 9$, temperature $\left(40{ }^{\circ} \mathrm{C}, 50^{\circ} \mathrm{C}\right.$ and $\left.60{ }^{\circ} \mathrm{C}\right), 100 \mathrm{rpm}$ and maximum error shown at $95 \%$ probability

The activity of the desorbed with EG from $\mathrm{pH} 9$ at $10 \% \mathrm{EG}$ and from $\mathrm{pH} 8$ at $5 \%$ and $10 \% \mathrm{EG}$ showed no improvement in the \% desorption of cellulases from Protobind.

\subsection{3 $\beta$-Glucosidase}

\section{Avicel PH 101}

The amount of cellulases desorbed in the presence of $5 \%, 10 \%$ and $18 \% \beta$-glucosidase (BG), of the concentration of cellulases used, from Avicel PH 101 is shown Figure 46 and Figure 47 gave $\%$ of cellulases desorbed and the activity of the desorbed cellulases at temperature of $40{ }^{\circ} \mathrm{C}, 50{ }^{\circ} \mathrm{C}$ and $60^{\circ} \mathrm{C}$, respectively. All the data points were average of 5 replicates and measured by separately conducted experiments. 


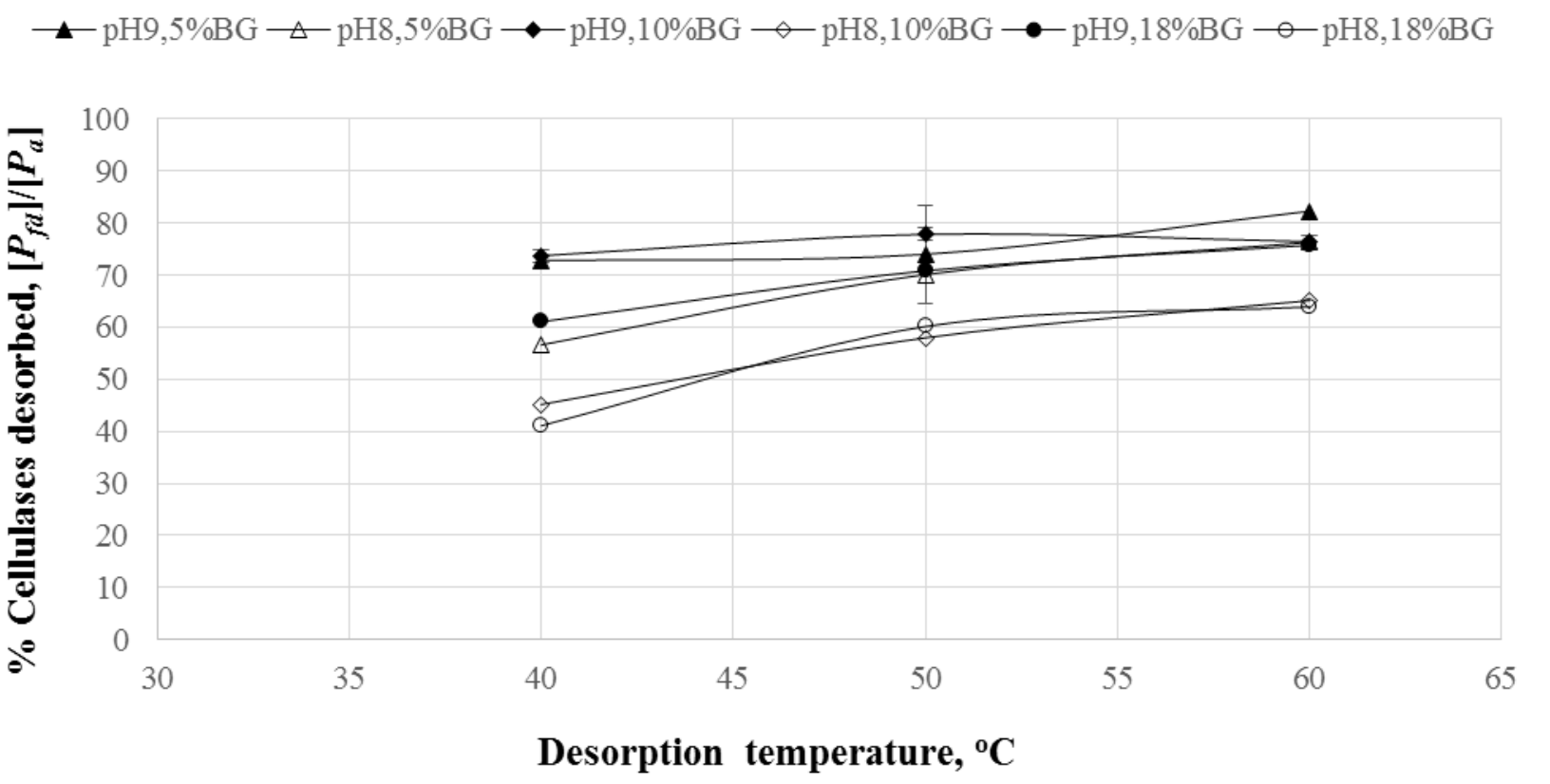

Figure 46 : Desorption of cellulases from Avicel by using $\beta$-glucosidases (BG $5 \%, 10 \%$ and $18 \%)$, pH 8 and pH 9, temperature $\left(40^{\circ} \mathrm{C}, 50^{\circ} \mathrm{C}\right.$ and $\left.60^{\circ} \mathrm{C}\right), 100 \mathrm{rpm}$ and maximum error shown at $95 \%$ probability

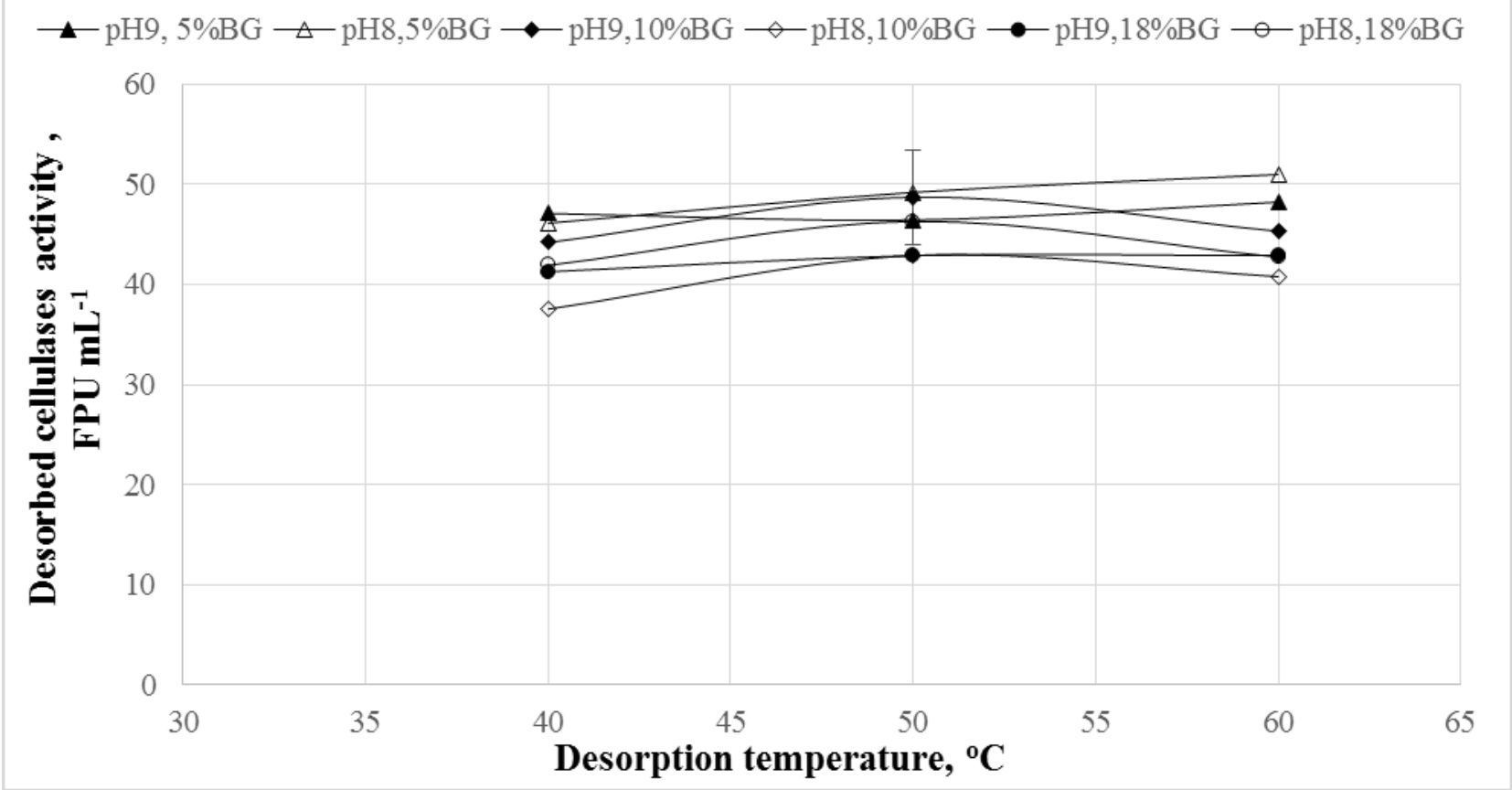

Figure 47: Activity of the desorbed cellulases from Avicel by using $\beta$-glucosidases (BG, $5 \%$, $10 \%$ and $18 \%), \mathrm{pH} 8$ and $\mathrm{pH} 9$, temperature $\left(40^{\circ} \mathrm{C}, 50^{\circ} \mathrm{C}\right.$ and $\left.60^{\circ} \mathrm{C}\right), 100 \mathrm{rpm}$ and maximum error shown at $95 \%$ probability 
The maximum cellulases desorbed $82 \%$ at $\mathrm{pH} 9,60{ }^{\circ} \mathrm{C}$ and $5 \% \beta$-glucosidases (BG). Desorption at $\mathrm{pH} 9$, with $10 \%$ and was almost the same for all temperature range from $40{ }^{\circ} \mathrm{C}$ to $60{ }^{\circ} \mathrm{C}(73 \%$ to 77 $\%)$. The maximum desorption with BG $9 \%$ higher than that obtained without $\beta$-glucosidase. Figure 42 gave activity of the desorbed cellulases from Avicel. All the data points were average of 5 replicates and measured by separately conducted experiments. The maximum activity obtained was $50 \mathrm{FPU} \mathrm{mL} \mathrm{m}^{-1}$ for $5 \%$ of $\beta$-glucosidase used at $60^{\circ} \mathrm{C}, \mathrm{pH} 8$ which is almost the same as at $\mathrm{pH} 9(48$ FPU $\mathrm{mL}^{-1}$ ) under same conditions. The maximum activity obtained is almost the same as that obtained by using glycerol.

\section{Protobind 1000}

Figure 48 shows the $\%$ of cellulases desorbed from Protobind under the influence of BG. All the data points were average of 5 replicates and measured by separate experiments.

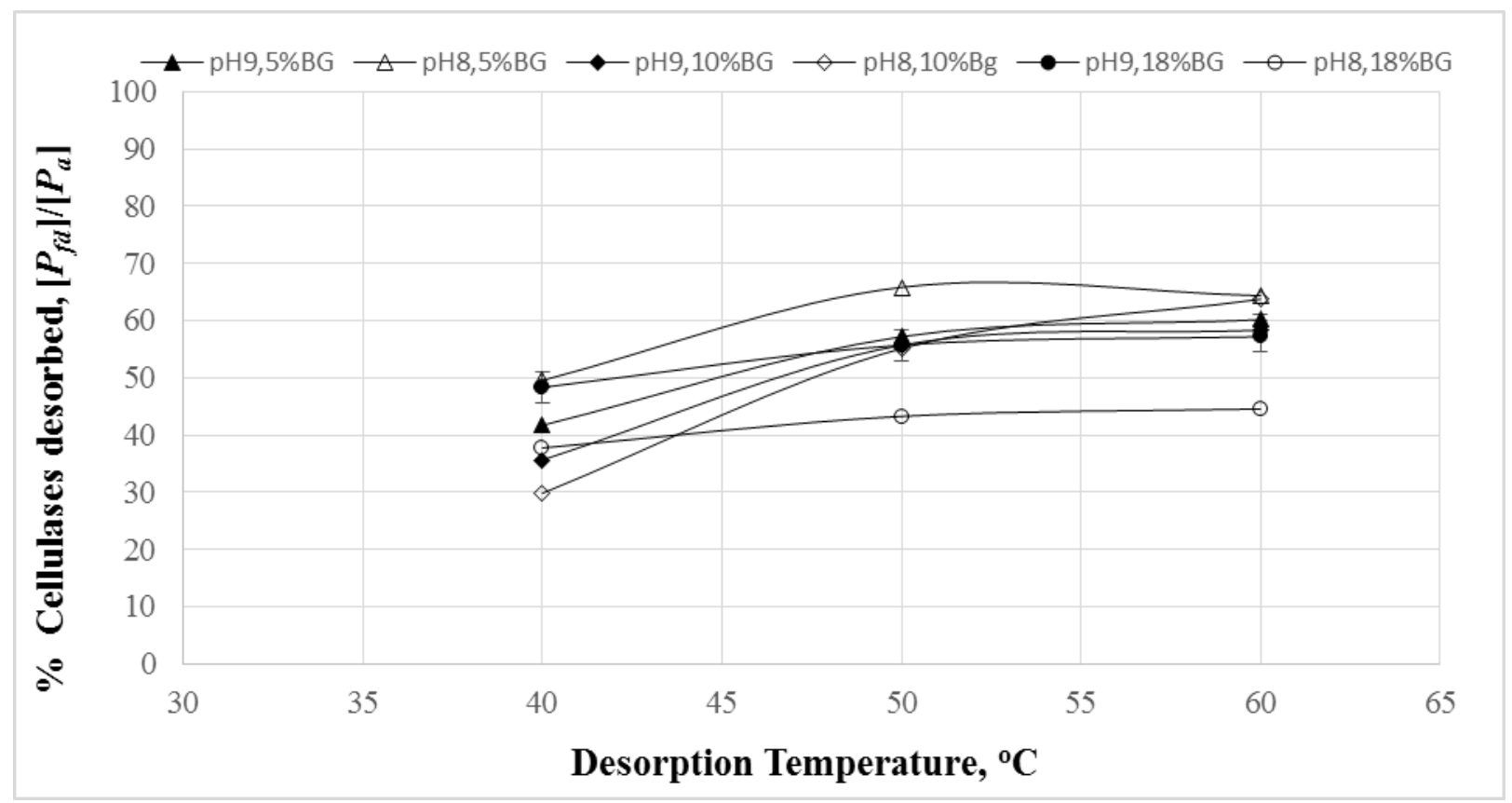

Figure 48 : Desorption of cellulases NS 50013 from Protobind 1000 by using $\beta$-glucosidases (BG, $5 \%, 10 \%$ and $18 \%)$, pH 8 and pH 9, temperature $\left(40{ }^{\circ} \mathrm{C}, 50{ }^{\circ} \mathrm{C}\right.$ and $\left.60{ }^{\circ} \mathrm{C}\right)$, and 100 rpm and maximum error shown at $95 \%$ probability 
The plots showed the trend that desorption increased from $40{ }^{\circ} \mathrm{C}$ to $50{ }^{\circ} \mathrm{C}$ and somehow it remained the same till $60{ }^{\circ} \mathrm{C}$. The maximum cellulases desorbed $65 \%$ for $\mathrm{pH} 8$ and $\mathrm{pH} 9$ for $5 \%$ addition of BG.

Figure 49 shows the activity of cellulases desorbed from Protobind under the influence of BG. All the data points were average of 5 replicates and measured by separately. The maximum activity of desorbed cellulases achieved at $\mathrm{pH} 9,5 \% \mathrm{BG} 50{ }^{\circ} \mathrm{C}$ was $29 \mathrm{FPU} \mathrm{mL}^{-1}$. The activity of desorbed cellulases by $\mathrm{pH} 8$ and $\mathrm{pH} 9$ with $5 \% \mathrm{BG}$ in the temperature range from $40{ }^{\circ} \mathrm{C}$ to $60{ }^{\circ} \mathrm{C}$ appear to be similar.

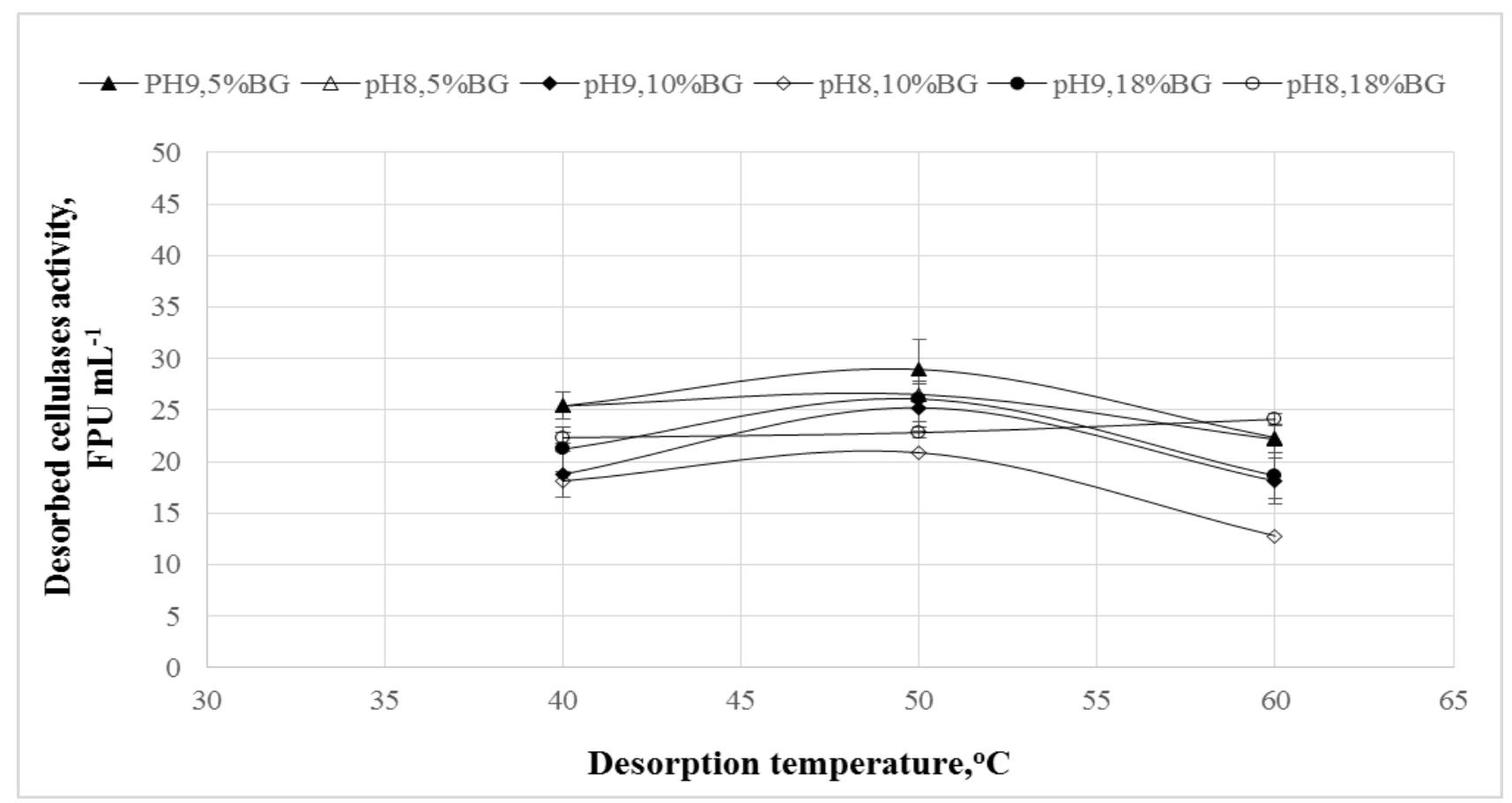

Figure 49 : Activity of the desorbed cellulases NS 500113 from Avicel PH 101 using $\beta$ glucosidases (BG, $5 \%, 10 \%$ and $18 \%), \mathrm{pH} 8$ and $\mathrm{pH}$ 9, temperature $\left(40{ }^{\circ} \mathrm{C}, 50{ }^{\circ} \mathrm{C}\right.$ and 60 $\left.{ }^{\circ} \mathrm{C}\right), 100 \mathrm{rpm}$ and maximum error shown at $95 \%$ probability

The maximum \% desorbed from Avicel at $\mathrm{pH} 8$ or $\mathrm{pH} 9$ at temperature $60{ }^{\circ} \mathrm{C}$ by using $5 \%$ glycerol was $85 \%$ and $96 \%$ with activity of 35 and $47 \mathrm{FPU} \mathrm{mL}^{-1}$. The maximum \% desorbed from Protobind at $\mathrm{pH} 8$ or $\mathrm{pH} 9$ at temperature $60{ }^{\circ} \mathrm{C}$ by using $5 \%$ glycerol was $66 \%$ and $63 \%$ with activity of 32 
FPU $\mathrm{mL}^{-1}$ and $26 \mathrm{FPU} \mathrm{mL} \mathrm{m}^{-1}$. Using $5 \% \beta$-glucosidase showed $82 \%$ desorption from Avicel and from Protobind it was $60 \%$ at $\mathrm{pH} 9$ almost the same at $\mathrm{pH}$. The activity with $5 \% \beta$-glucosidase was $22 \mathrm{FPU} \mathrm{mL}^{-1}$ and $28 \mathrm{FPU} \mathrm{mL}^{-1}$ at $60^{\circ} \mathrm{C}$ and $50{ }^{\circ} \mathrm{C}$. Glycerol provided $6 \%$ more cellulases desorbed from Protobind than that of $\beta$-glucosidase and $45 \%$ more activity at $60{ }^{\circ} \mathrm{C}$ and $15 \%$ more activity at $50{ }^{\circ} \mathrm{C}$. Therefore, from the exhausted feed stock from bioethanol producing industry, desorption of cellulases should be achieved by using $5 \%$ glycerol at $\mathrm{pH} 8$ or $\mathrm{pH} 9$ and temp $50{ }^{\circ} \mathrm{C}$ to $60{ }^{\circ} \mathrm{C}$. Therefore, desorption of active cellulases can be enhanced by use of $5 \%$ glycerol. 


\subsection{Application of novel desorption strategy on Lignocellulosic material Adsorption of cellulases on wheat straw}

Figure 50 shows the concentration of cellulases adsorbed $\left[P_{a}\right]$ on wheat straw at $\mathrm{pH} 5,25{ }^{\circ} \mathrm{C}$ temperature, $100 \mathrm{rpm}$ is given along $\mathrm{y}$-axis for varying adsorption time from 0 to 120 minutes. Each data point was measured individually. All the results were triplicates. In the start adsorption was rapid and increased with increasing time. Almost half of the cellulases adsorbed at equilibrium was adsorbed in first 5 minutes. Similar adsorption pattern is reported in literature [Steiner et al., 1988; Sing et al., 1991; Zeng et al., 2013]. The increase in adsorption time brought adsorption to an equilibrium at 40 minutes after that further increasing adsorption time the amount of cellulases adsorbed almost remained the same. The equilibrium time was important for desorption studies.

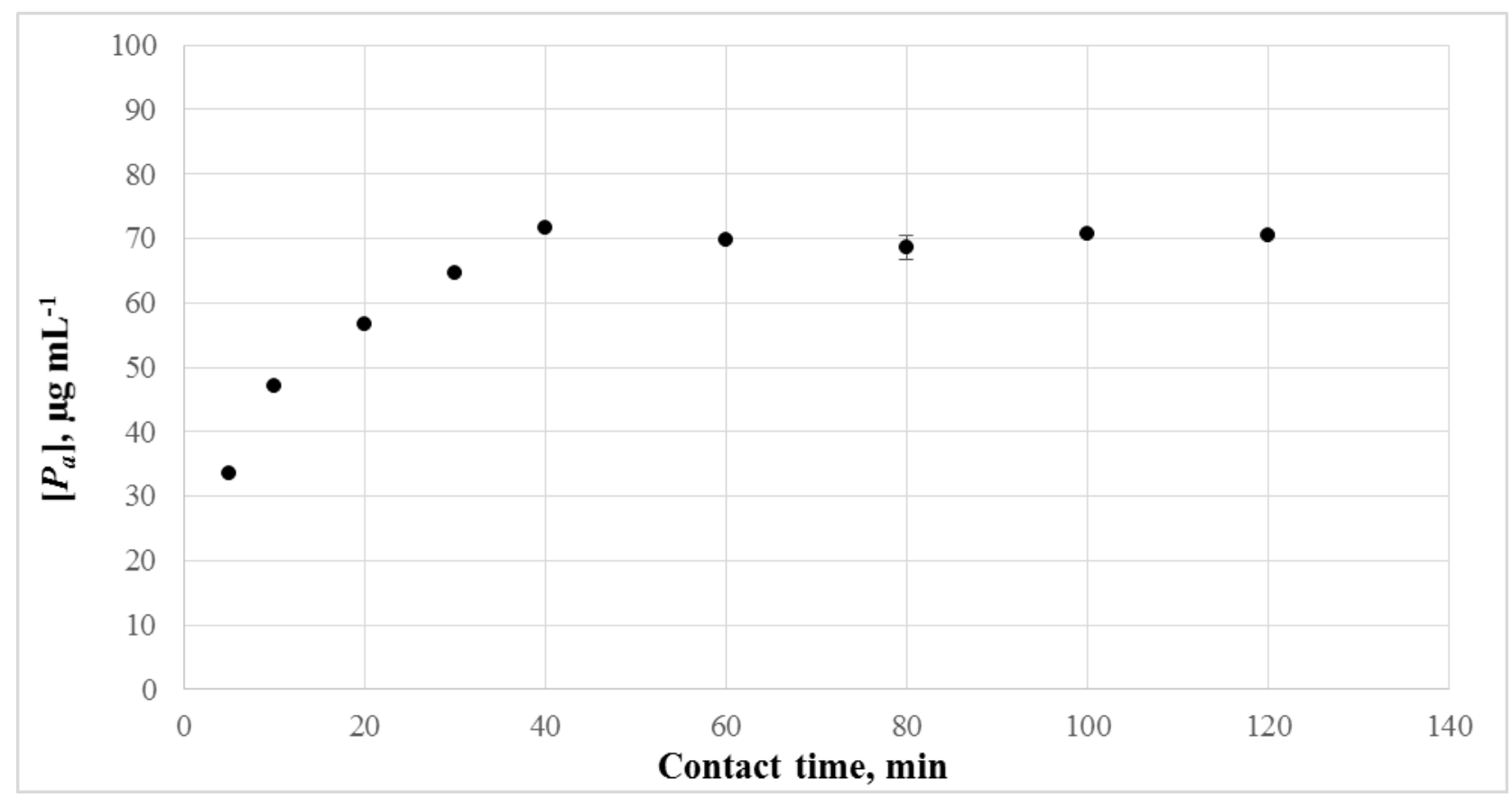

Figure 50 : Adsorption of cellulases NS 50013 onto wheat straw $(0.5 \mathrm{~mm})$ at $\mathrm{pH} 5,25^{\circ} \mathrm{C}, 100$ $\mathrm{rpm}, E_{0}=250 \mu \mathrm{g} \mathrm{mL} \mathrm{m}^{-1}$ and maximum error shown at $95 \%$ probability

Adsorption equilibrium time depends on substrate type, enzymes type and adsorption conditions. For example, Singh et al. (1991) has reported adsorption equilibrium time for Avicel as 30 minutes while in our studies it was 20 minutes for Avicel and 45 minutes for Protobind. Tu et al. (2009) reported 
adsorption equilibrium time of cellulase onto enzyme pretreated lignin obtained from ethanolpretreated Lodgepole pine (EPLP), but not on steam-exploded Lodgepole pine (SELP) as 3 hours. The equilibrium adsorption time on EPLP and SEPLP substrates was 30-60 minutes. Adsorption of pure cellulases components CBH I, EG I, EG II, and EG III on SolkaFloc was reported as $60 \mathrm{~min}$ [Kyriacos et al., 1988]. Li et al. (2011) showed that the equilibrium time for adsorption of Accelerase 1000 to lignocellulosic substrate was reported to be $45 \mathrm{~min}$ for delignified corncobs and $60 \mathrm{~min}$ for isolated lignin. Adsorption equilibrium time on raw biomass was not available in literature therefore it was not compared. But it was observed that the untreated lignocellulosic substrates even with high lignin content had slower adsorption than that onto cellulose. The equilibrium time of adsorption was used to set adsorption time for the desorption studies. Figure 51 shows results 7 pre-adsorbed samples and blanks a subjected to desorption at $25^{\circ} \mathrm{C}$ at $\mathrm{pH} 5$.

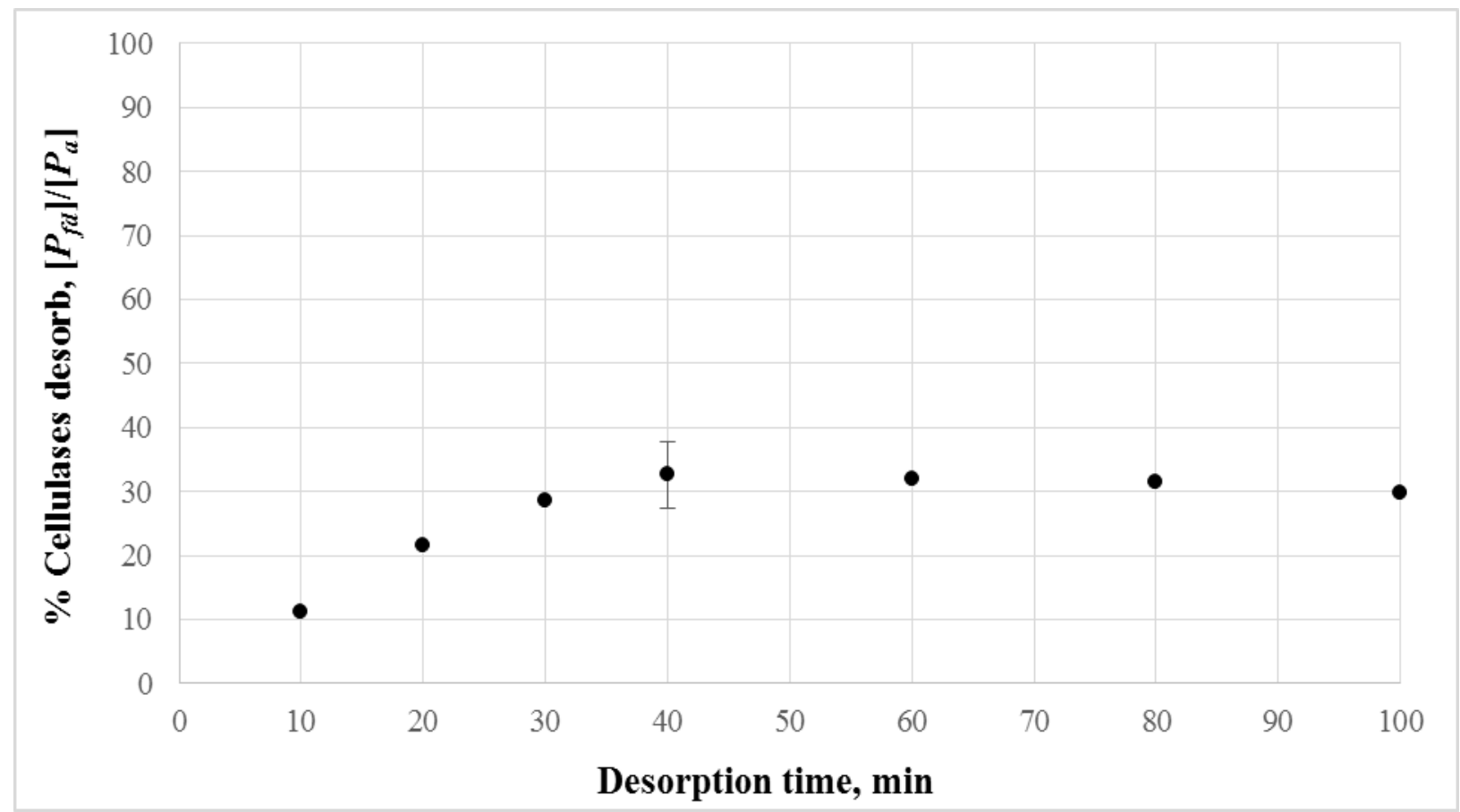

Figure 51 : Desorption of cellulases at $\mathrm{pH} 5,25^{\circ} \mathrm{C}$, and $100 \mathrm{rpm}$, from wheat straw and maximum error shown at $95 \%$ probability 
Each data point is an average of triplicate measured individually. The cellulases desorption started maintaining its maximum desorption at $30 \mathrm{~min}$. For further desorption studies 40 minutes were taken as desorption equilibrium time for cellulases from wheat straw samples.

After knowing adsorption equilibrium time and desorption equilibrium time, experiments were conducted at $\mathrm{pH} 9$ and $60{ }^{\circ} \mathrm{C}$ to determine $\%$ desorbed cellulases. Figure 52 shows $\%$ cellulases desorption and activity $\left(\mathrm{FPU} \mathrm{mL} \mathrm{m}^{-1}\right)$ of desorbed cellulase from wheat straw. The results from wheat straw were further compared with the same parameters from Avicel PH 101 and Protobind 1000 at the same conditions.

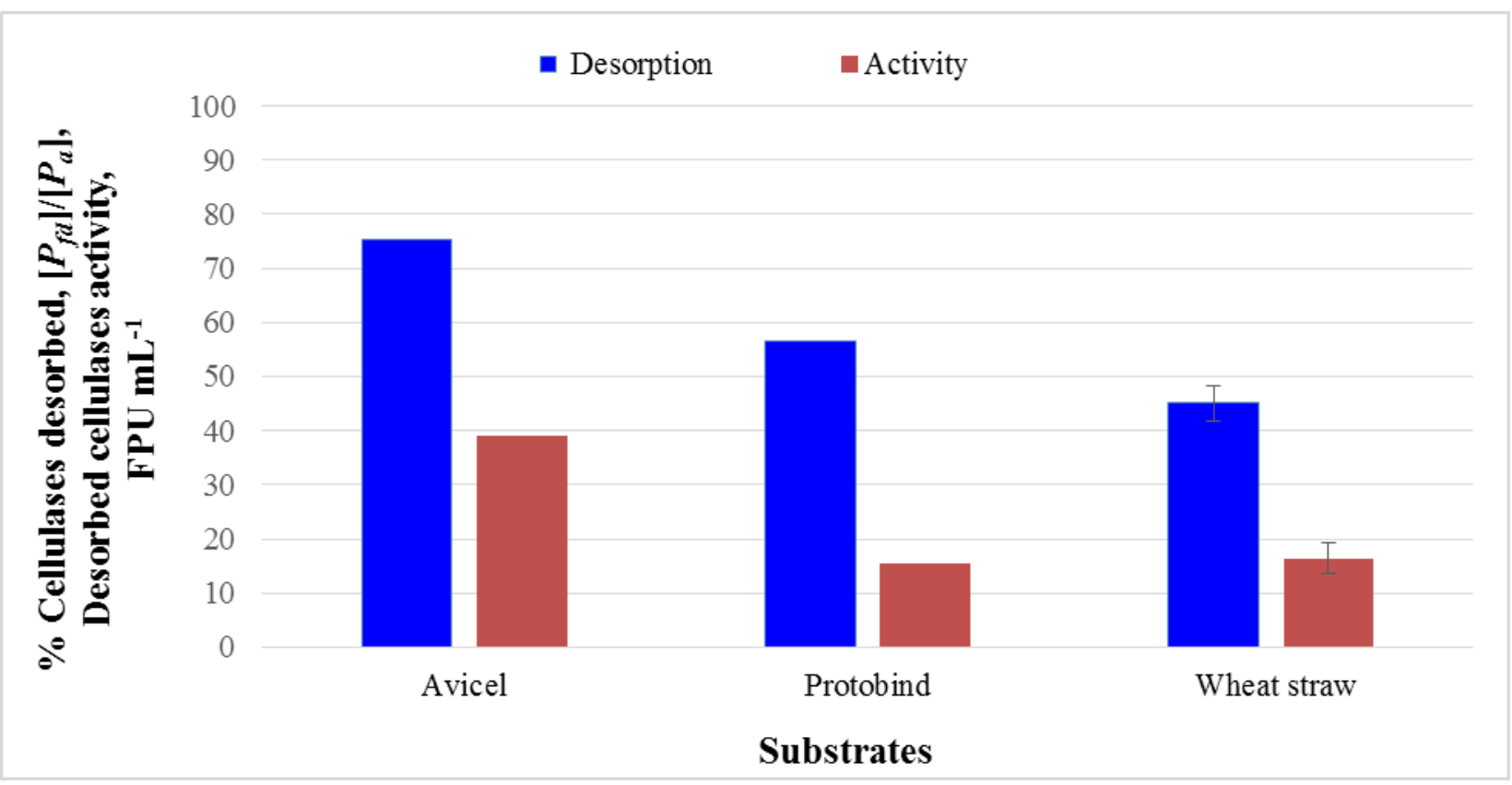

Figure 52 : Comparison of desorbed cellulases and activity of the desorbed cellulases among substrates at $\mathrm{pH} \mathrm{9,60}{ }^{\circ} \mathrm{C}, 100 \mathrm{rpm}$ and maximum error bar shown at $95 \%$ probability

The $\%$ desorbed cellulases from wheat straw were $30 \%$ less than those obtained from pure cellulose (i.e. Avicel). The activity of the desorbed cellulases was about $58 \%$ less than that of Avicel. The \% desorbed cellulases from Protobind were $10 \%$ higher than that of wheat straw which could be due to the structure of raw wheat straw which is more porous that than that of Protobind. In porous 
substrates enzymes get trapped in some of the pores. The activity of cellulases desorbed is almost the same as that of Protobind. Desorption from untreated lignocellulosic material (wheat straw) gives less desorption and activity than the pure cellulose and lignin.

\section{Desorption from 30\% delignified wheat straw (DWS)}

Figure 53 shows \% desorption and activity (FPU) of desorbed cellulase from $30 \%$ delignified wheat straw. The results from $30 \%$ DWS were further compared with the \% desorbed and activity of the desorbed cellulases at different experimental conditions. Each data point was measured separately and was an average of triplicates of a set of 5 tests $(3 \times 5=15)$.

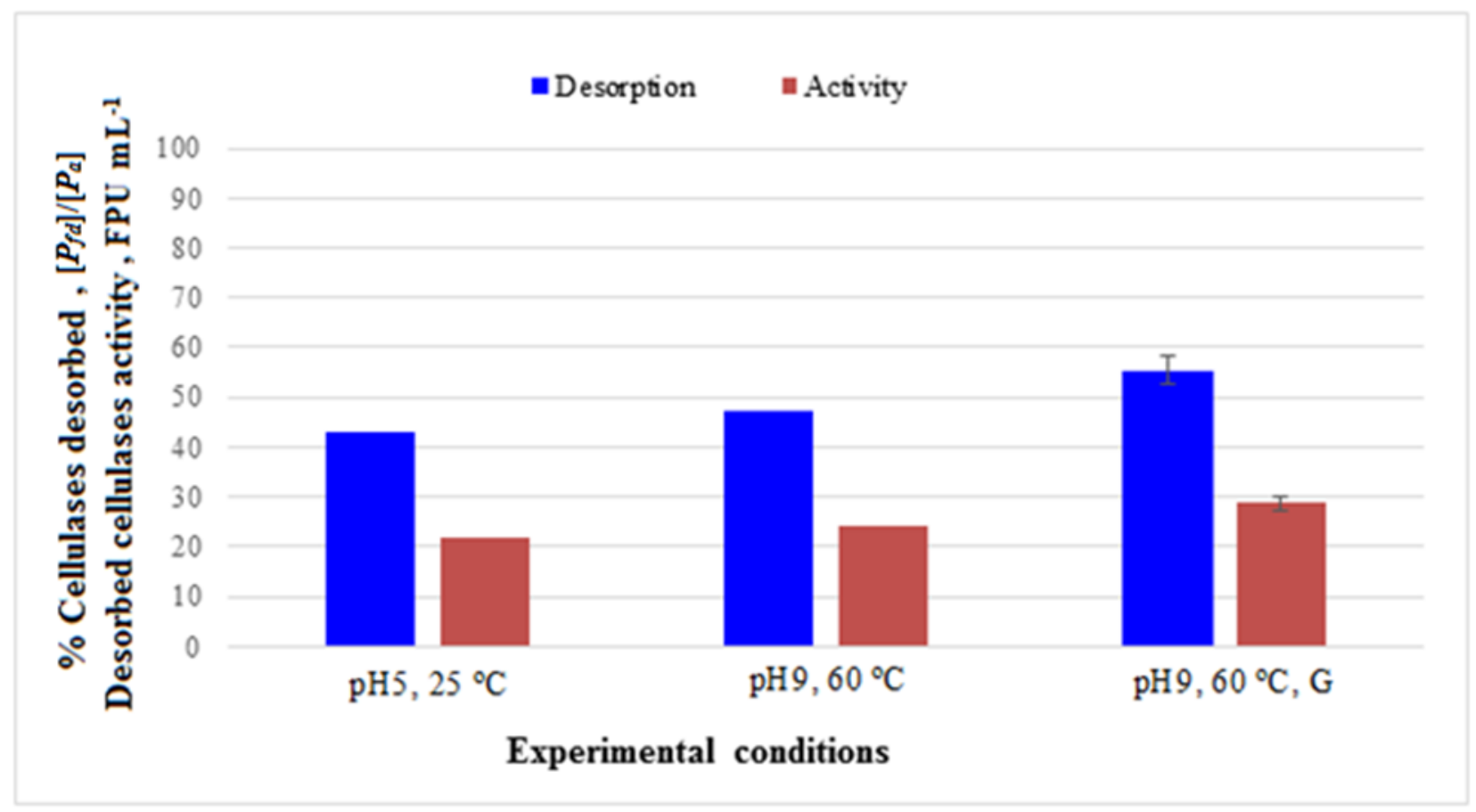

Figure 53 : Comparison of $\%$ desorbed and activity of the desorbed cellulases from $30 \%$ delignified wheat straw and different experimental conditions, and maximum error bar shown at $95 \%$ probability

The maximum cellulases were desorbed were around $55 \%$ with activity of around $29 \mathrm{FPU}$ at pH 9 , $60{ }^{\circ} \mathrm{C}$ with $5 \%$ glycerol. A $5 \%$ improvement in $\%$ desorption and $48 \%$ in activity was observed in 
comparison with that of raw wheat straw for $\mathrm{pH} 5$ and $60{ }^{\circ} \mathrm{C}$. Adding $5 \%$ glycerol to conditions of $\mathrm{pH} 9$ and $60{ }^{\circ} \mathrm{C}$, there was significant improve net in desorption $(23 \%)$ and activity (48\%) from 30 $\%$ DWS with respect to raw wheat straw.

\section{Desorption from $60 \%$ delignified wheat straw (DWS)}

Figure 54 shows \% desorption and activity (FPU) of desorbed cellulase from $60 \%$ delignified wheat straw. The results from $60 \%$ DWS were further compared with the $\%$ desorbed and activity of the desorbed cellulases at different experimental conditions. Each data point was measured separately and was an average of triplicates of a set of 5 tests $(3 \times 5=15)$.

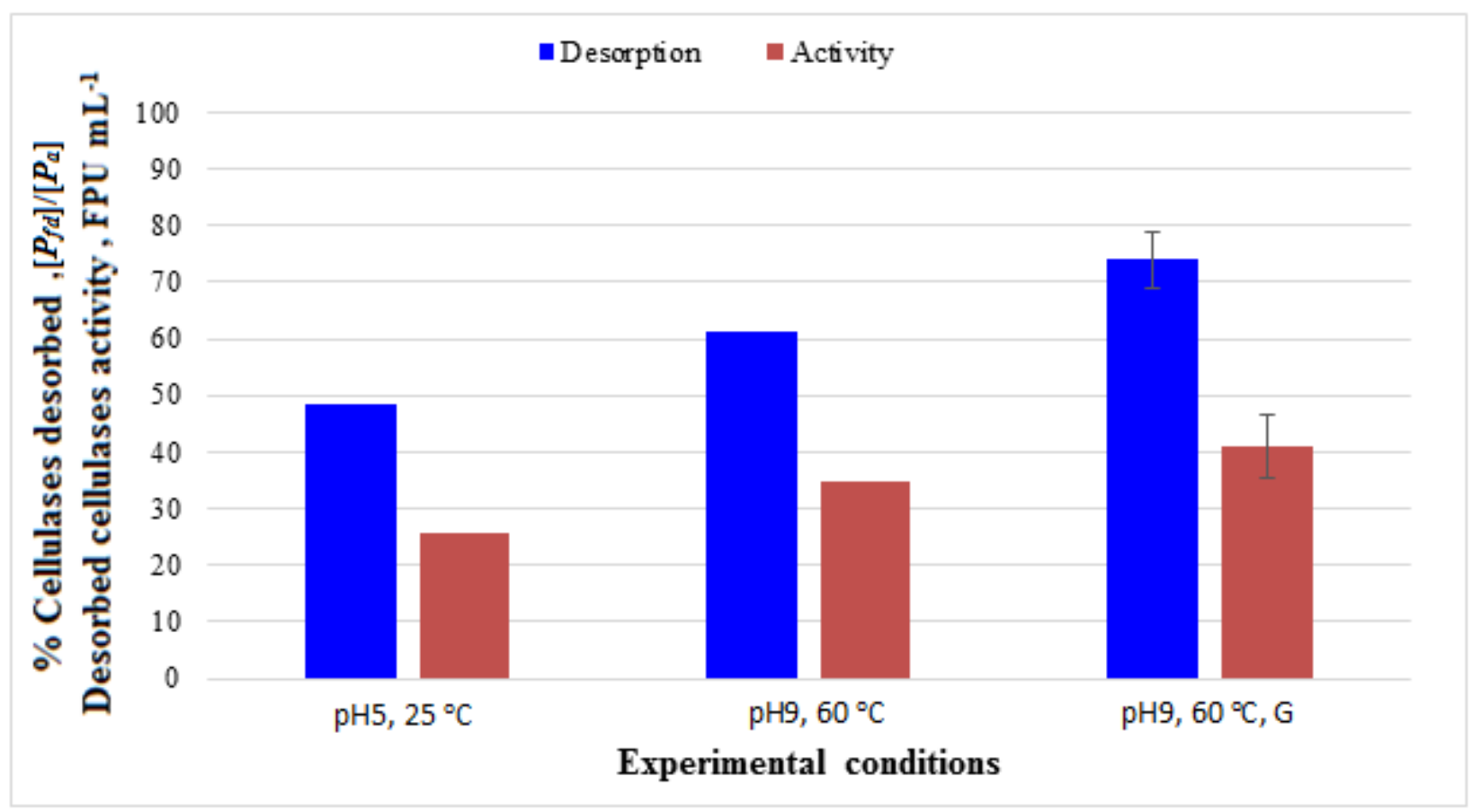

Figure 54: Comparison of \%desorbed and activity of the desorbed cellulases from $60 \%$ delignified wheat straw and different experimental conditions, and maximum error bar shown at $95 \%$ probability

The maximum cellulases were desorbed were around $75 \%$ with activity of around $41 \mathrm{FPU}$ at $\mathrm{pH} 9$, $60{ }^{\circ} \mathrm{C}$ with $5 \%$ glycerol. A $36 \%$ improvement in $\%$ desorption and $112 \%$ in activity was observed 
in comparison with that of raw wheat straw for $\mathrm{pH} 5$ and $60{ }^{\circ} \mathrm{C}$. Adding $5 \%$ glycerol to conditions of pH 9 and $60{ }^{\circ} \mathrm{C}$ there was significant improve net in desorption (64\%) and activity (150\%) from $60 \%$ DWS with respect to raw wheat straw. Isaacs (1984) conducted a simulation model to estimate enzymatic hydrolysis of corn stover and aspen wood and concluded that $60 \%$ of enzyme reuse can reduce $21.2 \%$ of the cost of the ethanol production process. At this stage of our research $(60 \%$ delignified wheat straw, $\mathrm{pH} 9,60{ }^{\circ} \mathrm{C}, 5 \%$ glycerol) our study is offering a $75 \%$ reuse of active cellulases which may reduce $26.5 \%$ of the cost of the ethanol production. 
6.0 Conclusion $_{\text {}}$ 
1. The concentration of cellulases adsorbed increased depending upon the amount and type of substrate

2. No hydrolysis/self-hydrolysis occurred during the time span of adsorption or desorption under suggested working conditions.

3. The adsorption of cellulases on Avicel PH 101 follow Langmuir isotherm while following Langmuir isotherm, Protobind 1000 has indicated cooperative adsorption. The results indicated that cellulases adsorb on the surface of substrates, one at one site, giving monolayer adsorption. Disagreement of experimental data with Freundlich isotherm indicated that cellulases do not interacts with each other to form multilayer on the substrates. Therefore all cellulases adsorbed on the substrates in monolayer.

4. Protobind (lignin) showed almost twice more adsorption capacity for cellulases than that of Avicel (cellulose). Therefore, delignification of lignocellulosic materials is important to avoid loss of cellulases by adsorption on lignin.

5. It was observed that cellulases adsorption appeared to be strongly influenced by the overall cellulases accessibility to substrates. Therefore, a substrate with porous structure (wheat straw) would have a more accessible surface (unless its natural wax coatings and lignin is removed) and hence more adsorption.

6. Thermodynamics parameters obtained from data could be used to indicate spontaneity of the adsorption and hence feasibility of adsorption. $\Delta \mathrm{G}_{\mathrm{a}}$ for Avicel is negative for $298 \mathrm{~K}$ to $323 \mathrm{~K}$ and for Protobind it is negative for all temperature range ( $298 \mathrm{~K}$ to $343 \mathrm{~K}$ ). In normal ethanol production operation the adsorption on lignin is least required, therefore, a working temperature between the ranges of $298 \mathrm{~K}$ to $323 \mathrm{~K}$ would have less loss of enzymes by adsorption on lignin. 
7. The solid residues obtained from bioethanol industry needs to be treated at the same time to desorb cellulases because desorption equilibrium for both cellulose and lignin reached at same time).

8. The minimum value of free energy change of desorption $\left(\Delta \mathrm{G}_{\mathrm{d}}\right)$ was obtained at $\mathrm{pH} 9$ and 333 K. Hence, pH 9 and $333 \mathrm{~K}$ was suggested to use for production of bioethanol.

9. Desorption with the help of $5 \%$ glycerol would improve desorption and activity of the desorbed cellulases from lignocellulosic material. Therefore, a $\mathrm{pH} 8$ or 9, temperature $323 \mathrm{~K}$ with $5 \%$ glycerol would give maximum desorption and activity (active desorption) of cellulases from wheat straw.

10. Delignification of natural lignocellulosic materials is important for active desorption of cellulases. Desorption increased as delignification increased. The complete delignification would be expensive, therefore, delignification of lignocellulosic material to an optimum level is recommended. 


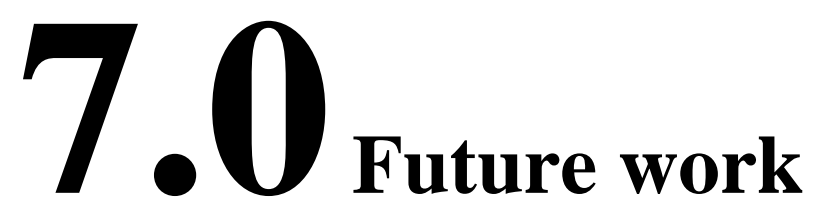


The results reported in this dissertation may have generated many questions, some of which may be important for further studies.

- In future, research needs to be focused on adaptation of results obtained from the components of lignocellulosic materials and delignified (ozonated) wheat straw to other lignocellulosic materials and then scaling-up these lab-results for large reactors. The problems foreseen for large scale production would include: handling of biomass at high solids concentrations, large particle sizes and high amounts of silica (coming from agricultural residues). Solutions for these identified problem have to be tested and verified to ensure long-term stability of a future bioethanol production.

- Cellulases with higher activity ranges should be developed and tested for wide ranges of $\mathrm{pH}$ and temperature.

- For further improvements of the enzymatic bioethanol production process, recyclability of desorbed cellulases (again and again) should be investigated.

- Because the addition of glycerol for desorption increased cellulase activity, it is desirable to determine the effect of glycerol on adsorption of cellulases because desorbed cellulases may contain glycerol with them when recycled.

- Addition of some chemicals that have preferential adsorption on lignin may inhibit all adsorption of cellulases on lignin and prevent non-productive adsorption on lignin. This will be due to the masking of adsorption sites on lignin through a process of competitive interactions. This research will save cost and time for delignification of lignocellulosic materials.

- Further investigations on the pore size of the pretreated lignocellulosic material is likely to be conducted to improve both pretreatment and enzymatic hydrolysis. 


\section{Appendices}




\section{Appendix A}

\section{Measurement of the Activity of cellulases}

Modified Laboratory Analytical Procedure \#006 (NREL, 1995)

Reagents and Materials

\section{DNS Reagent}

Dissolve $10.6 \mathrm{~g}$ of 3, 5 Dinitrosalicylic acid and $19.8 \mathrm{~g}$ of Sodium hydroxide then add $306 \mathrm{~g}$ of Rochelle salts (sodium potassium tartrate), $7.6 \mathrm{ml}$ of Phenol and $8.3 \mathrm{~g}$ of Sodium metabisulfite. Titrate $3 \mathrm{ml}$ sample with $0.1 \mathrm{~N} \mathrm{HCl}$ to the phenolphthalein endpoint. It should take $5-6 \mathrm{ml}$ of $\mathrm{HCl}$. Add $\mathrm{NaOH}$ if required.

\section{Citrate Buffer}

Novozymes Cellulase enzyme (NS 50013) assays are carried out in 0.05 M citrate buffer pH 5.0. To prepare 1.0 M citrate buffer, dissolve $210 \mathrm{~g}$ of Citric acid monohydrate in $750 \mathrm{ml}$ of distilled water. Adjust the $\mathrm{pH}$ of the solution to 4.3 by adding $\mathrm{NaOH}(50-60 \mathrm{~g})$. To prepare $0.05 \mathrm{M}$ citrate buffer, dilute $50 \mathrm{ml}$ of $1 \mathrm{M}$ citrate buffer stock to 1 liter by adding $950 \mathrm{ml}$ distilled water. Adjust the $\mathrm{pH}$ of the solution to 5.0 by adding $\mathrm{NaOH}$.

\section{Blank and controls}

Reagent blank: $1.5 \mathrm{ml}$ of $0.05 \mathrm{M}$ citrate buffer.

Enzyme control: $1.0 \mathrm{ml}$ of $0.05 \mathrm{M}$ citrate buffer $+0.5 \mathrm{ml}$ enzyme dilutions (prepare a separate control for each dilution tested).

Substrate control: $1.5 \mathrm{ml}$ of $0.05 \mathrm{M}$ citrate buffer + filter-paper strip. 


\section{Glucose standards}

A working stock solution of anhydrous glucose $\left(10 \mathrm{mg} \mathrm{mL}^{-1}\right)$ should be made up. Aliquots of this working stock should be tightly sealed and stored frozen. The standard should be vortexed after thawing to ensure adequate mixing. Dilutions are made from the working stock in the following manner:

$$
\begin{aligned}
& 1.0 \mathrm{ml}+0.5 \mathrm{ml} \text { buffer }=1: 1.5\left(3.35 \mathrm{mg}^{0.5} \mathrm{~mL}^{-1}\right) \text {. } \\
& 1.0 \mathrm{ml}+1.0 \mathrm{ml} \text { buffer }=1: 2\left(2.5 \mathrm{mg}_{\left.0.5 \mathrm{~mL}^{-1}\right)}\right. \text {. }
\end{aligned}
$$

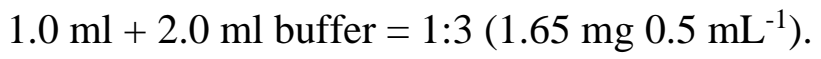

$$
\begin{aligned}
& 1.0 \mathrm{ml}+4.0 \mathrm{ml} \text { buffer }=1: 5\left(1.0 \mathrm{mg}_{\left.0.5 \mathrm{~mL}^{-1}\right)}\right. \text {. }
\end{aligned}
$$

Glucose standard tubes should be prepared by adding $0.5 \mathrm{~mL}$ of each of the above glucose dilutions to $1.0 \mathrm{~m}$ of $0.05 \mathrm{M}$ citrate buffer in a $13 \times 100 \mathrm{~mm}$ test tube.

Blanks, controls and glucose standards should be incubated at $50{ }^{\circ} \mathrm{C}$ along with the enzyme assay tubes, and then "stopped" at the end of 60 minutes by addition of $3.0 \mathrm{ml}$ of DNS reagent.

\section{Color development}

1) Boil all tubes for exactly 5.0 minutes in a vigorously boiling water bath containing sufficient water to cover the portions of the tubes occupied by the reaction mixture plus reagent. All samples, controls, blanks, and glucose standards should be boiled together. After boiling, transfer to a cold ice-water bath.

2) Let the tubes sit until all the pulp has settled, or centrifuge briefly. Dilute all tubes (assays, blanks, standards and controls $)$ in water $(0.200 \mathrm{~mL}$ of color-developed reaction mixture plus $2.5 \mathrm{~mL}$ of water 
in a spectrophotometer cuvette works well, use the pipette to mix by drawing the mixture into the pipette tip repeatedly). Determine color formation by measuring absorbance against the reagent blank at $540 \mathrm{~nm}$. With this dilution the glucose standards described above should give absorbance in the range of 0.1 to $1.0 \mathrm{~A}$.

\section{Calculations}

1) Construct a linear glucose standard curve using A 540 plotted against its concentration of glucose (mg $0.5 \mathrm{~mL}^{-1}$ ). Verify the standard curve by running a calibration verification standard, an independently prepared solution containing a known amount of glucose which falls about midpoint on the standard curve.

2) Using this standard curve determine the glucose released for each sample tube after subtraction of enzyme blank.

3) Estimate the concentration of enzyme which would have released exactly $2.0 \mathrm{mg}$ of glucose by means of interpolation. To find the required enzyme concentration take two data points that are very close to $2.0 \mathrm{mg}$ as in Table 14

Table 13: Dilution of Cellulase enzyme NS50013 from enzyme stock that had been diluted $1: 15$ in citrate buffer

\begin{tabular}{|c|c|c|c|c|c|}
\hline $\begin{array}{l}\text { Dilution } \\
\#\end{array}$ & $\begin{array}{l}\text { Citrate } \\
\text { buffer }\end{array}$ & $\mathbf{1 : 1 0}$ Enzyme & $\begin{array}{l}\text { Dilution } \\
\text { factor }\end{array}$ & $\begin{array}{l}\text { Absorbance } \\
\text { At 540 nm }\end{array}$ & [Glucose] \\
\hline & $\mathrm{mL}$ & $\mathrm{mL}$ & $\mathrm{mL} \mathrm{mL}^{-1}$ & $(-)$ & $\left({\left.\mathrm{mg} \mathrm{0.5} \mathrm{mL}^{-1}\right)}\right.$ \\
\hline 1 & 1.65 & 0.35 & 0.0166 & 0.789 & - \\
\hline 2 & 1.70 & 0.30 & 0.0100 & 0.713 & 3.278 \\
\hline 3 & 1.80 & 0.20 & 0.0067 & 0.545 & 2.505 \\
\hline 4 & 1.85 & 0.15 & 0.0050 & 0.438 & 2.013 \\
\hline 5 & 1.90 & 0.10 & 0.0033 & 0.346 & 1.59 \\
\hline
\end{tabular}


The term "Dilution factor" is used to represent the proportion of the original enzyme solution present in the dilution added to the assay mixture. For example a 1:15 dilution (Dilution \# 4) of the 1:15 working stock of enzyme will have:

$$
\text { Dilution Factor }=\frac{\frac{0.15}{0.15+1.85}}{15}=0.005
$$

In another word, the original enzyme was diluted two times. In the first dilution, it was diluted (1:15) and in the second dilution (1:10). Therefore, after performing the hydrolysis and the DNS test described in Appendix A, glucose concentrations of the five cellulase enzyme assays were determined using glucose standard curve of Figure 8.

$$
\text { Cellulase activity }\left(\frac{(F P U}{m L}\right)=\frac{0.37}{[\text { enzymes]releasing } 2.0 \mathrm{mg} \text { glucose }}
$$

[Enzyme] represents the proportion of original enzyme solution present in the directly tested enzyme dilution (that dilution of which $0.5 \mathrm{ml}$ is added to the assay mixture).

The numerator 0.37 in the equation is derived from the factor for converting the $2.0 \mathrm{mg}$ of glucose equivalents generated in the assay to $\mu$ moles of glucose

$$
\frac{\frac{2.0 \mathrm{mg} \text { glucose }}{0.180 \mathrm{mg} \text { glucose } / \mu \mathrm{mol}}}{0.5 \mathrm{~mL} \text { enzyme dilution } \times 60 \mathrm{~min}}=0.37 \frac{\mu \mathrm{mol}}{\mathrm{min} \mathrm{mL}}
$$

Table 14 shows the raw data for the change of absorbance with glucose concentration variation. These data were used to plot the glucose standard curve as shown in Figure 8. The absorbance values were measured using Biochrom UV spectrophotometer, model number: Ultraspec 50, England. 
Table 14: Data for glucose standard curve (DNS method)

\begin{tabular}{|l|l|l|l|l|l|l|}
\hline $\begin{array}{l}\text { [Glucose] } \\
\mathbf{X}_{\mathbf{i}}\end{array}$ & $\begin{array}{l}\text { Absorbance } \\
\text { Replicate \#1 }\end{array}$ & $\begin{array}{l}\text { Absorbance } \\
\text { Replicate \#1 }\end{array}$ & $\begin{array}{l}\text { Absorbance } \\
\text { mean, }(\mathbf{Y i})\end{array}$ & $\left(\mathbf{X}_{\mathbf{i}}\right)^{\mathbf{2}}$ & $\left(\mathbf{Y}_{\mathbf{i}}\right)^{\mathbf{2}}$ & $\mathbf{X}_{\mathbf{i}} \mathbf{Y}_{\mathbf{i}}$ \\
\hline $\mathrm{mg} / 0.5 \mathrm{~mL}$ & $(-)$ & $(-)$ & $(-)$ & $\mathrm{mg} / 0.5 \mathrm{~mL}$ & $(-)$ & $\mathrm{mg} / 0.5 \mathrm{~mL}$ \\
\hline 1.00 & 0.215 & 0.219 & 0.217 & 1 & 0.047 & 0.217 \\
\hline 1.65 & 0.346 & 0.350 & 0.348 & 2.722 & 0.121 & 0.574 \\
\hline 2.50 & 0.519 & 0.531 & 0.531 & 6.250 & 0.275 & 0.1312 \\
\hline 3.35 & 0.692 & 0.707 & 0.700 & 11.222 & 0.490 & 0.234 \\
\hline 8.500 & & & 1.790 & 21.195 & 0.934 & 4.448 \\
\hline
\end{tabular}

Columns 3, 4, and 5 of Table 14 contain computed values for $\mathrm{x}_{\mathrm{i}}, \mathrm{yi}_{\mathrm{i}}$ and $\mathrm{x}_{\mathrm{i}} \mathrm{y}_{\mathrm{i}}$, with their sums appearing as the last entry in each column which were used to analyze the glucose measurements by the least square method (Skoog et al., 2007). The calculation of the slope and intercept is simplified by defining three quantities $S_{x x}, S_{y y}$ and $S_{x y}$ as follows:

$$
\begin{gathered}
S_{x x}=\sum X_{i}^{2}-\frac{\left(\sum x_{i}\right)^{2}}{N}=21.195-\frac{(8.5)^{2}}{4}=3.1325\left(\frac{\mathrm{mg}}{0.5 \mathrm{ml}}\right)^{2} \\
S_{y y}=\sum y_{i}^{2}-\frac{\left(\sum y_{i}\right)^{2}}{N}=0.934-\frac{(1.790)^{2}}{4}=0.133(-) \\
S_{x y}=\sum x_{i} y_{i}-\frac{\sum x_{i} \sum y_{i}}{N}=4.448-\frac{(8.500 X 1.790)}{4}=0.645\left(\frac{\mathrm{mg}}{0.5 \mathrm{ml}}\right)^{2}
\end{gathered}
$$

The slope of the line, $\mathrm{m}$ :

$$
m=\frac{s_{x y}}{s_{x x}}=\frac{0.645}{3.13}=0.206\left(\frac{0.5 m l}{m g}\right)
$$

The means (averages) for $\mathrm{x}$ and $\mathrm{y}$ values:

$$
\begin{gathered}
\bar{x}=\frac{\sum x_{i}}{N}=\frac{8.500}{4}=2.125\left(\frac{\mathrm{mg}}{0.5 \mathrm{ml}}\right) \\
\bar{y}=\frac{\sum y_{i}}{N}=\frac{1.790}{4}=0.4475(-) \\
153
\end{gathered}
$$


The intercept, b:

$$
b=\bar{y}-m \bar{x}=0.4475-0.206 \times 2.125=0.009 \approx 0.000
$$

Thus the equation for the least square line of the standard curve is:

$$
\text { Absorbance }=0.206 X[\text { Glucose }]
$$

The standard deviation about regression:

$$
S_{r}=\sqrt{\frac{S_{y y}-m^{2} S_{x x}}{N-2}}=\sqrt{\frac{0.133-(0.206)^{2} \times 3.132}{4-2}}=0.00093(-)
$$

The standard deviation of the slope:

$$
S_{r}=\sqrt{\frac{S_{y y}}{S_{x x}}}=\sqrt{\frac{(0.00093)^{2}}{3.132}}=0.00526\left(\frac{0.5 m L}{m g}\right)
$$

The standard deviation of the intercept:

$$
S_{b}=S_{r} \sqrt{\frac{1}{N-\frac{\left(\sum X_{i}\right)^{2}}{\sum x_{i}^{2}}}}=0.00093 X \sqrt{\frac{1}{7-\frac{(8.500)^{2}}{21.195}}}=0.00049(-)
$$

The standard deviation for results obtained from the standard curve:

$$
\begin{gathered}
S_{c}=\frac{S_{r}}{m} \sqrt{\frac{1}{M}+\frac{1}{N}+\frac{\left(\overline{y_{c}}-\bar{y}\right)^{2}}{m^{2} S_{x x}}} \\
S_{c}=\frac{0.00093}{0.206} \sqrt{\frac{1}{2}+\frac{1}{4}+\frac{\left(\overline{y_{c}}-0.4475\right)^{2}}{(0.206)^{2} \times 3.132}}
\end{gathered}
$$

Where: 
$\mathrm{M}=$ number of replicates

$\mathrm{N}=$ number of points used in the standard curve

$\overline{y_{c}}=$ mean of the absorbance measured in replicates \#1 and \#2

The Confidence Function (CF) was calculated at $95 \%$ probability using the following equation:

$$
C F= \pm 1.96 X\left(\frac{S_{c}}{\sqrt{M}}\right)
$$

Tables 15 show the glucose concentration measured using DNS method for five dilutions of cellulase enzymes NS50013. The glucose concentration data was used to find the dilution that will release $2.000 \mathrm{gm} / 0.5 \mathrm{ml}$ of glucose sugar. Then this dilution was used to calculate the cellulase enzymes activity. A sample of the unknown enzyme activity measurement is shown in Appendix D.

Table 15: Dilution and glucose concentration of cellulase enzyme NS50013 stock that had been diluted in citrate buffer

\begin{tabular}{|c|c|c|c|c|c|c|c|}
\hline \multirow{3}{*}{$\begin{array}{l}\text { Run } \\
\#\end{array}$} & \multirow{2}{*}{$\begin{array}{l}\text { Dilution } \\
\text { factor }\end{array}$} & \multicolumn{2}{|c|}{ Replicate \# 1} & \multicolumn{2}{|c|}{ Replicate \# 2} & \multirow{2}{*}{$\begin{array}{l}\text { Glucose conc. } \\
\text { Mean } \pm \mathrm{CF}^{1}\end{array}$} & \multirow{2}{*}{$\begin{array}{l}\text { Standard } \\
\text { deviation } \\
\left(\mathrm{S}_{\mathrm{c}}\right)\end{array}$} \\
\hline & & $\begin{array}{l}\text { Abs. at } \\
540 \mathrm{~nm}\end{array}$ & $\begin{array}{l}\text { Glucose } \\
\text { conc. }\end{array}$ & $\begin{array}{l}\text { Abs. at } \\
540 \mathrm{~nm}\end{array}$ & $\begin{array}{l}\text { Glucose } \\
\text { conc. }\end{array}$ & & \\
\hline & $\mathrm{mL} / \mathrm{mL}$ & $(-)$ & $\mathrm{mg} / 0.5 \mathrm{~mL}$ & $(-)$ & $\mathrm{mg} / 0.5 \mathrm{~mL}$ & $\mathrm{mg} / 0.5 \mathrm{~mL}$ & $\mathrm{mg} / 0.5 \mathrm{~mL}$ \\
\hline 1 & 0.0250 & 0.740 & - & 0.789 & - & & \\
\hline 2 & 0.0150 & 0.658 & 3.185 & 0.675 & 3.277 & $3.213 \pm 0.029$ & 0.03 \\
\hline 3 & 0.0100 & 0.509 & 2.473 & 0.517 & 2.509 & $2.491 \pm 0.029$ & 0.03 \\
\hline 4 & 0.0075 & 0.438 & 2.128 & 0.416 & 2.018 & $2.073 \pm 0.019$ & 0.02 \\
\hline 5 & 0.0050 & 0.317 & 1.540 & 0.327 & 1.590 & $1.565 \pm 0.009$ & 0.01 \\
\hline
\end{tabular}

A standard deviation of 0.03 is negligible will not be considered in calculations of FPU. 
Table 16 shows cellulase enzymes NS50013 activities measured by using the filter paper unit method. The absorbance for the duplicate sets with the means, standard deviations and the confidence functions at $95 \%$ probability level are shown in Table 16.

Table 16: Activity of commercial cellulases NS 50013 measured by filter paper unit method.

\begin{tabular}{|l|l|l|}
\hline & [Enzymes] & $\begin{array}{l}\text { Cellulases, } \\
\text { Activity }\end{array}$ \\
\hline Replicate \#1 & 0.00695 & 53 \\
\hline Replicate \#2 & 0.00739 & 50 \\
\hline Mean & & 51.5 \\
\hline STDEV & & 2.12 \\
\hline
\end{tabular}

$\sigma\left(\mathrm{S}_{\mathrm{c}}\right)=$ Max. Standard deviation from the curve $=0.03$ (negligible)

$\sigma($ Samples $)=2.12$

$$
\begin{gathered}
\sigma_{\text {Total }}=\sqrt{\left(\sigma S_{c}\right)^{2}+\left(\sigma S_{\text {sample }}\right)^{2}} \\
95 \% \text { Probablity }= \pm 1.96 \times\left(\frac{\sigma(\text { Total })}{\sqrt{N}}\right)
\end{gathered}
$$

$\mathrm{N}=$ Number of replicates

$$
95 \% \text { Probablity }= \pm 1.96 \times\left(\frac{2.12}{\sqrt{2}}\right)=2.94
$$

Therefore, activity of cellulases $=51.5 \pm 2.94$ 


\section{Appendix B}

\section{Measurement of error in readings by using standard curve for concentration of cellulases}

Table 17: Data for absorbance of standard samples

\begin{tabular}{|c|c|c|c|c|}
\hline \multirow{2}{*}{$\begin{array}{l}\text { Stand. Conc., } \\
\mathrm{X}, \mu \mathrm{g} \mathrm{\textrm {mL } ^ { - 1 }}\end{array}$} & \multicolumn{3}{|c|}{ Absorbance } & \multirow{2}{*}{$\frac{\text { Mean }}{\mathrm{Yi}}$} \\
\hline & Replicate 1 & Replicate 2 & Replicate 3 & \\
\hline 0 & 0.000 & 0.000 & 0.000 & 0.000 \\
\hline 50 & 0.130 & 0.133 & 0.128 & 0.130 \\
\hline 100 & 0.233 & 0.236 & 0.238 & 0.235 \\
\hline 200 & 0.525 & 0.450 & 0.508 & 0.500 \\
\hline 300 & 0.610 & 0.725 & 0.638 & 0.664 \\
\hline 400 & 0.920 & 0.845 & 0.843 & 0.869 \\
\hline \multicolumn{5}{|c|}{ Sum } \\
\hline 1050 & & & & 2.387 \\
\hline
\end{tabular}

Data showing absorbance for varying concentrations of cellulases was plotted in Figure 13. There appeared to be a linear relationship between the absorbance and the concentration of standards. Therefore, the method of least squares was applied.

Table 18: Statistical manipulation of data given in Table 17

\begin{tabular}{|c|c|c|c|}
\hline $\mathbf{X}_{\mathbf{i}}^{\mathbf{2}}$ & $\mathbf{Y}_{\mathbf{i}}^{\mathbf{2}}$ & $\mathbf{X}_{\mathbf{i}} \mathbf{Y}_{\mathbf{i}}$ & $\left(\mathbf{X}_{\mathbf{i}} \mathbf{Y}_{\mathbf{i}}\right)^{\mathbf{2}}$ \\
\hline 0 & 0.0000 & 0.0000 & 0.0000 \\
\hline 2500 & 0.0169 & 6.5500 & 42.902 \\
\hline 10000 & 0.0557 & 23.600 & 556.96 \\
\hline 40000 & 0.2500 & 100.00 & 10000 \\
\hline 90000 & 0.4413 & 199.29 & 39716 \\
\hline 160000 & 0.7600 & 348.00 & 121104 \\
\hline \multicolumn{4}{|c|}{ Sum } \\
\hline 302500 & 1.5239 & 677.39 & 171419 \\
\hline
\end{tabular}

Columns 1, 2, and 5 of Table 18 contain computed values for $\mathrm{X}_{\mathrm{i}}^{2}, \mathrm{Y}_{\mathrm{i}}^{2}$ and $\mathrm{X}_{\mathrm{i}} \mathrm{Y}_{\mathrm{i}}, \mathrm{XiYi}^{2}$ and their sums appearing as the last entry in each column which were used to analyze the cellulases measurements by the least square method (Skoog et al., 2007). Xi and Yi the coordinated of the 
individual data points, $\mathrm{N}$ is the number of pairs of data used in preparation of the calibration curve. The calculation of the slope and intercept are simplified by defining three quantities $S_{x x}, S_{y y}$ and $S_{x y}$ as follows

$$
\begin{gathered}
\mathrm{S}_{\mathrm{xx}}=\sum \mathrm{X}_{\mathrm{i}}^{2}-\frac{\left(\sum \mathrm{X}_{\mathrm{i}}\right)^{2}}{\mathrm{~N}} \\
\mathrm{~S}_{\mathrm{yy}}=\sum \mathrm{Y}_{\mathrm{i}}^{2}-\frac{\left(\sum \mathrm{Y}_{\mathrm{i}}\right)^{2}}{\mathrm{~N}} \\
\mathrm{~S}_{\mathrm{xy}}=\sum \mathrm{X}_{\mathrm{i}} \mathrm{Y}_{\mathrm{i}}-\frac{\sum \mathrm{X}_{\mathrm{i}} \sum \mathrm{Y}_{\mathrm{i}}}{\mathrm{N}} \\
S_{x x}=302500-\frac{(1050)^{2}}{5}=82000 \\
S_{Y Y}=1.524-\frac{(2.387)^{2}}{5}=0.3844 \\
S_{x y}=677.39-\frac{1050 * 2.387}{N 5}=177.59
\end{gathered}
$$

Symbols $\dot{X}$ and $\dot{Y}$ are average values of the variables

$$
\begin{aligned}
& \dot{X}=\frac{\sum X_{i}}{N}=\frac{1050}{5}=210 \\
& \dot{Y}=\frac{\sum Y_{i}}{N}=\frac{2.387}{5}=0.476
\end{aligned}
$$

The standard deviation of residuals $\mathrm{S}_{\mathrm{y}}$, [the vertical deviation of each point from the straight line is called a residual], is given by: 


$$
\begin{gathered}
S_{y}=\sqrt{\frac{S_{y y}-m^{2} S_{x x}}{N-2}} \\
S_{y}=\sqrt{\frac{0.3844-(0.0216)^{2} * 82000}{5-2}}= \\
S_{y}=\sqrt{\frac{0.3844-0.38438}{3}}=0.0025
\end{gathered}
$$

The standard deviation of slope $S_{\mathrm{m}}$, is given by:

$$
\begin{array}{r}
S_{m}=\frac{S_{y}}{\sqrt{S_{x x}}} \\
S_{m}=\frac{0.0025}{\sqrt{82000}}=0.00017
\end{array}
$$

The standard deviation of intercept $\mathrm{S}_{\mathrm{b}}$, is given by:

$$
\begin{aligned}
& S_{b}=S_{y} * \sqrt{\frac{1}{N-\frac{\left(\Sigma X_{i}\right)^{2}}{\sum X_{i}^{2}}}} \\
& S_{b}=0.0025 * \sqrt{\frac{1}{5-\frac{(1050)^{2}}{302500}}}=0.00214
\end{aligned}
$$

The standard deviation of $S_{c}$ for analytical results obtained with the calibration curve:

$$
S_{c}=\frac{S_{r}}{m}\left(\sqrt{\frac{1}{L}+\frac{1}{N}+\frac{\left(Y_{c}-y\right)^{2}}{m^{2} S_{x x}}}\right)
$$


In this case, $1 / \mathrm{L}=0.33,1 / \mathrm{N}=0.2, \mathrm{~m}^{2} \mathrm{~S}_{\mathrm{xx}}=0.3845, \mathrm{Y}_{\mathrm{c}}$ is the average (i.e. $\mathrm{Y}_{\mathrm{c}}-\mathrm{Y}_{\mathrm{i}}$ ), $\mathrm{Y}$ represent values of absorbance in one set of data in Appendix B.

Table 19: Standard deviation of one set of data from Table 17 against Standard Curve

\begin{tabular}{|c|c|c|c|}
\hline $\mathbf{Y}_{\mathbf{c}}$ & $\mathbf{Y}$ & $\left(\mathbf{Y}_{\mathbf{c}^{-}} \mathbf{Y}\right)^{\mathbf{2}}$ & $\mathbf{S}_{\mathbf{c}}$ \\
\hline 0.13 & 0.13 & 0 & 0.8426 \\
\hline 0.236 & 0.233 & $9.00 \mathrm{E}-06$ & 0.8426 \\
\hline 0.5 & 0.525 & 0.0006 & 0.8426 \\
\hline 0.6643 & 0.61 & 0.0029 & 0.8426 \\
\hline 0.869 & 0.845 & 0.0005 & 0.8426 \\
\hline 0.869 & 0.92 & 0.0026 & 0.8426 \\
\hline
\end{tabular}

The value of 0.84 will be used to make up an error of cellulases concentration measurements. 


\section{Appendix C}

Measurement of error in readings by using standard curve for reducing sugars

Data in Table 20 showing absorbance for varying concentrations of cellulases was plotted in Figure 12.

Table 20: Data for absorbance of standard samples of glucose

\begin{tabular}{|c|c|c|c|c|}
\hline Stand. Conc., & \multicolumn{3}{|c|}{ Absorbance } & Mean \\
\cline { 2 - 5 } $\mathrm{X}, \mu \mathrm{g} \mathrm{mL}^{-1}$ & Replicate 1 & Replicate 2 & Replicate 3 & $\mathrm{Y}_{\mathrm{i}}$ \\
\hline 0 & 0.000 & 0.000 & 0.000 & 0.0000 \\
\hline 50 & 0.024 & 0.022 & 0.022 & 0.0227 \\
\hline 100 & 0.048 & 0.052 & 0.056 & 0.0520 \\
\hline 200 & 0.086 & 0.089 & 0.090 & 0.0880 \\
\hline 400 & 0.184 & 0.189 & 0.193 & 0.1890 \\
\hline 800 & 0.0 .384 & 0.381 & 0.374 & 0.3790 \\
\hline \multicolumn{5}{|l|}{ Sum } \\
\hline 1550 & \multicolumn{5}{|l}{} \\
\hline
\end{tabular}

There appeared to be a linear relationship between the absorbance and the concentration of glucose standards. Therefore, the method of least squares was applied.

Table 21: Statistical manipulation of data given in Table 20

\begin{tabular}{|l|l|l|l|}
\hline $\mathbf{X}_{\mathbf{i}}^{\mathbf{2}}$ & $\mathbf{Y}_{\mathbf{i}}^{\mathbf{2}}$ & $\mathbf{X}_{\mathbf{i}} \mathbf{Y}_{\mathbf{i}}$ & $\left(\mathbf{X}_{\mathbf{i}} \mathbf{Y}_{\mathbf{i}}\right)^{\mathbf{2}}$ \\
\hline 0 & 0.0000 & 0.0000 & 0.0000 \\
\hline 2500 & 0.0005 & 1.135 & 1.2880 \\
\hline 10000 & 0.0027 & 5.200 & 27.040 \\
\hline 40000 & 0.0077 & 17.60 & 309.76 \\
\hline 160000 & 0.0357 & 75.60 & 5715.3 \\
\hline 640000 & 0.1436 & 303.2 & 91930 \\
\hline Sum & 402.73 & 97983 \\
\hline 852500 & 0.1902 &
\end{tabular}

Columns 1, 2, 3 and 4 of Table 21 contain computed values for $\mathrm{X}_{\mathrm{i}}^{2}, \mathrm{Y}_{\mathrm{i}}^{2}$ and $\mathrm{X}_{\mathrm{i}} \mathrm{Y}_{\mathrm{i}}, \mathrm{X}_{\mathrm{i}} \mathrm{Y}_{\mathrm{i}}{ }^{2}$ and their sums appearing as the last entry in each column which were used to analyze the reducing sugars measurements by the least square method (Skoog et al., 2007). $\mathrm{X}_{\mathrm{i}}$ and $\mathrm{Y}_{\mathrm{i}}$ the coordinated of the 
individual data points, $\mathrm{N}$ is the number of pairs of data used in preparation of the calibration curve. The calculation of the slope and intercept are simplified by defining three quantities $S_{x x}, S_{y y}$ and $S_{x y}$ as follows

$$
\begin{gathered}
\mathrm{S}_{\mathrm{xx}}=\sum \mathrm{X}_{\mathrm{i}}^{2}-\frac{\left(\sum \mathrm{X}_{\mathrm{i}}\right)^{2}}{\mathrm{~N}} \\
\mathrm{~S}_{\mathrm{yy}}=\sum \mathrm{Y}_{\mathrm{i}}^{2}-\frac{\left(\sum \mathrm{Y}_{\mathrm{i}}\right)^{2}}{\mathrm{~N}} \\
\mathrm{~S}_{\mathrm{xy}}=\sum \mathrm{X}_{\mathrm{i}} \mathrm{Y}_{\mathrm{i}}-\frac{\sum \mathrm{X}_{\mathrm{i}} \sum \mathrm{Y}_{\mathrm{i}}}{\mathrm{N}} \\
S_{x x}=852500-\frac{(1550)^{2}}{5}=372000 \\
S_{Y Y}=0.1902-\frac{(0.7307)^{2}}{5}=0.0834 \\
S_{x y}=402.73-\frac{1550 * 0.7303}{5}=176.22
\end{gathered}
$$

Symbols $\dot{X}$ and $\dot{Y}$ are average values of the variables

$$
\begin{aligned}
& \dot{X}=\frac{\sum X_{i}}{N}=\frac{1550}{5}=310 \\
& \dot{Y}=\frac{\sum Y_{i}}{N}=\frac{0.7307}{5}=0.1461
\end{aligned}
$$

The standard deviation of residuals $\mathrm{S}_{\mathrm{y}}$, [the vertical deviation of each point from the straight line is called a residual], is given by: 


$$
\begin{gathered}
S_{y}=\sqrt{\frac{S_{y y}-m^{2} S_{x x}}{N-2}} \\
S_{y}=\sqrt{\frac{0.08341-(0.000473)^{2} * 372000}{5-2}}= \\
S_{y}=\sqrt{\frac{0.08341-0.08328}{3}}=0.0065
\end{gathered}
$$

The standard deviation of slope $S_{m}$, is given by:

$$
\begin{array}{r}
S_{m}=\frac{S_{y}}{\sqrt{S_{x x}}} \\
S_{m}=\frac{0.0065}{\sqrt{372000}}=0.0000106
\end{array}
$$

The standard deviation of intercept $\mathrm{S}_{\mathrm{b}}$, is given by:

$$
\begin{aligned}
& S_{b}=S_{y} * \sqrt{\frac{1}{N-\frac{\left(\Sigma X_{i}\right)^{2}}{\Sigma X_{i}^{2}}}} \\
& S_{b}=0.0065 * \sqrt{\frac{1}{5-\frac{(1550)^{2}}{852500}}}=0.0044
\end{aligned}
$$

The standard deviation of $\mathrm{S}_{\mathrm{c}}$ for analytical results obtained with the calibration curve:

$$
S_{c}=\frac{S_{y}}{m}\left(\sqrt{\frac{1}{L}+\frac{1}{N}+\frac{\left(Y_{c}-y\right)^{2}}{m^{2} S_{x x}}}\right)
$$


In this case, $1 / \mathrm{L}=0.33,1 / \mathrm{N}=0.2, \mathrm{~m}^{2} \mathrm{~S}_{\mathrm{xx}}=0.08328, \mathrm{Y}_{\mathrm{c}}$ is the average (i.e. $\mathrm{Y}_{\mathrm{c}^{-}} \mathrm{Y}_{\mathrm{i}}$ ), $\mathrm{Y}$ represent values of absorbance in one set of data in Appendix C.

Table 22: Standard deviation of one set of data from Table 20 against Standard Curve

\begin{tabular}{|l|l|l|l|}
\hline $\mathbf{Y}_{\mathbf{c}}$ & $\mathbf{Y}$ & $\left(\mathbf{Y}_{\mathbf{c}}-\mathbf{Y}\right)^{\mathbf{2}}$ & $\mathbf{S}_{\mathbf{c}}$ \\
\hline 0.0000 & 0.000 & 0.000 & 0.000 \\
\hline 0.0227 & 0.022 & $4.9 \mathrm{E}-07$ & 12.012 \\
\hline 0.0520 & 0.052 & 0 & 12.012 \\
\hline 0.0880 & 0.089 & 0.000001 & 12.012 \\
\hline 0.1890 & 0.189 & 0 & 12.012 \\
\hline 0.3790 & 0.381 & $4 \mathrm{E}-06$ & 12.012 \\
\hline
\end{tabular}

A standard deviation of 12.012 will be used to make up a propagation error for reducing sugars measurement 


\section{Appendix D}

Error analysis

\section{Error bars for Adsorption}

Cellulases adsorbed is calculated by the following formula.

$$
P_{a}=E_{0}-P_{f}
$$

Values of $\mathrm{P}_{0}$ and $\mathrm{P}_{\mathrm{f}}$ were calculated from the standard calibration curve

$\left[\mathrm{P}_{0}\right]$ : Initial concentration of cellulases, $\mu \mathrm{g} \mathrm{mL}-1$

$\left[\mathrm{P}_{\mathrm{f}}\right]$ : Cellulases in solution at equilibrium, $\mu \mathrm{g} \mathrm{mL}-1$

$\left[\mathrm{P}_{\mathrm{a}}\right]$ : Cellulases adsorbed at equilibrium, $\mu \mathrm{g} \mathrm{mL} \mathrm{m}^{-1}$

Values of $\mathrm{P}_{0}$ and $\mathrm{P}_{\mathrm{f}}$ were calculated from the standard calibration curve as given in Figure 17.

Probability of in the value of $\left[P_{a}\right]$ was calculated by the following formula using error propagation method. $\sigma_{\mathrm{sc}}$ is the standard deviation of results from the standard curve.

$$
\sigma_{P a}=\sqrt{\left(\sigma_{S c}\right)^{2}+\left(\sigma_{P 0}\right)^{2}+\left(\sigma_{P f}\right)^{2}}
$$

\section{Some parameters used in adsorption uncertainty calculation}

\begin{tabular}{|l|l|l|l|l|l|}
\hline Sample 1, $\mathrm{P}_{0}$ & Sample 2, $\mathrm{P}_{0}$ & Sample 3, $\mathrm{P}_{0}$ & Sample 1, $\mathrm{P}_{\mathrm{f}}$ & Sample 2, $\mathrm{P}_{\mathrm{f}}$ & Sample 3, $\mathrm{P}_{\mathrm{f}}$ \\
\hline 103.1 & 98.99 & 105.8 & 30.42 & 36.59 & 33.17 \\
\hline
\end{tabular}

\begin{tabular}{|l|l|l|l|l|}
\hline \multicolumn{2}{|l|}{ Average } & \multicolumn{4}{|l|}{ Standard deviation } \\
\hline $\mathrm{P}_{0}$ & $\mathrm{P}_{\mathrm{f}}$ & $\sigma_{\mathrm{sc}}$ & $\sigma_{\mathrm{P} 0}$ & $\sigma_{\mathrm{Pf}}$ \\
\hline 102.0 & 34.00 & 0.84 & 3.420 & 3.09 \\
\hline
\end{tabular}

$$
\begin{aligned}
\sigma_{P a} & =\sqrt{(0.84)^{2}+(3.42)^{2}+(3.09)^{2}} \\
& =4.68
\end{aligned}
$$

$$
95 \% \text { Probability }=1.96 \frac{\sigma}{\sqrt{n}}=1.96 \frac{4.68}{\sqrt{3}}=5.30
$$

Errors for all $\left[P_{a}\right]$ values were calculated in this way. Particularly, this error value was used in Figure 11. 


\section{Error Bar for an adsorption parameter $\left(\mathbf{P}_{\mathrm{f}} / \mathbf{P}_{\mathrm{e}}\right)$ of Langmuir plot}

Error bar for use in Langmuir plot was calculated and used the Figure 23. The plot was constructed by plotting $\left[P_{f}\right] / P_{e} \mathrm{Vs}\left[P_{f}\right]$. where

$P_{e}$ : Cellulases adsorbed per unit substrate, $\mu \mathrm{g} \mathrm{mg}^{-1}$

Calculation for uncertainty in an adsorption parameter $\left(E_{\mathrm{f}} / \mathrm{E}_{\mathrm{e}}\right)$ of Langmuir plot

\begin{tabular}{|c|c|c|c|c|c|c|c|c|c|}
\hline$P_{f}$ & $\sigma P_{e}$ & $\sigma P_{f}$ & $\begin{array}{l}\mathrm{A}= \\
\sigma P_{e} / P_{e}\end{array}$ & $\begin{array}{l}\mathrm{B}= \\
\sigma P_{f} / P_{f}\end{array}$ & $\begin{array}{l}\mathrm{C}= \\
\left(\mathrm{S}_{\mathrm{c}}\right)\end{array}$ & $(\mathrm{A})^{2}$ & $(\mathrm{~B})^{2}$ & $(\mathrm{C})^{2}$ & $\sqrt{A^{2}+B^{2}+C^{2}}$ \\
\hline 34 & 0.171 & 5.82 & 0.050 & 0.171 & 0.84 & 0.0025 & 0.0292 & 0.7056 & \\
\hline
\end{tabular}

$$
\begin{gathered}
\sigma\left(\frac{P_{e}}{P_{f}}\right)=\left|\frac{P_{e}}{P_{f}}\right| \sqrt{\left(\left(\frac{\sigma P}{P_{f}}\right)^{2}+\left(\frac{\sigma P_{e}}{P_{e}}\right)^{2}+\left(S_{C}\right)^{2}\right) 4} \\
\sigma\left(\frac{P_{f}}{P_{e}}\right)=\left|\frac{3.4}{34}\right| * 0.85=0.085 \\
95 \% \text { probability }=1.96 * \frac{0.085}{\sqrt{5}}=0.075
\end{gathered}
$$

Error Bar for an adsorption parameter $\left(\mathrm{E}_{\mathrm{e}} / \mathrm{E}_{\mathrm{f}}\right)$ of Langmuir plot in Figure 23 


\section{Sample calculations for \% desorbed}

\section{Step -1, calculations for adsorption, $P_{a}$}

$E_{0}$ was measured in the same way as given below as $P_{f}$

Amount remaining in solution at equilibrium, $\mathrm{P}_{\mathrm{f}}$

Sample $1=88.99 \mu \mathrm{g} \mathrm{mL}^{-1}$

Sample $2=90.81 \mu \mathrm{g} \mathrm{mL}^{-1}$

Sample $3=92.62 \mu \mathrm{g} \mathrm{mL}^{-1}$

Sample $4=91.26 \mu \mathrm{g} \mathrm{mL}^{-1}$

Sample $5=89.44 \mu \mathrm{g} \mathrm{mL}^{-1}$

Average mean

$$
\bar{X}=\frac{1}{N} \sum_{i=1}^{N} X_{i}
$$

Where $\mathrm{Xi}=\mathrm{X}_{1}, \mathrm{X}_{2}, \mathrm{X}_{3}, \mathrm{X}_{4}, \mathrm{X}_{5}$

$$
\bar{X}=90.62
$$

$\mathrm{S}_{\mathrm{c}}(0.84)$ is the standard deviation from the standard curve

Standard deviation is:

$$
\begin{aligned}
\sigma=\sqrt{\frac{1}{N}}\left(\sum_{i=1}^{5}\left(X_{i}-\bar{X}\right)^{2}+(S c)^{2}\right) & =1.61 \\
P_{a}=P_{0}-P_{f} & \\
P_{a} & =202-88.99=113.01
\end{aligned}
$$

For 5 samples $\mathrm{P}_{\mathrm{a}}$ was measured using Equation 3

$\mathrm{E}_{\mathrm{d}}$, from 5 adsorbed supernatants, average of 5 samples $=111.38$

Standard deviation of 5 samples $\quad=1.61$

Therefore, $\quad \mathrm{P}_{\mathrm{a}}=111.38 \pm 1.61$ 


\section{Step 2, calculations for desorption}

$\mathrm{P}_{\mathrm{d}}$, from 5 desorbed supernatants, average of 5 samples $=44.016$

Standard deviation for $\mathrm{P}_{\mathrm{d}}$ from desorbed supernatant, average of 5 samples $=4.13$

$\%$ desorbed

$$
\begin{gathered}
\% \text { Desorbed }=\frac{\text { amount desorbed }}{\text { amount adsorbed }} * 100 \\
\begin{array}{c}
\% \text { Desorbed }=\frac{44.016}{111.38} * 100 \\
\% \text { Desorbed }=39.52
\end{array}
\end{gathered}
$$

\section{Step 3 Propagation error}

$$
\begin{gathered}
\sigma \text { Desorbed }=\sqrt{\left(\frac{\sigma P_{d}}{P_{d}}\right)^{2}+\left(\frac{\sigma P_{a}}{P_{a}}\right)^{2}+\left(S_{c}\right)^{2}}=\ldots \\
\sigma \text { Desorbed }=\sqrt{\left(\frac{4.13}{44.01}\right)^{2}+\left(\frac{1.46}{111.38}\right)^{2}+(0.84)^{2}}=\ldots \\
\sigma \text { Desorbed }=\sqrt{0.00881+0.00017+0.7056}=0.845
\end{gathered}
$$

Therefore,

$$
\% \text { Desorbed }=39.52 \pm 0.845
$$

A $95 \%$ error bar would be

$$
95 \% \text { probability }=1.96 * \frac{0.845}{\sqrt{5}}=0.743
$$

Error bars added to all \% desorption curves including Figure 32, 34,36, 38,40 , 42, 44 etc were calculated in this way. 
Sample calculations for $\ln K_{a}$ and $\ln K_{d}$

$$
K_{a}=\frac{P_{a}}{P_{f}} \quad \ldots \quad \ldots \quad \text { A-15 }
$$

\section{Step 1}

Table 18 shows basic data to calculate $\ln K_{a}$ values and the corresponding error used in Figure 23 and other similar valuations of $\ln K_{d}$

Table 23: Calculation for $\ln K_{\mathrm{a}}$ from $\left[E_{a}\right]$ and $\left[E_{f}\right]$

\begin{tabular}{|l|l|l|l|l|}
\hline Sample 1 & Sample 2 & Sample 3 & Average & StdevA \\
\hline$P_{a}$ & \multicolumn{5}{|l|}{} \\
\hline 113.42 & 113.51 & 109.17 & 112.03 & 2.48 \\
\hline$P_{f}$ & 73.67 & 74.67 & 0.90 \\
\hline 75.42 & 74.92 & 7.5 & 0.016 \\
\hline$K_{a}$ & 1.48 & 1.5 & \\
\hline 1.50 & 1.51 & \multicolumn{5}{|l|}{} \\
\hline $\ln K_{a}$ & 0.41 & 0.39 & 1.21 & \\
\hline 0.41 & &
\end{tabular}

Step 2, Variance

$$
\begin{aligned}
\sigma \ln K_{a}=\sqrt{\left(\frac{\sigma P_{a}}{P_{a}}\right)^{2}+\left(\frac{\sigma P_{f}}{P_{f}}\right)^{2}+} & \\
= & \sqrt{0.00064} \\
= & 0.84
\end{aligned}
$$

Therefore,

$$
\ln K_{a}=1.21 \pm 0.84
$$

$$
K_{d}=\frac{P_{d}}{P_{a}}
$$


For desorption, the same steps as InKa were followed, except that variance was calculated as following formula

$$
\sigma \ln K_{d}=\sqrt{\left(\frac{\sigma P_{a}}{P_{a}}\right)^{2}+\left(\frac{\sigma P_{d}}{P_{d}}\right)^{2}}
$$

Calculations for $\Delta \mathrm{H}, \Delta \mathrm{S}$ and $\Delta \mathrm{G}$

$$
\ln K=-\frac{\Delta H}{R} \frac{1}{T}+\frac{\Delta S}{R}
$$

Plot ln $\mathrm{K}_{\mathrm{a}}$ vs $1 / \mathrm{T}$ for all temperatures, $25^{\circ} \mathrm{C}, 40{ }^{\circ} \mathrm{C}, 50^{\circ} \mathrm{C}, 70^{\circ} \mathrm{C}$. Lower plot in Figure 25 is for Avicel PH 101 to get $\Delta \mathrm{H}_{\mathrm{a}}, \Delta \mathrm{S}_{\mathrm{a}}$ and $\Delta \mathrm{G}_{a}$ as

$$
\text { Slope }=-\Delta H / R
$$

$$
\begin{aligned}
& \Delta \mathbf{H}=\text { - Slope } x \mathbf{R} \\
& \text {.. A-20 } \\
& =-(1962) \times 8.314 \\
& =-16.32
\end{aligned}
$$

\section{Similarly}

$$
\begin{aligned}
\Delta \mathbf{S}= & \text { Intercept } \times \mathbf{R} \\
= & (6.0957) \times 8.314 \\
= & 50.69
\end{aligned}
$$$$
\text { ... A-21 }
$$ 


\section{Sample calculation for activity of cellulases from supernatants}

Activity of unknown enzymes from the supernatant of adsorption which contain non-adsorbed cellulases $\left[P_{f a}\right]$ and similarly from the supernatant of desorption which contain desorbed enzymes $\left[P_{f d}\right]$ can also be found from by the Equation A-22.

$$
\frac{F P U}{m l}=\frac{A_{540}}{0.206} \times \frac{0.5 \mathrm{~mL}}{0.180 \mu \mathrm{mol}} \times 60 \mathrm{~min}
$$

Absorbance for true sample A540 for $\left[P_{f a}\right]$ was calculated by subtracting A540 from the A540 of substrate control, using stand calibration curve given in Figure 10.

For a sample which gave [Glucose] $=0.524$ showed $\mathrm{A}_{540}=0.108$ at the standard calibration curve in Figure 10.

The same curve showed A540 for Avicel $=0$

Therefore, true A540 for the sample $=0.108-0.000=0.108$

Putting this $\mathrm{A} 540=0.108$ in Equation A-22, we get activity

$$
\begin{gathered}
\frac{F P U}{m L}=\frac{0.108}{0.206} \times \frac{0.5}{0.180} \times 60 \\
\text { Activity }=87.37 \frac{F P U}{m L}
\end{gathered}
$$




\section{References}


Ababou, A., Ladbury, J.E. 2006. Survey of the year 2004: literature on applications of isothermal titration calorimetry. Journal of Molecular Recognition Vol. 19(1), p 79-89.

Abuja, P., Pilz, I., Claeyssens, M., Tomme, P. 1988. Domain-structure of cellobiohydrolases-II as studied by small-angle $\mathrm{x}$-ray-scattering-close resemblance to cellobiohydrolases-I. Biochemical and Biophysical Research Communications Vol. 156(1), p 180-185.

Acharya, B. 2010. Utilization of anaerobically treated distillery spent wash for production of cellulases under solid state fermentation. Environmental Management. Vol. 90(10), p 2019-2027.

Adney, B., Baker, J. 1996. Laboratory Analytical Procedure, Issue date: 08/12/1996. NREL Colorado, USA.

Aharoni, C., Sideman, S., Hoffer, E. 1979. Adsorption of phosphate ions by colloid ion-coated alumina. Journaal of Chemical Technology Biotechnology Vol. 29, p 404-412.

Aksu, Z., Yenner, J. 2001. A comparative adsorption/biosorption study of mono-chlorinated phenols onto various sorbents. Waste Management Vol. 21(8), p 695-702.

Al-Degs, Y.S., El-Bargouthi, M., El-Sheikh, A.H., Walker, G.M. 2007. Effect of solution pH, ionic strength, and temperature on adsorption behavior of reactive dyes on activated carbon. Dyes and Pigments, Vol. 20, p 1-8.

Alloue-Boraud, W.A.M., Lejeune, A., Koffi-Nevry, R., Destain, J., Paquot, M., Thonart, P. 2014. Electrostatic and water content effects on Yarrowia lipolytica lipase immobilization by adsorption. British Microbiology Research Journal Vol. 10(4), p 640-653.

Alstine, J.M.V., Malmsten, M. 1996. Adsorption of poly (ethylene glycol) amphiphiles to form coatings which inhibit protein adsorption. Colloids and Interface Science Vol. 177, p 502-512.

Alzaydien, A.S., Manasreh, W. 2009. Equilibrium, kinetic and thermodynamic studies on the adsorption of phenol onto activated phosphate rock. International Journal of Physical Sciences Vol. 4(4), p 172-181. 
Andersen, N., Johansen, K., Michelsen, M., Stenby, E., Krogh, K., Olsson, M. 2008. Hydrolysis of cellulose using mono-component enzymes shows synergy during hydrolysis of phosphoric acid swollen cellulose (PASC), but competition on Avicel. Enzyme Microbial Technology Vol. 42, p $362-370$.

Andreaus, J., Azevedo, H., Cavaco-Paulo, A. 1999. Effects of temperature on the cellulose binding ability of cellulase enzymes. Journal of Molecular Catalysis B: Enzymatic Vol. 7, p 233-239.

Annual Energy outlook 2011,

http://www.eia.gov/oil_gas/petroleum/data_publications/wrgp/mogas_history.html

Ateya, B.G., El-Anadouli, B.E., El-Nizamy, F.M. 1984. The effect of thiourea on the corrosion kinetics of mild steel in $\mathrm{H}_{2} \mathrm{SO}_{4}$. Corrosion Science, Vol. 24(6), p 497-507.

Azzam, A.M. 1989. Pretreatment of cane bagasse with alkaline hydrogen peroxide for enzymatic hydrolysis of cellulose and ethanol fermentation. Journal of Environmental Science and Health. B. Vol. 24, p 421-433.

Bachala, A.J., Wilkie, K.C.B. 1971. The ratio $\beta(1,3)$ to $\beta(1,4)$ glucosidic linkages in nonendospermic hemicellulosic $\beta$-glucans from oat plant (Avena sativa) tissues at different stages of maturity.

Bai, Y., Lin, D., Wu, F., Wang, Z., Xing, B. 2010. Adsorption of Triton X-series surfactants and its role in stabilizing multi-walled carbon nanotube suspensions. Chemosphere Vol.79, p 362-367.

Baig, K.S. 2008. Biosorption of Nickel and Zinc ions on wheat straw. Master's Thesis. Department of Chemical Engineering, Ryerson University, Toronto, Canada.

Baig, K.S., Turcotte, G., Doan, H. 2016. Looking at adsorption of cellulases NS 50013 onto Avicel PH 101 and Protobind 1000 through isotherms and thermodynamics. International Journal of Waste Resources. Vol. 6(2), p 1000222. 
Baig, K.S. 2016. Thermodynamics of adsorption/desorption of cellulases NS50013 on/from Avicel PH 101 and Protobind 1000. American Journal of Engineering Research. Vol. 5(2), p 157-165.

Baig, K.S., Wu, J., Turcotte, G., Doan, H. Novel ozonation technique to delignify wheat straw for biofuel production. Energy and Environment Journal, Vol. 26(3), 2015.Baig, K.S., Doan, H.D., Wu, J. 2009. Multicomponent isotherms for biosorption of Ni2+ and Zn2+. Desalination. Vol. 249, p 429-439.

Baig, K.S., Turcotte, G., Doan, H. 2013. Desorption of cellulases from lignocellulosic model compounds towards bioethanol production. Organized by Faculty of Engineering and Architectural Science Graduate Open House and Research Symposium, at Mattamy Athletic Centre, Ryerson University, Toronto, on Nov 15, 2013.

Baig, K.S., Doan, H.D., Wu, J. 2009. Multicomponent isotherms for biosorption of $\mathrm{Ni}^{2+}$ and $\mathrm{Zn}^{2+}$. Desalination. Vol. 249, p 429-439.

Baker, J.O., Tatsumoto, K., Grohmann, K., Woodward, J., Wichert, J.M., Shoemaker, S.P., Himmel, M.E. 1992. Thermal denaturation of Trichoderma reesei cellulases studied by differential scanning calorimetry and tryptophan fluorescence. Applied Biochemistry and Biotechnology. Vol. 34/35, p 217-231.

Bansal, P., Hall, M., Realff, M.J., Lee, H., Bommarius, A.S. 2009. Modeling cellulase kinetics on lignocellulosic substrates. Biotechnoligy Advances Vol. 27, p 833-848.

Baran, A., Bicak, E., Baysal, S.H., Onal, S. 2007, Comparative studies on the adsorption of Cr(VI) ions on to various sorbents. Bioresource Technology. Vol. 98(3), p 661-665.

Barrett E.P. 1951. The determination of pore volume and area distributions in porous substances. Computations from nitrogen isotherms. Journal of the American Chemistry Society. Vol. 73, p $373-380$. 
Bayne, L., Ulijin, R.V., Halling, P.J. 2013. Effect of pore size on the performance of immobilized enzymes. Chemical Society Reviews. Vol. 42, p 9000- 9010. DOI: 10.1039/c3cs60270b.

Belaich, A., Fierobe, H.-P., Baty, D., Busetta, B., Bagnara-Tardie, C., Gaudin, C., Belaich, J.P. 1992. The catalytic domain of endoglucanase A from Clostridium cellulolyticum: Effects of arginine 79 and histidine 122 mutations on catalysis. Journal of Bacteriology. Vol. 174(14), p. 4677-4682.

Beldman, G., Voragen, A.G.J., Rombouts, F.M., Leeuwen, M.F., Pilnik, W. 1987. Adsorption and kinetic behaviour of purified endoglucanases and exoglucanases from Trichoderma viride. Biotechnology and Bioengineering Vol. 30, p 251-257.

Beldman, G., Searle-van Leeuwen, M.F., Rombouts, F.M., Voragen, A.G.J. 1985. The cellulases of Trichoderma viride. Purification, characterization and comparison of all detectable endoglucanases, exoglucanases and $\beta$-glucosidases. European Journal of Biochemistry. Vol. 146, p 301-308.

Beltrame, P.L. Carniti, P., Focher, B., Marzetti, A, Cattaneo, M. 1982. Journal of Applied Polymer Science. Vol. 27, p 3493-3502.

Berlin, A.B., Gilkes, N., Kurabi, A., Bura, R., Tu, M., Kilburn, D., Saddler, N.J. 2005. Weak ligninbinding enzymes. A novel approach to improve activity of cellulases for hydrolysis of lignocellulosics. Applied Biochemistry and Biotechnology. Vol. 121-124, p 163-170.

Berman, K., Boyer, P.D. 1969. Characteristics of the reversible heat, solvent, and detergent denaturation of leucine binding protein. Biochemistry. Vol. 11(25), p 4650- 4657.

Bernardez, T.D., Lyford, K., Hogsett, D.A., Lynd, L.R. 1993. Adsorption of Clostridium thermocellum cellulases onto pretreated mixed hardwood, avicel, and lignin. Biotechnology and Bioengineering. Vol. 42, p 899-907.

Berti, C., Ulbig, P., Schulz, S. 2000. Correlations and prediction of adsorption from liquid mixtures on solids by using G-Models. Adsorption Vol. 6, p 79-91. 
Bhatnagar, R.S., Jackson-Machelski, E., McWherter, C.A., Gordon, J.I. 1994. Isothermal titration calorimetric studies of Saccharomyces cerevisiae myristoyl-CoA:protein Nmyristoyltransferase. Determinants of binding energy and catalytic discrimination among acylCoA and peptide ligands. Journal of Biological Chemistry. Vol. 269(15), p 11045-11053.

Billsten, P., Wahlgren, M., Arnebrant, T., McGuire, J., Elwing, H. 1995. Structural changes of T4 lysozyme upon adsorption to silica nanoparticles measured by circular dichroism. Journal of Colloid Interface Science. Vol. 175, p 77-82.

Bjerre, A.B., Olesen, A.B., Fernqvist, T. 1996. Pretreatment of wheat straw using combined wet oxidation and alkaline hydrolysis resulting in convertible cellulose and hemicellulose. Biotechnology and Bioengineering. Vol. 49, p 568-577.

Bogdanovic, G., Tiberg, F., Rutland, M.W. 2001. Sliding friction between cellulose and silica surfaces. Langmuir. Vol. 17, p 5911-5916.

Bomgardner, M.M. 2013. Seeking biomass feedstock that can compete. Chemical and Engineering News. Vol. 91(31), p 11-15.

Bommarius, A.S., Katona, A., Cheben, S.E., Patel, A.S., Ragauskas, A.J., Khudson, K., Pu, Y. 2008. Cellulase kinetics as a function of cellulose pretreatment. Metabolic Engineering Vol. 10, p 370381.

Bonomo, C.F., Minim, L.A., Coimbra, J.S.R., Fontan, R.C.I., Mendes da Silva, L.H., Minim, V.P.R. 2006. Hydrophobic interaction adsorption of whey proteins: effect of temperature and salt concentration and thermodynamic analysis. Journal of Chromatography B. Vol. 844, p 6-14.

Boraston, A.B., Bolam, D.N., Gilbert, H.J., Davies, G.J. 2004 Carbohydrate-binding modules: finetuning polysaccharide recognition. Biochememistry Journal. Vol. 382, p 769-781.

Boraston, A.B. 2005. The interaction of carbohydrate-binding modules with insoluble noncrystalline cellulose is enthalpically driven. Biochememistry Journal. Vol. 385, p 479-484. 
Borjesson, J., Peterson, R., Tjerneld, F. 2007. Enhanced enzymatic conversion of softwood lignocellulose by poly (ethylene glycol) addition. Enzyme and Microbial Technology. Vol. 40, p 754-762.

Borjesson, J., Enqqvist, M., Sipos, B., Tjerneld, F. 2007. Effect of poly (ethylene glycol) on enzymatic hydrolysis and adsorption of cellulase enzymes to pretreated lignocellulose. Enzyme and Microbial Technology. Vol. 41(1-2), p 186-195.

Bothwell, M. K., Daughhetee, S. D., Chaua, G. Y., Wilson, D. B., Walker, L. P. 1997. Binding capacities for Thermomonospora fusca E3, E4, and E5, the E3 binding domain, and Trichoderma reesei $\mathrm{CBHI}$ on Avicel and bacterial microcrystalline cellulose. Bioresource Technology. Vol. 60, p 169-178.

Boussaid, A., Saddler, J. N. 1999. Adsorption and activity profiles of cellulases during the hydrolysis of two Douglas fir pulps. Enzyme Microbial Technology. Vol. 24, p 138-143.

Boutard, M., Cerisy, T., Nogue, P., Alberti, A., Weissenbach, J., Salanoubat, M., Tolonen, A.C. 2014. Functional diversity of carbohydrate-active enzymes enabling a bacterium to ferment plant biomass. PLoS Genetics Vol. 6(11). DOI:10.1371/journal.pgen.1004773.

Brenda. The Comprehensive Enzyme Information System. Department of Bioinformatics \& Biochemistry, Technische Universität Carolo-Wilhelmina zu Braunschweig. Retrieved on March 20, 2016. http://www.brenda-enzymes.org/index.php.

Brigham, J.S., Adney, W.S., Himmel, M.E. 1996. Hemicelluloses: diversity and applications. In: Wyman, C.E. (ed.) Handbook on Bioethanol: Production and Utilization. Taylor and Francis, Washington, DC, p 119-142.

Brown, R.F., Agbogbo, F.K., Holtzapple, M.T. 2010. Comparison of mechanistic models in the initial rate enzymatic hydrolysis of AFEX-treated wheat straw Biotechnology for Biofuels. Vol. 3(6). DOI: 10.1186/1754-6834-3-6 
Brown, I. 2009. Pyrococcus furiosus $\alpha$-amylase as a Candidate Sterilisation Time-temperature Integrator. Ph.D. Thesis. Department of Chemical Engineering, School of Engineering. The University of Birmingham.

Bu, L., Nimlos, M.R., Shirts, M.R., Stahlberg, J., Himmel, M.E., Crowley, M.F., Beckham, G.T. 2012. Product binding varies dramatically between processive and nonprocessive cellulase enzymes. The Journal of Biological Chemistry, Vol. 287, p 24807-24813.

Bukhtojarov, F.E., Ustinov, B.B., Salanovch, T.N., Antonov, A.I., Gusakov, A.V., Okunev,O.N., Sinitsyn, A.P. 2004. Cellulase complex of the fungus Chrysosporium lucknowense: Isolation and characterization of endoglucanases and cellobiohydrolases. Biochemistry (Moscow). Vol. 69(5), p 542-551.

Bulut, Y., Gozubenli, N., Aydin, H. 2007. Equilibrium and kinetics studies for biosorption of direct blue 71 from aqueous solution by wheat shells. Journal of Hazardous Materials. Vol. 144(1-2), p-300-306.

Burns, D.S., Ooshima, H., Converse, A.O. 1989. Surface area of pretreated lignocellulosics as a function of the extent of enzymatic hydrolysis. Applied Biochemistry and Biotechnology Vol. 20-21, p 79-94.

Burton, J., Wood, S.G., Pedyczak, A., Siemion, I.Z. 1989. Conformational preferences of sequential fragments of the hinge region of human IgA1 immunoglobulin molecule: II. Biophys Chem. Vol.33 (1), p 39-45.

Bushuev, V.N., Gudkov, A.T., Liljas, A., Sepetov, N.F. 1989. The flexible region of protein L12 from bacterial ribosomes studied by proton nuclear magnetic resonance. Journal of Biology and Chemistry. Vol. 264(8), p 4498-4505. 
Bykov, I. 2008. Characterization of Natural and Technical Lignins using FTIR Spectroscopy. Master's Thesis. Department of Chemical Engineering and Geosciences. Lulea University of Technology. S-971 87 Lulea.

Cadoche, L., Lopez, G.D. 1989. Assessment of size reduction as a preliminary step in the production of ethanol from lignocellulosic wastes. Biological Wastes. Vol. 30, p 153-157.

Clementi, F., Palade, C. E. 1969. Permeability to peroxidase and ferritin. Journal of Cellular Biology. Vol. 41, p 33-58.

Cameselle, J. C., Meireles, R., Sillero, A. 1986. Derivation and use of a formula to calculate the net charge of acid-base compounds. Its application to amino acids, proteins and nucleotides. Biochemical Education Vol. 14(3), p 131-136.

Carey, F.A., Sundberg, R.J. 2007. Advanced Organic Chemistry, Part A: Structure and Mechanisms. Springer.

Carrard, G., Koivula, A., Soderlund, H., Beguin, P. 2000. Cellulose-binding domains promote hydrolysis of different sites on crystalline cellulose. Proceedings of the National Academy of Sciences, USA. Vol. 97, p 10342-10347.

Carrard, G., Linder, M. 1999. Widely different off rates of two closely related cellulose-binding domains from Trichoderma reesei. European Journal of Biochemistry. Vol. 262, p 637-643.

Champagne, P.P., Ramsay, J. 2010. Dye decolorization and detoxification by laccase immobilized on porous glass beads. Bioresource Technology. Vol. 101(7), p 2230-2235.

Cheminfo Services Inc. 2000. Ethanol Production in Alberta, http://www.cheminfoservices.com. www1.agric.gov.ab.ca

Chen, B., Miller, E.M., Miller, L., Maikner, J.J., Gross, R.A. 2006. Effects of macro porous resin size on Candida antarctica lipase B adsorption, fraction of active molecules, and catalytic activity for polyester synthesis. Vol.23 (3), p 1381-1387. 
Chen, H., Hayn, M., Esterbauer, H. 1992. Purification and charaterization of two extracellular Bglucosidases from Trichoderma reesei. Biochemistry Biophysics Acta. Vol. 1121, p 54- 60.

Chernoglazov, V.M., Ermolova, O.V., Klyosov, A.A. 1988. Adsorption of high- purity endo-1,4- $\beta$ glucanases from Trichoderma reesei on components of lignocellulosic materials - cellulose, lignin, and xylan. Enzyme and Microbial Technology. Vol. 10, p 503-507.

Choi, J.H., Bertram, P.G., Drenan, R., Carvalho, J., Zhou, H.H., Zheng, X.F. 2002. The FKBP12rapamycin-associated protein (FRAP) is a CLIP-170 kinase. EMBO Reports Vol. 3, p 988-994.

Chowdhury, S., Mishra, R., Khushwaha, P., Saha, P. 2010. Removal of safranin from aqueous solutions by $\mathrm{NaOH}$-treated rice husk: thermodynamics, kinetics and isosteric heat of adsorption. Asia - Pacific Journal of Chemical Engineering. Vol. 7, p 236-249.

Christensen, T., Svenssen, B., Sigurskjold, B.W. 1999. Thermodynamics of reversible and irreversible unfolding and domain interactions of glucoamylase from Aspergillus niger studied by differential scanning and isothermal titration calorimetry. Biochemistry Vol. 38(19), p 63006310.

Claesson, P.M., Blomberg, E., Fröberg, J.C., Nylander, T., Arnebrant, T. 1995. Protein interactions at solid surfaces. Advances in Colloid and Interface Science. Vol. 57, p 161-227.

Claeyssens, M., Tomme, P. 1989. Structure-activity relationships in cellulolytic enzymes. In: Coughlan, M.P. (ed.) Enzyme Systems for Lignocellulose Degradation. Elsevier, Applied Science, London, p 37-49.

Collins, T., Meuwis, M.A., Gerday, C., Feller, G. 2003. Activity, stability and flexibility in glycosidases adapted to extreme thermal environments. Journal of Molecular Biology. Vol. 328, p 419-428. 
Consalavi, V., Chiaraluce, R., Politi, L., Vaccaro, R., Derosa, M., Scandurra, R. 1991. Extremely thermostable glutamate dehydrogenase from the hyperthermophilic archaebacterium Pyrococcus furiosus. European Journal of Biochemistry. Vol. 202, p 1189-1196.

Converse, A.O., Girard, D.J. 1992. Effect of substrate concentration on multicomponent adsorption. Biotechnology Progress. Vol. 8, p 587-588.

Converse, A.O., Matsuno, R., Tamaka, M., Taniquchi. M. 1988. A model of enzyme adsorption and hydrolysis of microcrystalline cellulose with slow deactivation of the adsorbed enzyme. Biotechnology and Bioengineering. Vol. 32, p 38-45.

Coughlan, M.P. (Ed.). 1989. Linko, M., Poutanen, K., Viikari, L. New developments in the Applications of Enzymes. Elsevier Applied Science. London.

Cowling, E.B. 1975. Physical and chemical constraints in the hydrolysis of cellulase and lignocellulosic materials. Biotechnology and Bioengineering Symposium. Vol., p 163-181.

Quaiattini, G. 2010. Growing beyond Oil, Delivering an Energy Future, A Report Card on the Canadian Renewable Fuel Industry, Nov. 2010, Canadian Renewable Fuel Association (CRFA). Creagh, A.L., Ong, E., Jervis, E., Kilburn, D.G., Haynes, C.A. 1996. Binding of the cellulose-binding domain of exoglucanases Cex from Cellulomonas fimi to insoluble microcrystalline cellulose is entropically driven. Proceedings of the National Academy of Sciences USA. Vol. 93, p 12229_12234.

Dabarowski, A. 2001. Adsorption-from theory to practice. Advances in Colloid and Interface Science. Vol. 93(1-3), p 135-224.

D’Amico S., Gerday, C., Feller, G. 2003. Activity-stability relationships in extremophilic enzymes. Journal of Molecular Biology. Vol. 332, p 981-988.

Dahlquist, F.W. 1978. The meaning of Scatchard and Hill plots. Methods in Enzymology. Vol. 48, p 270-299. 
Danial, R.M., Danson, M.J. 2013. Temperature and the catalytic activity of enzymes: A fresh understanding. FEBS Letters Vol. 587(17), p 2738-2743.

Daoud, F.B. Kaddour, S., Sadoun, T. 2010. Adsorption of cellulase Aspergillus niger on a commercial activated carbon: Kinetics and equilibrium studies. Colloids and Surfaces B: Biointerfaces. Vol. 75(1), p 93-99.

Das, A., Paul, T., Halder, S.K., Jana, A., Ghosh, K., Maity, C., Mohapatra, P.K.D., Pati, B.R., Mondal, K.C. 2013. Low cost single-step purification of endoglucanase from Aspergillus fumigatus ABK-9. Indian Journal of Experimental Biology. Vol. 51, p 954-959.

Das, A., Ghosh, U., Mohapartra, P.K.D., Pati, B.R., Mondal, K.C. 2012. Study on thermodynamics and adsorption kinetics of purified endoglucanase (CMCase) from Penicillium notatum NCIM NO-923 produced under mixed solid-state fermentation of waste cabbage and bagasse. Brazilian Journal of Microbiology. Vol. 43(3), p 1103-1111.

Datta, S., Christena, L.R., Rajaram, Y.R.S. 2013. Enzyme immobilization: an overview on techniques and support materials. Biotechnology. Vol. 3(1), p 1-9.

Dehghanifard, E., Jafari, A.J., Kalantary, R.R., Mahvi, A.H., Faramarzi, M.A., Esrafili, A. 2013. Biodegradation of 2, 4-dinitrophenol with laccase immobilized on nano-porous silica beads. Iranian Journal of Environmental Health Science \& Engineering. Vol. 10, p 25.

Deere, J., Magner, E., Wall, J.G., Hodnett, B.K. 2002. Mechanistic and structural features of protein adsorption onto mesoporous silicates. Journal of Physics and Chemistry B. Vol. 106, p 73407347.

Deniz, F., Saygideger, S.D. 2010. Corrigendum to "Equilibrium, kinetic and thermodynamic studies of Acid Orange 52 dye biosorption by Paulownis tomentosa Steud. Leaf powder as a low-cost natural biosorbent" [Bioresource Technology Vol. 101 (2010), p 5137-5143]. Bioresource Technology. Vol. 101, p 7688-7690. 
Deshpande, M.V., Eriksson, K.E. 1984. Reutilization of enzymes for saccharification of lignocellulosic materials. Enzyme and Microbial Technology. Vol. 6, p 338-340.

Dien, B.S., Sarath, G., Pedersen, J.F., Sattler, S.E., Chen, H., Funnell-Harris, D.L., Nicholas, N.N., Cotta, M.A. 2009. Improved sugar conversion and ethanol yield for forage sorghum (Sorghum bicolor L.Moench) lines with reduced lignin contents. Bioengineering Research. Vol. 2, p 153164.

Din, N., Forsythe, I.J., Burtnick, L.D., Gilkes, N.R., Miller, R.C., Warren, R.A.J., Kilburn, D.G. 1994. The cellulose-binding domain of endoglucanase A (CenA) from Cellulomonas fimi: evidence for the involvement of tryptophan residues in binding. Molecular Microbiology. Vol. $11, \mathrm{p} 747-755$.

Ding, S.Y., Xu, Q., Ali, M.K., Baker, J.O., Bayer, E.A., Barak, Y., Lamed, R., Sugiyama, J., Rumbles, G., Himmel, M.E. 2006. Versatile derivatives of carbohydrate-binding modules for imaging of complex carbohydrates approaching the molecular level of resolution. Biotechniques. Vol. 41(4), p 435-440.

Dhir, B., Kumar, R. 2010. Adsorption of heavy metals by Salvinia biomass and agricultural residues. International Journal of Environmental Research. Vol. 4(3), p. 427-432.

Dong, M., Wu, Z., Lu, M., Wang, Z., Li, Z. 2012. Combining the physical adsorption approach and the covalent attachment method to prepare a bifunctional bioreactor. International Journal of Molecular Science. Vol. 13(9), p 11443-11454.

Divne, C., Stahlberg, J., Reinikainen, T., Ruohonen, L., Petterson, G., Knowles, J., Teeri, T., Jones, T.A. 1994. The three dimentional crystal structure of the catalytic core of cellobiohydrolases I from Trichoderma reesei. Science. Vol. 265, p 524-528.

Du, X., Liu, X., Li, Y., Wu, C., Wang, X., Xu, P. 2013. Efficient biocatalyst by encapsulating lipase into nanoporous gold. Nanoscale Research Letters. Vol. 8, p 180-186. 
Du, R., Su, R., Li, X. 2012. Controlled adsorption of cellulase onto pretreated corncob by $\mathrm{pH}$ adjustment. Cellulose. Vol.19, p 371-380.

Eder, A.F., McGrath, C.M., Dowdy, Y.G., Tomaszewski, J.E., Rosenberg, F.M., Wilson, R.B., Wolf, R.B., Wolf, B.A., Shaw, L.M. 1988. Ethylene glycol poisoning: toxicokinetic and analytical factors affecting laboratory diagnosis. Clinical Chemistry. Vol. 44, p 168-177.

Ekwe, N.B. 2012. The effect of delignification on the saccharification of abakaliki rice husk. Advances in Applied Science Research. Vol. 3(6), p 3902-3908.

Elmore, R.H., Wadkins, R.M., Graves, D.E. 1988. Cooperative binding of m-AMSA to nucleic acids. Nucleic Acids Research. Vol. 16, p 9707-9719.

El-Sayed, G.O., Mohammed, T.Y., El-Sayed, O.E. 2011. Removal of basic dyes from aqueous solutions by sugar corn stalks. Advances in Applied Science Research. Vol. 2(4), p 283-290.

Eriksson, T., Borjesson, J., Tjerneld, F. 2002. Mechanism of surfactant effect in enzymatic hydrolysis of lignocellulose. Enzyme and Microbial Technology. Vol. 31, p 353-364.

Evstigneev, E.I. 2011. Factors affecting lignin solubility. Russian Journal of Applied Chemistry. Vol. 84, p 1040-1045.

Eze, L.C., Echetebu, C.O. 1979. Some properties of aspartate and alanine aminotransferases from Trichoderma viride. Microbiology. Vol. 120(2), p 523-527.

Fagerstam, L.G., Pettersson, L.G., Engstrom, J.A. 1984. The primary structure of a 1,4, $\beta$-glucan cellobiohydrolases from the fungus Trichoderma reesei QM 9414. FEBS Letters. Vol. 167, p $309-315$.

Falt, S., Wagberg, L., Vesterlind, E.L. 2003. Swelling of model films of cellulose having different charge densities and comparison to the swelling behavior of corresponding fibers. Langmuir. Vol. 19, p 7895-7903. 
Fan, L.T., Lee, Y.-H., Beardmore, D. H. 1980. Mechanism of the enzymatic hydrolysis of cellulose: Effects of major structural features of cellulose on enzymatic hydrolysis. Biotechnology and Bioengineering. Vol. 22, p 177.

Fan, L.T., Gharpuray, M.M., Lee, Y.-H. 1987. In: Cellulose Hydrolysis Biotechnology Monographs. Springer-Verlag, Berlin, Heidelberg.

Fenley, A.T., Muddana, H.S., Gilson, M.K. 2012. Entropy-enthalpy transduction caused by conformational shifts can obscure the forces driving protein-ligand binding. PANS. Vol. 109(49), p 20006-20011.

Fox, J.M., Jess, P., Jambusaria, R.B., Moo, G.M., Liphardt, J., Clark, D.S., Blanch, H.W. 2013. A single-molecule analysis reveals morphological targets for cellulase synergy. Nature Chemical Biology. Vol. 9, p 356-361.

Freundlich, H. 1906. Adsorption in solution. Journal of Physical Chemistry. Vol. 40, p 1361-1368.

Fukuda, T., Ishikawa, T., Ogawa, M., Shiraga, S., Kato, M., Suye, S., Ueda, M. 2006. Enhancement of cellulase activity by clones selected from the combinatorial library of the cellulose-binding domain by cell surface engineering. Biotechnology Progress. Vol. 22, p 933-938.

Fungsin, B., Suttikul, S., Akaracharany, A., Srinorakutara, T. 2007. Conversion of cassava waste into sugar using Aspergillus niger and Trichoderma reesei for ethanol production. http://www.biomass-asia-workshop.jp/biomassws/04workshop/poster_pdf/Poster09.pdf

Gan, Z., Zhang, T., Liu, Y., Wu, D. 2012. Temperature-triggered enzyme immobilization and release based on cross-linked gelatin nanoparticles. PLoS ONE. Vol. 7(10). doi:10.1371/journal.pone.0047154. 
Gao, S., You, C., Renneckar, S., Bao, J., Zhang, Yi-H.P. 2014. New insights into enzymatic hydrolysis of heterogeneous cellulose by using carbohydrate-binding module 3 containing GFP and carbohydrate-binding module 17 containing CFP. Biotechnology for Biofuel. Vol. 7, p 24. DOI: 10.1186/1754-6834-7-24.

Gao, D., Chundawat, S. P.S., Uppugundla, N., Balan, V., Dale, B.E. 2011. Binding characteristics of Trichoderma reesei cellulases on untreated, ammonia fiber expansion (AFEX), and dilute-acid pretreated lignocellulosic biomass. Biotechnology and Bioengineering. Vol. 108(8), p 17881800.

Gao, J., Zhang, Q., Su, K., Chen, R., Peng, Y. 2010. Biosorption of Acid Yellow 17 from aqueous solution by non-living aerobic granular sludge. Journal of Hazardous Materials, Vol. 174, p 215225. ISSN: 0304-3894.

Gaouar, N., Aschi, A., Belbahri, L., Trabelsi, S., Ghrabi, A. 2009. Study of thermal and chemical effects on cellulase enzymes: Viscosity measurements. Physica B: Physics of Condensed Matter, Volume 404(21), p. 4246-4252.

Galbe, M., Zacchi, G. 2002. A review of the production of ethanol from softwood. Applied Microbiology Biotechnology. Vol. 59, p 618-628.

Gekko, K., Timasheff, S.N. 1981a. Mechanism of protein stabilization by glycerol: preferential hydration in glycerol-water mixtures. Biochemistry. Vol. 20(16), p 4667-4676.

Gekko, K., Timasheff, S.N. 1981b. Thermodynamic and kinetic examination of protein stabilization by glycerol. Biochemistry. Vol. 20(16), p 4677-4686.

Gharpuray, M., Lee, Y.-H., Fan, L.T. 1983. Structural modification of lignocellulosics by pretreatments to enhance enzymatic hydrolysis. Biotechnology and Bioengineering. Vol. 25(11), p 157-172. 
Ghosh, B., Ray, R.R. 2011. Adsorption and elution of isoamylase from Rhizopus oryzae PR7 onto different native raw starches. Archives of Applied Science Research. Vol. 3(1), p 241-249.

Gilkes, N., Jervis, E., Henrissat, B., Tekant, B., Miller Jr. F R., Warren, R., Kilburn, D. 1992. The adsorption of a bacterial cellulase and its two isolated domains to crystalline cellulose. Journal of Biological Chemistry. Vol. 267, p 6743-6749.

Gilkes, N.R., Warren, R.A.J., Miller, R.C.Jr., Kilburn, D.G. 1988. Precise excision of the cellulose binding domains from two Cellulomonas fimi cellulases by a homologous protease and the effect on catalysis. Journal of Biology and Chemistry. Vol. 263, p 10401-10407.

Girard, D.J., Converse, A.O. 1993. Recovery of cellulase from lignaceous hydrolysis residue. Applied Biochemistry and Biotechnology. Vol. 39-40, p 521-533.

Goel, S.C., Ramchandran, K.B. 1983. Studies on the adsorption of cellulase on lignocellulosics. Journal of Fermentation Technology. Vol. 61(3), p 281-286.

Goldstein, M.A., Takagi, M., Hashida, S., Shoseyov, O., Doi, R.H. 1993. Characterization of the cellulose-binding domain of the Clostridium cellulovorans cellulose-binding protein A. Journal of Bacteriology. Vol. 175, p 5762-5768.

Gosselink, R.J.A., Abächerli, A., Semke, H., Malherbe, R., Käuper, P., Nadif, A., van Dam, J.E.G. 2004. Analytical protocols for characterisation of sulphur-free lignin. Industrial Crops and Products. Vol. 19, p 271-281.

Grassic A., Murry, P.G., Thompson, R., Collins, C.M., Byrnes, L., Birrane, G., Higgins, T.M., Tuohy, M.G. 2004. Three-dimensional structure of a thermostable native cellobiohydrolase, CBH I B, and molecular characterization of the cel7 gene from the filamentous fungus, Talaromyces emersonii. European Journal of Biochemistry. Vol. 271(22), p 4495-4506. 
Gruno, M., Valjamae, P., Petterson, G., Johansson, G. 2004. Inhibition of the Trichoderma reesei cellulase by cellobiose is strongly dependent on the nature of the substrate. Biotechnology and Bioengineering. Vol. 86, p 503-511.

Gupta, N., Kushwaha, A.K., Chattopadhyaya, M.C. 2012. Adsorptive removal of $\mathrm{Pb}^{2+}, \mathrm{Co}^{2+}$ and $\mathrm{Ni}^{2+}$ by hydroxyapatite/chitosan composite from aqueous solution. Journal of the Taiwan Institute of Chemical Engineers. Vol. 43(1), p 125-131.

Gupta, V.G. (Ed.) 2011. New and Future Developments in Microbial Biotechnology and Bioengineering. Elsevier. Radarweg 29, 1000 AE Amsterdam, Netherlands.

Gumuskaya, E., Usta, M. 2001. Crystalline structure properties of bleached and unbleached wheat straw (Triticum Aestivum L.) soda-oxygen pulp. Turkish Journal of Agriculture Forestry. Vol. 26, p 247-252.

Gustafsson, C. 2000. Solid State Characterisation and Compaction Behaviour of Pharmaceutical Materials. Ph.D. Dissertations, Faculty of Pharmacy. Uppsala University.

Habibi, Y., Foulon, L., Aguie-Beghin, V., Molinari, M., Douillard, R. 2007. Langmuir-Blodgett films of cellulose nanocrystals: Preparation and characterization. Journal of Colloid Interface Science. Vol. 316, p 388-397.

Hayashi, N., Sugiyama, J., Okano, T., Ishihara, M. 1997. The enzymatic susceptibility of cellulose microfibrils of the algal-bacterial type and the cotton-ramie type. Carbohydrate Research. Vol. 305, p 261-269.

Haynes, C.A., Norde, W. 1995. Structures and stabilities of adsorbed proteins. Journal of Colloid and Interface Science. Vol. 169, p 313-328.

Haynes, C.A., Norde, W. 1994. Globular proteins at solid/liquid interfaces. Colloids and Surfaces B: Biointerfaces. Vol. 2, p 517-566. 
Hefford, M.A., Laderoute, K., Willick, G.E., Yaguchi, M., Seligy, V.L. 1992. Bipartite organization of the Bacillus subtilis endo--1, 4-glucanase revealed by C-terminal mutations. Protein Engineering. Vol. 5, p $433-439$.

Helmberger, S. 2009. Hemicellulose. http://www.responsiblebusiness.eu/display/rebwp7 Retrieved July 28, 2015.

Heinzelman, P., Snow, C.D., Wu, I., Nguyen, C., Villalobos, A., Govindarajan, S., Minshull, J., Arnold, F.H. 2009. A family of thermostable fungal cellulases created by structure-guided recombination. Proceedings of the Natational Academy of Science. Vol. 106, p 5610-5615.

Hendricks A.T., Zeeman, G. 2009. Pretreatments to enhance the digestibility of lignocellulosic biomass. Bioresource Technology. Vol. 100, p 10-18.

Henriksson, H., Stahlberg, J., Isaksson, R., Pettersson, G. 1996. The active sites of cellulases are involved in chiral recognition: a comparison of cellobiohydrolases I and endoglucanase I. FEBS. Letters. Vol. 390, p 339-344.

Henshaw, J.L., Bolam, D.N., Pires, V.M.R., Czjzek, M., Henrissat, B., Ferreira, L.M.A., Fontes, C., Gilbert, H.J. 2004. The family 6 carbohydrate binding module CmCBM6-2 contains two ligandbinding sites with distinct specificities. Journal of Biological Chemistry. Vol. 279, p 2155221559.

Hilden, L., Johansson, G. 2004. Recent developments on cellulases and carbohydrate-binding modules with cellulose affinity. Biotechnology Letters. Vol. 26, p 1683-1693.

Himmel, M.E., Ding, S.Y., Johnson, D.K., Adney, W.S., Nimlos, M.R., Brady, J.W., Foust, T.D. 2007. Biomass recalcitrance: Engineering plants and enzymes for biofuels production. Science. Vol. 315, p 804-807. 
Hofs, B., Brzozowska, A., Keizer, A., Norde, W., Stuart, M.A.C. 2008. Reduction of protein adsorption to a solid surface by a coating composed of polymeric micelles with a glass-like core. Journal of Colloid and Interface Science. Vol. 325(2), p 309-315.

Hoareau, W., Trindade, W.G., Siegmund, B., Castellan, A., Frollini, E. 2004. Sugar cane bagasse and curaua lignins oxidized by chlorine dioxide and reacted with furfuryl alcohol: Characterization and stability. Polymer Degradtion and Stability. Vol. 86, p 567-576.

Holtzapple, M.T., Jun, J., Ashok, G., Patribandla, S.L., Dale, B.E. 1991. The ammonia freeze explosion (AFEX) process: A practical lignocellulose pretreatment. Applied Biochemistry and Biotechnology. Vol. 28/29, p 59-74.

Hong, J., Ye, X., Zhang, Y.H.P. 2007. Quantitative determination of cellulose accessibility to cellulase based on adsorption of a nonhydrolytic fusion protein containing CBM and GFP with its applications. Langmuir. Vol. 23, p 12535-12540.

Hopkins, W.S. 1999. Introduction to Plant Physiology (2nd ed.), John Wiley \& Sons, Inc., New York, $\mathrm{p} 12$.

Horsfall, M.J., Spiff, A.I. 2005. Effects of temperature on the sorption of $\mathrm{Pb} 2+$ and $\mathrm{Cd} 2+$ from aqueous solution by Caladium bicolor (Wild Cocoyam) biomass. Electronic Journal of Biotechnology. Vol. 8(2), p162-169.

Horsfall, M.J., Spiff, A.I. 2004. Studies on the effect of $\mathrm{pH}$ on the sorption of $\mathrm{Pb}^{2+}$ and $\mathrm{Cd}^{2+}$ ions from aqueous solutions by Caladium bicolor (Wild Cocoyam) biomass. Electronic Journal of Biotechnology Vol. 7(3), p 313-323.

Horton, H.R., Moran, L.A., Ochs, R.S., Rawn, J.D., Scrimgeour, K.G. 1996. Principles of Biochemistry (2nd ed.), Prentice Hall Inc., NJ. 
Hoshino, E., Kanda, T., Sasaki, Y., Nisizawa, K. 1992. Adsorption mode of exo-cellulases and endocellulases from Irpex lacteus (Polyporus tulipiferae) on cellulose with different crystallinities. Journal of Biochemistry (Tokyo). Vol. 111, p 600-605.

Hu, J., Arantes, V., Saddler, J.K. 2011. The enhancement of enzymatic hydrolysis of lignocellulosic substrates by the addition of accessory enzymes such as xylanase: Is it an additive or synergistic effect? Biotechnology Biofuels. Vol. 4(36). doi: 10.1186/1754-6834-4-36.

Humphrey W., Dalke A., Schulten, K. 1996. VMD: visual molecular dynamics. Journal of Molecular Graphics. Vol. 14, p 33-38.

Hunter, A.K., Carta, G. 2002. Protein adsorption on novel acrylamido-based polymeric ionexchangers. IV. Effects of protein size on adsorption capacity and rate. Journal of Chromatography A. Vol. 971, p 105-116.

Hwang, S., Lee, K.T., Park, J.W., Min, B.R., Haam, S.J., Ahn, I.S., Jung, J.K. 2004. Stabilisation of Bacillus stearothermophilus lipase immobilised on surface-modified silica gels. Biochemical Engineering Journal. Vol. 17, p 85-90.

Imamura, K., Shimomura, M., Nagai, S., Akamatsu, M., Nakanish, K. 2008. Adsorption characteristics of various proteins to a titanium surface. Journal of Bioscience and Bioengineering Vol. 106(3), p 273-278.

Ioelovich, M. Morag, E. 2011. Effect of cellulose structure on enzymatic hydrolysis. Bioresources. Vol. 6(3), p 2818-2835.

Isaacs, S.H. 1984. Ethanol Production by Enzymatic Hydrolysis Parametric Analysis of a Case-case Process. Task No. 1372.35 Solar Energy Research Institute, 1617 Cole Boulevard, Golden, Colorado 80401. SERI/TR 231-2093 US.

Ito, A., Oikawa, T. 2004. Global mapping of terrestrial primary productivity and light use efficiency with a process based model. In: Shiyomi, M., Kawahatas, H., Koizumi, H., Tsuda, A., Awaya, 
Y. (Eds.). Global Environmental Changes in the Ocean and Land. Terrabup, Tokoyo, Japan, p 343-358.

Ito, J., Fujita, Y., Ueda, M., Fukuda, H., Kondo, A. 2004. Improvement of cellulose-degrading ability of a yeast strain displaying Trichoderma reesei endoglucanase II by recombination of cellulosebinding domains. Biotechnology Progress. Vol. 20, p 688-691.

Itodo, A.U., Abdulrahman, F.W., Hassan, L.G, Maigandi, S.A., Itodo, H.U. (2010b). Application of Methylene Blue and iodine adsorption number for the measurement of specific surface area by four acid and salt treated activated carbon. New York Science. Vol. 3(5), p 25-33.

Jackson, L.S., Joyce, T.W., Heitmann, J.A., Giesbrecht, F.G. 1996. Enzyme activity recovery from secondary fiber treated with cellulase and xylanase. Biotechnology. Vol. 45, p 33-44.

Jager, G., Wu, Z., Garscchammer, K., Engel, P., Klement, T., Rinaldi, Spiess, A.C., Buchs, J. 2010. Practical screening of purified cellobiohydrolases and endoglucanases with $\alpha$ cellulose and specification of hydrodynamics. Biotechnology for Biofuels. Vol. 3(18), p 1-12.

Jakab, E., Faix, O., Tiii, F. 1997. Thermal decomposition of milled wood lignins studied by thermogravimetry/mass spectrometry. Journal of Analytical and Applied Pyrolysis. Vol. 40-41, p 171-86.

Jeoh, T., Ishizawa, C.I., David, M.F., Himmel, M.E., Adney, W.S., Johnson, D.K. 2007. Cellulase digestibility of pretreated biomass is limited by cellulose accessibility. Biotechnology and Bioengineering. Vol. 98, p 112-122.

Jeon, S.I., Lee, J.H., Andrade, J.D., Degennes, P.G. 1991. Protein surface interactions in the presence of polyethylene oxide. 1. Simplified theory. Journal of Colloid Interfacial Science. Vol. 142(1), p149-158.

Johnson, B.B. 1990. Effect of pH, temperature, and concentration on the adsorption of cadmium on goethite. Environmental Science and Technology. Vol. 24, p 112-118. 
Jung, H., Wilson, D.B., Walker, L.P. 2002a. Binding mechanisms for Thermobifida fusca Cel5A, Cel6B, and Cel48A cellulose-binding modules on bacterial microcrystalline cellulose. Biotechnology and Bioengineering. Vol. 80, p 380-392.

Kalliopi, K.A. 2005. Pore Structure of Cement-Based Materials: Testing Interpretation and Requirements (Modern Concrete Technology). Taylor \& Francis, p 432.

Kanchagar, A.P. 2003. Adsorption of purified cellulases on cotton fibers. Division of Cellulose and Renewable Materials. The 225th ACS National Meeting, New Orleans, LA, March 23-27, 2003.

Kang, L. 2011. Bioconversion of Pulp and Paper Mills Sludge and Prehydrolysate Stream into Ethanol and Cellulase Enzyme. Ph.D. Dissertation. Auburn University, Albama, USA.

Kang, S.M., Titus, J.S. 1981. Characterization of glutamine synthetase in the apple. Physiologia Plantarum. Vol. 53(3), p 239-244.

Karaca, A., Cetin, S.C., Turgay, O.C., Kizilkaya, R. 2010b. Effects of heavy metals on soil enzyme activities. In: Sherameti, I., Varma, A. (eds.) Soil Heavy Metals, Soil Biology. Vol. 19. Springer, Berlin, p 237-262.

Karmakar, M., Ray, R.R. 2015. The endoglucanase producing fungal strain Rhizopus oryzae PR7 MTCC 9642 on activated charcoal. International Journal of Applied Biology and Paharmaceutical Technology. Vol. 6(2), p 100-107.

Kim, S., Dale, B.E. 2004. Global potential bioethanol production from wasted crops and crop residues. Biomass and Bioenergy Vol. 26 (4), p 361 - 375. doi:10.1016/j.biombioe.2003.08.002

Karlsson, J., Siika-aho, M., Tenkanen, M., Tjerneld, F. 2002. Enzymatic properties of the low molecular mass endoglucanases Cel12A (EGIII) and Cel45A (EGV) of Trichoderma reesei. Journal of Biotechnology. Vol. 99, p 63-78.

Karlsson, J., Medve, J., Tjerneld, F. 1999. Hydrolysis of steam-pretreated lignocellulose. Applied Biochemistry and Biotechnology, Vol. 82, p 243-258. 
Kawamoto, H., Nakatsubo, F., Murakami, K. 1992. Protein-adsorbing capacities of lignin samples. Mokuzai Gakkaishi. Vol. 38(1), p 81-84.

Kim, D.W., Jang. Y.H., Kim. C.S., Lee, N. 2001. Effect of metal ions on the degradation and adsorption of two cellobiohydrolases on microcrystalline cellulose. Bulletin of the Korean Chemical Society. Vol. 22(7), p 716-720.

Kim, D.W., Hong, Y.G. 2000. Ionic strength effect on adsorption of cellobiohydrolases I and II on microcrystalline cellulose. Biotechnology Letters. Vol. 22, p 1337-1342.

Kim, D.W., Jang, Y.H., Jeong, Y.K. 1998. Adsorption kinetics and behavior of two cellobiohydrolases from Trichoderma reesei on microcrystalline cellulose, Biotechnology and Applied Biochemistry. Vol. 27, p 97-102.

Kim, D.W., Yoon, Y.H., Jeong, Y.K., Lee, J.K., and Jang, Y.H. 1995a. Effect of adsorption of endoglucanase on the degradation of microcrystalline cellulose. Bulletin of the Korean Chemical Society, Vol. 16(8), p 720-726.

Kim, D.W., Jeong, Y.K., Jang, Y.H., Lee, J.K., Kim, K.S., Ryu, H. 1995b. Kinetic mechanism of cellulose hydrolysis by endoglucanase I and exoglucanases II purified from Trichoderma viride. Bulletin of the Korean Chemical Society. Vol. 16(8), p 742- 747.

Kim, D.W., Jeong, Y.K., Jang, Y.H., Lee, J. K. 1995c. Adsorption characteristics of Endo II and Exo II purified from Trichoderma viride on microcrystalline celluloses with different surface area. Bulletin of Korean Chemical Society. Vol. 16(6), p 498-503.

Kim, D.W., Kim, T.S., Jeong, Y.K., Lee, J. K. 1992. Adsorption kinetics and behaviors of cellulase components on microcrystalline cellulose. Journal of Fermentation and Bioengineering. Vol. 73(6), p 461-466.

Kim, D.W., Yang, J.H., Jeong, Y.K. 1988. Adsorption of cellulase from Trichoderma viride on microcrystalline cellulose. Applied Microbiology and Biotechnology. Vol. 28, p 148-154. 
Kirk, T.K., Farrell, R.L. 1987. Enzymatic combustion: The microbial degradation of lignin. Annual Reviews in Microbiology. Vol. 41, p 465-505.

Klemm, D., Heublein, B., Finl, H., Bohn, A. 2005. Cellulose: Fascinating biopolymer and sustainable raw material. Angewandte Chemie International Edition. Vol. 44, p 3358-3393.

Kleywegt, G.J., Zou, J.Y., Divne, C., Davies, G.J., Sinning, I., Stahlberg, J., Reinikainen, T., Srisodsuk, M., Teeri, T.T., Jones, T.A. 1997. The crystal structure of the catalytic core domain of endoglucanase I from Trichoderma reesei at $3.6 \AA$ resolution, and a comparison with related enzymes. Journal of Molecular Biology. Vol. 272, p 383-397.

Kaneko, H., Hosoya, S., Nakano, J. 1981. Degradation of lignin with ozone. Reactions of biphenyl and a-carbonyl type model compounds with ozone. Mokuzai Gakkaishi. Vol. 27, p 678-683.

Knowles, J., Lehtovaara, P., Teeri, T. 1987. Cellulase families and their genes. Tibtech. Vol. 5, p 255-261.

Kontturi, E., Tammelin, T., Osterberg, M. 2006.Cellulose-model films and the fundamental approach. Chemical Society Reviews. Vol. 35, p 1287- 1304.

Koshland, D.E.J. 1953. Stereochemistry and the mechanism of enzymatic reactions. Biology Reviews. Vol. 28(4), p 416-436.

Kotha, A., Raman, R.C., Ponrathnam, S., Kumar, K.K., Shewale, J.G. 1998. Beaded reactive polymers. 3. Effect of triacrylates as crosslinkers on the physical properties of glycidyl methacrylate copolymers and immobilisation of penicillin G acylase. Applied Biochemistry and Biotechnology. Vol. 74, p 191-203.

Knipping, S. 2016. Fuel Prices. The Ministry of Energy, Ontario. Retrieved Sept 1, 2016. http://www.energy.gov.on.ca/en/fuel-prices/. 
Kratzl, K., P. Claus, W. Lonsky, Gratzl, J.S. 1974. Model studies on reactions occurring in oxidations of lignin with molecular oxygen in alkaline media. Wood Science and Technology. Vol. 8, p. 3549.

Kraulis, P.J., Clore, G.M., Nilges, M., Jones, T.A., Pettersson, G., Knowles, J., Gronenborn, A.M. 1989. Determination of the three-dimensional solution structure of the C-terminal domain of cellobiohydrolase I from Trichoderma reesei. A study using nuclear magnetic resonance and hybrid distance geometry-dynamical simulated annealing. Biochemistry. Vol. 28, p 7241-7257.

Kumar, R., Wyman, C. E. 2008. An improved method to directly estimate cellulase adsorption on biomass solids. Enzyme and Microbial Technology. Vol. 42(5), p 426-433.

Kumar, R., Wyman, C.E. 2009a. Access of cellulase to cellulose and lignin for poplar solids produced by leading pretreatment technologies. Biotechnology Progress. Vol. 25(3), p 807-819.

Kumar, R., Wyman, C.E. 2009b. Cellulase adsorption and relationship to features of corn stover solids produced by leading pretreatments. Biotechnology and Bioengineering. Vol. 103(2), p 252-267.

Kumar, S.P., and Kirthika, K. 2009. Equilibrium and kinetics study of adsorption of nickel from aqueous solution onto Bael tree leaf powder. Journal of Engineering Science and Technology. Vol. 4(4), p $351-363$.

Kuhtreiber, W.M., Lanza, R.P., Chic, W.L. (Eds). 1999. Cell Encapsulation Technology and Therapeutics. Springer Science + Business Media, New York, USA.

Kushwaha, S., Sodaye, S., Padmaja, P. 2008. Equilibrium, kinetics and thermodynamic studies for adsorption of $\mathrm{Hg}$ (II) on palm shell powder. World Academy of Science, Engineering and Technology. Vol. 43, p 600-606. 
Kuutti L., Laaksonen L., Teeri T.T. 1991. Interaction studies of the tail domain of cellbiohydrolase I and crystalline cellulose using molecular modelling. Journal Chim. Phys. Chim. Biol. Vol. 88, p 2663-2667.

Kyriacou, A., Neufeld, R.J., Mackenzie, C.R. 1989. Reversibility and competition in the adsorption of Trichoderma reesei cellulase components. Biotechnology and Bioengineering. Vol. 33, p 631637.

Kyriacou, A., Neufeld, R.J., Mackenzie, C.R. 1988. Effect of physical parameters on the adsorption characteristics of fractionated Trichoderma reesei cellulase components. Enzyme Microbial Technology. Vol. 10, p 675-681.

Kauzman, W. 1959. Some factors in the interpretation of protein denaturation. Advances in Protein Chemistry Vol. 14, p 1-63.

Lamed, R., Tormo, J., Chirino, A.J., Morag, E., Bayer, E.A. 1994. Crystallization and preliminary X-ray analysis of the major cellulose-binding domain of the cellulosome from Clostridium thermocellum. Journal of Molecular Biology. Vol. 244, p 236-237.

Lante, A., Crapisi, A., Krastanov, A., Spettoli, P. 2000. Biodegradation of phenols by laccase immobilised in a membrane reactor. Process Biochemistry. Vol. 36, p 51-58.

Langmuir, I. 1918. The adsorption of gases on plane surfaces of glass, mica and platinum. Journal of the American Chemical Society. Vol. 40, p 1361-1403.

Lappalainen, M., Pitka, I., Heikkila, H, Nurmi, J. 2006. Melting behaviour and evolved gas analysis of xylose. Journal of Thermal Analysis and Calorimetry. Vol. 84, p 367-376.

Lazar, M.A., Truscott, R.J.W., Raese, J.D., Barchas, J.D. 1981. Thermal denaturation of native striatal tyrosine hydroxylase: Increased the mobility of the phosphorylated form of the enzyme. Journal of Neurochemistry. Vol. 36(2), p 677-682. 
Le Costaouec, T., Pakarinen, A., Varnai, A., Puranen, T., Viikari, L. 2013. The role of carbohydrate binding module (CBM) at high substrate consistency: Comparison of Trichoderma reesei and Thermoascus aurantiacus Cel7A (CBHI) and Cel5A (EGII). Bioresource Technology. Vol. 143, p 196-203.

Leavitt, E.F. 2001. Direct measurement of protein binding energetics by isothermal titration calorimetry. Current Opinion in Chemical Biology. Vol. 11, p 506-566.

Lee, J.H., Brown, R.M. 1997. A comparative structural characterization of two cellobiohydrolases from Trichoderma reesei: a high resolution electron microscopy study. Journal of Biotechnology. Vol. 57, p 127-136.

Lee, S.B., Kim, I.H., Ryu, S.Y., Taguchi, H. 1983. Structural properties of cellulose and cellulase reaction mechanism. Biotechnology and Bioengineering. Vol. 25, p 33-51.

Lee, S.B., Shin, H S., Ryu, D.D.Y. 1982. Absorption of cellulase on cellulose: effect of physicochemical properties of cellulose on adsorption and rate of hydrolysis. Biotechnology and Bioengineering. Vol. 24, p 2137-53.

Lee, Y.H., Fan, L.T. 1983. Kinetic studies of enzymatic-hydrolysis of insoluble cellulose. 2. Analysis of extended hydrolysis times. Biotechnology and Bioengineering. Vol. 25, p 939-66.

Lee, Y.H., and Kim, I.H. 1983. Structural properties of cellulose and cellulase reaction mechanism. Biotechnology and Bioengineering. Vol. 25, p 33-51.

Lee, D., Yu, A.H.C., Wong, K.K.Y., Saddler, J.N. 1994. Evaluation of the enzymatic susceptibility of cellulosic substrates using specific hydrolysis rates and enzyme adsorption. Applied Biochemistry and Biotechnology. Vol. 45/46, p 407-415.

Lee, Y.H., Fan, L.T. 1982. Kinetic-studies of enzymatic-hydrolysis of insoluble cellulose. 1. Analysis of the initial rates. Biotechnology and Bioengineering. Vol. 24(11), p 2383-2406. 
Lee, N. E., Woodward, J. 1989. Kinetics of the adsorption of Trichoderma reesei C30 cellulase to DEAE-Macrosorb. Journal of Biotechnology. Vol. 11, p 75-82.

Lee, S. 1999. Molecular Adsorption at Solid/ Liquid Interfaces Using Self-assembled Monolayer Films. Ph.D. Thesis. Department of Chemical Engineering. Massachusetts Institute of Technology.

Lee, D., Yu, A.H.C., Saddler, J.N. 1995. Evaluation of cellulase recycling strategies for the hydrolysis of lignocellulosic substrates. Biotechnology and Bioengineering. Vol. 45, p 328-336.

Lehtio, J., Sugiyama, J., Gustavsson, M., Fransson, L., Linder, M., Teeri, T.T. 2003. The binding specificity and affinity determinants of family 1 and family 3 cellulose binding modules. Proceedings of the National Academy of Sciences of the United States of America. Vol. 100, p 484-489.

Levine, S.E., Fox, J.M., Blanch, H.W., Clark, D.S. 2010. A mechanistic model of the enzymatic hydrolysis of cellulose. Biotechnology and Bioengineering. Vol. 107, p 37-51.

Li, J., Li, S.-Z., Fan, C.-Y., Yan, Z.-P. 2011. The mechanism of polyethylene glycol (PEG) 4000 effect on enzymatic hydrolysis of lignocellulose. Colloid Surfaces B. Vol. 89, p 203-120.

Li, L., Flora, R., King, K. 1965. Individual roles of cellulase components derived from Trichoderma viride, Archives of Biochemistry and Biophysics. Vol. 111, p 439.

Liao, Y.-C., Syu, M.-J. 2005. Novel immobilized metal affinity adsorbent based on cross-linked b cyclodextrin matrix for repeated adsorption of a -amylase. Biochemical Engineering Journal. Vol. 23, p 17-24.

Limayem, A., Ricke, S.C. 2012. Lignocellulosic biomass for bioethanol production: Current perspectives, potential issues and future prospects. Progress in Energy and Combustion Science. Vol. 38, p 449-467. 
Lin, K.W., Ladisch, M.R., Voloch, M., Patterson, J.A., Noller, C.H. 1985. Effect of pretreatments and fermentation on pore size in cellulosic materials. Biotechnology and Bioengineering. Vol. 27, p 1427-1433.

Linder, M., Teeri, T.T. 1996. The cellulose-binding domain of the major cellobiohydrolases of Trichoderma reesei exhibits true reversibility and a high exchange rate on crystalline cellulose. Proceedings of the National Academy of Science. Vol. 93, p 12251-12255.

Linder, M., Lindeberg, G., Reinikainen, T., Teeri, T.T., Pettersson, G. 1995.The difference in affinity between 2 fungal cellulose-binding domains is dominated by a single amino-acid substitution. FEBS Letters. Vol. 372, p 96-98.

Linder, M., Mattinen, M.L., Kontteli, M., Lindeberg, G., Stahlberg, J., Drakenberg, T., Reinikainen, T., Pettersson, G., Annila, A. 1995. Identification of functionally important amino acids in the cellulose binding domain of Trichoderma reesei cellobiohydrolases I. Protein Science. Vol. 4, p 1056-1064.

Linder, M., Teeri, T.T. 1997. The roles and function of cellulose-binding domains. Journal of Biotechnology. Vol. 57, p 15-28.

Lingstrom, R., Notely, S.M., Wagberg, L. 2007. Wettability changes in formation of polymeric multilayers on cellulose fibres and their influence on wet adhesion. Journal of Colloid and Interface Science. Vol. 314, p 1-9.

Liu, Y., Baker, J., Zeng, Y., Himmel, M., Haas, T., Ding, S. 2011. Cellobiohydrolase hydrolyzes crystalline cellulose on hydrophobic faces. Journal of Biology and Chemistry. Vol. 286(13), p $11195-11201$.

Liu, W, Hong, J, Bevan, D.R, Zhang, Y.-HP. 2009. Fast identification of thermostable betaglucosidase mutants on cellobiose by a novel combinatorial selection/screening approach. Biotechnology and Bioengineering. Vol. 3, p 1087-1094. 
Liu, F., Chen, J., Li, A., Fei, Z., Zhu, Z., Zhang, Q. 2003. Properties and thermodynamics of adsorption of benzoic acid onto XAD-4 and water-compatible hypercrosslinked adsorbent. Chinese Journal of Polymer Science. Vol. 21(3), p 317-324.

Lou, H., Zhu, J.Y., Lan, T.Q., Lai, H., Qiu, X. 2013. pH-induced lignin surface modification to reduce nonspecific cellulase binding and enhance enzymatic saccharification of lignocelluloses. Chemical Suspension Chemistry. Vol. 6, p 919-927.

Low, K.S., Lee, C.K., Leo, A.C. 1995. Removal of metals from electroplating wastes using banana pith. Bioresource Technology. Vol. 51(2-3), p. 227-231.

Lu, Y.P., Yang, B., Gregg, D., Saddler, J.N., Mansfield, S.D. 2002. Cellulase adsorption and an evaluation of enzyme recycle during hydrolysis of steam-exploded softwood residues. Applied Biochemistry and Biotechnology. Vol. 98, p 641-654.

Lu, S., An, Z., Li, J., He, J. 2011. pH-Triggered adsorption desorption of enzyme in mesoporous host to act on macro substrate. Journal of Physical Chemistry. Vol. 115, p 13695-13700.

Lutzen, N.W., Nielsen, H.N., Oxenboell, K.M., Schulein, M., and Stentebjerg-Olesen, B. 1983. Cellulases and their application in the conversion of lignocellulose to fermentable sugars. Philosophical Transactions of the Research Society London B. Vol. 300, p 283-291.

Lyddon, C. 2011. Focus on Canada, the grain and grain processing information site, world-grain.com http://www.world-grain.com/Departments/Country.

Lynd, L.R., Laser, M. S., Bransby, D., Dale, B.E., Davison, B., Hamilton, R., Himmel, M., Keller, M., McMillan, J.D., Sheehan, J., Wyman, C.E. 2008. How biotech can transform biofuels. Nature Biotechnology. Vol. 26, p 169-172.

Lynd, L.R., Weimer, P.J., van Zyl, W.H. 2002. Pretorius IS: Microbial cellulose utilization: fundamentals and biotechnology. Microbiology and Molecular Biology Reviews. Vol. 66, p 506577. 
McGuire, J., Wahlgren, M.C., Arnebrant, T. 1995. Structural stability effects on the adsorption and dodecyltrimethylammonium bromide-mediated elutability of bacteriophage T4 lysozyme at silica surfaces. Journal of Colloid and Interface Science. Vol. 170, p 182-192.

Machado, D.L., Neto, J.M., Pardella, J.G., Rabelo, S.C., Carvalho da Costa, A. 2014. Adsorption characteristics of cellulase and $\beta$-glucosidase on Avicel, pretreated sugarcane bagasse, and lignin. Biotechnology and Applied Biochemistry. Vol. , p 681-689.

Mackenzie, L.F., Sulzenbacher, G., Divne, C., Jones, T.A., Wöldike, H.F., Schülein, M., Withers, S.G., Davies, G.J. 1998. Crystal structure of the family 7 endoglucanase I (Cel7B) from Humicola insolens at $2.2 \AA$ resolution and identification of the catalytic nucleophile by trapping of the covalent glycosyl-enzyme intermediate. Biochemistry Journal. Vol. 335, p 409-416.

Mackenzie, L.F., Davies, G.J., Schulein, M., Withers, S.G. 1997. Identification of the catalytic nucleophile of endoglucanase I from Fusarium oxysporum by mass spectrometry. Biochemistry. Vol. 36(19), p 5893-5901.

Manara, S.R. 2012. Structural and mechanistic fundamentals for designing of cellulases. Computational and Structural Biotechnology Journal Vol. 2 (3), p 1-7.

Mandels, M., Weber, J. 1969. The production of cellulases. Advanced Chemical Series. Vol. 95, p $391-413$.

Mahadavi, M., Ahmad, M.B., Haron, M.J., Rahman, M.Z. 2011. Adsorption of Cr (III) from aqueous solutions by polyacrylamide-grafted rubberwood fiber: Kinetics, equilibrium and thermodynamic studies. BioResources. Vol. 6(1), p 22-33.

Mandels, M. 1982. Cellulases. In: Annual Reports on Fermentation Processes (Tsao, G.T., Ed.) New York: Academic Press. Vol. 5, pp. 35-78.

Masel, R.I. 1996. Principles of Adsorption and Reaction on Solid Surfaces, Wiley, New York 
Mathew, G.M., Sukumaran, R.K., Singhania, R., Pamdey, A. 2008. Progress in research on fungal cellulases for lignocellulosic degradation. Journal of Scientific and Industrial Research. Vol. 67, p 898-907.

Matsushita, Y. 2015. Conversion of technical lignins to functional materials with retained polymeric properties. Journal of Wood Science. Vol. 61(3), p 230-250. doi:10.1007/s10086$015-1470-2$

Mavrodineanu, R., Schultz, J. I., Menis, Oscar. 1973. Accuracy in spectrophotometry and luminescence measurements: Proceedings. Washington, D.C.: U.S. National Bureau of Standards. p. 2.

Maurer, S.A., Bedbrook, C.N., Radke, C.J. 2012. Competitive sorption kinetics of inhibited endoand exoglucanases on a model cellulose substrate. Langmuir. Vol. 28(41), p 14598-14608. DOI: 10.1021/la3024524.

McKendry, P. 2002. Energy production from biomass (part 1): overview of biomass. Bioresource Technology. Vol. 83, p 37-46.

Medve, J., Karlsson, J., Lee, D., Tjerneld, F. 1998. Hydrolysis of microcrystalline cellulose by Cellobiohydrolase I and Endoglucanase II from Trichoderma reesei: Adsorption, sugar production pattern, and synergism of the enzymes. Biotechnology and Bioengineering. Vol. 59(5), p $621-634$.

Medve, J., Stahlberg, J., Tjerneld, F. 1994. Adsorption and synergism of cellobiohydrolase I and II of Trichoderma reesei during hydrolysis of microcrystalline cellulose. Biotechnology and Bioengineering. Vol. 44(9), p 1064-1073.

Melanie, H., Bansal, P., Lee, J.H., Realff, M.J., Bommarius, A.S. 2010. Cellulose crystallinity - a key predictor of the enzymatic hydrolysis rate. The FEBS Journal. Vol. 277, p 1571-152. 
Messa, L., Gonzalez, E., Cara, C., Gonzalez, M., Castro, E., Mussatto, S.I. 2011. The effect of organosolv pretreatment variables on enzymatic hydrolysis of sugarcane bagasse. Chemical Engineering Journal. Vol. 168, p 1157-1162.

Miller, G.L. 1959. Use of dinitrosalicylic acid reagent for determination of reducing sugars. Analytical Chemistry. Vol. 31, p 426-428.

Monsan, P. 1978. Optimization of glutaraldehyde activation of a support for enzyme immobilization. Molecular Catalysis. Vol. 3(5), p 372-384.

Montane, D., Farriol, X., Salvadó, J., Jollez, P., Chornet, E. 1998. Fractionation of wheat straw by steam-explosion pretreatment and alkali delignification. Cellulose pulp and byproducts from hemicellulose and lignin. Journal of Wood Chemistry and Technology. Vol. 18, p 171-191.

Morag, E., Lapidot, A., Govorko, D., Lamed, R., Wilchek, M., Bayer, E.A., Shoman, Y. 1995. Expression, purification, and characterization of the cellulose-binding domain of the scaffolding subunit from the cellulosome of Clostridium thermocellum. Applied Environmental Microbiology. Vol. 61, p 1980- 1986.

Morrison, R. T., Boyd, R. N. 1992. Organic Chemistry (6 ${ }^{\text {th }}$ ed.). Prentice Hall, New Jersey, USA.

Morrow, R.M., Carbonell, R.G., McCoy, B.J. 1975. Electrostatic and hydrophobic effects in affinity chromatography. Biotechnology and Bioengineering. Vol. 17, p 895-914.

Mosier, N., Wyman, C.E., Dale, B.E., Elander, R.T., Lee, Y.Y., Holtzapple, M., Ladisch, M. 2005. Features of promising technologies for pretreatment of lignocellulosic biomass. Bioresource Technology. Vol. 96, p 673-686.

Mosolova, T.P., Kalyuzhnyi, S.V., Varfolomeyev, S.D., Velikodvorskaya, G.V. 1993. Purification and properties of Clostridium thermocellum endoglucanase-5 produced in Escherichia coli. Applied Biochemistry and Biotechnology. Vol. 42, p 9-18. 
Mukherjee, J., Gupta, M.N. 2015. Increasing importance of protein flexibility in designing biocatalytic processes. Biotechnology Reports. Vol. 6, p 119-123.

Mulakala, C., Reilly, P. J. 2005. Hypocrea jecorina (Trichoderma reesei) cel7a as a molecular machine: A docking study. Proteins: Structure, Function, and Bioinformatics. Vol. 60(4), p 598605.

Murikipudi, V., Gupta, P., Sihorkar, V. 2013. Efficient throughput method for hygroscopicity classification of active and inactive pharmaceutical ingredients by water vapor sorption analysis. Pharmaceutical Development and Technology. Vol. 18(2), p 348-358.

Murphy, L. 2011. Thermochemical screening of lignocellulosic enzymes for second generation bioethanol production. Ph.D. Thesis. Department of Science, Systems, and Models (NSM). Biomaterials, Roskilde University, Denmark.

Mussatto, S.I., Fernandes, M., Milagres, A.M.F. 2008. Effect of hemicellulose and lignin on enzymatic hydrolysis of cellulose from brewer's spent grain. Enzyme and Microbial Technology. Vol. 43, p 124-129.

Nagayama, K., Spieb, A.C., Buchs, J. 2012. Enhanced catalytic performance of immobilized Parvibaculum lavamentivorans alcohol dehydrogenase in a gas phase bioreactor using glycerol as an additive. Chemical Engineering Journal Vol. 207, p 342-348.

Nam, J.M., Fujita, Y., Arai, T., Kondo, A., Morikawa, Y., Okada, H., Ueda, M., Tanaka, A. 2002. Construction of engineered yeast with the ability of binding to cellulose. Journal of Molecular Catalysis B: Enzymes. Vol. 17, p 197-202.

Nakagame, S., Chandra, R., Saddler, J.N. 2010. The effect of isolated lignins, obtained from a range of pretreated lignocellulosic substrates, on enzymatic hydrolysis. Biotechnology and Bioengineering. Vol. 105, p 871-879. 
Nakagame, S., Chandra, R.P., Kadla, J.F., Saddler, J.N. 2011b. The isolation, characterization and effect of lignin isolated from steam pretreated Douglas-fir on the enzymatic hydrolysis of cellulose. Bioresource Technology. Vol. 102, p 4507-4517.

Nesbitt, W.E., Doyle, R.J., Taylor, K.G., Staat, R.H. Arnold, R.R. 1982. Positive cooperativity in the binding of Streptococcus sanguis to hydroxylapatite. Infection and Immunity Vol.35(1) , p 157165.

Netrabukkana, R. Lourvanij, K. Rorrer, G.L. 1996. Diffusion of glucose and glucitol in microporous and mesoporous silicate/alumino silicate catalysts. Industrial and Engineering Chemical Research. Vol. 35(2), p 458-464.

Neurath, H., Greenstein, J.P., Putnam, F.W., and Erickson, J.O. 1944. The chemistry of the protein denaturing. Chemical Reviews. Vol. 34(2), p 157-265.

Ngah, W.S.W., Hanafiah, M.A.K.M. 2008. Adsorption of copper on rubber (Hevea brasiliensis) leaf powder: Kinetic, equilibrium and thermodynamic studies. Biochemical Engineering Journal. Vol. 39, p 521-530.

Nicolucci, C., Rossi, S., Menale, C., Godjevargova, T., Ivanov, Y., Bianco, M. 2011. Biodegradation of bisphenols with immobilized laccase or tyrosinase on polyacrylonitrile beads. Biodegradation. Vol. 22(3), p 673-683.

Nidetzky, B., Steiner, W. 1993. A new approach for modeling cellulase-cellulose adsorption and the kinetics of the enzymatic hydrolysis of microcrystalline cellulose. Biotechnology and Bioengineering. Vol. 42(4), p 469-479.

Nidetzky, B., Steiner, W., Claeyssens, M. 1994. Cellulose hydrolysis by the cellulases from Trichoderma reesei: Adsorptions of two cellobiohydrolases, two endocellulases and their core proteins on filter paper and their relation to hydrolysis. Biochemistry Journal. Vol. 303(Pt 3), p 817-823. 
Nimlos, M.R., Matthews, J.F., Crowley, M.F., Walker, R.C., Chukkapalli, G., Brady, J.W., Adney, W.S., Cleary, J.M., Zhong, L., Himmel, M.E. 2007. Molecular modeling suggests induced fit of Family I carbohydrate-binding modules with a broken-chain cellulose surface. Protein Engineering, Design and Selection. Vol. 20(4), p 179-187.

Niku-Paavola, M.L., Lappalainen, A., Enari, T.M., Nummi, M. 1986. Trichoderma reesei cellobiohydrolases II: Purification by immune adsorption and hydrolytic properties. Biotechnology Application and Biochemistry. Vol. 8, p 449-458.

Ninfa, A.J., Ballou, D.P., Benore, M. 2010. Fundamental Laboratory Approaches for Biochemistry and Biotechnology (2 ${ }^{\text {nd }}$ Ed.). John Wiely and Sons. ISBN : 978-0-470-47131-9

Norde, W., Tan, W., Koopal, L. 2008. Protein adsorption at solid surfaces and protein complexation with humic acids. Journal of Soil Science Plant Nutrition. Vol. 8(noespecial), p 64-74. http://dx.doi.org/10.4067/S0718-27912008000400011.

Norde, W. 1996. Driving forces for protein adsorption at solid surfaces. Macromolecular Symposia. Vol. 103, p 5-18.

Norde, W. 1986. Adsorption of proteins from solution at the solid-liquid interface. Advances in Colloid and Interface Science. Vol. 25(4), p 267-340.

Notely, S. M., Wageberg, L. 2005. Morphology of modified regenerated model cellulose II surfaces studied by atomic force microscopy: Effect of carboxymethylation and heat treatment. Biomacromolecules. Vol. 6, p 1586-1591.

Novozyme and NREL reduce enzyme cost. 2005. News on: Science Direct-Focus on Catalysts. Vol. 2005(7), p 4. DOI: 10.1016/S1351-4180(05)71066-7.

Nutor, J.R.K., Converse, A.O. 1991. The Effect of enzyme and substrate levels on the specific hydrolysis rate of pretreated poplar wood. Applied Biochemistry and Biotechnology. Vol. 28/29, p $757-772$. 
Oberholzer, M.R., Lenhoff, A.M. 1999. Protein adsorption isotherms through colloidal energetics. Langmuir. Vol. 15, p 3905-3914.

Ofomaja, A.E., Nidoo, E.B., Modise, S.J. 2010, Kinetic and pseudo-second-order modeling of lead biosorption onto pine cone powder. Industrial Engineering Chemistry Research. Vol. 49, p 25622572.

Ofek, I., Doyle. R.J. 1994. Bacterial Adhesion to Cells and Tissues. Chapman and Hall Inc.

Ong, E., Gilkes, N.R, Miller, R.C. Jr., Warren, R.A.J., Kilburn, D.G. 1993. The cellulose-binding domain (CBDcex) of an exoglucanases from Cellulomonas fimi: production in Escherichia coli and characterization of the polypeptide. Biotechnology and Bioengineering. Vol. 42, p 401-409.

Ophardt, C.E. 2003. Virtual Chembook. Elmhurst College. Retrieved on March 21, 2016. http://chemistry.elmhurst.edu/vchembook/568denaturation.html

Ooshima, H., Burns, D.S., Converse, A.O. 1990. Adsorption of cellulase from Trichoderma reesei on cellulose and lignacious residue in wood pretreated by dilute sulfuric acid with explosive decompression. Biotechnology and Bioengineering. Vol. 36(5), p 446-452.

Ooshima, H., Sakata, M., Harano, Y. 1983. Adsorption of cellulase from Trichoderma viride on cellulose. Biotechnology and Bioengineering. Vol. 25, p 3103-3114.

Oscik, J., Cooper, I.L. 1982. Adsorption. John Wiley and Sons, New York and Printed in Poland. O’Sullivan, A. C. 1997. Cellulose: The structure slowly unravels. Cellulose. Vol. 4, p 173-207.

Otter, D.E., Munro, P.A., Geddes, R. 1984. Elution of Trichoderma reesei cellulase from cellulose by $\mathrm{pH}$ adjustment with sodium hydroxide. Biotechnology Letters. Vol. 6, p 369-374.

Otter, D.E., Munro, P.A., Scott, G.K., Geddes, R. 1989. Desorption of Trichoderma reesei cellulase from cellulose by a range of desorbents. Biotechnology and Bioengineering. Vol. 34, p 291-298. Padmavathy, V. 2008. Biosorption of nickel (II) ions by baker's yeast: Kinetic, thermodynamic and desorption studies. Bioresource Technology. Vol. 99, p 3100-3109. 
Pardo, A.G., Forchiassin, F. 1999. Influence of temperature and pH on cellulase activity and stability in Nectria catalinensis. Reviews of the Argentinian Microbiology. Vol. 31(1), p 31-35.

Pareek, N., Gillgren, T., Jonsson, L.F. 2013. Adsorption of proteins involved in hydrolysis of lignocellulose on lignins and hemicelluloses. Bioresource Technology. Vol. 148, p 70-77.

Park, D., Jhon, D.Y., Lee, C.W., Ryu, S.H., Rhee, S.G. 1993. Removal of the carboxyl-terminal region of phospholipase C-beta 1 by calpain abolishes activation by $\mathrm{G}$ alpha $\mathrm{q}$. Journal of Biological Chemistry. Vol. 268, p 3710-3714.

Palonen, H., Tjerneld, F., Zacchi, G., Tenkanen, M. 2004. Adsorption of Trichoderma reesei CBH I and EG II and their catalytic domains on steam pretreated softwood and isolated lignin. Journal of Biotechnology. Vol. 107, p 65-72.

Palonen, H., Tenkanen, M., Linder, M. 1999. Dynamic interaction of Trichoderma reesei cellobiohydrolases Cel6A and Cel7A and cellulose at equilibrium and during hydrolysis. Applied Environmental Microbiology. Vol. 65, p 5229-5233.

Pan, X.J. 2008. Role of functional groups in lignin inhibition of enzymatic hydrolysis of cellulose to glucose. Journal of Biobased Materials and Bioenergy. Vol. 2(1), p 25-32.

Pareek, N., Gillgren, T., Jönsson, L.J. 2013. Adsorption of proteins involved in hydrolysis of lignocellulose on lignins and hemicelluloses. Bioresoure Technology. Vol. 148, p 70-77.

Pauly, M., Keegstra, K. 2008. Cell-wall carbohydrates and their modification as a resource for biofuels. Plant Journal. Vol. 54, p 559-568.

Penttila, M., Lehtovaara, P., Nevalainen, H., Bhikhabhai, R., Knowles, J. 1986. Homology between cellulase genes of Trichoderma reesei: complete nucleodite sequence of the endoglucanase I gene. Gene. Vol. 45, p 253-263. 
Peterson, M.E., Daniel, R.M., Danson, M.J., Eisenthal, R. 2007. The dependence of enzyme activity on temperature: determination and validation of parameters. Biochemistry Journal. Vol. 402(2), p 331-337.

Phelps, M.R., Hobbs, J.B., Kilburn, D.G., Turner, R.F.B. 1995. Comparison of a fungal (family I) and bacterial (family II) cellulose-binding domain. Journal of Bacteriology. Vol. 177, p 43564363.

Piccolo, C., Wiman, M., Bezzo, F., Liden, G. 2010. Enzyme adsorption on $\mathrm{SO}_{2}$ catalyzed steampretreated wheat and spruce material. Enzyme and Microbial Technology. Vol. 46, p 159-169.

Pietersen, N., Medeiros, J., Mandels, M. 1977. Adsorption of Trichoderma cellulase on cellulose. Biotechnology and Bioengineering. Vol. 19(7), p 1091- 1094.

Pierre, G., Maache-Rezzoug, Z., Sannier, F., Rezzoug, S. 2011. High-performance hydrolysis of wheat straw using cellulase and thermomechanical pretreatment. Process Biochemistry. Vol. 46, p 2194-2200.

Pinto, R., Moreira, S., Mota, M., Gama, M. 2004. Studies on the cellulose-binding domains adsorption to cellulose. Langmuir. Vol. 20, p 1409-1413.

Pinto, R., Amaral, A.L., Carvalho, J., Ferreira, E.C., Mota, M., Gama, M. 2007. Development of a method using image analysis for the measurement of cellulose-binding domains adsorbed onto cellulose fibers. Biotechnology Progress. Vol. 23, p 1492-1497.

Privalov, P.L., Gil, S.J. 1988. Stability of protein structure and hydrophobic interaction. In: Advances in Protein Chemistry (Anfinsen, C.B., Edsal, J.T., Richards, F.M., Eisenberg, D.S., Eds.). Academic Press, San Diego, CA, p.191-234.

Pratt, S. 2015. Official see benefits of ethanol imports. The Western Producer, May 28, 2015.

Proctor, A., Toro-Vazquez, J. 1996. The Freundlich isotherm in studying adsorption in oil processing, Journal of the American Oil Chemists Society. Vol. 73, p 1627-1663. 
Qadeer, M. 2005. Ethnic segregation in a multicultural city. In Desegregating the City: Ghettos, Enclaves, and Inequality (Varady, D., Ed.). SUNY Press.

Qi, B., Chen, X., Su, Y., Wan, Y. 2011. Enzyme adsorption and recycling during hydrolysis of wheat straw lignocellulose. Bioresource Technology. Vol. 102, p 2881-2889.

Qi, M., Jun, H., Forsberg, C.W. 2007. Characterization and synergistic interactions of Fibrobacter succinogenes glycoside hydrolases. Applied Environmental Microbiology. Vol. 73(19), p 60986105.

Ragnar, M., Lindgren, C.T., Nilvebrant, N. 2000. pKa-values of guaiacyl and syringyl phenols related to lignin. Journal of Wood Chemistry and Technology. Vol. 20, p 277-305.

Radeva, G., Valchev, I., Petrin, S. 2011. Study of the adsorption equilibrium in cellulase-pulp system. Journal of the University of Chemical Technology and Metallurgy. Vol. 46(2), p 197-202.

Rahikainen, J. 2013. Cellulase-lignin interactions in the enzymatic hydrolysis of lignocellulose. Doctoral dissertation. University of Helsinki, Faculty of Agriculture and Forestry, Department of Food and Environmental Sciences VTT Technical Research Centre of Finland

Rahikainen, J., Mikander, S., Marjamaa, K., Tamminen, T., Lappas, A., Viikari, L., Kruus, K. 2011. Inhibition of enzymatic hydrolysis by residual lignins from softwood—study of enzyme binding and inactivation on lignin-rich surface. Biotechnology and Bioengineering. Vol. 108(12), p 28232834.

Ramalingam, K., Aimoto, S., Bello, J. 1992. Conformational studies of anionic melittin analogues: effect of peptide concentration, $\mathrm{pH}$, ionic strength and temperature-models for protein folding and halophilic proteins. Biopolymers. Vol. 32, pp. 981-992.

Ramdane, H., El Rhilassi, A., Mourabet, M., Bennani-Ziatni, M., Elabidi, A., Zinedine, A., Taitai, A. 2014. Calcium phosphates as adsorbents for the controlled release of carbofuran. Journal of Material and Environmental Sciences. Vol. 5(6), p 1715-1726. 
Ramos, L.P., Breuil, C., Saddler, J.N. 1992. Comparison of steam pretreatment of eucalyptus, aspen, and spruce wood chips and their enzymatic hydrolysis. Applied Biochemistry and Biotechnology. Vol. 34, p 37-47.

Raven, P.H., Evert, R.F., Eichhorn, S.E. 2005. Biology of Plants, 7th Edition. New York: W.H. Freeman and Company Publishers. P 124-127.

Receveur, V., Czjzek, M., Schulein, M., Panine, P., Henrissat, B. 2002. Dimension, shape, and conformational flexibility of a two domain fungal cellulase in solution probed by small angle Xray scattering. Journal of Biological Chemistry. Vol. 277, p 40887-40892.

Reed, B.E., Matsumoto, M.R. 1993. Modelling cadmium adsorption by activated carbon using the Langmuir and Freundlich isotherms. Separation Science and Technology. Vol. 28, p 21792195.

Reese, E.T. 1982. Elution of cellulase from cellulose. Process Biochemistry. Vol. 7, p 2-6.

Reinikainen, T., Teleman, O., Teeri T.T. 1995. Effects of $\mathrm{pH}$ and high ionic strength on the adsorption and activity of native and mutated cellobiohydrolase I from Trichoderma reesei. Proteins: Structure, Function and Bioinformatics. Vol. 22, p 392-403.

Reinikainen T., Ruohonen L., Nevanen T., Laaksonen L., Kraulis P., Jones T.A., Knowles J.K.C., Teeri T.T. 1992. Investigation of the function of mutated cellulose-binding domains of Trichoderma reesei cellobiohydrolase I. Proteins. Vol. 14, p 475-482.

Reinikainen T.R., Ruohonen L., Koivula A., Srisodsuk M., Jones A., Knowles J.K.C., Claeyssens M., Teeri T.T. 1991. How do Trichoderma reesei cellobiohydrolases bind to and degrade cellulose. The American Chemical Society. Vol. 202(Abstract of Papers, American Chemical Society). 
Reshamwala, Shawky, B.T., Dale, B.E. 1995. Ethanol production from enzymatic hydrolysates of AFEX-treated coastal Bermuda grass and switchgrass. Applied Biochemistry and Biotechnology. Vol. 51/52, p 43-55.

Rezus, Y.L.A., Bakker, H.J. 2007. Observation of immobilized water molecules around hydrophobic group. Physical Review Letters. Vol. 99, p 148301.

Rincon-Silva, N.G., Moreno-Pirajan, J.C., Giraldo, L.G. 2015. Thermodynamic study of adsorption of phenol, 4-chlorophenol, and 4-nitrophenol on activated carbon obtained from eucalyptus seed. Journal of Chemistry. Vol. 2015 http://dx.doi.org/10.1155/2015/569403

Rivers, D. B., Emert, G. H. 1988. Factors affecting the enzymatic hydrolysis of municipal-solidwaste components. Biotechnology and Bioengineering. Vol. 31, p 278-281.

Rodrigues, A.C., Leitao, A.F., Moreira, S., Felby, C., Gama, M. 2012. Recycling of cellulases in lignocellulosic hydrolysates using alkaline elution. Bioresource Technology. Vol. 110, p 526533.

Rodriguez, B. 1997. Characterization of an Affinity Purification System for Recombinant Proteins Containing a Cellulose Binding Domain. Master's Thesis. Department of Chemical and BioResource Engineering. University of British Columbia.

Rollin, J.A., Zhu, Z., Sathisuksanoh, N., Zhang, P.Y-H. 2011. Increasing cellulose accessibility is more important than removing lignin: A comparison of cellulose solvent-based lignocellulose fractionation and saking in aqueous ammonia. Biotechnology and Bioengineering. Vol. 108, p 22-30.

Roos, A.A., Chandra, R., Pan, X., Rio, L.D., Pribow, A., Ghatora, S., Saddler, J. 2009. The effect of substrate properties on enzyme adsorption during hydrolysis of ethanol organosolv pretreated hardwoods and soft woods: potential for enzyme recycling. 31st Symposium on Biotechnology for Fuels and Chemicals. San Francisco, CA. 
Rosgaard, L., Pedersen, S., Langston, J., Akerhielm, D., Cherry, J.R., Meyer, A. 2007. Evaluation of minimal Trichoderma reesei cellulose mixtures on differently pretreated barley straw substrates. Biotechnology Progress. Vol. 23, p 1270-1276.

Rout, M.P., Aitchison, J.D., Magnasco, M.O., Chait, B.T. 2003. Virtual gating and nuclear transport: the hole picture. Trends in Cell Biology. Vol. 13(12), p 622-628.

Rouvinen, J., Bergfors, T., Teeri, T., Knowles, J-K., Jones, T-A. 1990. Three-dimensional structure of cellobiohydrolase II from Trichoderma reesei. Science. Vol. 249, p 380-386.

Ryu, D.D.Y., Kim, J.Y., Lee, S.B. 1991. Bioprocess kinetics and modeling of recombinant fermentation. In: Biotechnology - A Multivolume Comprehensive Treatise (Rehm, H.J., Reed, G., Eds). VCH, Weinheim, Germany, pp. 486-505.

Ryu, D.D.Y., Kim, C., Mandels, M. 1984. Competitive adsorption of cellulase components and its significance in a synergistic mechanism. Biotechnology and Bioengineering Vol. 26, p 488-496.

Saha, B., Saikia, J., Das, G. 2014. Correlating enzyme density, conformation and activity on nanoparticle surface for high functional bio-nanocomposite. Electronic Supplementary Material (ESI) for Analyst. http://www.rsc.org/suppdata/an/c4/c4an01639d/c4an01639d1.pdf

Saha, P., Chowdhury, S. 2011. Insight into adsorption thermodynamics. Thermodynamics (Tadashi, M., Ed.) Intech Open Science, India.

Sahoo, S., Seydibeyoglu, M.O., Mohanty, A.K., Misra, M. 2011. Characterization of industrial lignins for their utilization in future value added applications. Biomass and Bioenergy. Vol. 35, p 4230-4237.

Sari, A., Tuzen, M., Uluozlu, O.D., Soylak, M. 2007. Biosorption of Pb (II) and Ni (II) from aqueous solution by lichen (Cladonia furcata) biomass. Biochemical Engineering Journal. Vol. 37, p 151158. 
Sari, A., Tuzen, M. 2008. Biosorption of cadmium (II) from aqueous solution by red algae (Ceramium virgatum): Equilibrium, kinetic and thermodynamic studies. Journal of Hazardous Materials. Vol. 157, p 448-454.

Sathitsuksanoh, N., Zhu, Z.G., Zhang, Y.H.P. 2012. Cellulose solvent-based pretreatment for corn stover and Avicel: concentrated phosphoric acid versus ionic liquid [BMIM] Cl. Cellulose. Vol. 19, p 1161-1172.

Sathitsuksanoh, N., Georgr, A., Zhang, Y-H.P. 2012. New lignocellulose pretreatments using cellulose solvents: a review. Journal of Chemical Technology and Biotechnology. DOI 10.1002/jctb.3959.

Sathitsuksanoh, N., Zhu, Z., Templeton, N., Rollin, J., Harvey, S., Zhang, Y-HP. 2009. Saccharification of a potential bioenergy crop, Phragmites australis (common reed), by lignocellulose fractionation followed by enzymatic hydrolysis at decreased cellulase loadings. Industrial and Engineering Chemistry Research. Vol. 48(13), p 6441-6447.

Savany, A., Cronenberger, L. 1982. Properties of histidine decarboxylase from rat gastric mucosa. European Journal of Biochemistry. Vol. 23, p 593-599.

Seo, D., Fujita, H., Sakoda, A. 2011. Effect of a non-ionic surfactant Tween 20, on adsorption/desorption of saccharification enzymes onto/from lignocelluloses and saccharification rate. Adsorption. Vol. 17, p 813:822.

Sendich, E., Laser, M., Kim, S., Alizadeh, H., Laureano-Perez, L., Dale, B., Lynd, L. 2008. Recent progress improvements for the ammonia fiber explosion (AFEX) process and resulting reductions in minimum ethanol selling price. Bioresource Technology. Vol. 99(17), p 8429-8435.

Sethi, B., Mishra, S., Bisaria, V.S. 1998. Adsorption characteristics of cellulases from a constitutive of Trichoderma reesei. Journal of Fermentation and Bioengineering Vol. 86(2), p 233-235. 
Sewalt, V.J.H., Glasser, W.G., Beauchemin, K.A. 1997. Lignin impact on fiber degradation. 3. Reversal of inhibition of enzymatic hydrolysis by chemical modification of lignin and by additives. Journal of Agricultural Food Chemistry. Vol. 45, p 1823-1828.

Shalabi, K., Abdallah, Y.M., Hassan, H.M., Fouda, A.S. 2014. Adsorption and corrosion inhibition of Atropa belladonna extract on carbon steel in $1 \mathrm{M} \mathrm{HCl}$ solution. International Journal of Electrochemical Science. Vol. 9, p 1468-1487.

Shao, X., Lynd, L., Wyman, C., Bakker, A. 2008. Kinetic modeling of cellulosic biomass to ethanol via simultaneous saccharification and fermentation: Part I. Accommodation of intermittent feeding and analysis of staged reactors. Biotechnology and Bioengineering. Vol. 102, p 59-65.

Shan, S., Herschlag, D. 1999. Hydrogen bonding in enzymatic catalysis: Analysis of energetic contributions. Methods in Enzymology. Vol. 308, p 246-276.

Shevelev, I. V., Hubscher, U. 2002. The 3‘-5'exonucleases. Nature Reviews in Molecular Cell Biology. Vol. 3(5), p 364-375.

Shewale, I.G., Sadana, J.C. 1979. Enzymatic hydrolysis of cellulosic materials by Sclerotium rolfsii culture filtrate for sugar production. Canadian Journal of Microbiology. Vol. 25, p 773-783.

Shoseyov, O., Shani, Z., Levy, I. 2006. Carbohydrate binding modules: Biochemical properties and novel applications. Microbiology and Molecular Biology Reviews. Vol. 70(2), p. 283-295.

Silverstein, R.A., Chen, Y., Sharma-Shivappa, R.R., Boyette, M.D., Osborne, J. 2007. A comparison of chemical pretreatment methods for improving saccharification of cotton stalks. Bioresource Technology. Vol. 98, p 3000-3011.

Singh, J., Kaur, M. 2014. Partial purification of cellulase enzyme from Fusarium oxysporium by using egg white matrix. British Biotechnology Journal. Vol. 4(2), p 108-15.

Singh, A., Kumar, P.K.R., Schugerl, K. 1991. Adsorption and reuse of cellulases during saccharification of cellulosic materials. Journal of Biotechnology. Vol. 18, p 205-212. 
Sinitsyn, A.P., Gusakov, A.V., Valsen, E.Y. 1991. Effect of structural and physic-chemical features of cellulosic substrates on the efficiency of enzymatic hydrolysis. Applied Biochemistry and Biotechnology. Vol. 30, p 43-59.

Srinivas, V., Balasubramanian, D. 1995. Proline is a protein-compatible hydrotrope. Langmuir. Vol. 11, p 2830-2833.

Srisodsuk, M., Reinikainen, T., Penttila, M., Teeri, T.T. 1993. Role of the inter-domain linker peptide of Trichoderma reesei cellobiohydrolase I in its interaction with crystalline cellulose. Journal of Biological Chemistry. Vol. 268, p 20756-20761.

Srivastava, P., Singh, B. 2006. Effect of ionic strength on cadmium adsorption onto kaolinite in single and multi-element systems. 19th World Congress of Soil Science, Soil Solutions for a Changing World 2010, Brisbane, Australia.

Srivasta, P., Hasan, S.H. 2011. Biomass of Mucor heimalis for the biosorption of Cd from aqueous: Equilibrium and kinetics studies. Bioresource. Vol. 6(4), p 3656-3675.

Sjostrom, E. 1993. Cellulose Derivative. Wood Chemistry, Fundamentals and Applications (2 ${ }^{\text {nd }}$ Ed.). Academic Press, San Diego, California, p 204.

Squire, P.G., Himmel, M. E. 1979. Hydrodynamics and protein hydration. Archives of Biochemistry and Biophysics. Vol. 196, p 165-177.

Stahlberg, J., Johansson, G., Pettersson, G. 1991. A new model for enzymatic hydrolysis of cellulose based on the two-domain structure of cellobiohydrolases I. Biotechnology. Vol. 9, p 286-290.

The Consumer Price Index, May 21, 2015. Statistics Canada. http://www.statcan.gc.ca/pub/62-001x/2013005/part-partie1-eng.htm, Retrieved on June 21, 2015.

The Consumer Price Index, March 23, 2012. Statistics Canada. http://www.statcan.gc.ca/subjectssujets/cpi-ipc/cpi-ipc-eng.pdf (PDF version, 3454.0 kb). Retrieved on June 21, 2015. 
Steiner, W., Sattler, W., Esterbauer, H. 1988. Adsorption of Trichoderma reesei cellulase on cellulose: Experimental data and their analysis by different equations. Biotechnology and Bioengineering. Vol. 32, p 853-865.

Stone, J.E., Scallan, A.M., Donefer, E., Ahlgren, A. 1969. Digestibility as a simple function of a molecule of similar size to a cellulase enzyme. In: Cellulases and their Applications (Hajny, G.J., Reese, E.T.). Volume 95. American Chemical Society, Washington DC, p 219-241.

Sun, X., Wang, S., Liu, X., Gong, W., Bao, N., Gao, B., Zhang, H. 2008. Biosorption of Malachite Green from aqueous solutions onto aerobic granules: Kinetic and equilibrium studies. Bioresource Technology. Vol. 99, p 3475-3483.

Sun, Y., Lin, C.X., Liu, M. H., Liu, Y.F. 2011. Equilibrium adsorption behaviors and kinetic characteristics of oxymatrine on a spherical cellulose adsorbent. Bioresources. Vol. 6(1), p 631640.

Sun, Y., Cheng, J. 2002. Hydrolysis of lignocellulosic materials for ethanol production: a review, Bioresource Technology. Vol. 83, p 1-11.

Sun, S., Tomkinson, J., Mao, F.C., Sun, X.F. 2001. Physicochemical characterisation of lignins from rice straw by hydrogen peroxide treatment. Journal of Applied Polymer Science. Vol. 79, p 719732.

Sutcliffe, R., Saddler, J.N. 1986. The role of lignin in the adsorption on cellulases during enzymatic treatment of lignocellulosic material. In: Biotechnology and Bioengineering Symposium (Scott, C.D., Ed.). John Wiley and Sons, New York, p. 749-762.

Tammelin, T., Saarinen, T., Osterberg, M., Laine, J. 2006. Preparation of Langmuir / Blodgettcellulose surfaces by using horizontal dipping procedure. Application for polyelectrolyte adsorption studies performed with QCM-D. Cellulose. Vol. 13, p 519-535. 
Tanaka, M., Ikesaka, M., Matsune, R., Converse, A.O. 1988. Effect of pore size in substrate and diffusion of enzyme on hydrolysis of cellulosic materials with cellulases. Biotechnology and Bioengineering. Vol.32 (5), p 698-706.

Tang, Y., Hu, T., Zeng, Y., Zhou, Q., Peng, Y. 2015. Effective adsorption of cationic dyes by lignin sulfonate polymer based on simple emulsion polymerization: isotherm and kinetic studies. Royal Society of Chemistry Advances. Vol. 5, p 3757-3766.

Tavares, A.P.M., Rodríguez, O., Fernández-Fernández, M., Domínguez, A., Moldes, D., Sanromán, M. A., Macedo, E.A. 2013. Immobilization of laccase on modified silica: stabilization, thermal inactivation and kinetic behaviour in 1-ethyl-3-methylimidazolium ethylsulfate ionic liquid. Bioresource Technology. Vol. 131, p 405-412.

Tazrouti, N., Amrani, M. 2009. Chromium VI adsorption onto activated kraft lignin produced from alfa grass (Stripa tenacissima). BioResource. Vol. 4(2), p 740-755.

Teeri, T.T., Lehtovaara, P., Kauppinen, S., Salovuori, I., Knowles, J. 1987. Homologous domains in Trichoderma reesei cellulolytic enzymes: gene sequence and expression of cellobiohydrolase II. Gene. Vol. 51, p 43-52.

Teeri, T.T. 1997. Crystalline cellulose degradation: New insight into the function of cellobiohydrolases. Trends in Biotechnology. Vol. 15, p 160- 167.

Thygesen, L., Hidayat, B.J., Johansen, K.S., Felby, C. 2010. The significance of supramolecular structures of cellulose for the enzymatic hydrolysis of plant cell walls. Proceeding of the 32nd Symposium on Biotechnology for Fuels and Chemicals. April 19-22 2010, Clearwater Beach.

Tormo, J., Lamed, R., Chirino, A.J., Morag, E., Bayer, E.A., Shoham, Y., Steitz, T.A. 1996. Crystal structure of a bacterial family-III cellulose-binding domain: a general mechanism for attachment to cellulose. EMBO Journal, Vol. 15, p 5739-5751. 
Tomme, P., Driver, D.P., Amandoron, E.A., Miller, R.C., Antony, R., Warren, J., Kilburn, D.G. 1995. Comparison of a fungal (family I) and bacterial (family II) cellulose-binding domain. Journal of Bacteriology. Vol. 177, p 4356-4363.

Tomme, P., Heriban, V., Claeyssens, M. 1990. Adsorption of two cellobiohydrolases from Trichoderma reesei to Avicel: evidence for exo-exo synergism and possible loose complex formation. Biotechnology Letters. Vol. 12, p 525-30.

Tomme, P., Van Tilbeurgh, H., Pettersson, G., Van Damme, J., Vandekerckhove, J., Knowles, J., Teeri, T. and Claeyssens, M. 1988. Studies of the cellulolytic system of Trichoderma reesei QM 9414. Analysis of domain function in two cellobiohydrolases by limited proteolysis. European Journal of Biochemistry. Vol. 170, p 575-581.

Trumbo, T. A., Schultz, E., Borland, M.G., Pugh, M.E. 2013. Applied spectrophotometry: analysis of a biochemical mixture. Biochemistry and Molecular Biology Education Vol. 41(4), p 242-250 Tu, M., Pan, X., Saddler, J.N. 2009. Adsorption of cellulase on cellulolytic enzyme lignin from Lodgepole pine. Journal of Agricultural Food Chemistry. Vol. 57, p 7771-7778.

Tu, M., Chandra, R.P., Saddler, J.N. 2007. Recycling cellulases during the hydrolysis of steam exploded and ethanol pretreated Lodgepole pine. Biotechnology Progress. Vol. 23, p 1130-1137.

Tu, M., Chandra, R.P., Saddler, J.N. 2007. Evaluating the distribution of cellulases and the recycling of free cellulases during the hydrolysis of lignocellulosic substrates. Biotechnology Progress. Vol. 23, p 398-406.

Tunc, O., Tanac, H, Aksu, Z. 2009. Potential use of cotton plant wastes for removal of Remazol black B reactive dye. Journal of Hazardous Materials. Vol. 163, p 187-198.

Ucar, T., Ekiz, H.I., Caglar, M.A. 1989. Surface effects of solvents in hydrolysis of water-soluble lipids by Candida lipase. Biotechnology and Bioengineering. Vol. 33, p 1213-1218. 
US Energy Information Administration, Online Petroleum Statistics, Accessed Sept 18. 2008: http://toronto.eia.doe.gov/dnav/pet/hist/wtotworldw.htm.

US Energy Administration, Energy Information Administration, Independent Statistics and Analysis, Petroleum and Other Liquids, 2011, http://www.eia.gov/petroleum/reports.cfm?t=66

Vadi, M., Abbasi, M., Zakeri, M., Yazdi, B.J. 2010. Application of the Freundlich Langmuir Temkin and Harkins-Jura adsorption isotherms for some amino acids and amino acids complexation with manganese ion (II) on carbon nanotube. Journal of Physical and Theoretical Chemistry. Vol. $7(2)$, p 95-104.

Vallander, L., Eriksson, K.-E. 1987. Enzyme recirculation in saccharification of lignocellulosic materials. Enzyme and Microbial Technology. Vol. 9, p 714-720.

Varnai, A., Siikaaho, M., Viikari, L. 2010. Restriction of the enzymatic hydrolysis of steampretreated spruce by lignin and hemicellulose. Enzyme and Microbial Technology. Vol. 46, p $185-193$.

Van Wyk, J.P.H. 1997. Cellulase adsorption-desorption and cellulose saccharification during enzymatic hydrolysis of cellulose materials. Biotechnology Letters. Vol. 19(8), p 775-778.

Vehovec, T., Gartner, O., Planinsek, O., Obreza, A. 2012. Influence of different types of commercially available microcrystalline cellulose on degradation of perindopril erbumine and enalapril maleate in binary mixtures. Acta Pharmaticeutica. Vol. 62, p 515-528.

Velisek, J. 2014. The Chemistry of Food. John Wiley and Sons Ltd. Oxford, UK.

Viikari, L., Alapuranen, M., Puranen, T., Vehmaanperä, J., Siika-Aho, M. 2007. Thermostable enzymes in lignocellulose hydrolysis. Advances in Biochemical Engineering/Biotechnology. Vol. 108, p 121-145.

Violet, M., Meunier, J.C. 1989. Kinetic study of the irreversible thermal denaturation of Bacillus licheniformis $\alpha$-amylase. Biochemistry Journal. Vol. 263, p 665-670. 
van Tilbeurgh, H., Tomme, P., Caleyssens, M., Bhikhabhai, R., Pettersson, G. 1986. Limited proteolysis of the cellobiohydrolases I from Trichoderma reesei, FEBS Letters. Vol. 204, p 223227.

Vinzanti, T.B., Adney, W.S., Decker, S.R., Baker, J.O., Kinter, M.T., Sherman, N.E., Fox, J.W., Himmel, M.E. 2001. Fingerprinting Trichoderma reesei hydrolases in a commercial cellulase preparation. Applied Biochemistry and Biotechnology. Vol. 91-93, p 99-107.

Vyas, N.K. 1991. Atomic features of protein-carbohydrate interactions. Current Opinion in Structural Biology. Vol. 1, p 732-740.

Wang, G., Post, W.M., Mayes, M.A. 2013. Development of microbial-enzyme-mediated decomposition model parameters through steady-state and dynamic analyses. Ecological Applications. Vol. 23(1), p 255-272.

Wang, Q.Q., He, Z., Zhu Z., Zhang, Y.H., Ni, Y., Luo, X.L. Zhu, J.Y. 2012. Evaluations of cellulose accessibilities of lignocelluloses by solute exclusion and protein adsorption techniques. Biotechnology and Bioengineering. Vol. 109(8), p 381-389.

Wang, P., Zhang, L.M., Zheng, Z.M., Wang, L., Wang, H., Yuan, C.L., Gong, G.H. 2011. Microbial lipid production by co-fermentation with Mortierella alpine obtained by ion beam implantation. Chemical Engineering and Technology. Vol. 34, p 422-428.

Wang, D.W. 2010. Optimizing Enzymatic Preparations of Mechanical Pulp through the Characterization of New Laccases and Non-productive Interactions between Enzymes and Lignin. Master's thesis, Department of Chemical Engineering and Applied Chemistry, University of Toronto.

Warden, A.C., Little, B.A., Haritos, V.S. 2011. A cellular automaton model of crystalline cellulose hydrolysis by cellulases. Biotechnology for Biofuels. Vol. 4, p 39. Doi: 10.1186/1754-6834-439. 
Waterberg, J.H. 2002. The lowery method for protein quantitation. In: The Protein Protocols Handbook (2nd ed., Walker, J.M., Ed.). Humana Press, Totawa, NJ, p 7-9.

Weimer, P.J., Weston, W.M. 1985. Relationship between the fine structure of native cellulose and cellulose degradability by the cellulase complexes of Trichoderma reesei and Clostridium thermocellum. Biotechnology and Bioengineering. Vol. 27, p 1540-1547.

Weiss, N., Borjesson, J., Pedersen, L.S., Meyer, A.S. 2013. Enzymatic lignocellulose hydrolysis: Improved cellulase productivity by insoluble solids recycling. Biotechnology Biofuels. Vol. 6, p 5. Doi: 10.1186/1754-6834-6-5.

Wenbin, O., Yongdoo, P., Fanguo, M., Haimeng, Z. 2002. Effects of glycerol in the refolding and unfolding of creatine kinase. Tsinghua Science and Technology. Vol. 7(4), p 352 - 362.

Komarova, K. 2008. Strategy for cellulase immobilization and its partial purification and characterization. Master's Thesis. Chemical Engineering. Ryerson University. Toronto. Canada.

Westmoreland, D.G., Matthews, C.R. 1973. Nuclear magnetic resonance study of the thermal denaturation of ribonuclease A: Implications for multistate behavior at low $\mathrm{pH}$. Proceedings of the National Academy of Science. Vol. 70(3), p 914-918.

Wilkins, F.J. 1934. Statistical mechanics of the adsorption of gases at solid surfaces. Proceedings of the Royal Society of London, Series A Mathematical and Physical Sciences. Vol 169(919), p 496-509.

Wilson, D.B. 1992. Biochemistry and genetics of Actinomycetes cellulases. Critical Review of Biotechnology. Vol. 12, p 45-63.

Wylie, R.G. 1952. On the hysteresis of adsorption on solid surfaces. Australian Journal of Scientific Research, Series A Physical Sciences. Vol. 5, p 188-302. 
Xiao, Z., Zhang, X., Gregg, D. J, Saddler, J.N. 2004. Effects of sugar inhibition on cellulases and glucosidase during enzymatic hydrolysis of softwood substrates. Applied Environmental Microbiology. Vol. 113-116, p 1115-26.

Xu, F., Ding, H., Osborn, D., Tejirian, A., Brown, K., Albano, W., Sheehy, N., Langston, J. 2008. Partition of enzymes between the solvent and insoluble substrate during the hydrolysis of lignocellulose by cellulases. Journal of Molecular Catalysis B Enzymatic. Vol. 51(1-2), p 4248.

Xu, Z., Miao, Y., Chen, J.Y., Jiang, X., Lin, L., Ouyang, P. 2011, Co-immobilization mechanism of cellulase and xylanase on a reversibly soluble polymer. Applied Biochemistry and Biotechnology. Vol. 163, p 153-161.

Yang, Q., Luo, K., Li, X.M., Wang, D.B., Zheng, W., Zeng, G.M., Liu, J.J. 2010. Enhanced efficiency of biological excess sludge hydrolysis under anaerobic digestion by additional enzymes. Bioresource Technology. Vol. 101, p 2924-2930.

Ye, Z. 2012. The Impact of Adsorbed Cellulase Inactivation on Enzymatic Hydrolysis Kinetics. Ph.D. Dissertation. Department of Chemical Engineering. Louisville, KY. U.S.A.

Yousuf, A. 2012. Biodiesel from lignocellulosic biomass-Prospects and challenges. Waste Management. Vol. 32(11), p 2061-2067.

Yu, A.H.C., Lee, D., Saddler, J.N. 1995. Adsorption and desorption of cellulase components during the hydrolysis of a steam-exploded birch substrate. Biotechnology and Applied Biochemistry. Vol. 21, p 203-216.

Zagursky, R.J., Berman, M.L., Baumeister, K., Lomax, N. 1986. Rapid and easy sequencing of large linear double stranded DNA and supercoiled plasmid DNA. Gene Analysis Technology. Vol. 2, p 89-94. 
Zhang, C.L., Qiao, G.L., Zhao, F., Wang, Y. 2011. Thermodynamic and kinetic parameters of ciprofloxacin adsorption onto modified coal fly ash from aqueous solution. Journal of Molecular Liquids. Vol. 163(1), p 53-56.

Zhang, Y.H.P. 2008. Reviving the carbohydrate economy via multiproduct biorefineries. Journal of Industrial Microbiology and Biotechnology. Vol. 35(5), p 367-375.

Zhang, Y.H.P., Lynd, L.R. 2004. Toward an aggregated understanding of enzymatic hydrolysis of cellulose: noncomplex cellulase systems. Biotechnology and Bioengineering. Vol. 88, p 797824.

Zhang, X., Zhang, P.Y. 2010. One-step production of biocommodities from lignocellulosic biomass by recombinant cellulolytic Bacillus subtilis: Opportunities and challenges. Engineering in Life Sciences. Vol. 10, p 1-9.

Zhao, X., Zhang, L., Liu, D. 2012. Biomass recalcitrance. Part I: the chemical compositions and physical structures affecting the enzymatic hydrolysis of lignocellulose. Biofuels, Bioproduction Biorefineries (2012). DOI: 10.1002/bbb.

Zheng, Y.M., Zhao, Q.B., Yu, H.Q. 2005. Adsorption of a cationic dye onto aerobic granules. Process Biochemistry. Vol. 40, p 3777-3782.

Zheng, A.Q., Zhao, Z.L., Chang, S., Huang, Z., Wang, X.B., He, F., Li, H.B. 2013. Effect of torrefaction on structure and fast pyrolysis behavior of corncobs. Bioresource Technology. Vol. 128, p 370-377.

Zheng, Y., Zhang, S., Miao, S., Su, Z. Wang, P. 2013. Temperature sensitivity of cellulase adsorption on lignin and its impact on enzymatic hydrolysis of lignocellulosic biomass. Journal of Biotechnology. Vol. 166(3) p 135-145. 
Zhu, Z., Sathitsuksanoh, N., Zhang, Y.H.P. 2009. Direct quantitative determination of adsorbed cellulase on lignocellulosic biomass with its application to study cellulase desorption for potential recycling. Analyst. Vol. 134, p 2267-2272.

Zimmerman, J., Dessureault, D. 2014. Canada Biofuel Annual 2014. GAIN Report Number CA14109. USA Foreign Agricultural Service. Global Agricultural Information Network. 